\title{
Polymastiidae (Porifera: Demospongiae) of the Nordic and Siberian Seas
}

\author{
ALEXANDER PLOTKIN ${ }^{1}$, ELENA GERASIMOVA ${ }^{2}$ AND HANS TORE RAPP ${ }^{1,3,4}$ \\ ${ }^{1}$ Department of Biology, University of Bergen, Postbox 7803, 5020 Bergen, Norway, ${ }^{2}$ Rådgivende Biologer AS, Bredsgården, Bryggen, \\ 5003 Bergen, Norway, ${ }^{3}$ Centre for Geobiology, University of Bergen, Postbox 7803, 5020 Bergen, Norway, ${ }^{4}$ Uni Environment, \\ Uni Research AS, Postbox 7810, 5020 Bergen, Norway
}

\begin{abstract}
Polymastiidae (Porifera: Demospongiae) of the Nordic and Siberian Seas are revised and compared with the related species of the North Atlantic based on the morphological data from the type and comparative material and the molecular data from fresh samples. Twenty species from six polymastiid genera are recorded. Two species, Polymastia svenseni from Western Norway and Spinularia njordi from the Norwegian Sea, are new to science. One species, Polymastia andrica, is new to the Nordic Seas and two species, Polymastia cf. bartletti and P. penicillus, are new to the Scandinavian Coast. Distribution of the polymastiids in the North Atlantic and Arctic is discussed and the allegedly wide distribution of Spinularia sarsii and S. spinularia is questioned.
\end{abstract}

Keywords: sponges, Demospongiae, Polymastiidae, North Atlantic, Nordic and Siberian Seas, new species

Submitted 16 July 2016; accepted 16 February 2017; first published online 3 April 2017

\section{INTRDDUCTION}

The Nordic Seas, a collective geographic name usually referring to the Greenland, Iceland and Norwegian Seas (Drange et al., 2005; Korablev et al., 2014), but here extended to also include the Barents Sea, constitute the main gateway where the relatively warm and saline North Atlantic Current enters the cold and subsaline waters of the Arctic Ocean (Hansen \& Østerhus, 2000; Blindheim \& Østerhus, 2005) and, consequently, the Atlantic and Arctic biotas interchange (Loeng \& Drinkwater, 2007). Hence the biodiversity studies of the Nordic Seas are of great significance, especially in regard to a possible shutdown of thermohaline circulation. Furthermore, this region is characterized by a quite variable geomorphology with steep slopes and deep fjords along the coastline and seamounts, ridges and trenches in the offshore areas (Blindheim \& Østerhus, 2005). Due to such varying environments, the Nordic Seas host a highly diverse sessile invertebrate fauna (Shields \& Hughes, 2009; Anisimova et al., 2010; Schander et al., 2010; Kędra et al., 2013). One of the most prominent groups is the phylum Porifera, the sponges, which, in some areas, form dense aggregations known as 'sponge grounds' and play a crucial role in the functioning of bottom ecosystems (Klitgaard et al., 1997; Klitgaard \& Tendal, 2004; Cárdenas et al., 2013; Maldonado et al., 2016). The Nordic sponge fauna was extensively studied during more than 200 years, starting with the classical survey by Müller (1806) and followed by Schmidt (1870, 1875), Sars (1872), von Marenzeller (1878), Sollas (1882), Vosmaer (1882, 1885), Hansen (1885), Fristedt (1887), Arnesen (1900, 1903, 1920), Lundbeck (1902, 1905, 1907, 1909, 1910), Breitfuss

Corresponding author:

A. Plotkin

Email: alexander.s.plotkin@gmail.com
(1911, 1912, 1930), Topsent (1913), Rezvoj (1924, 1928), Brøndsted (1914, 1932, 1933), Hentschel (1916, 1929), Burton (1930a, 1959a), Arndt (1935), Koltun (1964, 1966) and Ereskovsky (1993a, 1994a, b, 1995a, b, c). Although these studies have provided us with thorough descriptions of species and a comprehensive knowledge on their distribution, their data are nowadays seriously re-considered based on the novel material from poorly studied areas (e.g. Rapp, 2006, 2015 on calcareous sponges) and the molecular approaches in sponge taxonomy (e.g. Cárdenas et al., 2013 on geodiid sponges).

Vast marine areas north of Russia, known as the Siberian Seas, are characterized by an inhospitable environment, with, for the most part, shallow depths, a strong influx of fresh water from the great Siberian rivers and considerable temperature fluctuations between winter, when the sea surface is covered with ice and the water temperature sinks below zero, and the warm season, when the surface water layers may be heated (Coachman \& Aagaard, 1974). The impact of the freshwater inflow, the ice movements and the summer heating is especially severe in the large shallow-water areas along the coast. The bottom here comprises spacious plains covered with mud and clay (Herman, 1974; Weber, 1989). Due to the unstable environment, both in the water body and on the seabed, the biodiversity, especially the diversity of sessile macrobenthos, of these areas is considerably poorer than along the coasts of the Nordic Seas (Golikov \& Scarlato, 1989). On the contrary, in the offshore areas of the Siberian Seas the salinity is more stable, a branch of the Atlantic current brings warm water to the deep (Coachman \& Aagaard, 1974), and the northern coast of large offshore archipelagos, e.g. Severnaya Zemlya and New Siberian Islands, is characterized by the rock cliffs and steep slopes running to great depths (Herman, 1974; Weber, 1989). These areas are oases hosting a relatively rich bottom fauna, particularly some diverse sponge communities (Golikov 
et al., 1990). The studies of the sponge fauna in the Siberian Seas were started by Fristedt (1887) and Levinsen (1887) and continued by Rezvoj (1924, 1928), Gorbunov (1946) and Koltun (1966). The latter study until now remains the most comprehensive description of the Arctic sponge species, although some data presented there are obviously out of date and need a serious revision based on the modern taxonomic concepts. Among the northern seas of Russia, the White Sea, a large semi-isolated, brackish gulf of the Barents Sea, stands out for its peculiar hydrological conditions affecting the biodiversity. The deep waters of the White Sea, where the temperature is below zero all the year round, are inhabited predominantly by Arctic species. Conversely, the shallow depths, where seasonal fluctuations of the water temperature are considerable, host opportunistic Atlantic species (Babkov \& Golikov, 1984). The exploration of the White Sea sponge communities begun by Merejkowsky (1878) was continued by Swarczewsky (1906), Koltun (1966) and Ereskovsky (1993a, b, 1994a, b, 1995a, b, c). However, these unique communities still need further studies based on up-to-date approaches.

Among all diverse sponge taxa inhabiting the Nordic and Siberian Seas the family Polymastiidae Gray, 1867 is one of the most common. Despite the polymastiids never reaching such large sizes as, for example, the astrophorid species do (Cárdenas et al., 2013), they are subdominants of shallowwater hard bottom communities in some Norwegian fjords (Svensen, personal communication), in the White Sea (Plotkin et al., 2005) and Laptev Sea (Golikov et al., 1990). In the deep waters common polymastiids such as Tentorium semisuberites (Schmidt, 1870) and Radiella spp. are often the most frequently recorded macrobenthic species (Barthel \& Tendal, 1993; Witte, 1996). Polymastiidae were described in all studies on the Nordic and Russian sponge faunas (see the references above) and these records were summarized by Koltun (1966), who listed eight polymastiid species for the Greenland Sea, 12 species for the Norwegian and Barents Sea, four species for the White Sea and eight species for the Siberian Seas and the Arctic Ocean. The White Sea list was appended by one more polymastiid by Ereskovsky (1993b), while Plotkin (2004) provided the re-descriptions of all these species and proposed some changes in their taxonomy.

Meanwhile, the records of most species presented by Koltun (1966) and Plotkin (2004) were based on non-type material that may question their identification. Furthermore, the polymastiids of the Scandinavian Coast and Svalbard have been never properly revised. Additionally, rich sponge samples recently taken from the poorly studied underwater mountains and vents in the Greenland and Norwegian Sea must be examined. Finally, recently recovered sponge phylogenies based on molecular data (e.g. Cárdenas et al., 2012; Morrow et al., 2012, 2013; Redmond et al., 2013; Morrow \& Cárdenas, 2015) challenge the traditional taxonomy based on morphology. Particularly they question the generally accepted concept of the relationships between the polymastiid genera (Boury-Esnault, 2002) as well as between the Polymastiidae and other families (Hooper \& Van Soest, 2002). A monotypic order, Polymastiida Morrow \& Cárdenas, 2015, is established for the polymastiids, and a homoplasy of most morphological characters traditionally used in the taxonomy of this family and a non-monophyly of four genera from 15 polymastiid genera altogether known (Van Soest et al., 2016) are revealed (Plotkin et al., 2016b).
The aim of the present study is to revise the polymastiid fauna of the Nordic and Siberian Seas based on morphological examination of the type material and other historical collections as well as on both morphological and molecular data from fresh material. We also provide a key for identification of the polymastiid species in the area of study (Appendix 1). The area covered by the study comprises the Scandinavian Coast from the Swedish Western Coast and Southern Norway to the Norwegian-Russian border, Russian Coasts (including the White Sea) from the border to the easternmost point, Icelandic Coast, Southern and Eastern Coasts of Greenland, offshore archipelagos Svalbard, Franz Josef Land, Novaya Zemlya, Nordenskjold and Severnaya Zemlya, offshore areas of the Greenland, Norwegian, Barents, Kara, Laptev, East-Siberian and Chukchi Seas and adjacent areas of the Arctic Ocean. We also compare the Nordic and Siberian sponges with individuals from the British Isles, Canadian Atlantic Coast and some other regions in order to explore the dispersal of the species.

\section{MATERIALS AND METHODS}

The study was based on historical and fresh material stored in 14 museums (Table 1). Altogether more than 1700 sponge individuals were studied (Online resource 1 ). The architecture of their skeletons was examined under light microscope on histological sections prepared on a precise saw with a diamond wafering blade after embedding of sponge fragments in epoxy resin as described by Boury-Esnault et al. (2002), Vacelet (2006) and Boury-Esnault \& Bézac (2007). Spicules were examined under light microscope and SEM after their isolation from organic matter in nitric acid following standard procedures. The number of specimens used for spicule measurements is given in the corresponding section of the description of each species. The number of spicules of each category measured in one specimen is indicated as N. Measurements are presented as minimum-mean-maximum, unless otherwise indicated.

Table 1. List of museums whose collections were used in the present study.

\begin{tabular}{|c|c|}
\hline Museum acronym & Museum title and affiliation \\
\hline BELUM & $\begin{array}{l}\text { Ulster Museum, National Museums of } \\
\text { Northern Ireland, Belfast }\end{array}$ \\
\hline $\mathrm{BMNH}$ & Natural History Museum, London \\
\hline CMNI & Canadian Museum of Nature, Ottawa \\
\hline GNM & Göteborgs Naturhistoriska Museum \\
\hline MNHN & Muséum National d'Histoire Naturelle, Paris \\
\hline MOM & Musée Océanographique de Monaco \\
\hline NHMUO & Naturhistorisk museum, Universitetet i Oslo \\
\hline NTNU-VM & $\begin{array}{l}\text { Vitenskapsmuseet, Norges teknisk- } \\
\text { naturvitenskapelige universitet, Trondheim }\end{array}$ \\
\hline RMNH & Naturalis Biodiversity center, Leiden \\
\hline UPSZTY & Evolutionsmuseet, Uppsala Universitet \\
\hline ZIN RAS & $\begin{array}{l}\text { Zoological Institute of Russian } \\
\text { Academy of Sciences, Saint-Petersburg }\end{array}$ \\
\hline $\mathrm{ZMB}$ & Museum für Naturkunde, Berlin \\
\hline ZMBN & Universitetsmuseet i Bergen \\
\hline ZMUC & $\begin{array}{l}\text { Statens Naturhistoriske Museum, } \\
\text { Københavns Universitet }\end{array}$ \\
\hline
\end{tabular}


Genetic synapomorphies and autapomorphies of the species were defined in the $5^{\prime}$-end barcoding region of cytochrome oxidase subunit I (CO1) and the region coding the RNA of the large ribosomal subunit (28S rDNA) from helix B10 to helix E19. The sequences, the alignments and the respective phylogenies were presented by Plotkin et al. (2016b). GenBank accessions are indicated in Online resource 1 , this study. Alignments and the respective phylogenetic trees are deposited in TreeBase and available at http://purl.org/ phylo/treebase/phylows/study/TB2:S18487 (see Matrix M34248 and Tree Tr91844 for CO1, Matrix M34250 and Trees Tr91846-Tr91847 for $28 \mathrm{~S}$ rDNA, complete dataset, and Matrix M34256 and Tree Tr91856 for $28 \mathrm{~S}$ rDNA fragment D1-D19 demonstrating intragenomic polymorphism). Generalized phylogeny reconstructed from the concatenated dataset is presented in Figure 1, while the main apomorphies are indicated in Online resources 2 (for $\mathrm{CO}_{1}$ ) and 3 (for $28 \mathrm{~S}$ rDNA), this study. Apomorphies in $28 \mathrm{~S}$ rDNA were defined only within the unambiguously aligned parts of the matrix (positions 1-449, 492-577, 585-667, 685-940 and 9492155 in the alignment). Based on the phylogenies recovered by Plotkin et al. (2016b) we accept the abandonment of Radiella Schmidt, 1870. However, we stick to the traditional taxonomy of other genera (Boury-Esnault, 2002; Van Soest et al., 2016) even, if they are not monophyletic in these phylogenies, until a new classification of Polymastiidae is built.
SYSTEMATICS

Systematic index

Class DEMOSPONGIAE Sollas, 1885

Suborder HETEROSCLEROMORPHA Cárdenas, Perez \& Boury-Esnault, 2012

Order POLYMASTIIDA Morrow \& Cárdenas, 2015 Family POLYMASTIIDAE Gray, 1867 Genus Polymastia Bowerbank, 1862

P. andrica de Laubenfels, 1949

P. arctica (Merejkowsky, 1878)

P. cf. bartletti de Laubenfels, 1942

P. boletiformis (Lamarck, 1815)

P. grimaldii (Topsent, 1913)

P. hemisphaerica (Sars, 1872)

P. mamillaris (Müller, 1806)

$P$. nivea (Hansen, 1885)

P. penicillus (Montagu, 1814)

P. svenseni sp. nov.

P. thielei Koltun, 1964

P. uberrima (Schmidt, 1870) Polymastia sp.

Genus Quasillina Norman, 1869

Q. brevis Bowerbank, 1866

Genus Sphaerotylus Topsent, 1898

S. borealis (Swarczewsky, 1906)

S. capitatus (Vosmaer, 1885)

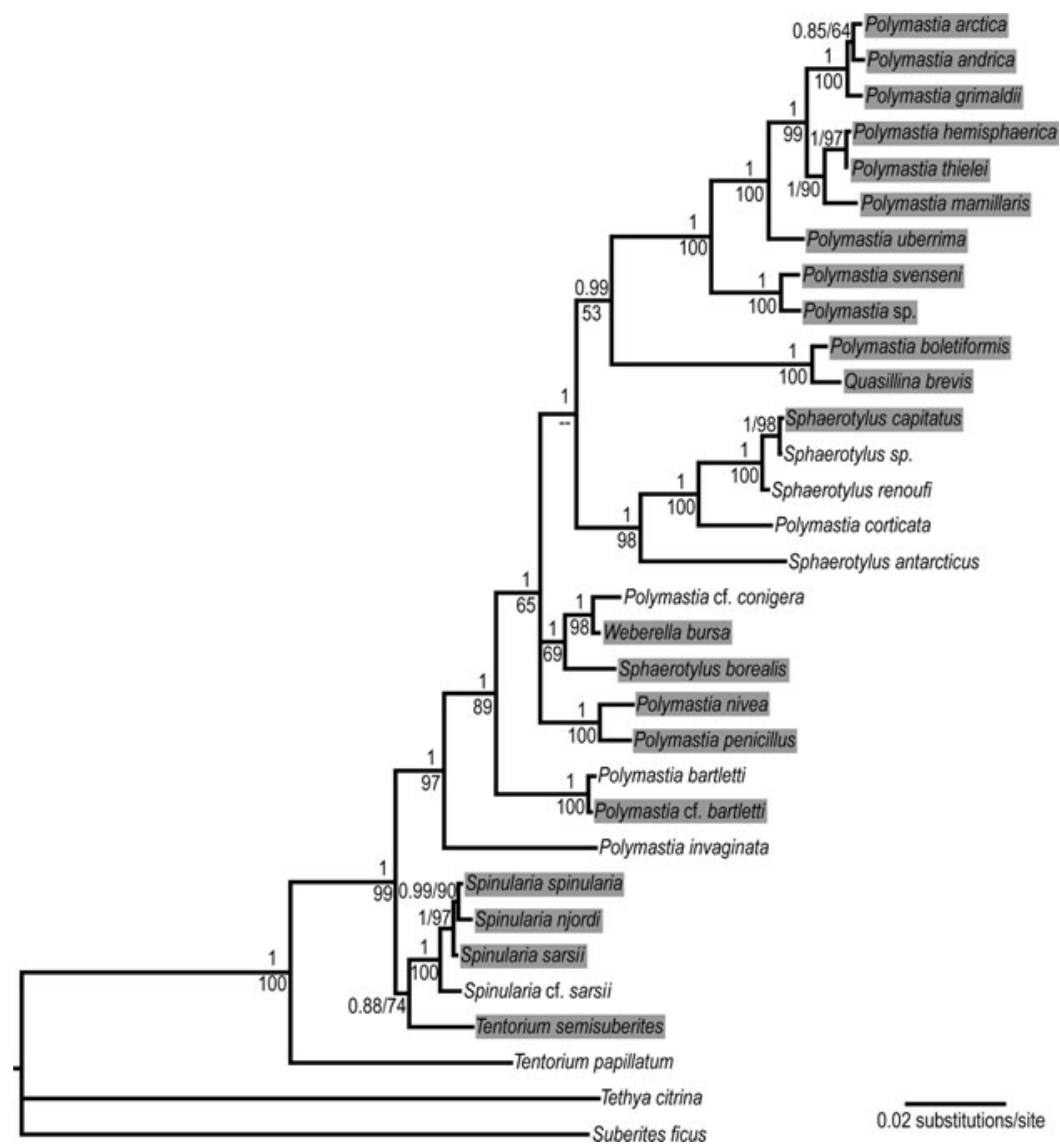

Fig. 1. Bayesian consensus tree reconstructed from the concatenated dataset $\mathrm{CO} 1+28 \mathrm{~S}$ rDNA of 30 polymastiid species. Nodal supports: upper values Bayesian posterior probabilities, lower values - ML bootstrap supports in percentages. Data are taken from Plotkin et al. (2016b). Complete 28S rDNA alignment is used. The original trees are available at http://purl.org/phylo/treebase/phylows/study/TB2:S18487. Branches corresponding to different individuals of the same species are collapsed. The species from the Nordic and Siberian Seas are highlighted. The following species from Plotkin et al. (2016b) are renamed according to the classification accepted in the present study: Polymastia sp. 1 as Polymastia svenseni, Radiella hemisphaerica as Polymastia hemisphaerica, Radiella sarsii as Spinularia sarsii, Radiella sp. as Spinularia njordi and Sphaerotylus sp. 2 as Sphaerotylus renoufi. 
Genus Spinularia Gray, 1867

S. njordi sp. nov.

S. sarsii (Ridley \& Dendy, 1886) comb. nov.

S. spinularia (Bowerbank, 1866)

Genus Tentorium Vosmaer, 1887

T. semisuberites (Schmidt, 1870)

Genus Weberella Vosmaer, 1885

W. bursa (Müller, 1806)

Description of taxa

Family POLYMASTIIDAE Gray, 1867

\section{DIAGNOSIS}

Sponges of encrusting, massive, globular, hemispherical, discoid, columnar or pedunculate body shape. Oscula are often located at the summits of papillae or, sometimes, directly on the surface of the main body. Assortment of spicules comprises at least two size categories of smooth monactines. Tracts of principal monactines radiating from the sponge base or forming a reticulation constitute the main choanosomal skeleton or the innermost layer of the cortex. Auxiliary choanosomal skeleton comprises smaller spicules, freescattered or grouped in little bundles, which may be smooth monactines, smooth or acanthose oxeas, raphides in trichodragmata or astrotylostyles. A complex specialized cortical skeleton is developed to a greater or lesser degree, composed of at least a palisade of smooth tylostyles, subtylostyles, or oxeas and/or exotyles. A fringe of extra-long monactines may be present at the edge of the body where it is in contact with the substrate.

Genus Polymastia Bowerbank, 1862

Original description: Polymastia Bowerbank, 1862, p. 1104.

\section{SYNONYMS}

Pencillaria Gray, 1867, p. 527.

Polymastica Gray, 1867, p. 527.

Rinalda Schmidt, 1870, p. 51.

Trichostemma Sars, 1872, p. 62.

\section{TYPE SPECIES}

Halichondria mamillaris Johnston, 1842 (= Spongia mamillaris Müller, 1806) (by original designation).

\section{DIAGNOSIS}

Polymastiidae of encrusting, massive, globular, hemispherical or discoid body shape, always bearing papillae with oscula at the summits. Main choanosomal skeleton composed of tracts of principal monactines radiating from the sponge base or forming a reticulation. Auxiliary choanosomal skeleton comprises smaller monactines, free-scattered or grouped in little bundles. Cortical skeleton constituted at least by a superficial palisade of small smooth tylostyles or subtylostyles and an internal layer of larger monactines lying obliquely to the surface and may include middle layers. A fringe of extra-long monactines may be present at the edge of the body.

\section{DISCUSSION}

Polymastia Bowerbank, 1862, with its currently accepted assortment of species (Boury-Esnault, 2002; Van Soest et al., 2016), is not monophyletic as was suggested by Plotkin et al. (2012) based on morphological data and confirmed by
Plotkin et al. (2016b) based on the CO1 and 28S rDNA phylogenies (see also Figure 1, this study). In both phylogenies the type species of Polymastia, P. mamillaris (Müller, 1806), formed a strongly supported clade with only five other species of this genus, $P$. andrica de Laubenfels, 1949, $P$. arctica (Merejkowsky, 1878), P. grimaldii (Topsent, 1913), P. uberrima (Schmidt, 1870) and P. thielei Koltun, 1964, along with Trichostemma hemisphaericum Sars, 1872, which was in fact the type species of Trichostemma Sars, 1872 accepted as Radiella hemisphaerica at the time of the study by Plotkin et al. (2016b). However, no morphological synapomorphies of this clade could be defined. In the $28 \mathrm{~S}$ rDNA tree a pair of unidentified species Polymastia sp. 1 and Polymastia sp. 2 was the sister to the Polymastia-clade with a strong Bayesian support. In the $\mathrm{CO}_{1}$ tree a trio of unidentified species Polymastia sp. 1, Polymastia sp. 2 and Polymastia sp. 3 was the sister to the Polymastia-clade, although with a weak support. All other Polymastia spp. including four species described in the present study, $P$. boletiformis (Lamarck, 1815), P. bartletti de Laubenfels, 1942, P. nivea (Hansen, 1885) and P. penicillus (Montagu, 1814), fell in the clades with the species of other genera in both molecular trees.

In the present study based on these phylogenies Trichostemma is regarded as a junior synonym of Polymastia, Polymastia sp. 1 is described as P. svenseni sp. nov., Polymastia sp. 2 is described as an unidentified species and Polymastia sp. 3 is not considered because it occurs outside the area covered by the study. Meanwhile, for the sake of taxonomic stability until a new classification of Polymastiidae is built, we retain the allocation of $P$. boletiformis, $P$. bartletti, $P$. nivea and $P$. penicillus to Polymastia, though it contradicts the molecular phylogenies. Consequently, the diagnosis of Polymastia (see above) is emended accordingly.

\section{Polymastia andrica de Laubenfels, 1949}

(Figure 2)

Original description: Polymastia andrica de Laubenfels, 1949, p. 22, figures $19 \& 20$.

\section{SYNONYMS AND CITATIONS}

Polymastia mamillaris (Whiteaves, 1874 , p. 184; Lambe, 1896 , p. 196, pl. III figure 1; Whiteaves, 1901, p. 13).

\section{TYPE MATERIAL}

Holotype (lost?): Gulf of St. Lawrence, Canada, coll. Whiteaves.

Several individuals sampled by Whiteaves from various localities in the Gulf of St. Lawrence in 1871-1872 were identified by him (Whiteaves, 1874, 1901) as Polymastia mamillaris. Lambe (1896) studied four of these individuals and confirmed the identification. De Laubenfels (1949) designated one of these sponges, with field number 8 , as the holotype of his new species Polymastia andrica. Only three individuals of the four described by Lambe (1896) are now available in the Canadian Museum of Nature (Online resource 1), but none of them bear field number 8 . We have examined histological sections and spicules from these sponges and found that they fit with the descriptions by Lambe (1896) and de Laubenfels (1949). 

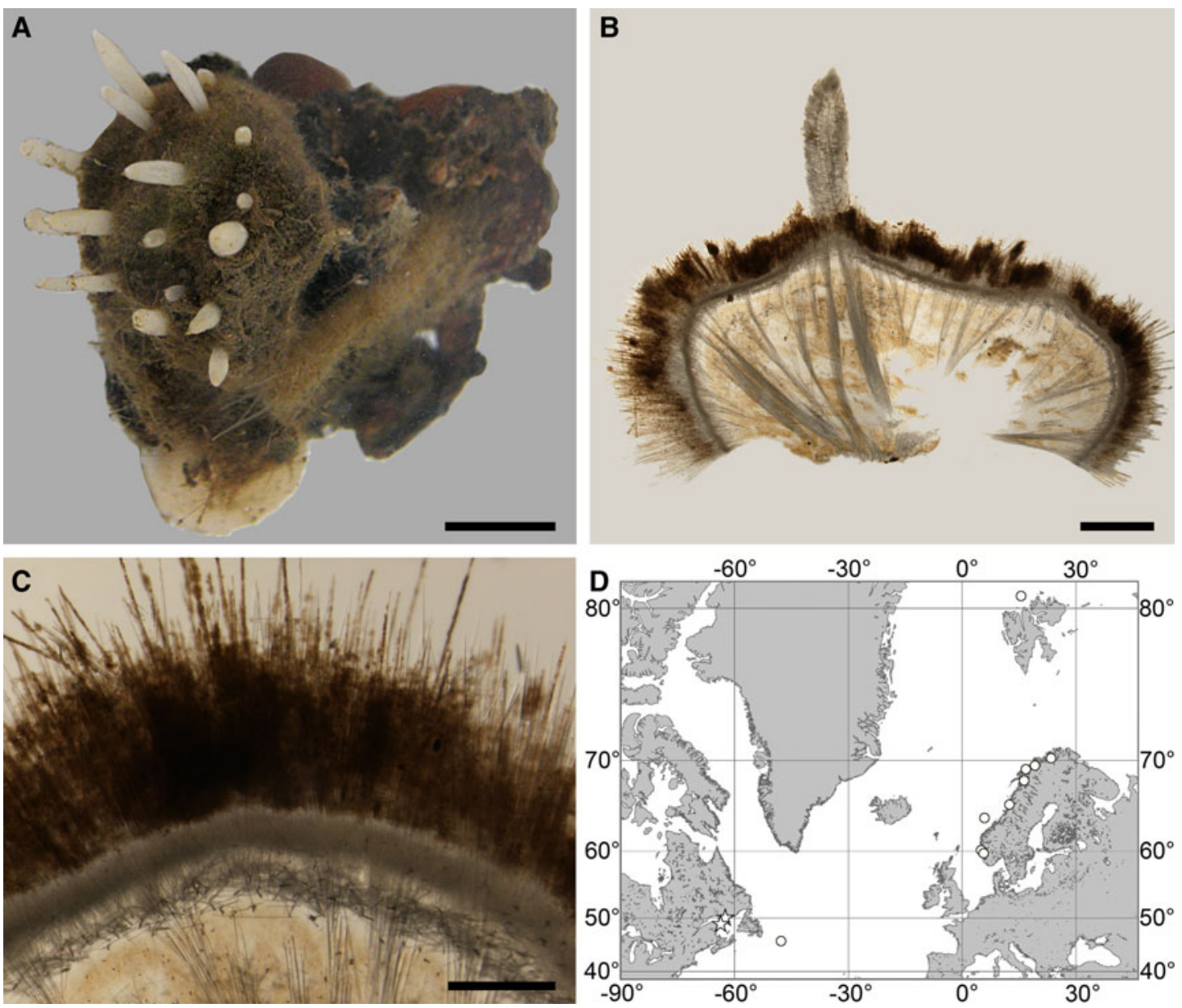

Fig. 2. Polymastia andrica: (A) ZMBN 098057, habitus; (B) the same individual, longitudinal section through the body, general view; (C) the same section, detail of cortex; (D) distribution: white stars, type localities; white circles, our data. Scale bars: A, $1 \mathrm{~cm}$;, $2 \mathrm{~mm}$;, $0.5 \mathrm{~mm}$.

\section{MATERIAL EXAMINED}

(see Online resource 1 for details)

Canada: Quebec, Gulf of St. Lawrence: CMNI 1980-0436 (spicule slide from one specimen), CMNI 1980-0437/0440/ 0441 (histological sections and spicule slides from one specimen), CMNI 1980-0438 (spicule slide from one specimen), Newfoundland: ZMBN 098102 (one specimen).

Norway: Hordaland: ZMBN 098057 and ZMBN 107572 (two specimens), Nordland: NTNU-VM-54990, NTNU-VM55034 and NTNU-VM-72533 (three specimens), Troms: NTNU-VM-55603 and ZMBN 098074 (two specimens), Finnmark: NTNU-VM-54850 (one specimen), Svalbard: ZMBN 098055 (one specimen).

Norwegian Sea, offshore: ZMBN 098108 (one specimen).

\section{DESCRIPTION}

\section{External morphology}

Cushion-shaped sponges covering the substrate and occupying up to $6 \mathrm{~cm}^{2}$ (Figure 2A). Surface strongly hispid, covered with sediment, with up to several tens of cylindrical or flattened, greyish or whitish papillae which are 1-12 mm long and 1-5 mm wide. In preserved sponges exhalant and inhalant papillae do not differ in size or shape.

\section{Anatomy}

Choanosome in alcohol yellowish or greyish, dense. Main choanosomal skeleton composed of radiating tracts (88-
$417 \mu \mathrm{m}$ thick) of principal spicules crossing the cortex and forming a surface hispidation reinforced with exotyles (Figure $2 \mathrm{~B}$ ). Ascending tracts also form a framework of the papilla skeleton. Auxiliary choanosomal skeleton comprises free-scattered small spicules, being especially abundant in the subcortical area. Cortex in alcohol light-coloured, firm, not detachable. Cortical skeleton constituted by a superficial palisade (116-232 $\mu \mathrm{m}$ thick) of small spicules, a middle layer $(40-272 \mu \mathrm{m}$ thick) of collagen fibres with low density of spicules and an internal layer (56-170 $\mu \mathrm{m}$ thick) of tangentially arranged intermediary spicules (Figure $2 \mathrm{C}$ ). Skeleton of the papilla walls composed of two layers only, the superficial palisade and the internal tangential layer. Single small and intermediary spicules reinforce the bulkheads separating aquiferous canals and vestibules in the papillae.

\section{Spicules}

(Measurements based on seven specimens, individual variation presented in Table 2)

Principal spicules - styles (in the Canadian sponges) or subtylostyles to styles (Norwegian sponges), usually straight, fusiform, with tyles (if present) slightly displaced along the shafts, occasionally polytylote. Length $613-1248-2132 \mu \mathrm{m}$, diameter of tyle (if present) $5.1-11.1-14.3 \mu \mathrm{m}$, proximal diameter of shaft $3.8-11.1-18.2 \mu \mathrm{m}$, maximum diameter of shaft 8.9$23.9-33.8 \mu \mathrm{m}, \mathrm{N}=230$. 
Table 2. Individual variation of spicule dimensions of Polymastia andrica (given in $\mu \mathrm{m}$ as minimum-mean-maximum). Parameters: length, diameter of tyle, proximal diameter of shaft, maximum diameter of shaft, number of spicules measured $(\mathrm{N})$.

\begin{tabular}{|c|c|c|c|c|}
\hline Specimen & Principal spicules & Intermediary spicules & Small spicules & Exotyles \\
\hline CMNI 1980-0436 (Canada, Gulf of St. Lawrence) & $\begin{array}{l}969-1226-1474 \\
\text { Tyles absent } \\
5.2-11.3-14.3 \\
13-25.8-33.8 \\
\mathrm{~N}=30\end{array}$ & $\begin{array}{l}427-538-857 \\
6.5-9.9-11.7 \\
5.2-9.5-13 \\
9.1-12.8-18.2 \\
\mathrm{~N}=30\end{array}$ & $\begin{array}{l}100-149-286 \\
2.1-4-7.8 \\
1.8-3.1-7.8 \\
2.1-3.7-7.8 \\
\mathrm{~N}=40\end{array}$ & $\begin{array}{l}1632-1908-2145 \\
\text { Tyles absent } \\
5.2-7.5-11.7 \\
13-19.7-31.2 \\
\mathrm{~N}=5\end{array}$ \\
\hline CMNI 1980-0438 (Canada, Gulf of St. Lawrence) & $\begin{array}{l}1013-1360-1605 \\
\text { Tyles absent } \\
5.2-12.1-18.2 \\
15.6-26.3-33.8 \\
\mathrm{~N}=30\end{array}$ & $\begin{array}{l}403-586-898 \\
7.8-9.6-11.7 \\
6.5-9-13 \\
13-15.2-20.8 \\
N=19\end{array}$ & $\begin{array}{l}145-178-247 \\
4.7-7.1-10.4 \\
3.9-4.8-6.5 \\
5.2-7.8-10.4 \\
\mathrm{~N}=30\end{array}$ & $\begin{array}{l}1895-2689-3763 \\
\text { Tyles absent } \\
5.2-7.3-10.4 \\
13-16.6-20.8 \\
\mathrm{~N}=5\end{array}$ \\
\hline CMNI 1980-0440/0441 (Canada, Gulf of St. Lawrence) & $\begin{array}{l}1118-1464-2132 \\
\text { tyles absent } \\
9.1-11.9-15.6 \\
20.8-26.1-31.2 \\
\mathrm{~N}=50\end{array}$ & $\begin{array}{l}316-575-837 \\
9.1-11.4-15.6 \\
6.5-10.2-14.3 \\
10.4-14.2-26 \\
N=60\end{array}$ & $\begin{array}{l}153-192-280 \\
3.9-7.3-13 \\
2.6-5.2-10.4 \\
3.9-8.7-15.6 \\
\mathrm{~N}=90\end{array}$ & $\begin{array}{l}2395-3553-5500 \\
\text { tyles absent } \\
5.2-8.9-13 \\
14.3-16.9-18.2 \\
\mathrm{~N}=6\end{array}$ \\
\hline ZMBN 98055 (Norway, Svalbard) & $\begin{array}{l}905-1226-1624 \\
11.4-12.4-14 \\
8.9-10.8-12.7 \\
16.5-18.8-20.3 \\
N=30\end{array}$ & $\begin{array}{l}417-510-784 \\
7.6-9.5-12.7 \\
6.4-7.5-8.9 \\
7.6-11.1-14 \\
\mathrm{~N}=30\end{array}$ & $\begin{array}{l}140-177-229 \\
7.6-8.4-10.2 \\
4.6-5.2-6.4 \\
7.6-8.4-10.2 \\
N=30\end{array}$ & $\begin{array}{l}2058-2598-3125 \\
2.5-7.8-12.7 \\
2-6.2-11.4 \\
7.6-10-15.2 \\
N=11\end{array}$ \\
\hline ZMBN 98057 (Norwegian Coast, Hordaland) & $\begin{array}{l}992-1208-1637 \\
5.1-10.3-12.7 \\
3.8-9.1-11.4 \\
12.7-19.4-25.4 \\
N=30\end{array}$ & $\begin{array}{l}362-485-563 \\
7.6-8.5-10.2 \\
6.4-7.6-10.2 \\
10.2-12.1-14 \\
N=30\end{array}$ & $\begin{array}{l}140-177-231 \\
3.8-5.3-6.4 \\
2.5-3.6-5.1 \\
5.1-5.8-8.9 \\
\mathrm{~N}=30\end{array}$ & $\begin{array}{l}2604 \\
6.4 \\
5.1 \\
12.7 \\
\mathrm{~N}=1\end{array}$ \\
\hline ZMBN 98074 (Norwegian Coast, Troms) & $\begin{array}{l}613-783-1045 \\
7.1-10.3-14 \\
5.1-8.4-12.7 \\
8.9-12-16.5 \\
\mathrm{~N}=30\end{array}$ & $\begin{array}{l}372-420-523 \\
7.6-8.4-10.7 \\
5.6-7.2-7.6 \\
7.6-9.3-11.4 \\
\mathrm{~N}=30\end{array}$ & $\begin{array}{l}132-169-216 \\
5.1-5.8-7.6 \\
2.5-3.8-5.1 \\
3-4.8-6.4 \\
\mathrm{~N}=30\end{array}$ & $\begin{array}{l}1314-1493-1736 \\
\text { tyles absent } \\
2.5-3.5-5.1 \\
5.1-8.3-10.2 \\
\mathrm{~N}=16\end{array}$ \\
\hline ZMBN 98102 (Canada, Newfoundland) & $\begin{array}{l}1017-1322-1637 \\
8.1-10.9-12.7 \\
7.6-9.3-10.2 \\
20.3-22.7-26.7 \\
N=30\end{array}$ & $\begin{array}{l}362-472-704 \\
6.4-8.9-11.4 \\
5.1-7.5-10.2 \\
10.2-12.7-14 \\
\mathrm{~N}=30\end{array}$ & $\begin{array}{l}138-167-241 \\
5.1-6.9-8.1 \\
2.5-4-5.1 \\
3.8-6.2-7.6 \\
\mathrm{~N}=30\end{array}$ & $\begin{array}{l}1786-2671-3497 \\
\text { tyles absent } \\
3.8-5-7.6 \\
11.4-13.5-15.2 \\
\mathrm{~N}=14\end{array}$ \\
\hline
\end{tabular}

Intermediary spicules - subtylostyles to styles, straight or gently bent, fusiform, occasionally with tyles slightly displaced along the shafts. Length 316-517-898 $\mu \mathrm{m}$, diameter of tyle (if present) $6.4-9.9-15.6 \mu \mathrm{m}$, proximal diameter of shaft 5.1-9.1-14.3 $\mu \mathrm{m}$, maximum diameter of shaft $7.6-13.2-$ $26.0 \mu \mathrm{m}, \mathrm{N}=229$.

Small spicules - tylostyles, often gently bent in the proximal part, usually slender, occasionally stout. Length 100-176$286 \mu \mathrm{m}$, diameter of tyle $2.1-6.5-13 \mu \mathrm{m}$, proximal diameter of shaft $1.8-4.5-10.4 \mu \mathrm{m}$, maximum diameter of shaft $2.1-$ $7.1-15.6 \mu \mathrm{m}, \mathrm{N}=280$.

Exotyles - filiform styles (Canadian sponges and individual ZMBN 98074 from Troms) or filiform subtylostyles with weakly developed, often slightly displaced tyles (other Norwegian sponges). Length 1314-2358-5500 $\mu \mathrm{m}$, diameter of tyle (if present) 2.5-6.7-12.7 $\mu \mathrm{m}$, proximal diameter of shaft 2.0-5.6-13 $\mu \mathrm{m}$, maximum diameter of shaft 5.1$12.6-31.2 \mu \mathrm{m}, \mathrm{N}=58$.

Strongyles (registered only in individual CMNI1980-0436 from the Gulf of St. Lawrence) - straight, fusiform or slender, occasionally with one or two weakly developed tyles. Length 26-47-156 $\mu \mathrm{m}$, proximal diameter of shaft
9.1-15.3-18.2 $\mu \mathrm{m}$, maximal diameter of shaft 9.1-21$41.6 \mu \mathrm{m}, \mathrm{N}=30$.

\section{Genetic data}

$\mathrm{CO}_{1}$ sequences obtained from five individuals of Polymastia andrica are identical, but an intragenomic polymorphism was observed in $28 \mathrm{~S}$ rDNA of one individual (Matrix M34256 in TreeBase). Polymastia andrica is closely related to $P$. arctica and P. grimaldii, sharing with them five synapomorphies in $\mathrm{CO}_{1}$ (Online resource 2, p. 1) and four synapomorphies in $28 \mathrm{~S}$ rDNA (Online resource 3, p. 1), which distinguish these three species from all other polymastiids. $28 \mathrm{~S}$ rDNA of $P$. andrica, $P$. arctica and $P$. grimaldii displays a high level of intraspecific and intragenomic polymorphism with some identical gene versions found in the individuals from different species (Plotkin et al., 2016b; Matrices M34250 and M34256 in TreeBase). On the contrary, the CO1 data are consistent. In this gene $P$. andrica and $P$. arctica share one synapomorphy distinguishing them from all other polymastiids, and, additionally $P$. andrica has one autapomorphy (Online resource 2, p. 1). Apart from this autapomorphy, $P$. andrica differs from $P$. arctica by eight base pairs (bps), from $P$. grimaldii by 12 bps and from the type species of Polymastia, P. mamillaris, by 32 bps in $\mathrm{CO}_{1}$ (Matrix M34248 in TreeBase). 


\section{OCCURRENCE}

(Figure 2D)

Canadian Atlantic Coast: Gulf of St. Lawrence (218-382 m according to Lambe, 1896), Newfoundland (619-699 m). Norwegian Coast: Hordaland $(28-300 \mathrm{~m})$, Nordland (120$721 \mathrm{~m})$, Troms $(25-220 \mathrm{~m})$, Finnmark (30-80 m). Norwegian Sea, offshore areas (626-628 m). Svalbard (215 m).

\section{DISCUSSION}

Before our study, Polymastia andrica was recorded only from the type locality, the Gulf of St. Lawrence (de Laubenfels, 1949). We have identified as $P$. andrica a sponge from Newfoundland and 10 Norwegian individuals based on their morphological similarities with the material from the type locality (although the exotyles in the Norwegian specimens are shorter than those in the Canadian sponges) and the identity of $\mathrm{CO}_{1}$ from the Newfoundland specimen and the Norwegian specimens. Polymastia andrica is morphologically very similar to $P$. arctica and $P$. mamillaris, but differs from these two by the presence of exotyles. Additionally $P$. andrica differs from $P$. arctica by the absence of threads with buds at the summits of the inhalant papillae and by the absence of size difference between the inhalant and exhalant papillae. All genetic data obtained support the discrimination between $P$. andrica and $P$. mamillaris based on morphology. The morphological differences between $P$. andrica and $P$. arctica are only confirmed by the $\mathrm{CO}_{1}$ data, but not by $28 \mathrm{~S}$ rDNA.
Polymastia arctica (Merejkowsky, 1878)

(Figure 3)

Original description: Rinalda arctica Merejkowsky, 1878, p. 4, pl. I figures 7-12, pl. II figures 6-8, pl. III figures 1-3, $6-10,20-22,30-39$.

\section{SYNONYMS AND CITATIONS}

Polymastia arctica (Plotkin, 2004, p. 541, figures 1a \& 2a; Plotkin \& Boury-Esnault, 2004, p. 15, figures 1-3).

Polymastia mammillaris (Arnesen, 1918, p. 8, pl. 1 figures 1 4, pl. 2 figures $1-5$, pl. 3 figures 6-9, pl. 4 figures 1-2; pl. 5 figures 1-2, pl. 6 figures 1-4; Ereskovsky, 1993a, p. 22, 1995c, p. 724; Plotkin \& Ereskovsky, 1997, p. 127).

Polymastia mammillaris mammillaris (Koltun, 1966, p. 69, text-figure 38 , pl. XX figure 6 pars.).

Polymastia penicillus (Swarczewsky, 1906, p. 313, pl. 13 figure 1).

Rinalda arctica (Merejkowsky, 1880, p. 421).

\section{TYPE MATERIAL}

Lectotype (designated by Plotkin \& Boury-Esnault, 2004): ZIN RAS 10610 (specimen and slide 5526a), Archipelago of Solovki, Onega Bay, White Sea, $64^{\circ} 57.0^{\prime} \mathrm{N} 35^{\circ} 29.4^{\prime} \mathrm{E}-$ $65^{\circ} 10.8^{\prime} \mathrm{N} \quad 35^{\circ} 51.6^{\prime} \mathrm{E}, \quad 9-22 \mathrm{~m}$, summer 1877, coll. Merejkowsky.

Paralectotypes: ZIN RAS 10611 (specimen and slide 5526b) and ZIN RAS 10612 (four specimens), from the same sample as the lectotype.
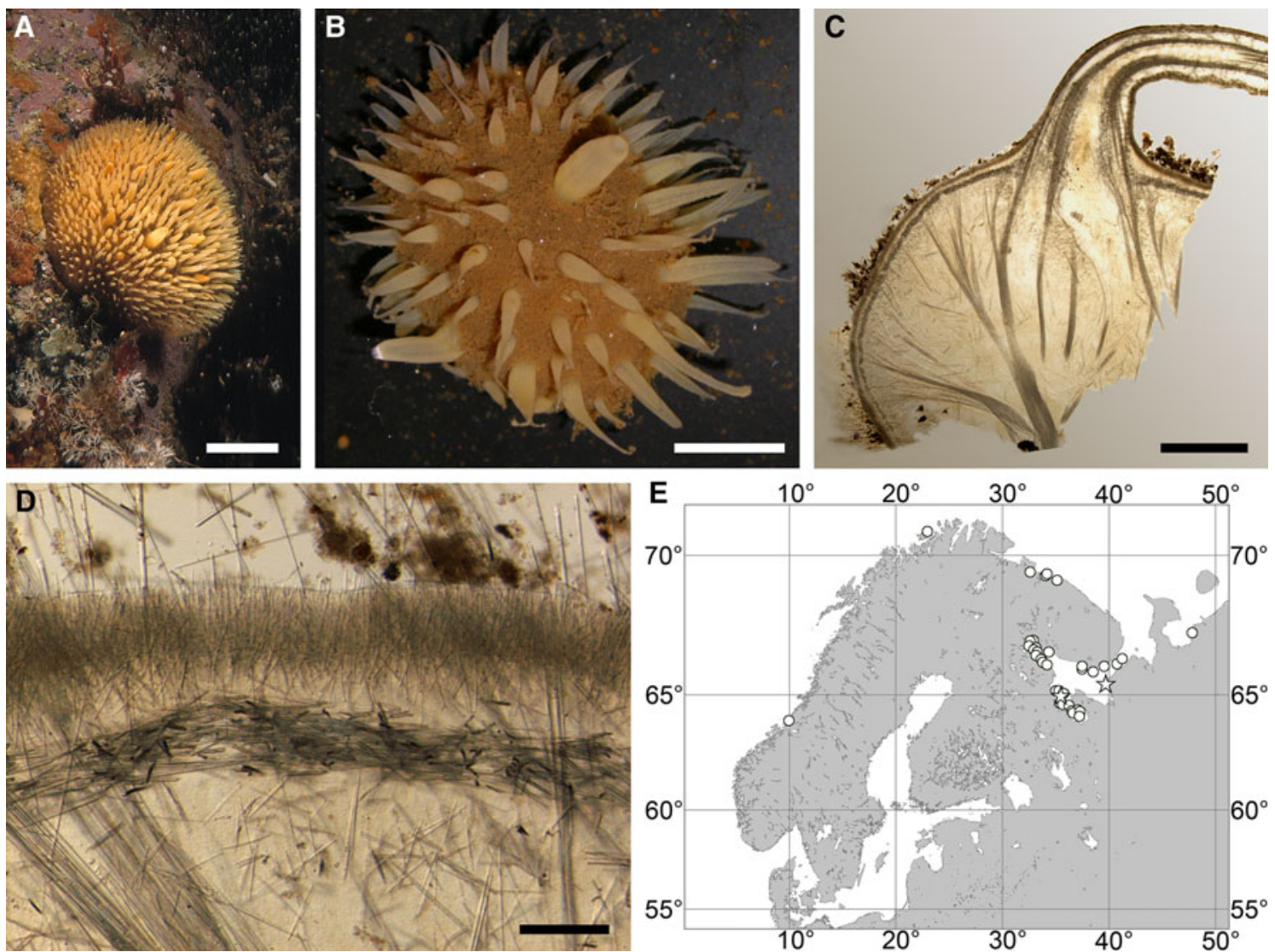

Fig. 3. Polymastia arctica: (A) an individual in situ, Kandalaksha Bay, White Sea (courtesy of M. Fedyuk, St. Petersburg State University); (B) an individual in aquarium; (C) ZMBN 098068, longitudinal section through the body, general view; (D) the same section, detail of cortex; (E) distribution: white stars, type localities; white circles, our data. Scale bars: A, $2 \mathrm{~cm}$; B, $1 \mathrm{~cm}$; C, $3 \mathrm{~mm}$; D, $0.2 \mathrm{~mm}$. 
Paralectotypes: ZIN RAS 10613 (two specimens and slide 9112), Cape Kerets, Dvina Bay, White Sea, $65^{\circ} 25^{\prime} \mathrm{N} 39^{\circ} 38^{\prime} \mathrm{E}$, $11 \mathrm{~m}, 22.06 .1876$, coll. Merejkowsky.

Detailed description of the type material was presented by Plotkin \& Boury-Esnault (2004).

\section{COMPARATIVE MATERIAL}

(see Online resource 1 for details)

Norway: Sør-Trøndelag: NTNU-VM-55865 (two specimens), Finnmark: ZMBN 098065 and ZMBN 098068 (two specimens).

Russia: Murman Coast: ZIN RAS ocpmo78, ZIN RAS ocpmo79, ZIN RAS ocpm131, ZIN RAS ocpm132, ZIN RAS ocpm148 (five specimens), Chyosha Bay of the Barents Sea: ZIN RAS ocpm145 (one specimen), White Sea: ZMBN 098060, ZMBN 098062, ZMBN 098063 (three specimens) and 114 specimens deposited in ZIN RAS.

\section{DESCRIPTION}

\section{External morphology}

Cushion-shaped sponges covering the substrate and occupying up to $100 \mathrm{~cm}^{2}$ (Figure $3 \mathrm{~A}, \mathrm{~B}$ ). Surface thickly or thinly hispid, usually covered with sediment, with up to several hundred papillae. In living sponges the colour of papillae and the areas of the surface free of sediment cream to yellowish. Most papillae inhalant, cylindrical in shape, $2-18 \mathrm{~mm}$ in length and 1-6 mm in diameter. Average density of the inhalant papillae 13 per $1 \mathrm{~cm}^{2}$ of the surface. The inhalant papillae may bear at the summits threads with up to six buds arranged in line (Figure ${ }_{3} \mathrm{~B}$ ). Exhalant papillae usually conical, 3$12 \mathrm{~mm}$ long, 3-7 mm wide at base and $1-5 \mathrm{~mm}$ wide at summit, with oscula about $0.5 \mathrm{~mm}$ in diameter. One sponge may have up to 19 exhalant papillae.

\section{Anatomy}

Choanosome in life orange, dense. Main choanosomal skeleton composed of radial, or longitudinal tracts (170$460 \mu \mathrm{m}$ thick) of principal spicules branching in the subcortical area, crossing the cortex and forming a surface hispidation (Figure $3 \mathrm{C}$ ). Ascending tracts also form a framework of the papilla skeleton. Auxiliary choanosomal skeleton comprises free-scattered bundles, each of two to five small spicules, being especially abundant in the subcortical area. Cortex in life cream-coloured, firm, not detachable. Cortical skeleton constituted by a superficial palisade $(180-310 \mu \mathrm{m}$ thick $)$ of small spicules, a middle layer ( $90-180 \mu \mathrm{m}$ thick) of collagen fibres with low density of spicules and an internal layer $(160-250 \mu \mathrm{m}$ thick) of tangentially arranged intermediary spicules (Figure $3 \mathrm{D}$ ). Skeleton of the papilla walls composed of two layers only, the superficial palisade and the internal tangential layer. Single intermediary spicules reinforce the bulkheads separating aquiferous canals and vestibules in the papillae.

\section{Spicules}

(measurements based on 43 specimens)

Principal spicules - subtylostyles, straight, fusiform. Length $620-868-1100 \mu \mathrm{m}$, maximal diameter of shaft $8.8-14.3^{-}$ $20.0 \mu \mathrm{m}, \mathrm{N}=500$.

Intermediary spicules - subtylostyles, straight or gently bent, slender. Length $270-414-550 \mu \mathrm{m}$, diameter of shaft $5.0-$ 9.5-17.5 $\mu \mathrm{m}, \mathrm{N}=500$.
Small spicules - tylostyles, gently bent, fusiform. Length $120-$ $161-215 \mu \mathrm{m}$, diameter of tyle $3.8-5.5-7.5 \mu \mathrm{m}$, maximal diameter of shaft $3.8-4.8-6.3 \mu \mathrm{m}, \mathrm{N}=500$.

\section{Genetic data}

CO1 sequences obtained from five individuals of Polymastia arctica are identical, but these individuals differ in $28 \mathrm{~S}$ rDNA (Matrix M34250 in TreeBase) and, moreover, three of them exhibit a polymorphism in this gene (Matrix M34256 in TreeBase). By both genes P. arctica is closely related to $P$. andrica and $P$. grimaldii (see the synapomorphies in the Genetic data section for P. andrica above). $28 \mathrm{~S}$ rDNA of these three species displays a high level of intraspecific and intragenomic polymorphism, while the $\mathrm{CO}_{1}$ data are consistent (Plotkin et al., 2016b). In this gene P. arctica has two autapomorphies (Online resource 2, p. 1). Apart from them, $P$. arctica differs from $P$. andrica by 7 bps, from $P$. grimaldii by 11 bps and from the type species of Polymastia, P. mamillaris, by 28 bps in $\mathrm{CO}_{1}$ (Matrix M34248 in TreeBase).

\section{OCCURRENCE}

\section{(Figure ${ }_{3} \mathrm{E}$ )}

Literature data: Norwegian Coast: Troms and Finnmark (73$182 \mathrm{~m}$ ) (as Polymastia mammilaris - Arnesen, 1918). Norwegian and Barents Sea (as P. mamillaris - Koltun, 1966). White Sea (as Rinalda arctica - Merejkowsky, 1878, 1880; as P. penicillus - Swarczewsky, 1906; as P. mamillaris - Koltun, 1966).

Our data: Norwegian Coast: Sør-Trøndelag (27-50 m), Finnmark $(127 \mathrm{~m})$. Barents Sea: Murman Coast (6o$108 \mathrm{~m})$, Chyosha Bay (7 m). White Sea (4-109 m).

\section{DISCUSSION}

Polymastia arctica is morphologically very similar to $P$. andrica and $P$. mamillaris. The main feature distinguishing $P$. arctica from the latter two is the presence of threads with buds at the summits of some inhalant papillae (Arnesen, 1918; Plotkin \& Ereskovsky, 1997), although the budding intensity in the populations displays a considerable seasonal fluctuation with some individuals stopping bud formation in the warmest period (Plotkin \& Ereskovsky, 1997). Additionally $P$. arctica differs from $P$. andrica by the absence of exotyles and from $P$. mamillaris by the relatively thicker middle cortical layer and the presence of spicules in the bulkheads separating aquiferous canals in the papillae. Some minute differences between these three species in the shape of spicules were also reported, e.g. principal spicules usually being fusiform subtylostyles in P. arctica and strongyloxeas in P. mamillaris (Plotkin \& Boury-Esnault, 2004), but our study has revealed instability of this character. All genetic data obtained support the discrimination between $P$. arctica and P. mamillaris based on morphology. The morphological differences between $P$. arctica and $P$. andrica are only confirmed by the $\mathrm{CO}_{1}$ data, but not by $28 \mathrm{~S}$ rDNA.

\section{Polymastia cf. bartletti de Laubenfels, 1942} (Figure 4)

Original description: Polymastia bartletti de Laubenfels, 1942, p. 265. 

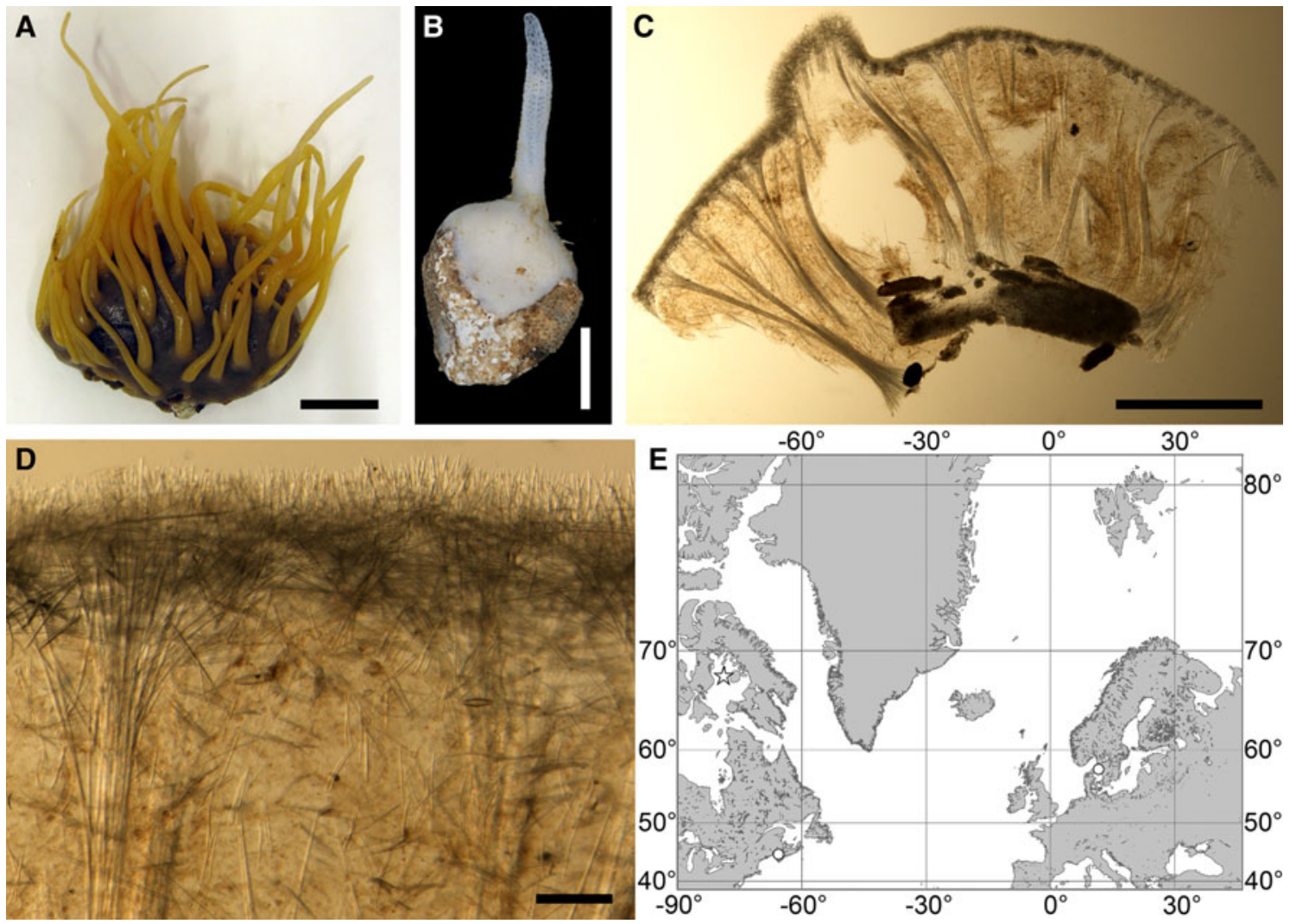

Fig. 4. Polymastia bartletti: (A) ZMBN 098111, habitus; (B) GNM 904:1, habitus; (C) ZMBN o98111, longitudinal section through the body, general view; (D) the same section, detail of cortex; (E) distribution: white stars, type localities; white circles, our data. Scale bars: A, $2 \mathrm{~cm}$; B, o.5 cm; C, $3 \mathrm{~mm}$; D, o.2 mm.

TYPE MATERIAL

Holotype (not studied): USNM 22692 (in the Smithsonian National Museum of Natural History, Washington), Foxe Basin, Nunavut, Canada, $67^{\circ} 45^{\prime} \mathrm{N} \quad 79^{\circ} 09^{\prime} \mathrm{W}, 69 \mathrm{~m}$, 24.08.1927, coll. Bartlett.

\section{MATERIAL EXAMINED}

(see Online resource 1 for details)

Canada: Nova Scotia: ZMBN 098111 (one specimen).

Sweden: Västra Götaland, Kattegat: GNM 904:1 (one specimen, identification under doubt).

\section{DESCRIPTION}

\section{External morphology}

Cushion-shaped sponges covering the substrate. Surface smooth, free of sediment, with long papillae lacking visible oscula. Canadian sponge $\sim 51 \times 42 \times 4 \mathrm{~mm}$ in size, with 45 cylindrical papillae, which are 14-44 $\mathrm{mm}$ long and 1-4 $\mathrm{mm}$ wide. In life the surface is brown and the papillae are yellowish (Figure $4 \mathrm{~A}$ ). In alcohol both the surface and the papillae have become whitish. Swedish sponge $12 \times 9 \times 0.7 \mathrm{~mm}$ in size, with one cylindrical papilla which is $12 \mathrm{~mm}$ long and $1.8 \mathrm{~mm}$ wide (Figure $4 \mathrm{~B}$ ). Surface and papilla are whitish in alcohol.

\section{Anatomy}

Choanosome in alcohol whitish, dense. In both sponges studied main choanosomal skeleton composed of tracts of principal spicules (Figure ${ }_{4} \mathrm{C}$ ). The tracts, $71-135 \mu \mathrm{m}$ thick in the middle of the body, radiate towards the base and the cortex. Ascending tracts also form a framework of the papilla skeleton. Examination of the auxiliary choanosomal skeleton and the cortex in the Swedish individual was not possible because of its small size. In the Canadian sponge the auxiliary choanosomal skeleton comprises small and intermediary spicules, most free-scattered, some in bundles of three to seven. Cortex dense, but friable, not detachable. Cortical skeleton constituted by a superficial palisade (106$166 \mu \mathrm{m}$ thick) of small spicules, which is overlapped with an inner layer (203-286 $\mu \mathrm{m}$ thick) of criss-cross intermediary spicules (Figure $4 \mathrm{D}$ ).

\section{Spicules}

GNM 904:1 (Sweden):

Principal spicules - mainly styles, occasionally subtylostyles with weakly developed tyles, usually straight, fusiform. Length 568-752-905 $\mu \mathrm{m}$, proximal diameter of shaft 2.510.2-12.7 $\mu \mathrm{m}$, maximum diameter of shaft 6.4-14.1$16.5 \mu \mathrm{m}, \mathrm{N}=30$.

Intermediary spicules - subtylostyles to styles, usually gently curved, slightly fusiform. Length 246-391-503 $\mu \mathrm{m}$, diameter of tyle (if present) 6.4-9.2-12.7 $\mu \mathrm{m}$, proximal diameter of shaft 5.1-8.0-10.2 $\mu \mathrm{m}$, maximum diameter of shaft 7.610.1-12.7 $\mu \mathrm{m}, \mathrm{N}=30$.

Small spicules - tylostyles, usually gently curved, slender. Length $94-134-165 \mu \mathrm{m}$, diameter of tyle $3.8-5.2-7.6 \mu \mathrm{m}$, proximal diameter of shaft 2.0-3.6-5.1 $\mu \mathrm{m}$, maximum diameter of shaft $2.5-4.0-5.1 \mu \mathrm{m}, \mathrm{N}=30$.

ZMBN 098111 (Canada):

Principal spicules - styles, usually straight, fusiform. Length 930-1162-1327 $\mathrm{m}$, proximal diameter of shaft 10.2- 
12.1-15.2 $\mu \mathrm{m}$, maximum diameter of shaft 14.0-17.1$20.3 \mu \mathrm{m}, \mathrm{N}=30$.

Intermediary spicules - subtylostyles to styles, usually gently curved, slightly fusiform. Length $467-565-648 \mu \mathrm{m}$, diameter of tyle (if present) 8.9-10.2-12.7 $\mu \mathrm{m}$, proximal diameter of shaft 7.6-8.4-10.2 $\mu \mathrm{m}$, maximum diameter of shaft $10.2-$ $11.8-15.2 \mu \mathrm{m}, \mathrm{N}=30$.

Small spicules - tylostyles, usually gently curved, slender. Length 127-161-192 $\mu \mathrm{m}$, diameter of tyle 4.6-5.3$6.4 \mu \mathrm{m}$, proximal diameter of shaft $2.5-3.5-5.1 \mu \mathrm{m}$, maximum diameter of shaft $3.8-5-6.4 \mu \mathrm{m}, \mathrm{N}=30$.

Holotype USNM 22692 (according to de Laubenfels, 1942): Principal choanosomal spicules - tylostyles. Length 540$600 \mu \mathrm{m}$, diameter of shaft $9-12 \mu \mathrm{m}$.

Small choanosomal spicules - length $200 \mu \mathrm{m}$, diameter of shaft $4 \mu \mathrm{m}$.

Cortical spicules (de Laubenfels did not distinguish between small and intermediary cortical spicules) - tylostyles. Length 350-400 $\mu \mathrm{m}$, diameter of shaft $6 \mu \mathrm{m}$.

\section{Genetic data}

The Canadian Polymastia bartletti and the Swedish Polymastia cf. bartletti are distinguished by two bps in $\mathrm{CO}_{1}$ (Matrix M34248 in TreeBase) and four bps in $28 \mathrm{~S}$ rDNA (Matrix M34250 in TreeBase). At the same time these sponges share nine synapomorphies in $\mathrm{CO}_{1}$ (Online resource 2 , p. 3) and two synapomorphies in $28 \mathrm{~S}$ rDNA (Online resource 3, p. 3) distinguishing them from other polymastiids. Apart from these synapomorphies, both $P$. bartletti and $P$. cf. bartletti differ from morphologically similar $P$. nivea by 27 bps in CO1 (Matrix M34248 in TreeBase) and 6o bps in $28 \mathrm{~S}$ rDNA (Matrix M34250 in TreeBase) and from the type species of Polymastia, $P$. mamillaris, by $61 \mathrm{bps}$ in $\mathrm{CO}_{1}$ (Matrix M34248 in TreeBase) and $84 \mathrm{bps}$ in $28 \mathrm{~S}$ rDNA (Matrix M34250 in TreeBase).

\section{OCCURRENCE}

(Figure $4 \mathrm{E}$ )

Literature data: Canadian Atlantic Coast: Foxe Basin (69 m) (de Laubenfels, 1942).

Our data: Canadian Atlantic Coast: Nova Scotia (depth unknown). Swedish Western Coast: Kattegat (19-31 m).

\section{DISCUSSION}

Before our study Polymastia bartletti was known only from the type locality, the Foxe Basin (de Laubenfels, 1942). We have identified as $P$. bartletti a specimen from Newfoundland based on its external and anatomical similarities with the original description, and a specimen from Sweden based on the similarities of its external features and DNA with the Newfoundland sponge. But we cannot exclude that the Swedish individual may in fact represent another species since its spicules in all categories are slightly shorter than those in the Canadian individual, and the sequences of the phylogenetic markers from these sponges are not completely identical. More careful morphological examination and genetic studies of larger material are required to check this assumption.

Polymastia bartletti is morphologically very similar to the NE Atlantic species, $P$. nivea. Discrimination between these two species is based mainly on their large genetic difference. In its turn $P$. nivea was often confused with $P$. robusta
Bowerbank, 1862 and P. boletiformis (e.g. Koltun, 1966). Polymastia nivea and P. boletiformis in fact differ considerably both in morphology (Plotkin, 2004; Plotkin et al., 2012; present study) and genetics (Plotkin et al., 2016b; present study), while the status of $P$. robusta is questionable (Plotkin et al., 2012; present study). The records of $P$. robusta from the Canadian Atlantic (e.g. Lambe, 1896; Whiteaves, 1901) may indicate $P$. bartletti, but the respective material should be re-examined to test this assumption.

\section{Polymastia boletiformis (Lamarck, 1815)}

(Figure 5)

Original description: Alcyonium boletiforme Lamarck, 1815, p. 332.

\section{SYNONYMS AND CITATIONS}

Polymastia boletiformis (Burton, 1959a, 11 pars.; Van Soest et al., 2000, 2016; Van Soest, 2001, p. 74; Morrow et al., 2012, p. 177; Plotkin et al., 2012, p. 25, figure 1i).

Polymastia robusta (Topsent, 1900, p. 147, pl. IV figures 37, 14; Arndt, 1928, p. 31, figure 29a; 1933, p. 45; Burton, 1930a, p. 496; Arndt, 1935, p. 34, figure 51; Alander, 1942, p. 75 ; Borojevic, 1967 , p. 1 , pls I-II; Cabioch, 1968 , p. 215 ; Boury-Esnault, 1987, p. 44, figure 8).

\section{TYPE MATERIAL}

Lamarck (1815) reported neither the museum number, nor the type locality in the original description. Topsent (1933) examined a sponge with Lamarck's original label 'Alcyonium boletiforme' considered as the holotype of this species and stored in MNHN. Since then nobody has re-examined this individual and it is regarded as lost by MNHN.

\section{MATERIAL EXAMINED}

(see Online resource 1 for details)

Sweden: Västra Götaland: GNM 901:1, GNM 903:1 and GNM 903:2 (three specimens).

Norway: Vest-Agder: ZMBN 098088 and ZMBN 098089 (two specimens), Rogaland: ZMBN 107584 and ZMBN 107585 (three specimens), Hordaland: ZMBN 098047, ZMBN 098048, ZMBN 098081, ZMBN 107559, ZMBN 107560, ZMBN 107562, ZMBN 107563, ZMBN 107564, ZMBN 107565, ZMBN 107566, ZMBN 107567, ZMBN 107568, ZMBN 107569, ZMBN 107571 (14 specimens), Møre and Romsdal: ZMBN 107493, ZMBN 107570 (two specimens).

\section{DESCRIPTION}

\section{External morphology}

Sponges cushion-shaped, covering the substrate or massive (Figure $5 \mathrm{~A}$ ). The largest individuals may occupy up to $100 \mathrm{~cm}^{2}$. Surface smooth, sometimes covered with sediment, with cylindrical or conical papillae. In living sponges both the surface and the papillae bright orange or yellow. Inhalant papillae 6-18 $\mathrm{mm}$ long and $2-5 \mathrm{~mm}$ wide. About $2-3$ inhalant papillae per $1 \mathrm{~cm}^{2}$ of the surface. Exhalant papillae $16-36 \mathrm{~mm}$ long and $3-6 \mathrm{~mm}$ wide, with well visible oscula at the summits. A sponge may bear 1-6 exhalant papillae.

\section{Anatomy}

Choanosome in life slightly darker than cortex, crumbly. Main choanosomal skeleton composed of tracts of principal spicules 

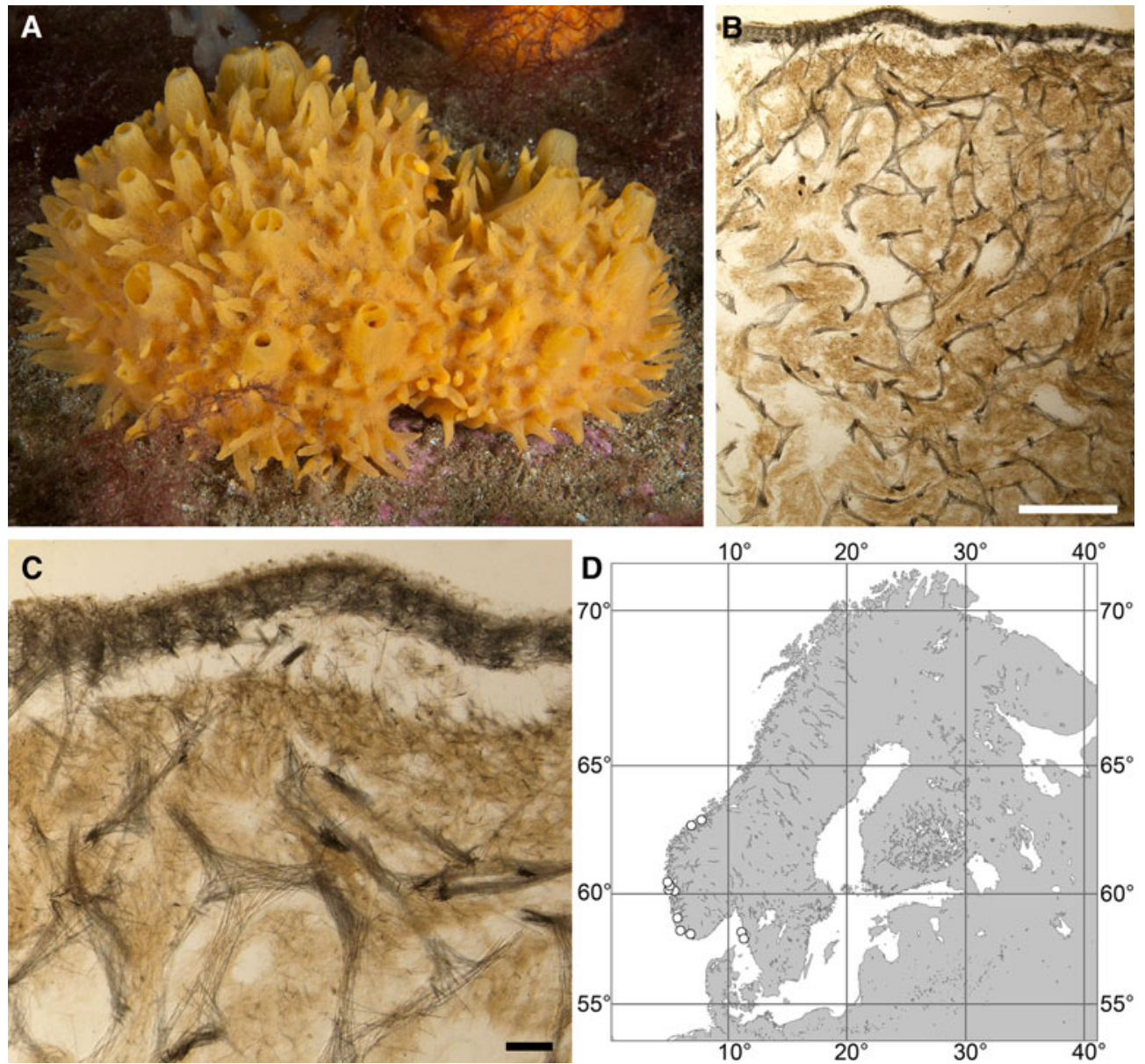

Fig. 5. Polymastia boletiformis: (A) an individual in situ, Tingelsædet, Egersund, Norway (courtesy of E. Svensen, OceanPhoto/Dalane Tidende AS, Egersund); (B) ZMBN 107563, longitudinal section through the body, general view; (C) the same section, detail of cortex and subcortical area; (D) distribution along the Scandinavian Coast: white circles, our data; for distribution in other regions see Boury-Esnault (1987; as Polymastia robusta). Scale bars: B, 2 mm; C, 0.5 mm.

forming a reticulation or meanders (Figure ${ }_{5} \mathrm{~B}, \mathrm{C}$ ). Ascending tracts form a framework of the papilla skeleton. Auxiliary choanosomal skeleton comprises free-scattered principal spicules. Cortex leather-like, easily detachable. Cortical skeleton constituted by a superficial palisade $(80-250 \mu \mathrm{m}$ thick) of small spicules and an internal layer $(169-420 \mu \mathrm{m}$ thick) of criss-cross principal spicules (Figure $5 \mathrm{C}$ ). Aquiferous cavities connected with ostia in the surface and separated by bundles of intermediary spicules lie in a space $(125-400 \mu \mathrm{m}$ thick) between the cortex and the choanosome. Both cortical layers extend to the walls of papillae. Each papilla bears several inhalant canals, and in exhalant papilla there are also one to three exhalant canals located midmost. Bulkheads separating the canals are reinforced with free-scattered principal spicules.

\section{Spicules}

(Measurements based on four specimens)

Principal spicules - subtylostyles, straight or gently curved, slender or slightly fusiform. Length $261-540-735 \mu \mathrm{m}$, proximal diameter of shaft 5.1-6.7-9.0 $\mu \mathrm{m}$, maximum diameter of shaft 7.5-10.4-12.7 $\mu \mathrm{m}, \mathrm{N}=120$.

Small spicules - subtylostyles with weakly developed tyles, usually gently bent in the proximal part, slender. Length 91-153-232 $\mu \mathrm{m}$, proximal diameter 2.0-3.1-3.9 $\mu \mathrm{m}$, maximum diameter of shaft $2.0-3.2-3.9 \mu \mathrm{m}, \mathrm{N}=124$.

\section{Genetic data}

In both $\mathrm{CO} 1$ and $28 \mathrm{~S}$ rDNA phylogenies Polymastia boletiformis is the sister to morphologically quite distinct Quasillina brevis (Bowerbank, 1866) (Plotkin et al., 2016b). These species share three synapomorphies in $\mathrm{CO}_{1}$ (Online resource 2 , p. 4) and 24 synapomorphies in $28 \mathrm{~S} \mathrm{rDNA}$ (Online resource 3, p. 4). CO1 data were obtained from two specimens of $P$. boletiformis, of which one differs from $Q$. brevis just by one bp in this gene, while the other differs from Q. brevis by six bps (Matrix M34248 in TreeBase). 28S rDNA sequences obtained from six Scandinavian P. boletiformis are identical to the sequences of a British P. boletiformis (GenBank accessions HQ379232, HQ379306 and HQ379372, Morrow et al., 2012) and display six synapomorphies distinguishing them from all other polymastiids (Online resource 3, p. 4). Apart from these synapomorphies, $P$. boletiformis differs from $Q$. brevis by 17 bps in $28 \mathrm{~S}$ rDNA (Matrix M34250 in TreeBase) and from the type species of Polymastia, P. mamillaris by 64-67 bps in $\mathrm{CO}_{1}$ (considering the intraspecific polymorphism, Matrix M34248) and 89 bps in $28 \mathrm{~S}$ rDNA (Matrix M34250).

\section{OCCURRENCE}

Literature data: Portuguese, Spanish and French Atlantic Coast (as Polymastia robusta - Topsent, 1900; Borojevic, 1967; Cabioch, 1968; Boury-Esnault, 1987). Mediterranean 
Sea, English Channel (as Polymastia robusta - Boury-Esnault, 1987). British Isles (as P. robusta - Boury-Esnault, 1987; as P. boletiformis - Van Soest et al., 2000, 2016). Sweden (as $P$. robusta - Alander, 1942). Depths - from $10 \mathrm{~m}$ and deeper down the shelf (Boury-Esnault, 1987). Records from the continental slope, $2354 \mathrm{~m}$ by Burton (1959a) and $1267 \mathrm{~m}$ by Boury-Esnault (1987), cause doubt.

Our data (Figure 5D): Skagerrak: Swedish Western Coast (22$60 \mathrm{~m})$. Norwegian Coast: Vest-Agder $(30-40 \mathrm{~m})$, Rogaland $(18-31 \mathrm{~m})$, Hordaland $(18-40 \mathrm{~m})$, Møre and Romsdal (20$130 \mathrm{~m})$.

\section{DISCUSSION}

Polymastia boletiformis has a confused taxonomic history. Since the description of Alcyonium boletiforme from an unknown locality by Lamarck (1815) this name had not been in use until Topsent (1933) reported that Lamarck's type material and Polymastia robusta Bowerbank, 1862 from the British Isles were the same species. Although A. boletiforme was an older name than $P$. robusta Topsent (1933) relegated the former to a synonym of the latter, and this was followed by most of the later authors (e.g. Arndt, 1935; Alander, 1942; Koltun, 1966; Cabioch, 1968; Boury-Esnault, 1987) except for Burton (1959a) who retained the name $P$. boletiformis. In the recent literature (Van Soest et al., 2000; Van Soest, 2001, 2016; Morrow et al., 2012; Plotkin et al., 2012) the name $P$. boletiformis was, however, prioritized instead of $P$. robusta following the principle of priority (Article 23.1 in Anonymous, 1999).

Polymastia robusta/P. boletiformis was recorded from a large geographic area from the Canadian Atlantic Coast (Lambe, 1896; Whiteaves, 1901) and Iceland (Burton, 1959a) to the European Atlantic Coast (Topsent, 1900; Arndt, 1935; Borojevic, 1967; Cabioch, 1968; Boury-Esnault, 1987), British Isles (Boury-Esnault, 1987; Van Soest et al., 2000), Swedish Coast (Alander, 1942), Norwegian Coast (Burton, 1930a), Barents Sea (Topsent, 1913) and Arctic Ocean (Koltun, 1966). The depth range recorded for $P$. robusta/P. boletiformis was also very large with the extreme deep-sea records by Burton (1959a) and BouryEsnault (1987). Furthermore, four species were relegated to synonyms of $P$. robusta: $P$. bulbosa Bowerbank, 1866 and $P$. ornata Bowerbank, 1866 from the British Isles by Topsent (1900), Reniera nivea Hansen, 1885 from the Norwegian Sea by Burton (1930a) and P. euplectella Rezvoj, 1927 from the Barents and White Sea by Koltun (1966).

However, Plotkin (2004) demonstrated clear morphological distinctions between $P$. euplectella and $P$. robusta, a radial choanosomal skeleton and three size categories of spicules in the former against a reticulate skeleton and two spicule categories in the latter. The present study has confirmed these differences by genetic data. Meanwhile, we have revealed the strong similarities between $P$. euplectella and Reniera nivea, relegating the former to a synonym of the latter (see Description of Polymastia nivea below). We can now assume that all records of $P$. robusta/P. boletiformis to the North and North-East from Nordmøre Coast in Norway very probably indicate $P$. nivea. Moreover, the present study has shown that $P$. bartletti, a Canadian species morphologically very similar to the Arctic-Scandinavian $P$. nivea, differs greatly from the latter as well as from the European $P$. boletiformis by genetics. We can therefore assume that the records of $P$. robusta/P. boletiformis from
Canada may indicate $P$. bartletti (see the description of this species above). Finally, we have examined one of the dry syntypes of $P$. robusta BMNH 1930.7.3.20 and found that its choanosomal skeleton is radial as distinct from the commonly accepted definition of P. boletiformis (Boury-Esnault, 1987; Van Soest et al., 2000; Plotkin et al., 2012), but the condition of the syntypes prevents us from more detailed study. Unfortunately we have not examined $P$. bulbosa and $P$. ornata, and therefore we cannot conclude whether these two are separate species or conspecific with P. boletiformis, $P$. robusta or some other species.

Thus, for the moment, we gather under the name $P$. boletiformis South European, British and South Scandinavian Polymastia with intensive orange or yellow colour, a smooth surface with differentiated exhalant and inhalant papillae, a reticulate choanosomal skeleton and two spicule categories. These morphological similarities are confirmed by the genetic identity of the British and South Scandinavian individuals.

\section{Polymastia grimaldii (Topsent, 1913)} (Figure 6)

Original description: Trichostemma grimaldii Topsent, 1913, p. 21, pl. I figure 4 .

\section{SYNONYMS AND CITATIONS}

Polymastia grimaldii (Topsent, 1927a, p. 257; Boury-Esnault, 1987 , p. 42, figure 7; Plotkin, 2004, p. 542, figures 1e \& 2e; Plotkin et al., 2012, p. 25, figure 2l).

Polymastia mamillaris (Vosmaer, 1885, p. 14, text-figure 5, pl. I figure 5, pl. III figures 10, 11-14, 21).

Polymastia mamillaris grimaldii (Koltun, 1966, p. 70, textfigures 39-40, pl. XX figures 1-5).

Polymastia mamillaris var. hyperborea Hentschel, 1916, p. 8 (Hentschel, 1929, pp. 868 and 923).

Polymastia penicillus (Vosmaer, 1882, p. 26, pl. I figures 12 \& 13, pl. IV figures 127-132; Hansen, 1885, p. 9; Fristedt, 1887, p. 434; Levinsen, 1887 , p. 346).

Radiella grimaldii (Burton, 1959a: 13; Koltun, 1964, p. 149).

\section{TYPE MATERIAL}

Lectotype of Trichostemma grimaldii (designated herein, Figure 6A-C): MOM 04-0840e, East off Iceland, $65^{\circ} 21^{\prime} \mathrm{N}$ $10^{\circ} 42^{\prime} \mathrm{W}, 650 \mathrm{~m}$, Campagnes scientifiques accomplies par le Prince Albert I de Monaco, RV 'Princesse-Alice', station 1040, 07.09.1898.

Paralectotypes of Trichostemma grimaldii: MOM 04o840a-d, f-1 (11 specimens), from the same sample as the lectotype.

Holotype of Polymastia mamillaris var. hyperborea Hentschel, 1916 (Figure 6D-F; herein considered as a synonym of Polymastia grimaldii): UPSZTY 2103, mouth of Nordfjorden, Svalbard, $\sim 78^{\circ} 27.5^{\prime} \mathrm{N} 15^{\circ} 03.0^{\prime} \mathrm{E}, 197-190 \mathrm{~m}$, Swedish expedition to Spitzbergen, station 99, 27.08.1908.

\section{COMPARATIVE MATERIAL}

(see Online resource 1 for details)

Canada: Newfoundland: ZIN RAS ocpgo59, ZIN RAS ocpgo6o, ZIN RAS ocpgo61, ZIN RAS ocpgo83, ZIN RAS ocpgog6 and ZMBN 098110 (six specimens).

Greenland: Kangerdlugssuaqfjord: ZMBN 107579 (one specimen). 

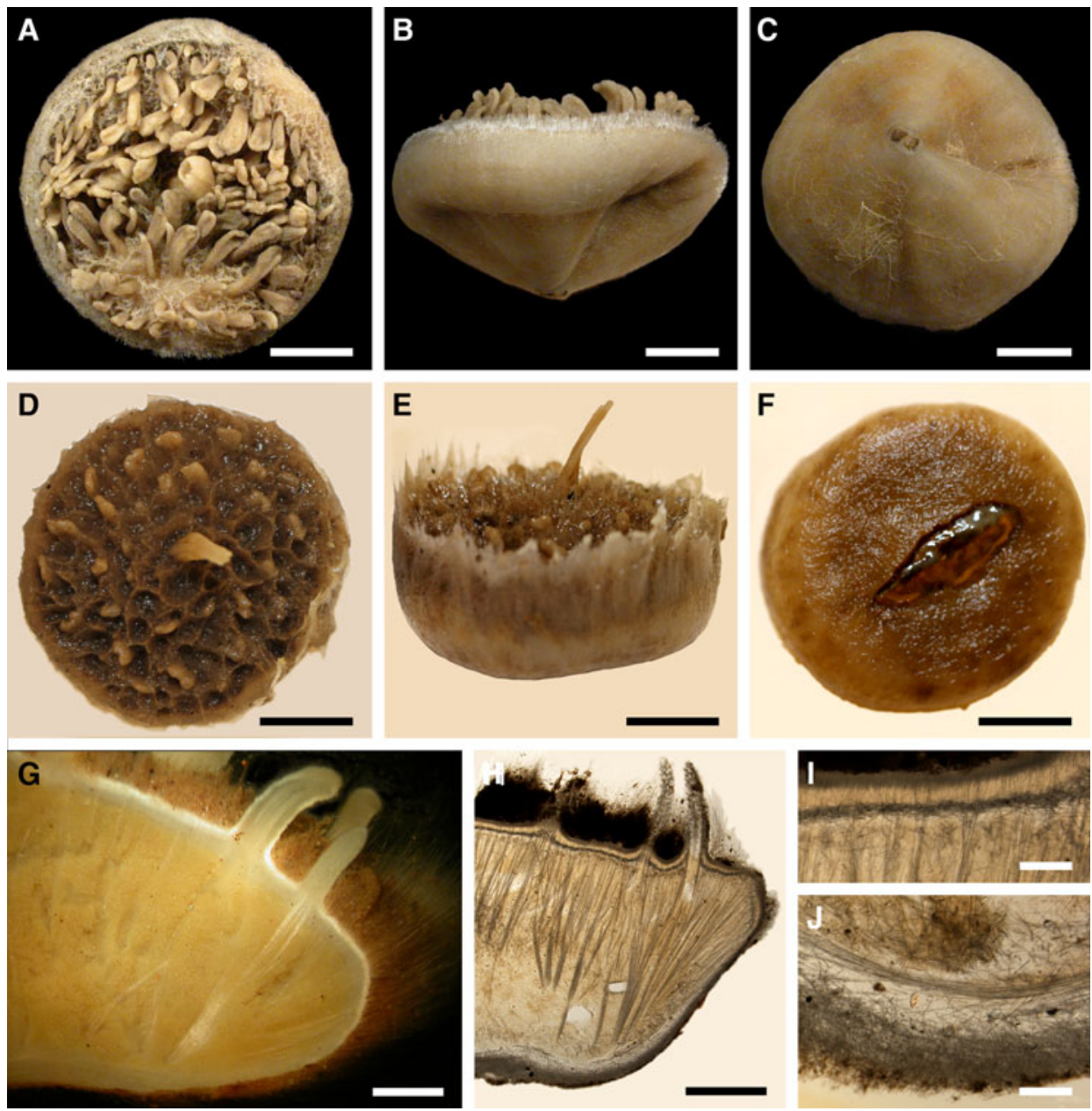

Fig. 6. Polymastia grimaldii: (A) lectotype of Trichostemma grimaldii, MOM o4-o840e, habitus, view from above; (B) the same, side view; (C) the same, bottom view; (D) holotype of Polymastia mamillaris var. hyperborea (synonym of P. grimaldii), UPSZTY 2103, habitus, view from above; (E) the same, side view; (F) the same, bottom view; $(\mathrm{G})$ a fresh dissected individual from the Kandalaksha Bay, White Sea, $(\mathrm{H}) \mathrm{ZMBN}$ 107576, longitudinal section through the body, general view; (I) the same section, detail of upper cortex; (J) the same section, detail of basal cortex. D-F: courtesy of P. Cárdenas, BioMedical Centre, University of Uppsala. Scale bars: A-F, $1 \mathrm{~cm}$; G-H, $3 \mathrm{~mm}$; $-\mathrm{J}$, $0.5 \mathrm{~mm}$.

Denmark Strait: ZIN RAS ocpg133 (one specimen).

Norwegian Sea, offshore: ZIN RAS ocpgo29, ZIN RAS ocpgo3o, ZIN RAS ocpgo82 and ZIN RAS ocpg116 (five specimens).

Barents Sea, offshore: ZMBN 098112, ZMBN 107576 (two specimens) and 156 specimens deposited in ZIN RAS.

Norway: Troms: ZIN RAS ocpgo75 (one specimen), Finnmark: ZMBN 098064 (one specimen).

Russia: Murman Coast: ZIN RAS ocpgo51 (one specimen), White Sea: ZIN RAS ocpgoo1, ZIN RAS ocpgoo2, ZIN RAS ocpgoo3, ZIN RAS ocpgoo4, ZIN RAS ocpg147, ZIN RAS ocpg 165 , ZIN RAS ocpg166 and ZIN RAS ocpg167 (10 specimens), Kanin Peninsula: ZIN RAS ocpgo88 (one specimen), Novaya Zemlya: ZIN RAS ocpg10, ZIN RAS ocpgoro and ZIN RAS ocpgo97 (seven specimens), Taymyr Peninsula: ZIN RAS ocpgo79, ZIN RAS ocpg126, ZIN RAS ocpg135, ZIN RAS ocpg143 and ZIN RAS ocpg158 (five specimens), Severnaya Zemlya: ZIN RAS ocpg16o (one specimen). Kara Sea: ZIN RAS ocpgo15, ZIN RAS ocpgo64, ZIN RAS ocpgo69, ZIN RAS ocpgo95, ZIN RAS ocpgo98, ZIN RAS ocpg100, ZIN RAS ocpg105, ZIN RAS ocpg113, ZIN RAS ocpg125 and ZIN RAS ocpg131 (10 specimens). Laptev Sea: ZIN RAS ocpg146 (one specimen).
East Siberian Sea: ZIN RAS ocpg163 (seven specimens). Arctic Ocean: ZIN RAS ocpg164 (four specimens).

\section{DESCRIPTION}

\section{External morphology}

Lectotype with almost circular, flat upper surface, $40-41 \mathrm{~mm}$ in diameter, and convex basal surface with a central point $22 \mathrm{~mm}$ distant from the upper surface (Figure 6A-C). Upper surface strongly hispid, greyish, with a single central exhalant papilla, cylindrical in shape, $9 \mathrm{~mm}$ long and $4 \mathrm{~mm}$ in diameter, and 118 inhalant papillae, most flattened, slightly widened towards the top, $1-6 \mathrm{~mm}$ in length and $0.7-2 \mathrm{~mm}$ in diameter at base (Figure 6A). Basal surface sleek, beige to grey, damaged in a central point indicating that the sponge was attached to a tiny substrate (Figure 6C). A fringe of extra-long spicules, $1.5 \mathrm{~mm}$ wide, developed at the sponge edge between the upper and basal surface (Figure 6B). Other sponges discoid, hemispherical with either the upper or the basal surface being convex, or sometimes lenticular. Upper surface up to $200 \mathrm{~cm}^{2}$, strongly hispid, usually covered with sediment, with up to 300 papillae, of which most are inhalant and one to six are exhalant, with well-visible oscula. The exhalant papillae cylindrical or conical, up to $16 \mathrm{~mm}$ in length. The inhalant 
papillae flattened, leaf-shaped, or sometimes cylindrical, up to $9 \mathrm{~mm}$ in length. Basal surface smooth, sometimes even sleek, attached to a small substrate only by a central point. Marginal fringe of extra-long spicules preventing sinking of the sponge into the sediment may be reduced in some individuals.

\section{Anatomy}

Choanosome in life pale orange or beige, firm (Figure 6G) Main choanosomal skeleton composed of tracts (65$655 \mu \mathrm{m}$ thick) of principal spicules radiating from sponge base and dividing into two to four thinner tracts, which cross the upper cortex and form a surface hispidation (Figure 6G, H). Ascending tracts also form a framework of the papilla skeleton. Auxiliary choanosomal skeleton comprises free-scattered small spicules, especially concentrating below the upper cortex. Cortex in life whitish, firm, not detachable (Figure 6G). Skeleton of the upper cortex constituted by a superficial palisade $(170-210 \mu \mathrm{m}$ thick) of small spicules, a middle layer $(100-180 \mu \mathrm{m}$ thick) of collagen fibres with low density of spicules and an internal layer $(100-140 \mu \mathrm{m}$ thick) of tangentially arranged intermediary spicules (Figure 6I). Skeleton of the basal cortex (520$700 \mu \mathrm{m}$ thick) formed by the peripheral tracts of principal spicules running parallel to the surface overlapped by a superficial palisade of small spicules and an inner confused mass of intermediary spicules (Figure 6J). Marginal fringe composed of bundles of extra-long spicules (exotyles) embedded into the cortex. Skeleton of the papilla walls composed of the superficial palisade and the internal tangential layer. Both inhalant and exhalant papillae with single central canals.

\section{Spicules}

(measurements based on 15 specimens)

Principal spicules - strongyloxeas, straight or gently curved. Length 1450-2358-3235, maximum diameter of shaft $21.0-24.8-29.2 \mu \mathrm{m}, \mathrm{N}=450$.
Intermediary spicules - tylostyles, straight or gently bent, fusiform. Length $212-445-671 \mu \mathrm{m}$, maximum diameter of shaft $15.8-18.4-24.0 \mu \mathrm{m}, \mathrm{N}=450$.

Small spicules - tylostyles to subtylostyles, straight or gently bent, usually slender. Length 147-228-287 $\mu \mathrm{m}$, maximum diameter of shaft $3.8-6.4-7.8 \mu \mathrm{m}, \mathrm{N}=450$.

Exotyles (spicules of the marginal fringe) - flexuous styles, occasionally subtylostyles. Length 2020-4527-7000 $\mu \mathrm{m}$, maximum diameter 8.0-9.4-10.6 $\mu \mathrm{m}, \mathrm{N}=150$.

\section{Genetic data}

CO1 sequences obtained from three individuals of Polymastia grimaldii are identical. $28 \mathrm{~S}$ rDNA available only from one of these individuals is polymorphic (Matrix M34256 in TreeBase). By both genes $P$. grimaldii is closely related to $P$. andrica and $P$. arctica (see the synapomorphies in the Genetic data section for $P$. andrica above). $28 \mathrm{~S}$ rDNA of these three species displays intraspecific and intragenomic polymorphism, while the $\mathrm{CO}_{1}$ data are consistent (Plotkin et al., 2016b). In CO1 P. grimaldii has one autapomorphy (Online resource 2, p. 1). Apart from the latter, this species differs from $P$. andrica by 12 bps, from $P$. arctica by 12 bps and from the type species of Polymastia, P. mamillaris, by 31 bps in $\mathrm{CO}_{1}$ (Matrix M34248 in TreeBase).

\section{OCCURRENCE}

(Figure 7)

Our data (agree with the literature data): Canadian Atlantic Coast: Newfoundland (315-440 m). Greenland Sea: (640$680 \mathrm{~m})$. Denmark Strait: $(511 \mathrm{~m})$. Norwegian Sea, offshore areas $(120-420 \mathrm{~m})$. Norwegian Coast: Troms $(320 \mathrm{~m})$, Finnmark $(211 \mathrm{~m})$. Barents Sea: Murman Coast (190 m), Kanin Peninsula $(62 \mathrm{~m})$, offshore areas $(53-460 \mathrm{~m})$. White Sea $(18-100 \mathrm{~m})$. Svalbard $(190-197 \mathrm{~m})$. Novaya Zemlya (93-459 m). Taymyr Peninsula $(23-58 \mathrm{~m})$. Severnaya Zemlya $(237 \mathrm{~m})$. Kara Sea $(49-305 \mathrm{~m})$. Laptev Sea $(51 \mathrm{~m})$. East Siberian Sea (73 m). Arctic Ocean (1900-1630 m).

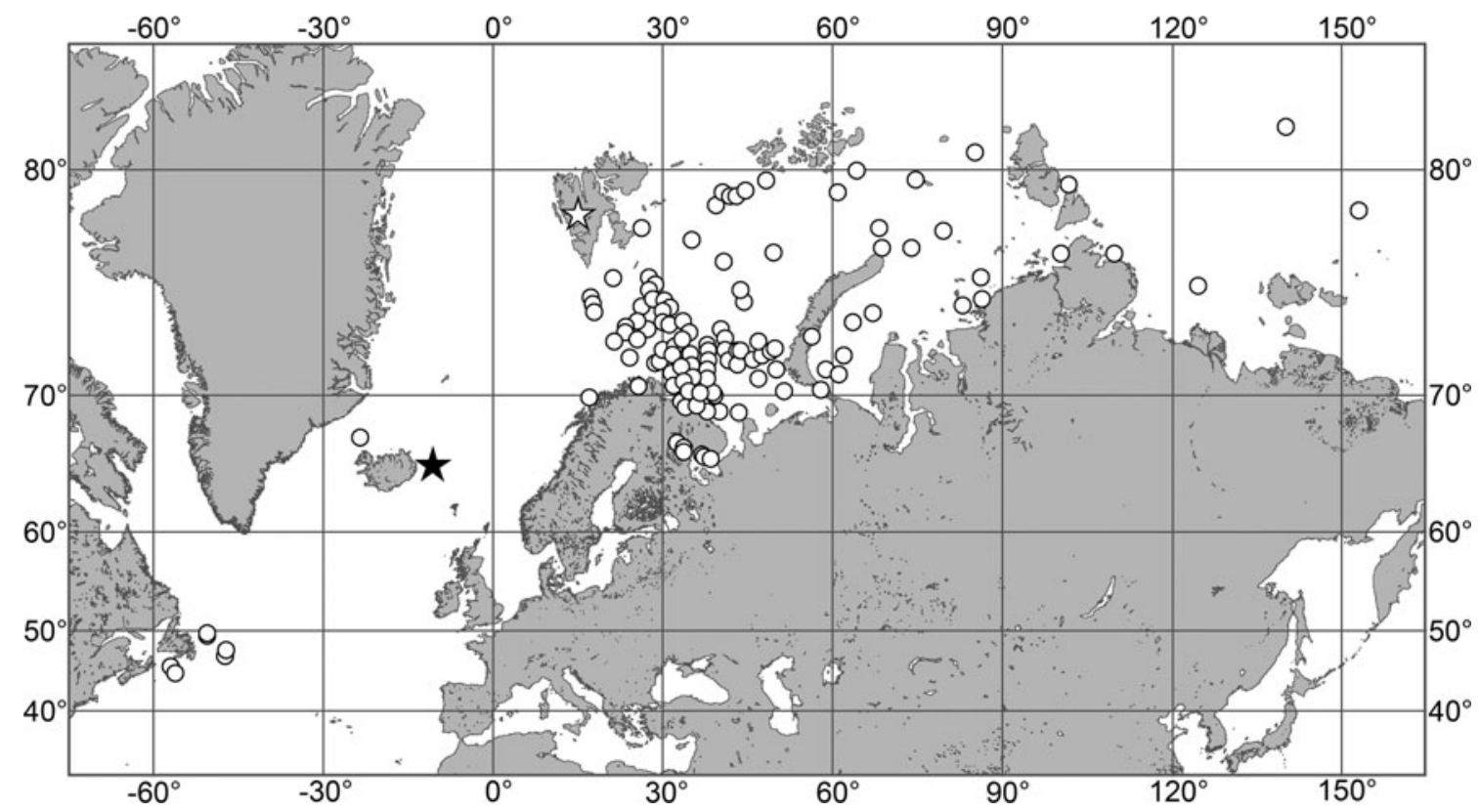

Fig. 7. Polymastia grimaldii, distribution: black star, type locality of Trichostemma grimaldii; white star, type locality of Polymastia mamillaris var. hyperborea (synonym of $P$. grimaldii); white circles, our data. 


\section{DISCUSSION}

Polymastia grimaldii was a key species in a long discussion on the relationships between a broadly acknowledged genus Polymastia and two genera with uncertain status, Radiella Schmidt, 1870 and Trichostemma Sars, 1872. The latter two names were since Schmidt (1880) often regarded as the synonyms for the same genus, but there were some debates about which of them should be considered as the senior name (see Discussion on Polymastia hemisphaerica (Sars, 1872) below) until Boury-Esnault (2002) relegated Trichostemma to a synonym of Radiella following the principle of priority (Article 23.1 in Anonymous, 1999).

Radiella/Trichostemma was usually distinguished from Polymastia by a radial growth pattern (a sponge attached to the substrate by a small point of the basal surface), the presence of a basal cortex distinct from the upper cortex and the presence of a fringe of extra-long monactines at the boundary between the upper and basal surface (Boury-Esnault, 2002; Plotkin et al., 2012). All these features are displayed by Polymastia grimaldii, but at the same time this species possesses numerous papillae and a three-layered cortex including a middle layer of collagen fibres that rather resemble the type species of Polymastia, P. mamillaris, than Radiella spp. or Trichostemma spp. (Boury-Esnault, 1987; Plotkin, 2004; Plotkin et al., 2012). Based on the similarities between P. grimaldii, P. mamillaris and other Polymastia spp. several early authors identified some sponges with evident distinctive features of Radiella/Trichostemma as P. penicillus (Vosmaer, 1882; Hansen, 1885; Fristedt, 1887; Levinsen, 1887) or P. mamillaris (Vosmaer, 1885). It was Topsent (1913) who established a new species, Trichostemma grimaldii, for the sponges combining the features of Radiella/Trichostemma and Polymastia. But, after a time, he re-considered the generic allocation of this species transferring it to Polymastia (Topsent, 1927a). In the same manner Koltun (1964) initially placed grimaldii in Radiella, but two years later (Koltun, 1966) relegated it to a subspecies of Polymastia mamillaris. The uncertainty about the taxonomic affinities of $P$. grimaldii was perfectly expressed by BouryEsnault (1987, p. 44): 'P. grimaldii may be considered as a step on the evolutionary line which starts at Polymastia advancing to Trichostemma'.

This uncertainty was recently resolved by the phylogenies reconstructed from $\mathrm{CO} 1$ and $28 \mathrm{~S}$ rDNA datasets (Plotkin et al., 2016b), where P. grimaldii formed a clade with Radiella hemisphaerica (formerly Trichostemma hemisphaericum, the type species of Trichostemma), P. mamillaris (the type species of Polymastia) and four other Polymastia spp. At the same time two species of Radiella grouped with the type species of Spinularia Gray, 1867, S. spinularia (Bowerbank, 1866), outside the Polymastia-clade (see Discussion on the genus Spinularia below). Consequently, grimaldii and hemisphaerica are now affiliated with Polymastia.

\section{Polymastia hemisphaerica (Sars, 1872)}

(Figure 8)

Original description: Trichostemma hemisphaericum Sars, 1872 , p. 62, pl. VI figures $1-15$.

\section{SYNONYMS AND CITATIONS}

Halicnemia hemisphaerica (von Marenzeller, 1878, p. 371).
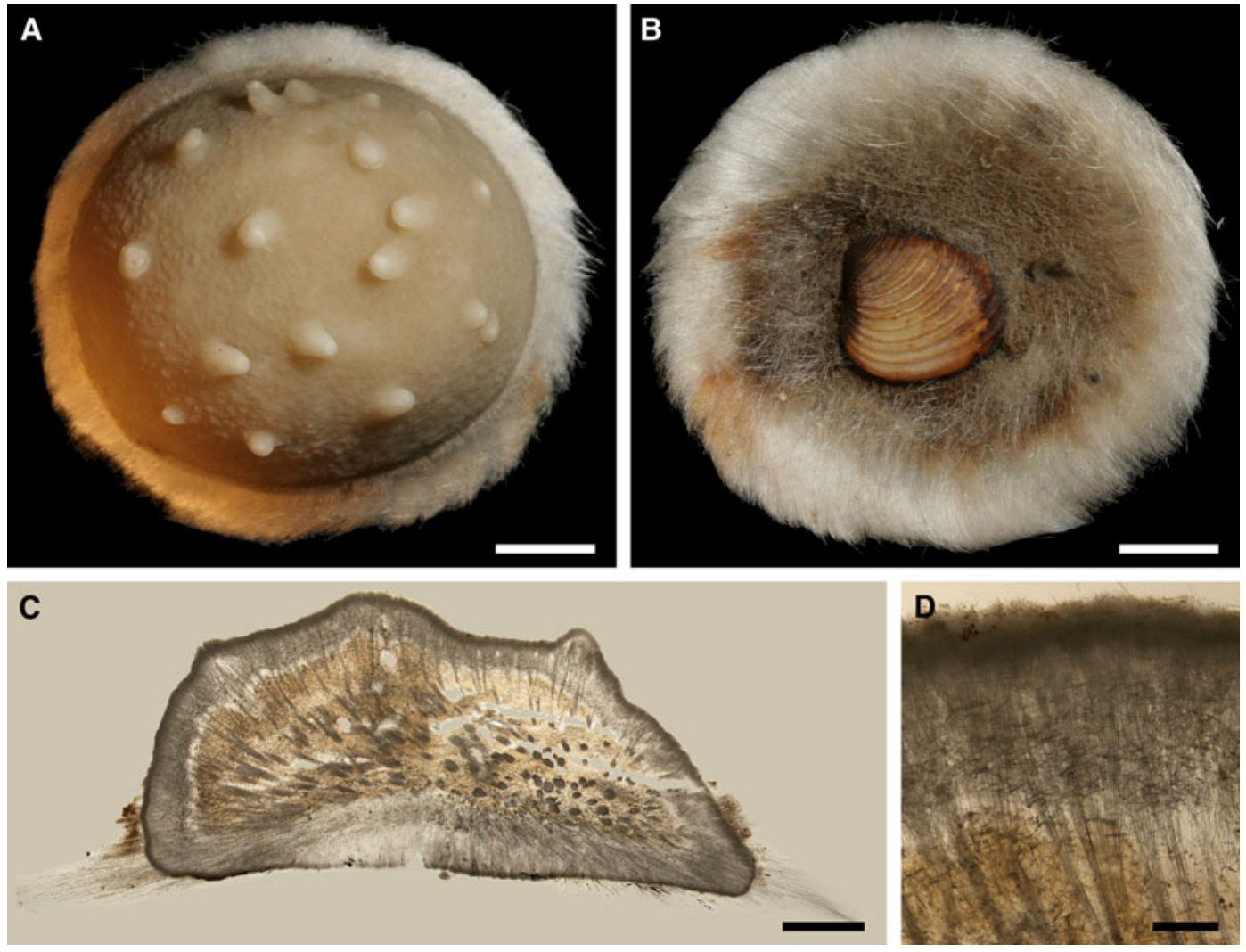

Fig. 8. Polymastia hemisphaerica: (A) holotype, NHMUO B862, habitus, view from above; (B) the same, bottom view; (C) ZMBN o98043, longitudinal section through the body, general view; (D) the same section, detail of upper cortex. Scale bars: A-B, $1 \mathrm{~cm} ; \mathrm{C}, 3 \mathrm{~mm}$; D, $0.5 \mathrm{~mm}$. 
Polymastia hemisphaerica (Vosmaer, 1885, p. 12; Topsent, 1892, p. 132; Rezvoj, 1924, p. 242).

Polymastia hemisphaericum (Koltun, 1966, p. 78, text-figure 51, pl. XXIX figures 1-5).

Radiella hemisphaerica (Plotkin, 2004, p. 542, figures if \& 2f; Plotkin et al., 2012, p. 27, figure 2k).

Radiella sol (Hansen, 1885, p. 7; Burton, 1930a: 510 pars., 1959a: 12 pars.).

Suberites radians Hansen, 1885, p. 10, pl. II figure 7.

Trichostemma hemisphaericum (Sars, 1869, p. 250, 265, 268 nomen nudum; Whiteaves, 1874, p. 184, 1901, p. 14; Lambe, 1896, p. 197, pl. II figures 7 \& 7a-e; Lundbeck, 1909, p. 451; Topsent, 1913, p. 20, pl. I figure 2, pl. II figures $1 \& 2$ ).

\section{TYPE MATERIAL}

Holotype (specimen in alcohol): NHMUO B862, Lofoten, Nordland, Norway, 218-546 m.

Paralectotypes (three dry specimens): NHMUO B863, Brattesnes, Lofoten, Nordland, Norway, 182-218 m.

Paralectotype (specimen in alcohol): ZMBN o00136, Lofoten, Nordland, Norway, $218 \mathrm{~m}$.

\section{COMPARATIVE MATERIAL}

(see Online resource 1 for details)

Canada: Nova Scotia: ZIN RAS ocphoor (one specimen), Labrador and Newfoundland: ZIN RAS ocphoo4, ZIN RAS ocpho24, ZIN RAS ocpho25 and ZIN RAS ocpho32 (four specimens), offshore areas of NW Atlantic: ZIN RAS ocpho22, ZIN RAS ocpho23, ZIN RAS ocpho26, ZIN RAS ocpho31 and ZIN RAS ocpho38 (five specimens).

Greenland, SE Coast: ZIN RAS ocpho37 and ZIN RAS ocpho43 (two specimens).

Iceland: ZIN RAS ocphoo7, ZIN RAS ocpho42 and ZMBN 098069 (three specimens).

Norwegian Sea, offshore: ZIN RAS ocpho29, ZIN RAS ocpho34, ZIN RAS ocpho36 and ZIN RAS ocpho41 (four specimens).

Barents Sea, offshore: ZIN RAS ocphoo8, ZIN RAS ocpho11, ZIN RAS ocpho12, ZIN RAS ocpho13, ZIN RAS ocpho14, ZIN RAS ocpho15, ZIN RAS ocpho16, ZIN RAS ocpho17, ZIN RAS ocpho18, ZIN RAS ocpho19, ZIN RAS ocpho20, ZIN RAS ocpho27, ZIN RAS ocpho28, ZIN RAS ocpho3o, ZIN RAS ocpho35, ZIN RAS ocpho40, ZIN RAS ocpho44, ZMBN 098071 and ZMBN 107577 (19 specimens).

Norway: Hordaland: ZMBN 098043, ZMBN 098056, ZMBN 098058, ZMBN 098077 and ZMBN 107561 (five specimens), Møre and Romsdal: ZMBN 107486 (one specimen); Nord-Trøndelag: NTNU-VM-72542 (21 specimens), Nordland: NTNU-VM-66581 and NTNU-VM-72513 (two specimens).

Russia: Novaya Zemlya: ZIN RAS ocphoo1 and ZIN RAS ocpho21 (two specimens).

Kara Sea: ZIN RAS ocphoo6 (one specimen).

\section{DESCRIPTION}

\section{External morphology}

Holotype hemispherical, $80-86 \mathrm{~mm}$ in diameter. Upper surface convex, knobbly, cream-coloured, with 18 papillae (Figure 8A). Papillae conical, 1-5 mm long and 1.5$3.5 \mathrm{~mm}$ wide at base, with considerably contracted oscula at the summits. Basal surface shaggy, pale grey in colour, attached to a bivalve shell by the central point (Figure $8 \mathrm{~B}$ ).
A fringe of extra-long spicules, 4-9 $\mathrm{mm}$ wide, developed at the sponge edge separating the upper and basal surface. Other sponges hemispherical or discoid, up to $65 \mathrm{~mm}$ in diameter, with the marginal spicule fringe up to $13 \mathrm{~mm}$ in width. Upper surface whitish or cream-coloured in life, knobbly, with up to 30 conical papillae. In living sponges the papillae with well visible oscula. Under sampling and preservation the papillae stretch and the oscula contract. Basal surface shaggy or hispid, attached to a small substrate.

\section{Anatomy}

Choanosome in life yellowish or pale orange, firm. Main choanosomal skeleton composed of tracts $(190-416 \mu \mathrm{m}$ thick) of principal spicules radiating from the basal area and entering the cortex (Figure 8C). In the upper cortex the tracts run perpendicular to the surface and do not protrude. Some tracts ascend to the papillae. In the basal cortex the tracts run obliquely to the surface and stick out forming a thick hispidation. Auxiliary choanosomal skeleton comprises free-scattered small spicules and bundles of intermediary spicules concentrated in the subcortical area. Cortex in life whitish, firm, not detachable. Cortical skeleton constituted by a notched superficial palisade $(366-522 \mu \mathrm{m}$ thick) of small spicules and an internal layer $(663-930 \mu \mathrm{m}$ thick in the upper cortex and up to $1280 \mu \mathrm{m}$ thick at the basal central point) of criss-cross intermediary spicules (Figure 8C, D). Marginal fringe composed of bundles of extra-long spicules (exotyles) embedded into the cortex. In the upper part of the body the cortex and the choanosome separated by an area with low concentration of spicules (127-206 $\mu \mathrm{m}$ thick). Papilla walls reinforced with the cortical palisade. Each papilla with a central exhalant canal and several peripheral inhalant canals.

Spicules

(Measurements based on 10 specimens)

Principal spicules - styles to subtylostyles, straight or gently curved, slightly fusiform. Length 1920-3125-5400, maximum diameter of shaft 10.9-20.2-32.3 $\mu \mathrm{m}, \mathrm{N}=200$. Intermediary spicules - tylostyles, straight, fusiform. Length $390-512-618 \mu \mathrm{m}$, maximum diameter of shaft 17.2-19.9$26.2 \mu \mathrm{m}, \mathrm{N}=300$.

Small spicules - tylostyles, usually gently bent in the distal part, slender. Length 160-229-305 $\mu \mathrm{m}$, maximum diameter of shaft $4.2-5.8-8.4 \mu \mathrm{m}, \mathrm{N}=300$.

Exotyles (spicules of the marginal fringe) - styles, straight, slightly fusiform. Length $4990-6511-8015 \mu \mathrm{m}$, maximum diameter $45.8-47.5-50.1 \mu \mathrm{m}, \mathrm{N}=100$.

\section{Genetic data}

CO1 was obtained from six individuals of Polymastia hemisphaerica, while $28 \mathrm{~S}$ rDNA were sequenced only from three of them. By both genes P. hemisphaerica is closely related to morphologically quite different $P$. thielei (Plotkin et al., $2016 \mathrm{~b})$. These species share two synapomorphies in $\mathrm{CO}_{1}$ (Online resource 2, p. 2) and two synapomorphies in $28 \mathrm{~S}$ rDNA (Online resource 3, p. 2) and, apart from them, differ from the type species of Polymastia, P. mamillaris, by $18 \mathrm{bps}$ in $\mathrm{CO}_{1}$ (Matrix $\mathrm{M}_{34248}$ in TreeBase) and six bps in $28 \mathrm{~S}$ rDNA (Matrix M34250 in TreeBase). At the same time $P$. hemisphaerica demonstrates an intraspecific polymorphism. In $\mathrm{CO}_{1}$ five individuals of this species differ from $P$. thielei just by one $\mathrm{bp}$, while one individual, ZMBN 098056, differs from $P$. thielei by two bps (Matrix M34248 
in TreeBase). On the contrary, by $28 \mathrm{~S}$ rDNA ZMBN 098056 is identical to two other conspecific sponges differing from $P$. thielei just by one insertion in this gene, while another individual of $P$. hemisphaerica, ZMBN 098043 possessing the same insertion, is distinguished from both the conspecific individuals and $P$. thielei by three bps in $28 \mathrm{~S}$ rDNA (Matrix M34250 in TreeBase).

\section{OCCURRENCE}

\section{(Figure 9)}

Literature data: Canadian Atlantic Coast: Gulf of St. Lawrence (204 m) (Whiteaves, 1874, 1901; Lambe, 1896).

Our data: Canadian Atlantic Coast: Nova Scotia (355-48o m), Newfoundland (our data: 383-415 m, Topsent, 1892: $1267 \mathrm{~m})$, Labrador $(225-485 \mathrm{~m})$, offshore areas $(230-$ $450 \mathrm{~m})$. Greenland, SE Coast $(212-405 \mathrm{~m})$. Iceland (214$650 \mathrm{~m})$. Norwegian Sea, offshore $(250-480 \mathrm{~m})$. Norwegian Coast: Hordaland $(300-312 \mathrm{~m})$, Møre and Romsdal (100 m), Nord-Trøndelag (200 m), Nordland (182-850 m) Barents Sea, offshore $(180-369 \mathrm{~m})$. Russia: Novaya Zemlya (153-270 m). Kara Sea (our data: 368 m, Rezvoj, 1924: $91-$ $200 \mathrm{~m})$.

\section{DISCUSSION}

Polymastia hemisphaerica was originally described as Trichostemma hemisphaericum Sars, 1872 designated as the type species of Trichostemma Sars, 1872 . In fact, this genus and this species were first mentioned in a list of the Norwegian sponges three years earlier (Sars, 1869), although without any description. Von Marenzeller (1878) regarded Trichostemma as a synonym of Halicnemia Bowerbank, 1864, while Schmidt (1880) put T. hemisphaericum in synonymy with Radiella sol Schmidt, 1870, one of the two species for which he had earlier established Radiella Schmidt, 1870 (for more details on the taxonomic history of Radiella see Discussion on the genus Spinularia below). Consequently, Trichostemma was regarded as a synonym of Radiella (Schmidt, 1880). This was encouraged by Hansen (1885) and Burton (1930a, b, 1959a). However, all other authors recognized Trichostemma hemisphaericum and $T$. sol as two different species, although they agreed that Trichostemma and Radiella were synonyms. Most authors encouraged the precedence of the former over the latter, referring to its first record in Sars (1869) (Whiteaves, 1874, 1901; Ridley \& Dendy, 1886, 1887; von Lendenfeld, 1887; Lambe, 1896; Topsent, 1904, 1913, 1928; Lundbeck, 1909; Wilson, 1925; Boury-Esnault, 1987; Uriz \& Rosell, 1990; Boury-Esnault et al., 1994). Conversely, Vacelet (1961) and Koltun (1964) considered Radiella as the senior synonym, while Vosmaer (1885), Levinsen (1887) and Rezvoj (1924) relegated Trichostemma to a synonym of Polymastia and Vosmaer (1887) and Koltun (1966) relegated both Radiella and Trichostemma to synonyms of Polymastia. BouryEsnault (2002) recognized Radiella as a valid genus and the record of Trichostemma by Sars (1869) as nomen nudum, and hence acknowledged the synonymization of Trichostemma with Radiella based on the principle of priority (Article 23.1 in Anonymous, 1999). This decision was further encouraged by Plotkin (2004) and Plotkin et al. (2012).

However, very recently, Plotkin et al. (2016b) reconsidered the relationships between Trichostemma, Radiella and Polymastia based on genetic data. In the $\mathrm{CO}_{1}$ and $28 \mathrm{~S}$ rDNA phylogenies Trichostemma hemisphaericum (referred to as Radiella hemisphaerica by Plotkin et al., 2016b) appeared in a strongly supported clade including the type species of Polymastia, P. mamillaris, and five other Polymastia spp. At the same time two species of Radiella, R. sarsii (Ridley \& Dendy, 1886) and Radiella sp., fell in a remote clade (for details on the current status of Radiella see Discussion on the genus Spinularia below). Since Polynastia was an older name than Trichostemma, the latter was relegated to a synonym of the former (Plotkin et al., 2016b). This is followed in the present study.

\section{Polymastia mamillaris (Müller, 1806)}

(Figure 10)

Original description: Spongia mamillaris Müller, 1806, p. 44.

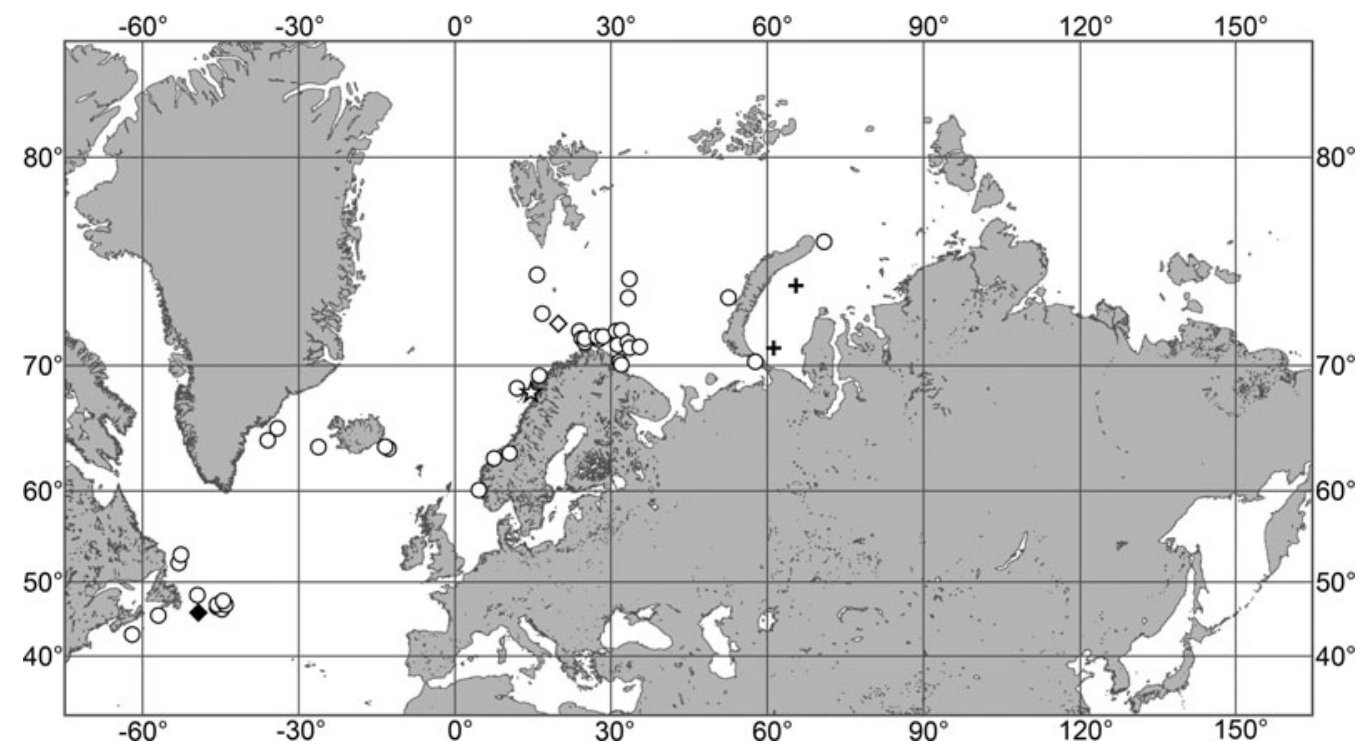

Fig. 9. Polymastia hemisphaerica, distribution: white star, type locality; black crosses, data from Rezvoj (1924); black diamond, data from Topsent (1892); white diamond, data from Topsent (1913); white circles, our data. 

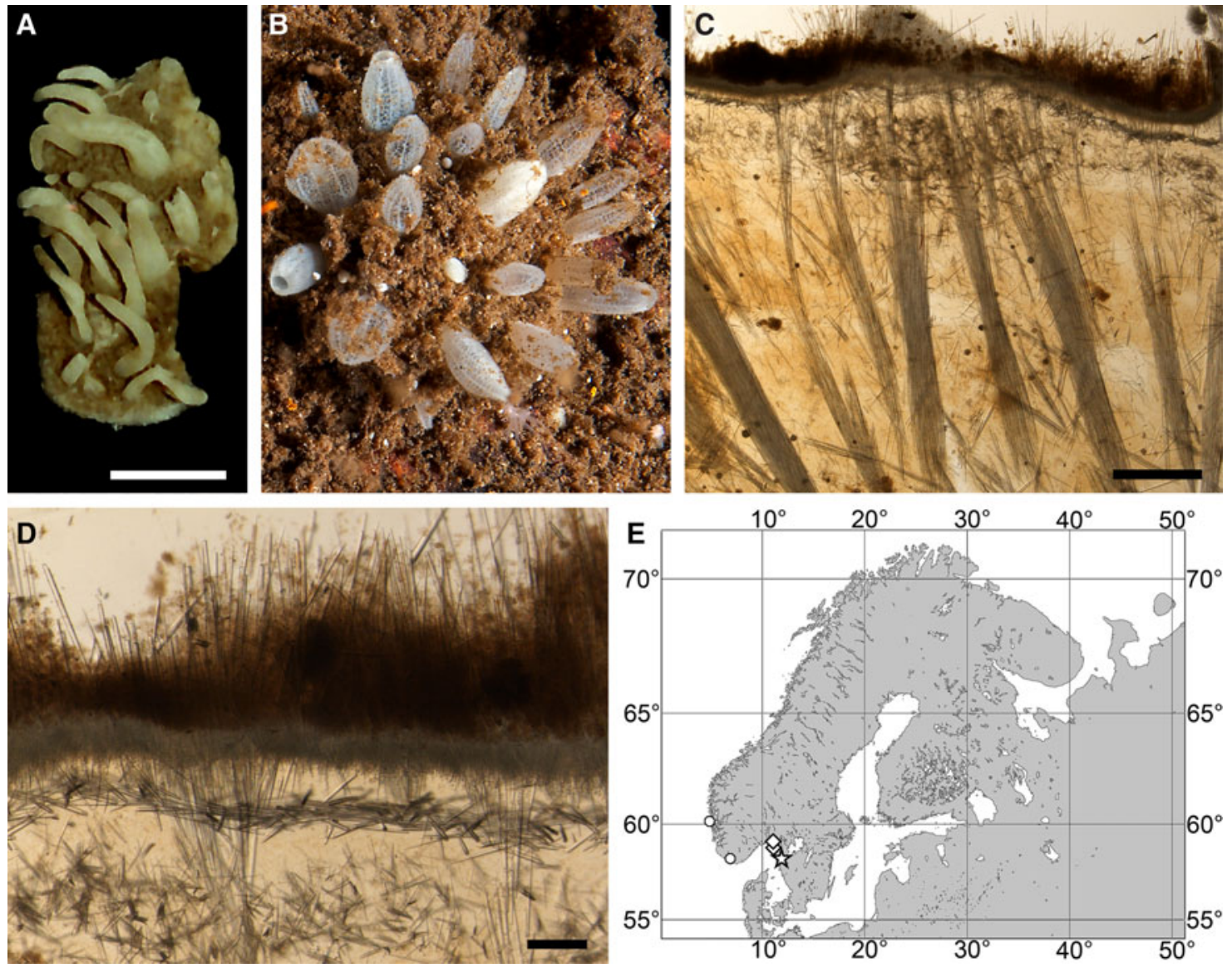

Fig. 10. Polymastia mamillaris: (A) holotype, ZMUC-DEM-394, habitus; (B) ZMBN 098083 in situ, Fedafjorden, Norway (courtesy of E. Svensen, OceanPhoto/ Dalane Tidende AS, Egersund); (C) holotype, ZMUC-DEM-394, longitudinal section through the body, general view; (D) the same section, detail of upper cortex; (E) distribution: white star, type locality; white diamonds, data from Morrow \& Boury-Esnault (200o); white circles, our data. Scale bars: A, $1 \mathrm{~cm}$; C, 1 mm; D, $0.2 \mathrm{~mm}$.

\section{SYNONYMS AND CITATIONS}

Pencillaria penicillus (Gray, 1867, p. 527 pars.).

Polymastia mamillaris (Fristedt, 1885, p. 15; Alander, 1942, p. 75; Morrow \& Boury-Esnault, 2000, p. 329, figures 1 \& 2D-F; Boury-Esnault, 2002, p. 203, figure 2; Plotkin et al., 2012, p. 25, figure 11).

Non Polymastia mamillaris (Bowerbank, 1862, p. 1104, 1864 p. 178,1866 , p. 71 ; Vosmaer, 1885 , p. 14 , text-figure 5, pl. I figure 5, pl. III figures 10, 11-14, 21; Verrill, 1874, p. 505; Whiteaves, 1874 , p. 184; Lambe, 1896, p. 196, pl. III figure 1; Whiteaves, 1901, p. 13; Arnesen, 1918, p. 8, pl. 1 figures $1-4$, pl. 2 figures $1-5$, pl. 3 figures $6-9$, pl. 4 figures $1-2$; pl. 5 figures 1-2, pl. 6 figures 1-4; Koltun, 1966, p. 69; Boury-Esnault, 1987, p. 32, figure 1; Ereskovsky, 1993a, p. 22; Plotkin \& Ereskovsky, 1997, p. 127).

\section{TYPE MATERIAL}

Holotype (Figure 10A): ZMUC-DEM-394, East of Aspholmen in Byfjorden, Orust, Västra Götaland, Sweden, $58^{\circ} 15^{\prime} \mathrm{N}$ $11^{\circ} 50^{\prime} \mathrm{E}$, depth unknown.

Detailed description of the holotype was presented by Morrow \& Boury-Esnault (2000).

\section{COMPARATIVE MATERIAL}

(see Online resource 1 for details)
Norway: Vest-Agder: ZMBN 098083 (one specimen), Hordaland: ZMBN 098078 (one specimen).

\section{DESCRIPTION}

\section{External morphology}

Cushion-shaped sponges covering the substrate and occupying up to $9 \mathrm{~cm}^{2}$. Surface hispid, usually covered with sediment, with up to 30 papillae, 5-12 $\mathrm{mm}$ long and $2-5 \mathrm{~mm}$ wide at base (Figure 10A, B). In living sponges the papillae tapering towards the summits, some with visible oscula (Figure $10 \mathrm{~B}$ ). Colour of papillae whitish in life and cream-coloured in alcohol.

\section{Anatomy}

Choanosome in life cream-coloured, firm. Main choanosomal skeleton of radiating tracts $(240-370 \mu \mathrm{m}$ thick $)$ of principal spicules dividing into two to three thinner tracts, which cross the cortex and form a surface hispidation (Figure $10 \mathrm{C}$ ). Ascending tracts also form a framework of the papilla skeleton. Auxiliary choanosomal skeleton comprises free-scattered bundles, each of two to five small spicules, being especially abundant in the subcortical area. Cortex in life whitish, firm, not detachable. Cortical skeleton constituted by a superficial palisade (120-150 $\mu \mathrm{m}$ thick) of small spicules, a middle layer $(65-105 \mu \mathrm{m}$ thick) of collagen fibres with low density of spicules and an internal layer (85-155 $\mu \mathrm{m}$ thick) of 
tangentially arranged intermediary spicules (Figure 1oD). Skeleton of the papilla walls composed of two layers only, the superficial palisade and the internal tangential layer.

\section{Spicules}

(Measurements based on three specimens, individual variation presented in Table 3 )

Principal spicules - straight strongyloxeas or straight, fusiform styles to subtylostyles. Length 603-1075-1761 $\mu \mathrm{m}$, diameter of tyle (if present) 5.6-9.8-15.2 $\mu \mathrm{m}$, proximal diameter of shaft 2.5-8.3-12.7 $\mu \mathrm{m}$, maximum diameter of shaft $7.6-18.0-29.2 \mu \mathrm{m}, \mathrm{N}=90$.

Intermediary spicules - styles, occasionally subtylostyles, usually straight, slightly fusiform. Length $241-422-538 \mu \mathrm{m}$, diameter of tyle (if present) $5.1-7.4-10.2 \mu \mathrm{m}$, proximal diameter of shaft $2.5-6.1-8.9 \mu \mathrm{m}$, maximum diameter of shaft $6.4-8.9-14.0 \mu \mathrm{m}, \mathrm{N}=90$.

Small spicules - tylostyles, gently curved or straight, stout. Length 94-148-206 $\mu \mathrm{m}$, diameter of tyle 3.8-6.0$10.2 \mu \mathrm{m}$, proximal diameter of shaft $1.3-3.8-8.9 \mu \mathrm{m}$, maximum diameter of shaft $2.5-6.3-11.4 \mu \mathrm{m}, \mathrm{N}=90$.

\section{Genetic data}

CO1 sequences obtained from two individuals of Polymastia mamillaris are identical (Matrix M34248 in TreeBase), but these sponges are distinguished by one bp in $28 \mathrm{~S}$ rDNA (Matrix M34250 in TreeBase). Polymastia mamillaris differs from all other polymastiids by five autapomorphies in $\mathrm{CO} 1$ (Online resource 2, p. 1) and one autapomorphy in $28 \mathrm{~S}$ rDNA (Online resource 3, p. 1). More details on the differences between P. mamillaris and other Polymastia spp. are presented in the Genetic data sections for these species.

\section{OCCURRENCE}

(Figure 10E)

Literature data: Swedish Western Coast: Skagerrak (76-225 m) (Morrow \& Boury-Esnault, 2000).

Our data: Norwegian Coast: Vest-Agder (40-45 m), Hordaland $(300-310 \mathrm{~m})$.

\section{DISCUSSION}

Polymastia mamillaris has a very confused taxonomic history. This species was originally described from the Swedish Western Coast as Spongia mamillaris (Müller, 1806). Johnston, 1842 transferred it to Halichondria Fleming, 1828 and simultaneously relegated a British species Spongia penicillus Montagu, 1814 to a synonym of $H$. mamillaris. Bowerbank (1862) erected a new genus, Polymastia, for $H$. mamillaris. For unclear reason Gray (1867) erected another new genus, Pencillaria, for Polymastia mamillaris, but this was not acknowledged by the later authors. Vosmaer (1882) admitted that Spongia mamillaris and S. penicillus were the same species of Polymastia, but considered penicillus as the senior synonym for this species despite it having been described earlier than mamillaris. Moreover, in the same paper Vosmaer synonymized a White Sea species Rinalda arctica Merejkowsky, 1878 with $P$. penicillus and also placed in this species some Barents Sea sponges which were in fact distinguished from the original descriptions of Spongia mamillaris, S. penicillus and $R$. arctica by a radial growth type and a marginal spicule fringe (i.e. the evident features of the species now recognized as $P$. grimaldii, see the respective Description and Discussion above). Three years later (Vosmaer, 1885) he re-considered the synonymy by declaring Polymastia mamillaris the senior synonym. Fristedt $(1885)$ recorded P. mamillaris along the Swedish Western Coast. Later (Fristedt, 1887) he identified as P. penicillus some sponges with the radial growth type and the marginal spicule fringe from Greenland, Svalbard and the Siberian Seas referring to Vosmaer (1882) and noted that P. penicillus (Montagu, 1814) sensu Vosmaer (1882) from the Arctic region and Polymastia mamillaris (Müller, 1806) from Sweden were different species. Levinsen (1887) recorded P. penicillus from the Kara Sea and agreed with Vosmaer (1882), although with some doubt, that $P$. mamillaris and Rinalda arctica were the synonyms of $P$. penicillus. Whiteaves $(1874,1901)$ and Lambe (1896) recorded P. mamillaris in the Canadian Atlantic. But de Laubenfels (1949) established a new species $P$. andrica for these Canadian sponges, although without good argumentation. Topsent (1913) erected a new species, Trichostemma grimaldii, for the Nordic Polymastia-looking

Table 3. Individual variation of spicule dimensions of Polymastia mamillaris (given in $\mu \mathrm{m}$ as minimum-mean-maximum). Parameters: length, diameter of tyle, proximal diameter of shaft, maximum diameter of shaft, number of spicules measured $(\mathrm{N})$.

\begin{tabular}{|c|c|c|c|}
\hline Specimen & Principal spicules & Intermediary spicules & Small spicules \\
\hline \multirow[t]{5}{*}{ Holotype ZMUC 2-1-93 (Swedish Coast, Skagerrak) } & $794-1097-1426$ & $241-411-462$ & $94-163-206$ \\
\hline & Tyles absent & Tyles absent or weakly developed & $3.8-7.2-10.2$ \\
\hline & $6.4-9.5-12.7$ & $3.8-7.0-8.9$ & $2.5-5.1-8.9$ \\
\hline & $22.9-26.0-29.2$ & $6.4-9.9-14.0$ & $6.4-8.7-11.4$ \\
\hline & $\mathrm{N}=30$ & $\mathrm{~N}=30$ & $\mathrm{~N}=30$ \\
\hline \multirow[t]{5}{*}{ ZMBN 98078 (Norwegian Coast, Vest-Agder) } & $1005-1309-1761$ & $377-445-503$ & $127-147-178$ \\
\hline & $8.9-11.8-15.2$ & $6.4-7.9-10.2$ & $5.1-5.8-6.4$ \\
\hline & $6.4-10.0-12.7$ & $5.1-6.6-8.9$ & $2.5-3.7-5.1$ \\
\hline & $14-17.5-20.3$ & $7.6-9.5-12.7$ & $3.8-5.7-7.6$ \\
\hline & $\mathrm{N}=30$ & $\mathrm{~N}=30$ & $\mathrm{~N}=30$ \\
\hline \multirow[t]{5}{*}{ ZMBN 98078 (Norwegian Coast, Hordaland) } & $603-820-1045$ & $251-411-538$ & $102-133-179$ \\
\hline & $5.6-7.9-10.2$ & $5.1-6.9-8.9$ & $3.8-5-5.1$ \\
\hline & $2.5-5.1-7.6$ & $2.5-4.6-6.4$ & $1.3-2.6-3.8$ \\
\hline & $7.6-10.4-12.7$ & $6.4-7.2-10.2$ & $2.5-4.5-5.1$ \\
\hline & $\mathrm{N}=30$ & $\mathrm{~N}=30$ & $\mathrm{~N}=30$ \\
\hline
\end{tabular}


sponges with the radial growth type and the marginal spicule fringe. But later (Topsent, 1927a) he transferred grimaldii to Polymastia. Hentschel (1916) described a new variety, $P$. mamillaris var. hyperborea from Svalbard, which in fact resembled $P$. grimaldii. Koltun (1966) relegated grimaldii to a subspecies of $P$. mamillaris. According to his extended definition $P$. mamillaris included three subspecies, $P$. mamillaris mamillaris comprising all sponges similar to Spongia mamillaris Müller, 1806 and Rinalda arctica Merejkowsky, 1878 from the North Atlantic, Nordic Seas and Arctic, P. mamillaris grimaldii comprising all sponges from the same regions, resembling $P$. mamillaris mamillaris by numerous papillae and architecture of the upper cortex, but differing by the radial growth type and the marginal spicule fringe, and $P$. mamillaris rara Koltun, 1966, a NW Pacific subspecies differing from $P$. mamillaris mamillaris by longer principal spicules.

Since Boury-Esnault (1987) P. mamillaris and P. grimaldi are, however, recognized as two separate species. Later, based on a careful comparison between the holotypes of Spongia mamillaris and $S$. penicillus and additional material Morrow \& Boury-Esnault (2000) demonstrated that P. mamillaris and $P$. penicillus were different species too. According to this study most of the previous records of $P$. mamillaris from the British Isles, French, Spanish and Portuguese Coasts in fact represent $P$. penicillus characterized by a twolayered cortex and spicules in all size categories being tylostyles. Polymastia mamillaris distributed only along the
Swedish Coast is distinguished by a three-layered cortex (with a middle layer of collagen fibres), principal spicules being strongyloxeas and intermediary spicules being styles. Furthermore, Plotkin \& Boury-Esnault (2004) proved that Polymastia arctica (originally placed in Rinalda) commonly synonymized either with $P$. mamillaris or with $P$. penicillus was actually a valid species distributed in the White and Barents Sea and distinguished by the bud formation on the papillae, relatively thick middle and intermediate layers in the cortex and the presence of spicules in the bulkheads separating canals in the papillae. Now we can finally confirm the morphological differences between $P$. arctica, $P$. grimaldii, $P$. mamillaris and $P$. penicillus by genetic evidence (Plotkin et al., 2016b; present study). Moreover, we have revealed that $P$. andrica erected by de Laubenfels (1949) for the Canadian records of $P$. mamillaris is a valid species distributed from Canada to the Norwegian Coast and Svalbard, differing from the similar Polymastia spp. by genetics and morphologically distinguished by the presence of extra-long cortical spicules (exotyles) (see the respective description above).

\section{Polymastia nivea (Hansen, 1885)}

(Figure 11)

Original description: Reniera nivea Hansen, 1885, p. 5, pl. I figure 6 .
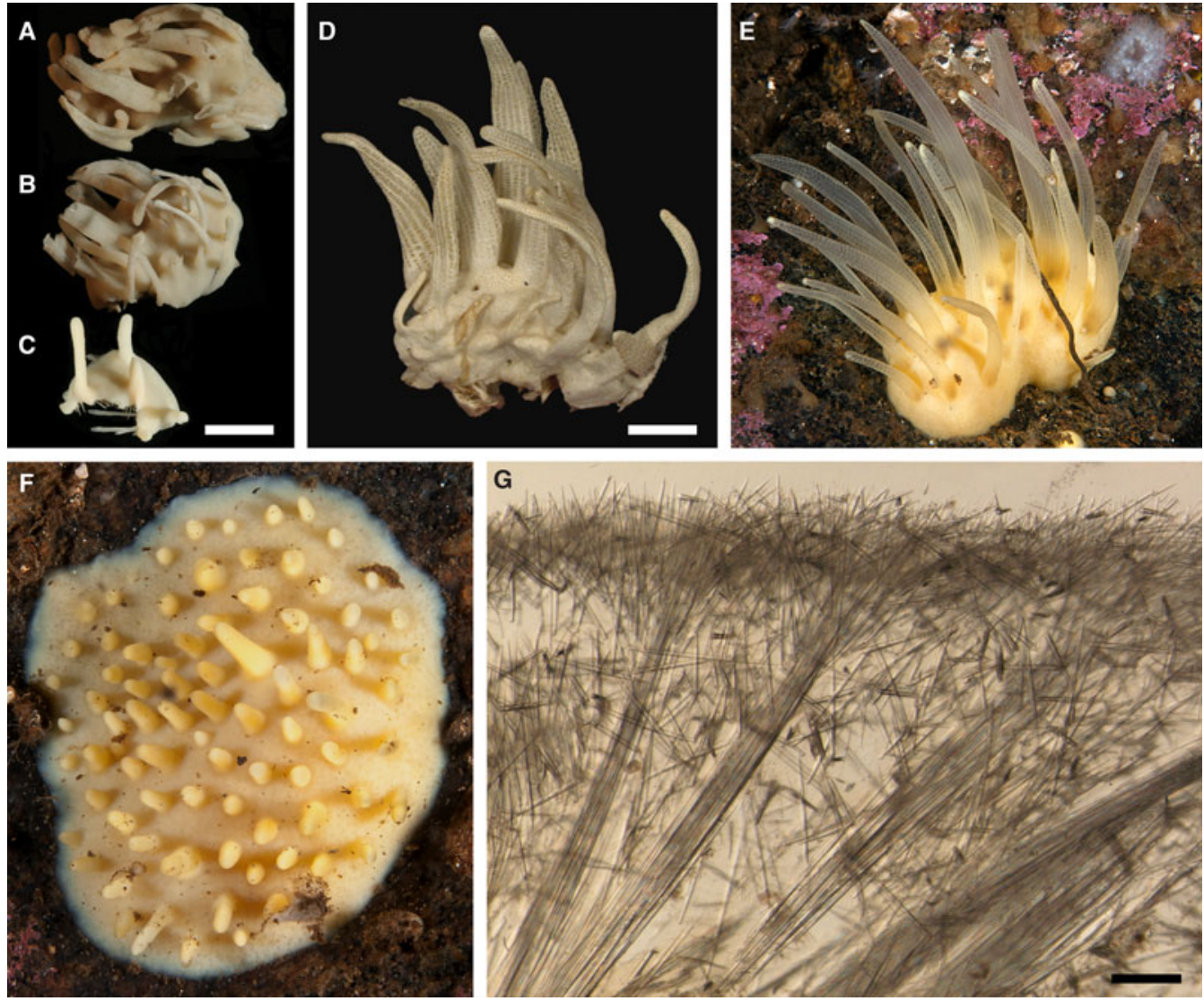

Fig. 11. Polymastia nivea: (A) lectotype of Reniera nivea, ZMBN o00055, habitus; (B) and (C) paralectotypes of Reniera nivea, ZMBN oooo55, habitus; (D) holotype of Polymastia euplectella (synonym of P. nivea), ZIN RAS 7102/7103, habitus; (E) an individual in situ, Sør-Trøndelag, Norway (courtesy of E. Svensen, OceanPhoto/Dalane Tidende AS, Egersund); (F) an individual in situ, Fedafjorden, Norway (courtesy of E. Svensen); (G) lectotype of Reniera nivea, ZMBN 000055 , longitudinal section through the body. Scale bars: A-D, $1 \mathrm{~cm} ; \mathrm{G}, 0.2 \mathrm{~mm}$. 


\section{SYNONYMS AND CITATIONS}

Polymastia euplectella Rezvoj, 1927, p. 301, figure a, b (Plotkin, 2004, p. 541, figures 1b \& 2b; Plotkin et al., 2012, p. 25, figure $1 \mathrm{k})$.

Polymastia robusta robusta (Koltun, 1966, p. 74, text-figure 44, pl. XXI figures 1-4).

\section{TYPE MATERIAL}

Lectotype (designated herein, Figure $11 \mathrm{~A}$ ) and two paralectotypes of Reniera nivea Hansen, 1885: ZMBN 000055, Norwegian Sea, precise locality and depth unknown, Norwegian North Atlantic Expedition, 1876-1878.

Holotype of Polymastia euplectella Rezvoj, 1927: ZIN RAS 7102/7103 (slide 125), Three Sisters Rocks, Kildin Strait, Murman Coast of the Barents Sea, Russia, $69^{\circ} 18.31^{\prime} \mathrm{N}$ $34^{\circ} 18.82^{\prime} \mathrm{E}$, depth unknown, 31.07 .1924 . Herein P. euplectella is relegated to a synonym of $P$. nivea.

\section{COMPARATIVE MATERIAL}

(see Online resource 1 for details)

Norway: Vest-Agder: ZMBN 098085, ZMBN 098086 and ZMBN 098087 (three specimens), Hordaland: ZMBN 009667 (one specimen), Møre and Romsdal: ZMBN 107484 (one specimen), Sør-Trøndelag: NTNU-VM-54701 (one specimen), Nordland: NTNU-VM-55006, NTNU-VM-58254, NTNU-VM-72508, NTNU-VM-72514 (18 specimens), Finnmark: NTNU-VM-5488o and ZMBN 098044 (three specimens).

Barents Sea, offshore: ZIN RAS ocpeo14 (one specimen). Russia: Murman coast: ZIN RAS ocpeoo1, ZIN RAS ocpeoo9, ZIN RAS ocpeo10, ZIN RAS ocpeo11, ZIN RAS ocpeo12, ZIN RAS ocpe12 and ZIN RAS ocpe15 (seven specimens), White Sea: ZIN RAS ocpeoo2, ZIN RAS ocpeoo4, ZIN RAS ocpeo05, ZIN RAS ocpeoo6 and ZIN RAS ocpeoo8 (12 specimens).

\section{DESCRIPTION}

External morphology

All type specimens of Reniera nivea cream-coloured in alcohol, with smooth surface bearing damaged cylindrical papillae (Figure $11 \mathrm{~A}-\mathrm{C}$ ). Lectotype $\sim 30 \times 17 \times 6 \mathrm{~mm}$, with 19 papillae (Figure $11 \mathrm{~A}$ ). Larger paralectotype $24 \times 18 \times$ $5 \mathrm{~mm}$, with 20 papillae (Figure $11 \mathrm{~B}$ ). Smaller lectotype is a small sponge fragment with five papillae (Figure $11 \mathrm{C}$ ). Holotype of Polymastia euplectella $\sim 30 \times 12 \times 5 \mathrm{~mm}$ (Figure $11 \mathrm{D}$ ). Surface smooth, with 18 papillae, $10-40 \mathrm{~mm}$ long and 3-7 mm wide at base, gently pointed at the summits. Colour of both the surface and papillae whitish in alcohol. Papilla walls display a conspicuous tracery network of spicules.

Other sponges cushion-shaped, covering the substrate and occupying up to $20 \mathrm{~cm}^{2}$. Surface smooth, free of sediment, with up to 30 papillae (Figure $11 \mathrm{E}, \mathrm{F}$ ). Colour of the surface in life pale orange or pale yellow, sometimes whitish, in alcohol always becoming whitish. Papillae of most living individuals cylindrical, $8-60 \mathrm{~mm}$ in length and $2-8 \mathrm{~mm}$ in diameter, semitransparent with well-visible spicule network, oscula not visible (Figure 11E). Some sponges with much smaller (2$6 \mathrm{~mm}$ in length and $1-4 \mathrm{~mm}$ in diameter) papillae of the same colouration as the surface (Figure $11 \mathrm{~F}$ ).

\section{Anatomy}

Choanosome dense. Main choanosomal skeleton composed of longitudinal or radial tracts $(110-310 \mu \mathrm{m}$ thick) of principal spicules (Figure $11 \mathrm{G}$ ). Auxiliary choanosomal skeleton comprises small and intermediary spicules, most free-scattered, some in bundles of three to seven. Cortex $275-460 \mu \mathrm{m}$ thick, dense, but friable, not detachable, with small aquiferous cavities connected with ostia in the surface. Cortical skeleton constituted by a superficial palisade of small spicules, which is overlapped with an inner layer of criss-cross intermediary spicules (Figure $11 \mathrm{G}$ ). Papilla with a single central canal enveloped by a network made of the tracts of principal spicules

Table 4. Individual variation of spicule dimensions of Polymastia nivea (given in $\mu \mathrm{m}$ as minimum-mean-maximum). Parameters: length, diameter of tyle, proximal diameter of shaft, maximum diameter of shaft, number of spicules measured $(\mathrm{N})$.

\begin{tabular}{|c|c|c|c|}
\hline Specimen & Principal spicules & Intermediary spicules & Small spicules \\
\hline \multirow[t]{5}{*}{ Lectotype of Reniera nivea, ZMBN 00055 (Norwegian Sea) } & $967-1355-1686$ & $342-484-719$ & $132-161-198$ \\
\hline & Tyles absent or weakly developed & $5.1-12-17.8$ & Tyles weakly developed \\
\hline & $7.6-11.2-15.2$ & $3.8-8.6-11.4$ & $2.5-3.8-4.6$ \\
\hline & $16.5-20.8-25.4$ & $10.2-17.5-21.6$ & $3.8-4.7-5.1$ \\
\hline & $\mathrm{N}=30$ & $\mathrm{~N}=30$ & $\mathrm{~N}=30$ \\
\hline \multirow{5}{*}{$\begin{array}{l}\text { Holotype of Polymastia euplectella, ZIN RAS 07102/07103 } \\
\quad \text { (Barents Sea, Murman Coast) }\end{array}$} & $1087-1197-1370$ & $498-634-771$ & $138-173-210$ \\
\hline & Tyles absent & $4.5-11.6-18.2$ & Tyles weakly developed \\
\hline & $7.6-10.9-14.8$ & $4.0-9.2-12.0$ & $2.5-3.9-4.7$ \\
\hline & $17.3-19.9-21.8$ & $9.4-14.8-18.4$ & $4.0-4.5-5.5$ \\
\hline & $\mathrm{N}=30$ & $\mathrm{~N}=30$ & $\mathrm{~N}=30$ \\
\hline \multirow[t]{5}{*}{ ZMBN 98085 (Norwegian Coast, Vest-Agder) } & $573-916-1141$ & $271-408-598$ & $127-170-197$ \\
\hline & $8.9-10.2-11.4$ & $7.6-9.7-12.7$ & $3.8-4.4-5.1$ \\
\hline & $2.5-7-8.9$ & $5.1-6.6-8.9$ & $2.5-3.1-4.6$ \\
\hline & $8.9-11.6-15.2$ & $7.6-9.9-15.2$ & $2.5-4.6-5.1$ \\
\hline & $\mathrm{N}=30$ & $\mathrm{~N}=30$ & $\mathrm{~N}=30$ \\
\hline \multirow[t]{5}{*}{ ZMBN 98044 (Norwegian Coast, Finnmark) } & $930-1309-1513$ & $296-410-563$ & $114-161-231$ \\
\hline & Tyles absent & $11.4-14.2-16.5$ & $5.1-6.1-7.6$ \\
\hline & $7.6-10.7-14$ & $7.6-10.3-12.7$ & $2-3.6-5.1$ \\
\hline & $17.8-19.7-21.6$ & $12.7-17.3-20.3$ & $3-5-7.6$ \\
\hline & $\mathrm{N}=30$ & $\mathrm{~N}=30$ & $\mathrm{~N}=30$ \\
\hline
\end{tabular}


ascending from the choanosome crossed by bundles of intermediary spicules from the outside. Superficial layer of small spicules covers this network.

\section{Spicules}

(Measurements based on four specimens, individual variation presented in Table 4)

Principal spicules - strongyloxeas (ZMBN 000055), slender styles to subtylostyles (ZIN RAS 07102/07103, ZMBN 098044), or fusiform subtylostyles with displaced tyles (ZMBN 098085), usually straight, occasionally gently curved. Length 573-1194-1686 $\mu \mathrm{m}$, diameter of tyle (if present) $8.9-10.2-11.4 \mu \mathrm{m}$, proximal diameter of shaft 2.5-9.6-15.2 $\mu \mathrm{m}$, maximum diameter of shaft 8.9-17.4$25.4 \mu \mathrm{m}, \mathrm{N}=120$.

Intermediary spicules - gently curved tylostyles, usually stout or slightly fusiform (most sponges), occasionally slenderer (ZMBN 098085). Length 271-434-771 $\mu \mathrm{m}$, diameter of tyle (if present) 5.1-11.9-18.2 $\mu \mathrm{m}$, proximal diameter of shaft 3.8-8.4-12.7 $\mu \mathrm{m}$, maximum diameter of shaft 7.6$14.7-21.6 \mu \mathrm{m}, \mathrm{N}=120$.

Small spicules - subtylostyles with weakly developed tyles, usually curved and slender. Length 114-164-231 $\mu \mathrm{m}$, diameter of tyle $3.8-5.2-7.6 \mu \mathrm{m}$, proximal diameter of shaft $2.0-$ 3.5-5.1 $\mu \mathrm{m}$, maximum diameter of shaft 2.5-4.8-7.6 $\mu \mathrm{m}$, $\mathrm{N}=120$.

\section{Genetic data}

CO1 was obtained from four individuals of Polymastia nivea, $28 \mathrm{~S}$ rDNA was sequenced from three of them and no intraspecific polymorphism was revealed. In the phylogenies based on these genes $P$. nivea is closely related to $P$. penicillus (Plotkin et al., 2016b), although these species share just two synapomorphies in $28 \mathrm{~S}$ rDNA distinguishing them from other polymastiids (Online resource 3, p. 3) and no such synapomorphies in $\mathrm{CO} 1$. At the same time $P$. nivea possesses one autapomorphy in $\mathrm{CO}_{1}$ (Online resource 2, p. 3) and four autapomorphies in $28 \mathrm{~S}$ rDNA (Online resource 3, p. 3). Apart from these autapomorphies, $P$. nivea differs from $P$. penicillus by 6 bps in CO1 (Matrix M34248 in TreeBase) and 19 bps in $28 \mathrm{~S}$ rDNA (Matrix M34250 in TreeBase) and from the type species of Polymastia, P. mamillaris, by 56 bps in $\mathrm{CO}_{1}$ (Matrix M34248 in TreeBase) and 85 bps in $28 \mathrm{~S}$ rDNA (Matrix M34250 in TreeBase).

\section{OCCURRENCE}

(Figure 12)

Our data: Norwegian Coast: Vest-Agder (40-45 m), Hordaland (75 m), Møre and Romsdal (70-130 m), SørTrøndelag (100-300 m), Nordland (80-360 m), Finnmark $(250-284 \mathrm{~m})$. Barents Sea: Murman Coast $(9-127 \mathrm{~m})$, offshore areas $(122 \mathrm{~m})$. White Sea $(10-78 \mathrm{~m})$.

\section{DISCUSSION}

Describing his new species, Reniera nivea from the Norwegian Sea, Hansen $(1885$, p. 5) apparently confused individuals with quite different morphology, pyriform sponges ('isolated individuals' in his interpretation, depicted in pl. I figure 6a in his paper) and encrusting sponges with papillae ('collections of individuals on plates' depicted in pl. I figure 6b). Burton (1930a) synonymized Hansen's sponges bearing papillae with Polymastia robusta and pyriform sponges with Quasillina brevis. Later P. robusta was synonymized with

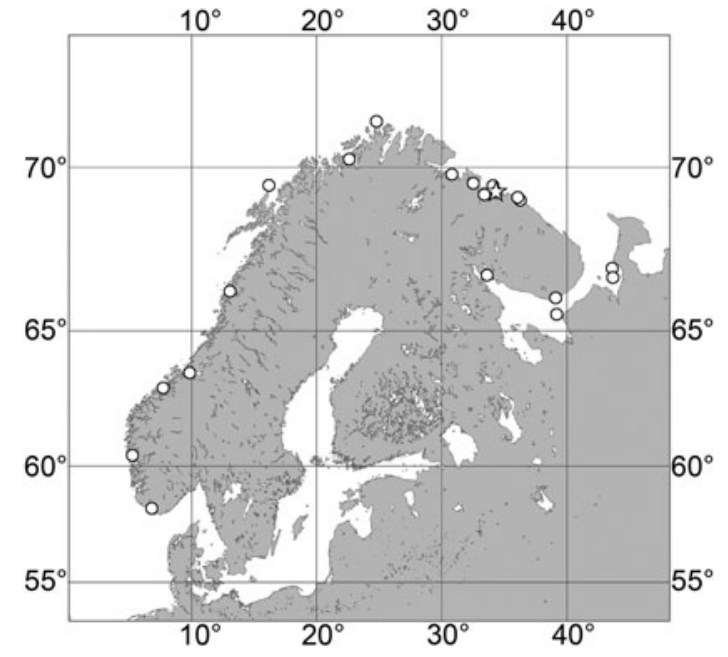

Fig. 12. Polymastia nivea, distribution: white star, type locality of Polymastia euplectella (synonym of $P$. nivea); white circles, our data. Precise type locality of Reniera nivea is unknown.

P. boletiformis (Topsent, 1933; see also Discussion on the latter species above in the present paper). Meanwhile, a new species $P$. euplectella strongly resembling Hansen's sponges with papillae was described from the Barents Sea by Rezvoj (1927). Koltun (1966) relegated P. euplectella to a synonym of P. robusta, but Plotkin (2004) resurrected the status of $P$. euplectella. Based on the re-examination of the type material of both $P$. euplectella and $R$. nivea (except for Hansen's pyriform sponges which are considered as lost) we can conclude that they belong to the same species, which gets the name Polymastia nivea in accordance with the principle of priority (Anonymous, 1999). This species is distinguished from $P$. boletiformis by its pale colouration, longer papillae, all without visible oscula, longitudinal choanosomal skeleton, overlapping spicule layers in the cortex and the presence of three spicule categories. Meanwhile, $P$. nivea is morphologically very similar to $P$. bartletti (see the description of the latter above). Genetic data clearly indicate that P. bartletti, P. boletiformis and $P$. nivea are three separate species (Plotkin et al., 2016b).

\section{Polymastia penicillus (Montagu, 1814)}

(Figure 13)

Original description: Spongia penicillus Montagu, 1814, p. 93, pl. XIII figure 7 .

\section{SYNONYMS AND CITATIONS}

Halichondria mamillaris (Jonhston, 1942, p. 142, pl. XVI figure 2).

Pencillaria mamillaris (Gray, 1867, p. 527).

Polymastia mamillaris (Bowerbank, 1862, p. 1104, 1864, p. 178, 1866, p. 71; Boury-Esnault, 1987, p. 32, figure 1).

Polymastia penicillus (Morrow \& Boury-Esnault, 2000, p. 330, figures $2 \mathrm{~A}-\mathrm{C} \& 3$ ).

Non Polymastia penicillus (Vosmaer, 1882, p. 26, pl. I figures 12 \& 13, pl. IV figure 127-132; Hansen, 1885, p. 9; Fristedt, 1887 , p. 434; Levinsen, 1887 , p. 346; Swarczewsky, 1906, p. 313, pl. 13 figure 1). 

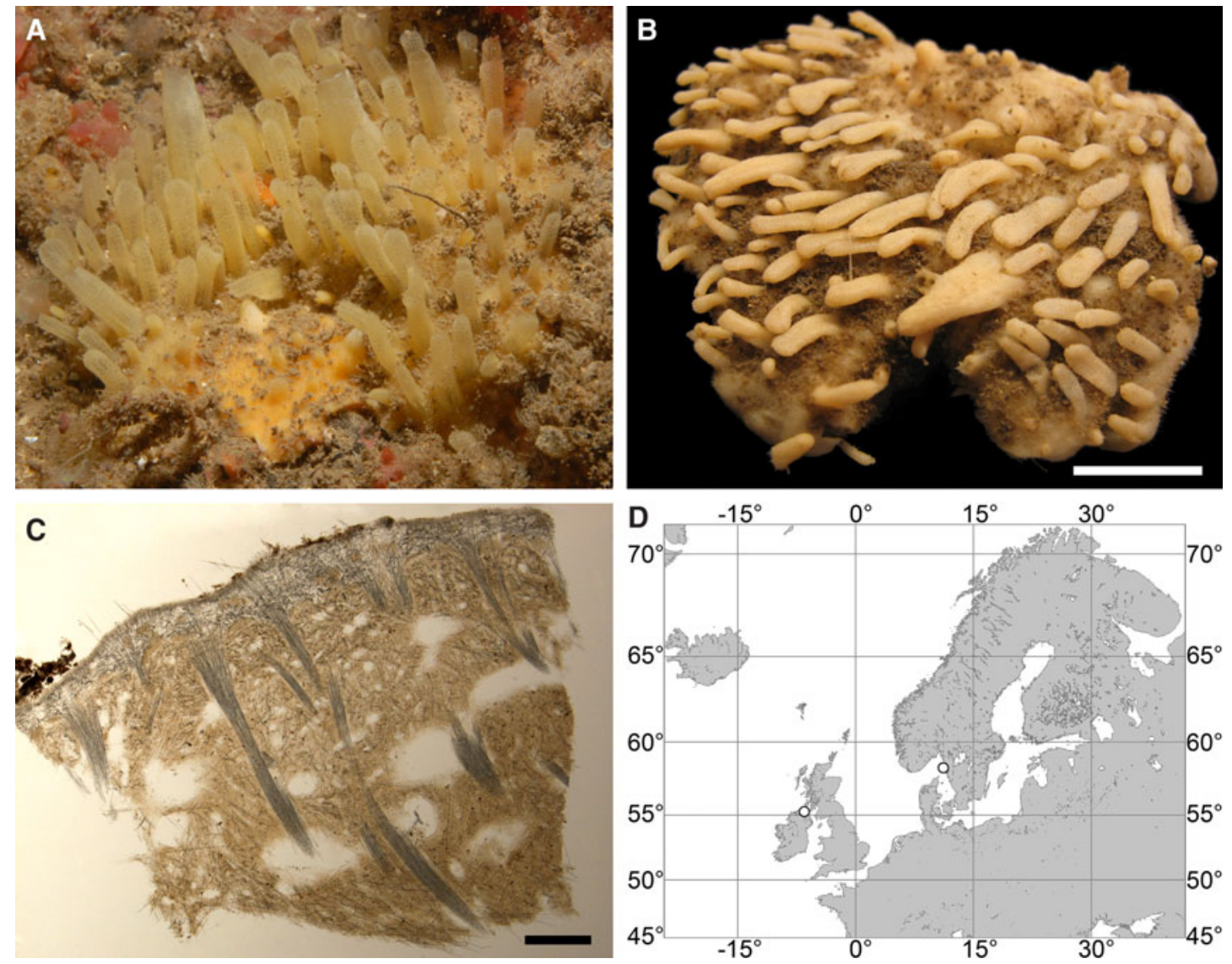

Fig. 13. Polymastia penicillus: (A) BELUM MC6505 in situ, North Channel, Irish Coast (courtesy of B.E. Picton, Ulster Museum, Belfast); (B) the same individual in preserved state, $(\mathrm{C})$, the same individual, longitudinal section through the body; $(\mathrm{D})$ distribution of the individuals studied; for other documented localities see Boury-Esnault (1987; as P. mamillaris). Scale bars: B, $1 \mathrm{~cm}$; C, $1 \mathrm{~mm}$.

\section{TYPE MATERIAL}

Holotype: BMNH 1930.7.3.26, Devon Coast, England, precise locality and depth unknown.

Detailed description of the holotype was presented by Morrow \& Boury-Esnault (2000).

\section{COMPARATIVE MATERIAL}

(see Online resource 1 for details)

Northern Ireland, Co Antrim, North Channel: BELUM MC6505 (one specimen).

Sweden: Västra Götaland, Skagerrak: GNM 460:1 and GNM 460:2 (two specimens).

\section{DESCRIPTION}

\section{External morphology}

Cushion-shaped sponges up to $10 \mathrm{~mm}$ thick, covering the substrate and occupying up to $300 \mathrm{~cm}^{2}$ (Figure $13 \mathrm{~A}, \mathrm{~B}$ ). Surface velvety rather than hispid, with up to 200 papillae, of which several (one to five depending on sponge size) with visible oscula at the summits. In life the surface dirty grey to yellow or pale orange. The papillae cream-coloured to pale yellow, up to $12 \mathrm{~mm}$ in length and $5 \mathrm{~mm}$ in diameter, cylindrical or gently tapering towards the summits (Figure 13A). Under sampling the papillae contract and the oscula close (Figure 13 B). Sponges usually buried in sediment with only the papillae protruding outwards.

\section{Anatomy}

Choanosome in alcohol firm, cream-coloured. Main choanosomal skeleton composed of longitudinal or radial tracts (125-360 $\mu \mathrm{m}$ thick) of principal spicules fanning under the cortex, crossing the cortex and forming a fine surface hispidation (Figure $13 \mathrm{C}$ ). Auxiliary choanosomal skeleton comprises free-scattered intermediary spicules. Cortex in alcohol whitish, firm, not detachable. Cortical skeleton constituted by a superficial palisade $(110-140 \mu \mathrm{m}$ thick) of small spicules and an internal layer $(350-500 \mu \mathrm{m}$ thick) of tangentially arranged intermediary spicules (Figure ${ }_{13} \mathrm{C}$ ). Skeleton of the papilla walls is a framework of the tracts ascending from the choanosome and covered with the cortical layers.

\section{Spicules}

(Measurements based on four specimens)

Principal spicules - tylostyles (holotype and the Irish individual) or styles to subtylostyles with weakly developed, displaced tyles (Swedish sponges), usually straight and fusiform. Length $603-959-1490 \mu \mathrm{m}$, proximal diameter of shaft $2.5-8.3-$ $12.7 \mu \mathrm{m}$, maximum diameter of shaft $7.6-12.3-20.3 \mu \mathrm{m}$, $\mathrm{N}=120$.

Intermediary spicules - tylostyles, occasionally subtylostyles with weakly developed tyles, gently curved or straight, usually slender, occasionally fusiform. Length 300-478$710 \mu \mathrm{m}$, diameter of tyle $5.1-8.0-10.2 \mu \mathrm{m}$, proximal diameter of shaft $2.5-6.4-8.9 \mu \mathrm{m}$, maximum diameter of shaft $5.1-10.0-15.2 \mu \mathrm{m}, \mathrm{N}=120$. 
Small spicules - tylostyles, gently curved, slender or slightly fusiform. Length 79-155-201 $\mu \mathrm{m}$, diameter of tyle $3.8-$ $4.7-6.4 \mu \mathrm{m}$, proximal diameter of shaft $1.5-3.0-5.1 \mu \mathrm{m}$, maximum diameter of shaft $1.5-3.3-6.4 \mu \mathrm{m}, \mathrm{N}=120$.

\section{Genetic data}

$28 \mathrm{~S}$ rDNA sequences obtained from three individuals of Polymastia penicillus, two from Sweden and one from Northern Ireland, are identical. CO1 was obtained only from the Irish sponge, and this sequence is identical to the $\mathrm{CO}_{1}$ sequence from a Portuguese $P$. penicillus (GenBank accessions KF225486 and KF225487, Alex et al., 2013). In both $28 \mathrm{~S}$ rDNA and $\mathrm{CO}_{1}$ phylogenies $P$. penicillus is related to $P$. nivea (Plotkin et al., 2016b), although these species share just two synapomorphies and display many differences (for details see the Genetic data section for P. nivea above). Polymastia penicillus is distinguished from all other polymastiids by two autapomorphies in $28 \mathrm{~S}$ rDNA (Online resource 3 , p. 3). Apart from them, P. penicillus differs from the type species of Polymastia, P. mamillaris, by $51 \mathrm{bps}$ in $\mathrm{CO}_{1}$ (Matrix M34248 in TreeBase) and 82 bps in $28 \mathrm{~S}$ rDNA (Matrix M34250 in TreeBase).

\section{OCCURRENCE}

Literature data: Portuguese, Spanish and French Atlantic Coast, Mediterranean Sea, English Channel, British Isles (as Polymastia mamillaris - Boury-Esnault, 1987; as P. penicillus - Van Soest et al., 2000, 2016). Depth - 0-600 m (Boury-Esnault, 1987). Records of Polymastia penicillus from the deep-sea, $2500 \mathrm{~m}$ near Jan Mayen and $1267 \mathrm{~m}$ near Newfoundland (Boury-Esnault, 1987) most likely represent other species.

Our data (Figure 13D): North Channel between Ireland and Great Britain: Irish Coast (depth unknown). Skagerrak: Swedish Western Coast (23-44 m).

\section{DISCUSSION}

Polymastia penicillus was for a long time confused with the sympatric species P. mamillaris (Johnston, 1842; Bowerbank, 1862; Gray, 1867; Vosmaer, 1885; Boury-Esnault, 1987) and P. grimaldii (Vosmaer, 1882; Fristedt, 1887; Levinsen, 1887) until Morrow \& Boury-Esnault (2000) demonstrated that these three were separate species (see the detailed taxonomic history in Discussion on P. mamillaris above), that is now confirmed by genetic data (Plotkin et al., 2016b; present study). Morphologically $P$. penicillus is distinguished by a surface smoother than in $P$. mamillaris and $P$. grimaldii and by a two-layered cortex against the three-layered cortex in the latter two species. At the same time $P$. penicillus and $P$. mamillaris share the encrusting growth pattern and the presence of just three spicule categories that differentiate them from $P$. grimaldii. Minor differences between $P$. penicillus and P. mamillaris in spicule shape emphasized by Morrow \& Boury-Esnault (2000) appear to be unstable.

\section{Polymastia svenseni sp. nov.} (Figure 14)

\section{TYPE MATERIAL}

Holotype: ZMBN 098092, Ramsvik in Stavanger, Rogaland, Norway, $58^{\circ} 57.404^{\prime} \mathrm{N} 05^{\circ} 45.796^{\prime} \mathrm{E}, 25-18 \mathrm{~m}$, coll. Plotkin and Svensen, 02.09.2012.
Paratype: ZMBN 098091, from the same sample as the holotype.

COMPARATIVE MATERIAL

ZMBN 107558, from the same sample as the holotype.

\section{ETYMOLOGY}

Named after Erling Svensen, a Norwegian underwater photographer, who has discovered a large population of this species in Stavanger.

\section{DESCRIPTION}

External morphology

Both holotype and paratype cushion-shaped, removed from a rock cliff. Surface, for the most part, smooth, cream-coloured in alcohol, with sparse rests of sediment and papillae, which may be conical tapering towards the summits, cylindrical or leaf-shaped expanding towards the summits. Holotype $105 \times 52 \times 13 \mathrm{~mm}$, with 157 papillae $2-13 \mathrm{~mm}$ long and $1.5-5.5 \mathrm{~mm}$ (Figure 14A). Paratype $67 \times 44 \times 12 \mathrm{~mm}$, with 76 papillae $2-15 \mathrm{~mm}$ long and $1.4-6.7 \mathrm{~mm}$ wide. Other sponges cushion-shaped, occupying up to $250 \mathrm{~cm}^{2}$ of the substrate (Figure 14B). Surface cream-coloured or whitish in life, smooth, partly covered with sediment, with up to 400 papillae tapering towards the summits. Few papillae with visible oscula at the summits.

\section{Anatomy}

Choanosome in life pale orange or yellowish, firm. Main choanosomal skeleton composed of tracts $(112-321 \mu \mathrm{m}$ thick) of large spicules radiating from the base and ending in the cortex (Figure 14C). Ascending tracts also form a framework of the papilla skeleton. Auxiliary choanosomal skeleton comprises free-scattered large and small spicules. Cortex in life whitish, firm, not detachable. Cortical skeleton constituted by a superficial palisade (220-240 $\mu \mathrm{m}$ thick) of small spicules, a middle layer (130-150 $\mu \mathrm{m}$ thick) and an internal layer $(100-125 \mu \mathrm{m}$ thick), both composed of criss-cross large spicules lying loosely in the middle layer and much more condensed in the internal layer (Figure ${ }_{14} \mathrm{C}$ ). Skeleton of the papilla walls composed of two cortical layers, the superficial palisade and the internal layer.

\section{Spicules}

(Measurements based on three specimens, individual variation presented in Table 5)

Large spicules - mainly styles (Figure $14 \mathrm{D}-\mathrm{F}$ ), occasionally subtylostyles with weakly developed and displaced tyles (Figure $14 \mathrm{G}-\mathrm{I}$ ), usually straight, sometimes gently curved, fusiform to a greater or lesser extent. Length 312-658$1364 \mu \mathrm{m}$, diameter of tyle (if present) $3.0-7.8-14.0 \mu \mathrm{m}$, proximal diameter of shaft $2.5-6.8-11.4 \mu \mathrm{m}$, maximum diameter of shaft $3.8-10.9-16.5 \mu \mathrm{m}, \mathrm{N}=187$. The large spicules vary greatly in size, both in the cortex and choanosome, but the frequency distribution of their dimensions exhibits just one peak and hence they cannot be divided into two size categories.

Small spicules - tylostyles, usually gently curved, slender (Figure 14J-O). Length 132-175-225 $\mu \mathrm{m}$, diameter of tyle 3.6-4.7-5.1 $\mu \mathrm{m}$, proximal diameter of shaft $2.0-2.8-$ $3.8 \mu \mathrm{m}$, maximum diameter of shaft $2.5-3.7-5.1 \mu \mathrm{m}$, $\mathrm{N}=90$. 

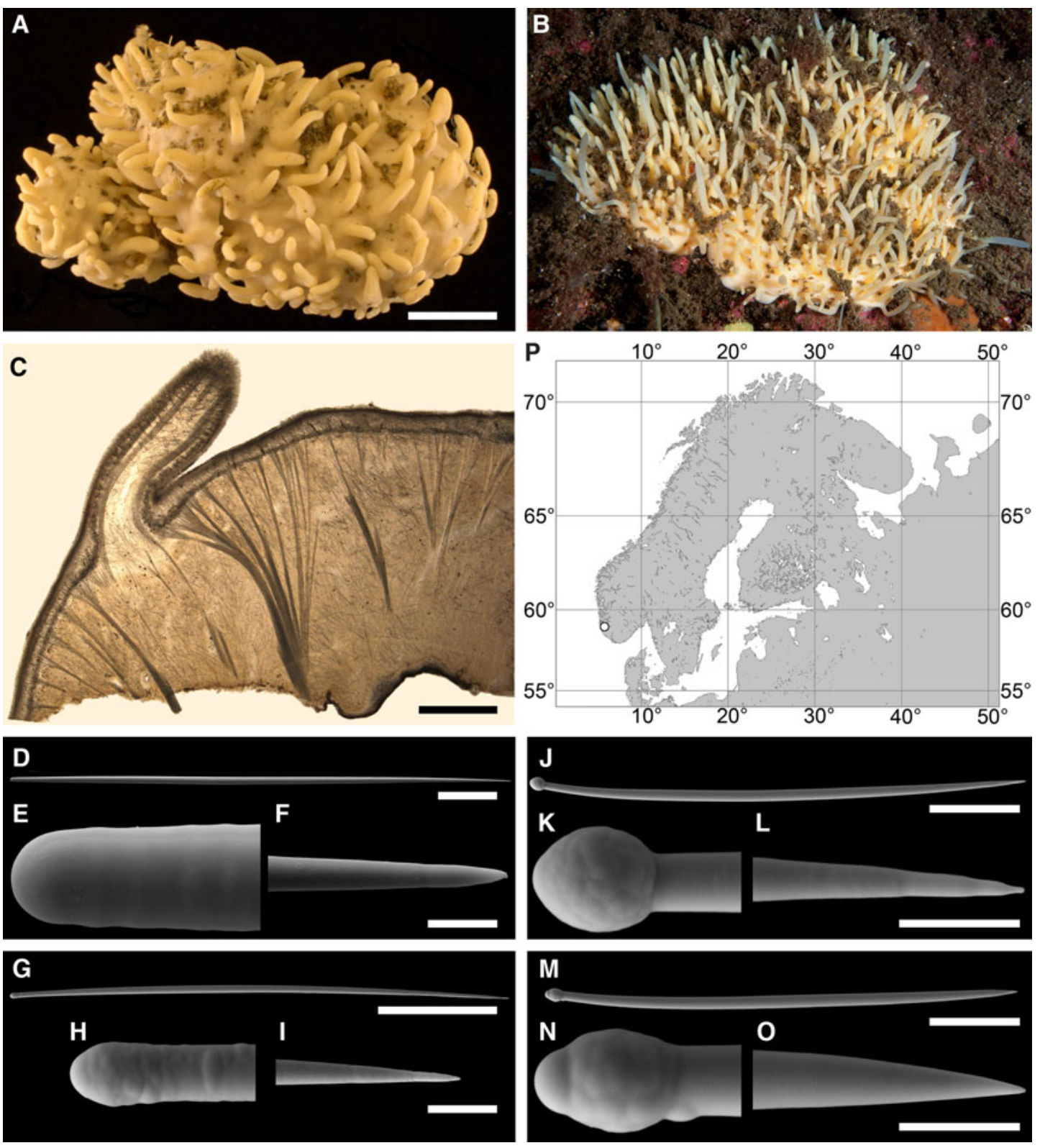

Fig. 14. Polymastia svenseni: (A) holotype ZMBN 098092, habitus; (B) an individual in situ, Ramsvik, Stavanger, Norway (courtesy of E. Svensen, OceanPhoto/ Dalane Tidende AS, Egersund); (C) holotype ZMBN 098092, longitudinal section through the body; (D) - (O) spicules of the holotype: (D) large style, general view; (E) the same style, detailed view of the proximal tip; (F) the same style, detailed view of the distal tip; (G) large subtylostyle, general view; (H) the same subtylostyle, detailed view of the proximal tip; (I) the same subtylostyle, detailed view of the distal tip; (J) small tylostyle with terminal tyle, general view; (K) the same tylostyle, detailed view of the tyle; (L) the same tylostyle, detailed view of the distal tip; (M) small tylostyle with displaced tyle, general view; (N) the same tylostyle, detailed view of the tyle; $(\mathrm{O})$ the same tylostyle, detailed view of the distal tip; (P), type locality (white circle). Scale bars: A, $2 \mathrm{~cm}$; C, 2 mm; $\mathrm{D}$, $0.1 \mathrm{~mm}$; E and F, $0.005 \mathrm{~mm}$; G, $0.1 \mathrm{~mm}$; H and I, $0.005 \mathrm{~mm}$; J, $0.03 \mathrm{~mm}$; K and L, $0.005 \mathrm{~mm}$; M, $0.03 \mathrm{~mm}$; $\mathrm{N}$ and $\mathrm{O}, 0.005 \mathrm{~mm}$.

\section{Genetic data}

$\mathrm{CO}_{1}$ and $28 \mathrm{~S}$ rDNA obtained from two individuals of Polymastia svenseni display no intraspecific polymorphism. B10-C 1 region of $28 \mathrm{~S}$ rDNA sequenced by Morrow et al. (2012) from an unidentified Irish Polymastia sp. (GenBank accession KFo17187) is identical to the corresponding gene fragment of $P$. svenseni (about $1 / 3$ length of our sequences). By both CO1 and $28 \mathrm{~S}$ rDNA P. svenseni is closely related to a Norwegian Polymastia sp. described below, and by $\mathrm{CO} 1$ alone these two are closely related to an unidentified Canadian Polymastia (Plotkin et al., 2016b), for which no $28 \mathrm{~S}$ rDNA is available and which is not covered by the present study. These sponges share nine synapomorphies in
CO1 (Online resource 2, p. 3, Matrix M34248 in TreeBase). Polymastia svenseni and the Norwegian Polymastia sp. also share two synapomorphies in $28 \mathrm{~S}$ rDNA distinguishing these taxa from all other polymastiids (Online resource 3, p. 3 ). At the same time P. svenseni is distinguished by two autapomorphies in $28 \mathrm{~S}$ rDNA (Online resource 3, p. 3). Apart from these autapomorphies, it differs from the Norwegian Polymastia sp. by 21 bps in CO1 (Matrix $\mathrm{M}_{34248}$ in TreeBase), from the Canadian Polymastia sp. by 17 bps in CO1 (Matrix $\mathrm{M}_{34248}$ in TreeBase), and from the type species of Polymastia, $P$. mamillaris, by 65 bps in CO 1 (Matrix M34248 in TreeBase) and 21 bps in $28 \mathrm{~S}$ rDNA (Matrix M34250 in TreeBase). In the CO1 phylogeny the 
Table 5. Individual variation of spicule dimensions of Polymastia svenseni (given in $\mu \mathrm{m}$ as minimum-mean-maximum). Parameters: length, diameter of tyle, proximal diameter of shaft, maximum diameter of shaft, number of spicules measured $(\mathrm{N})$.

\begin{tabular}{lll}
\hline Specimen & Principal spicules & Small spicules \\
\hline Holotype ZMBN 98092 & $312-632-965$ & $135-177-224$ \\
& $3.8-7.4-12.7$ & $3.8-4.7-5.1$ \\
& $2.5-6.6-10.2$ & $2.5-3.0-3.8$ \\
& $5.1-10.5-16.5$ & $2.5-3.7-4.6$ \\
Paratype ZMBN 98091 & $\mathrm{N}=63$ & $\mathrm{~N}=30$ \\
& $322-694-1364$ & $137-174-225$ \\
& $3.0-7.7-11.4$ & $3.6-4.5-5.1$ \\
& $2.5-6.9-10.7$ & $2.0-2.7-3.8$ \\
& $3.8-11.3-15.2$ & $2.5-3.3-4.6$ \\
ZMBN 107558 & $\mathrm{N}=64$ & $\mathrm{~N}=30$ \\
& $372-645-930$ & $132-175-203$ \\
& $6.4-8.3-14$ & $3.8-5-5.1$ \\
& $3.8-6.8-11.4$ & $2.5-2.8-3.8$ \\
& $6.4-10.3-15.2$ & $3.8-4.1-5.1$ \\
& $\mathrm{~N}=60$ & $\mathrm{~N}=30$ \\
\hline
\end{tabular}

trio Polymastia svenseni + Norwegian Polymastia sp. + Canadian Polymastia sp. is the sister to the clade of seven other Polymastia spp. including P. mamillaris, although with a weak Bayesian support (Plotkin et al., 2016b). In the $28 \mathrm{~S}$ rDNA phylogeny the pair Polymastia svenseni + Norwegian
Polymastia sp. is the sister to the same clade with a high support (the same study).

\section{OCCURRENCE}

Literature data: Ireland (Morrow et al., 2012: the record based only on the genetic data).

Our data (Figure 14P): Norwegian Coast: Rogaland $(18-25 \mathrm{~m})$.

\section{DISCUSSION}

Polymastia svenseni is established as a new species of Polymastia primarily based on the $\mathrm{CO}_{1}$ and $28 \mathrm{~S}$ rDNA phylogenies and on its autapomorphies in the latter gene. However, no morphological autapomorphies distinguishing this species from other Polymastia spp. are revealed. Polymastia svenseni resembles $P$. boletiformis by the smooth surface and the presence of only two categories of spicules. On the contrary, by its radial main choanosomal skeleton and three-layered cortex $P$. svenseni resembles $P$. andrica, $P$. arctica, $P$. grimaldii and $P$. mamillaris.

\section{Polymastia thielei Koltun, 1964}

(Figure 15)

Original description: Polymastia thielei Koltun, 1964, p. 149, figure 4 .
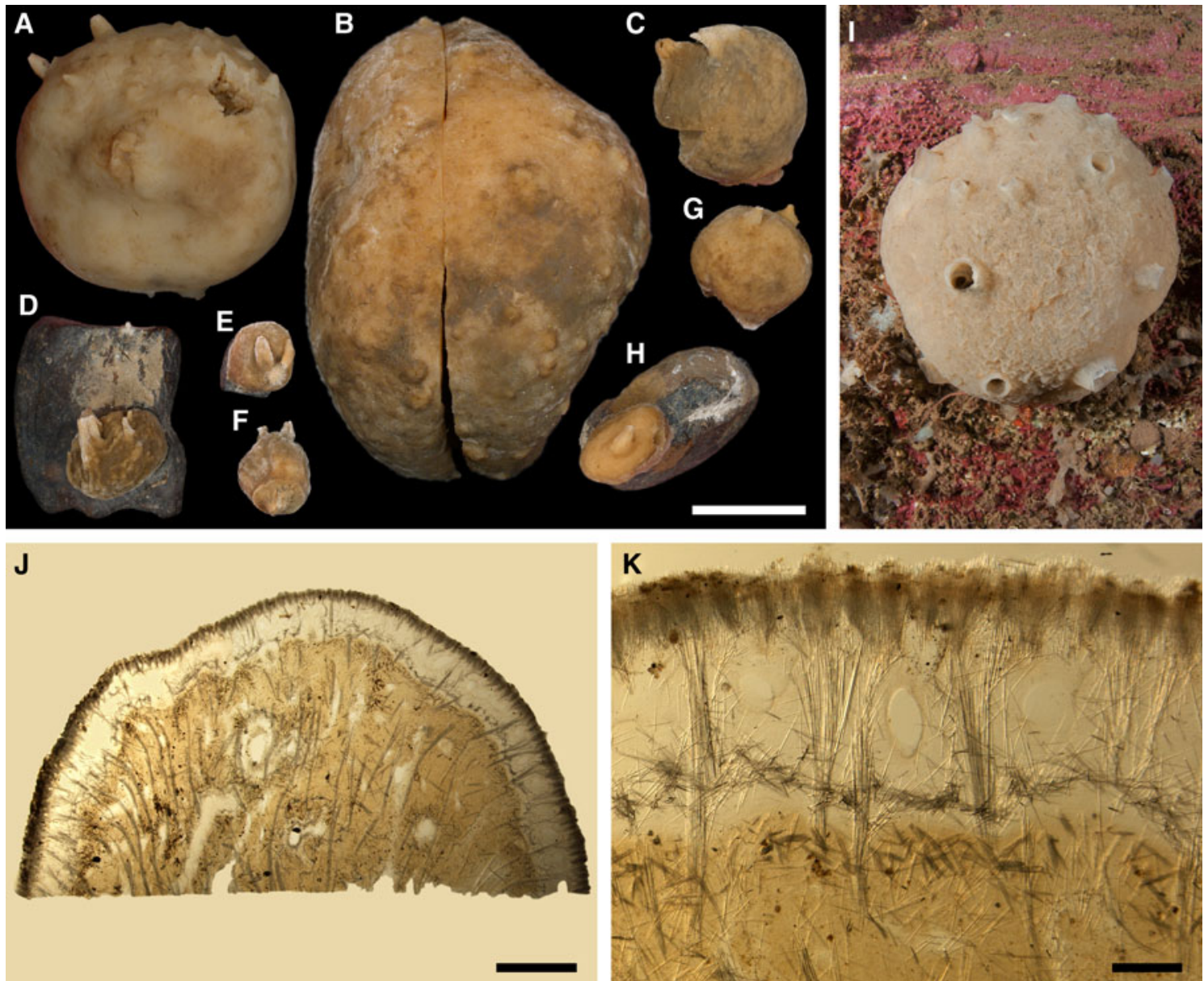

Fig. 15. Polymastia thielei: (A) lectotype ZIN RAS 10640, habitus; (B) paralectotype ZIN RAS10638, habitus; (C) -(H) paralectotypes ZIN RAS10639, habitus; (I) an individual in situ, Hinlopenstretet, Svalbard, Norway (courtesy P. Leopold, University of Tromsø); (J) ZMBN 9807o, longitudinal section through the body general view; $(\mathrm{K})$, the same section, detail of cortex and subcortical area. Scale bars: $\mathrm{A}-\mathrm{H}, 2 \mathrm{~cm}$; $, 3 \mathrm{~mm}, \mathrm{~K}, 0.5 \mathrm{~mm}$. 


\section{SYNONYMS AND CITATIONS}

Polymastia thielei (Koltun, 1966, p. 76, text-figures 47-48, pl. XXVII figures 1-5; Plotkin, 2004, p. 541, figures 1c \& 2c).

Polymastia uberrima (Lundbeck, 1909, p. 450, pl. XIV figure 4; Topsent, 1913, p. 18, pl. II figure 5; Burton, 1959a: 12 pars.; Boury-Esnault, 1987, p. 48, figure 10).

Rinalda uberrima (Hansen, 1885 , p. 8, pl. VI figure 18; Thiele, 1903, p. 376, figure 2).

\section{TYPE MATERIAL}

Lectotype (designated herein, see figure 1C in Plotkin, 2004 and Figure $15 \mathrm{~A}$ in the present study): ZIN RAS 10640 (slide 6153), Greenland Sea, $80^{\circ} 31^{\prime} \mathrm{N} 06^{\circ} 59^{\prime} \mathrm{W}, 259 \mathrm{~m}, \mathrm{RV}$ 'Ob”, station 33 28.08.1956, coll. Koltun.

Paralectotype: ZIN RAS 10638 (slide 6024), North-East off Franz Josef Land, Arctic Ocean, $81^{\circ} 52.5^{\prime} \mathrm{N} 60^{\circ} 32^{\prime} \mathrm{E}$, $230-$ 246 m, RV 'Litke', station 14, 15.09.1955, coll. Koltun.

Six paralectotypes: ZIN RAS 10639 (slide 6085), North-West off Franz Josef Land, Arctic Ocean, $82^{\circ} \mathrm{oo}^{\prime} \mathrm{N} 42^{\circ} \mathrm{oo}$ 'E, $418-$ 415 m, RV 'Litke', station 26, 18.09.1955, coll. Koltun.

\section{COMPARATIVE MATERIAL}

(see Online resource 1 for details)

Canada, Newfoundland: ZIN RAS ocpto17 (one specimen).

Denmark Strait: ZIN RAS ocpto3o and ZMBN 098107 (two specimens).

Iceland: ZIN RAS ocptoo4 and ZMBN 098070 (two specimens).

Iceland Sea: ZIN RAS ocptor6 (one specimen).

Faroes: ZIN RAS ocpto13 (one specimen).

Norwegian Sea, offshore: MOM 04-0851 (identified as Polymastia uberrima by Topsent, 1913), NTNU-VM-54993, NTNU-VM-72524, ZMBN 098109, ZMBN 107580 and ZMBN 107581 (six specimens).

Barents Sea, offshore: ZIN RAS ocptoo7, ZIN RAS ocptoo9, ZIN RAS ocpto11, ZIN RAS ocpto14, ZIN RAS ocpto27 and ZIN RAS ocpto29 (six specimens).

Norway: Møre and Romsdal: |NTNU-VM-54960, ZMBN 107495 and ZMBN 107496 (three specimens), NordTrøndelag: NTNU-VM-54884, NTNU-VM-54887, NTNUVM-54888 and NTNU-VM-72537 (five specimens), Nordland: NTNU-VM-72519 and NTNU-VM-72540 (two specimens), Troms: ZIN RAS ocptoo5 (one specimen), Finnmark: ZIN RAS ocptoo1 (one specimen), Svalbard: ZIN RAS ocptoo2, ZIN RAS ocpto28, ZMBN 098052 and ZMBN 098053 (four specimens).

Russia: Murman Coast: ZIN RAS ocptoo6 (one specimen), Franz Josef Land: ZIN RAS ocptor2 (one specimen), Novaya Zemlya: ZIN RAS ocpto16 (one specimen), Taymyr Peninsula: ZIN RAS ocptoo3, ZIN RAS ocpto21 and ZIN RAS ocpto25 (three specimens), Nordenskjold Archipelago: ZIN RAS ocpto2o (one specimen).

Kara Sea: ZIN RAS ocptoo8, ZIN RAS ocpto12, ZIN RAS ocpto15, ZIN RAS ocpto18, ZIN RAS ocpto19, ZIN RAS ocpto23 and ZIN RAS ocpto24 (seven specimens).

\section{DESCRIPTION}

\section{External morphology}

Lectotype globular, about $50 \mathrm{~mm}$ in diameter, attached to small stones (Figure 15A). Surface velvety, pale beige with sparsely scattered small brown stains, bearing 18 papillae. The papillae crater-shaped (very short and wide) or conical,
1.5-5.5 mm long and 1.7-9.2 mm wide at base, most with well-visible oscula at the summits. Paratype ZIN RAS 10638 irregularly ovoid, $81 \times 60 \mathrm{~mm}$ in diameter, split across, removed from the substrate (Figure $15 \mathrm{~B}$ ). Surface velvety, pale brown with darker stains, bearing 23 wart-like small papillae, the largest with oscula at the summits. Paratypes ZIN RAS 10639 are small, massive sponges on stones or removed from the substrates (Figure $15 \mathrm{C}-\mathrm{H}$ ). Surface, for the most part, velvety or knobbly, porous in some individuals, brownish, with one or few conical or crater-shaped papillae, all with oscula at the summits. Some paratypes with minute hispidation around the base. Other sponges massive, fistshaped, globular or ovoid, up to $250 \mathrm{~mm}$ in diameter (Figure 15I). Surface knobbly, velvety or smooth, with wellvisible ostia. Colour in life whitish, cream-coloured or beige, occasionally with large dark brown spots. In alcohol the colouration darkens and the ostia contract. Up to 30 papillae, all with oscula at the summits, crater-shaped in life and often stretching under sampling.

\section{Anatomy}

Choanosome pale brown to dark brown, both in life and in alcohol, somewhat loose, porous, with prominent meandering and anastomosing exhalant canals (up to $8 \mathrm{~mm}$ in diameter) running to the papillae. Main choanosomal skeleton composed of tracts $(90-360 \mu \mathrm{m}$ thick) of principal spicules radiating from the sponge base (Figure 15J). In the central part of the choanosome the tracts often meander and ramify, sometimes anastomose and form a network. Auxiliary choanosomal skeleton comprises small spicules, free-scattered or grouped in little bundles, especially abundant in a subcortical area $(200-350 \mu \mathrm{m}$ thick). Within the choanosome the walls of the exhalant canals paved with criss-cross small and intermediary spicules. Cortex in life cream-coloured, dense, but detachable. Cortical skeleton includes a superficial layer (340-650 $\mu \mathrm{m}$ thick) formed by bouquets of small spicules and an internal layer (150-250 $\mu \mathrm{m}$ thick) of criss-cross intermediary spicules (Figure $15 \mathrm{~K})$. A space $(650-880 \mu \mathrm{m}$ thick) between the spicule layers is occupied by oval aquiferous cavities $(190-480 \times 70-240 \mu \mathrm{m}$ in diameter) connected with ostia which are located between the superficial spicule bouquets. Bulkheads between the aquiferous cavities reinforced with the ascending choanosomal tracts and criss-cross intermediary spicules. The papillae walls reinforced with the ascending choanosomal tracts and covered with the spicule cortical layers.

\section{Spicules}

(Measurements based on 10 specimens)

Principal spicules - styles to subtylostyles, usually straight and fusiform. Length 693-1277-1705 $\mu \mathrm{m}$, proximal diameter of shaft 5.0-9.8-14.2 $\mu \mathrm{m}$, maximum diameter of shaft 12.5$18.4-25.1 \mu \mathrm{m}, \mathrm{N}=300$.

Intermediary spicules - subtylostyles to tylostyles, straight or gently curved, fusiform. Length $445-539-648 \mu \mathrm{m}$, diameter of tyle 4.2-7.0-8.2 $\mu \mathrm{m}$, proximal diameter of shaft $3.2-$ 5.8-7.1 $\mu \mathrm{m}$, maximum diameter of shaft 10.5-11.2$12.3 \mu \mathrm{m}, \mathrm{N}=300$.

Small spicules - tylostyles, gently curved, slender or slightly fusiform. Length $219-297-363 \mu \mathrm{m}$, diameter of tyle $3.8-$ 5.5-7.4 $\mu \mathrm{m}$, proximal diameter of shaft $1.7-3.8-5.7 \mu \mathrm{m}$, maximum diameter of shaft $4.1-6.8-9.3 \mu \mathrm{m}, \mathrm{N}=300$. 


\section{Genetic data}

$\mathrm{CO}_{1}$ sequences obtained from five individuals of Polymastia thielei are identical. $28 \mathrm{~S}$ rDNA was obtained only from one of these sponges. By both genes $P$. thielei is closely related to morphologically quite different $P$. hemisphaerica (Plotkin et al., 2016b). The synapomorphies and differences between these species are described above in the Genetic data section for P. hemisphaerica.

\section{OCCURRENCE}

(Figure 16)

Our data (agree with the literature data): Canadian Atlantic Coast: Newfoundland $(340-375 \mathrm{~m})$. Denmark Strait (317$650 \mathrm{~m})$. Iceland $(165-318 \mathrm{~m})$. Iceland Sea $(1280 \mathrm{~m})$. Faroes $(350 \mathrm{~m})$. Greenland Sea $(259 \mathrm{~m})$. Norwegian Coast: Møre and Romsdal: $(120-200 \mathrm{~m})$, Nord-Trøndelag: $(28-400 \mathrm{~m})$ Nordland: $(200-800 \mathrm{~m})$, Troms $(280 \mathrm{~m})$, Finnmark $(275 \mathrm{~m})$. Norwegian Sea, offshore areas (440-1580 m). Barents Sea: Murman Coast: $(272 \mathrm{~m})$, offshore areas: (165$365 \mathrm{~m})$. Svalbard (40-820 m). Franz Josef Land: (122-246 m). Novaya Zemlya $(293 \mathrm{~m})$. Taymyr Peninsula $(49-60 \mathrm{~m})$. Nordenskjold Archipelago (75 m). Kara Sea (85-446 m). Arctic Ocean (415-418 m).

\section{DISCUSSION}

Before Koltun (1964) established Polymastia thielei the sponges with the characteristic features of this species had usually been identified as $P$. uberrima because of some external similarity between these species (e.g. Hansen, 1885; Thiele, 1903; Lundbeck, 1909; Topsent, 1913). Polymastia thielei also displays some similarities in body shape and architecture of the cortex with Weberella bursa (Müller, 1806). The main distinctive features of $P$. thielei are much smaller number of papillae and their conspicuous crater-like shape. Weberella bursa differs from both $P$. thielei and P. uberrima by the pale colouration of both the cortex and the choanosome, much thinner cortex, the reticulate choanosomal skeleton and the presence of just two size categories of spicules. Polymastia uberrima is distinguished by the presence of a marginal hispid collar absent in both $P$. thielei and $W$. bursa and the regular radial choanosomal skeleton, while in $P$. thielei the choanosomal skeleton is less regular, with a tendency to meandering and anastomosing. The morphological differences between $P$. thielei, $P$. uberrima and $W$. bursa are clearly confirmed by the genetic data.

\section{Polymastia uberrima (Schmidt, 1870)}

(Figure 17)

Original description: Rinalda uberrima Schmidt, 1870, p. 51, pl. VI figure 3.

\section{SYNONYMS AND CITATIONS}

Polymastia infrapilosa Topsent, 1927b, p. 4 (Topsent, 1928, p. 147, pl. II figures 25-26, pl. VI figure 3; Boury-Esnault, 1987, p. 40, figure 6).

Polymastia uberrima (Hentschel, 1929, p. 868 and 923; Arndt, 1935, p. 35 pars.; Gorbunov, 1946, p. 37; Burton, 1959a, p. 12 pars.; Koltun, 1966, p. 75, text-figure 46, pl. XXV figures 1-3; Plotkin, 2004, p. 542, figures 1d \& 2d; Plotkin et al., 2012, p. 25, figure 1f).

Rinalda uberrima (? von Marenzeller, 1878 , p. 369, pl. II figure 2).

Non Polymastia uberrima (Lundbeck, 1909, p. 450, pl. XIV figure 4; Topsent, 1913, p. 18, pl. II figure 5; Boury-Esnault, 1987 , p. 48 , figure 10 ).

Non Rinalda uberrima (Hansen, 1885 , p. 8, pl. VI figure 18; Thiele, 1903, p. 376, figure 2).

\section{TYPE MATERIAL}

Holotype of Polymastia uberrima (Figure 17A): ZMUCDEM-395, Iceland, precise locality unknown.

Lectotype (designated herein, Figure $17 \mathrm{~B}, \mathrm{C}$ ) and two paralectotypes of Polymastia infrapilosa Topsent, 1927: MOM 04-1449, SE of Halifax, Nova Scotia, Canada, $44^{\circ} 10^{\prime} \mathrm{N}$ $62^{\circ} 27.5^{\prime} \mathrm{W}, 75 \mathrm{~m}$, Scientific campaigns by Albert the 1 st of Monaco, station $3425,13.08 .1913$. Herein P. infrapilosa is

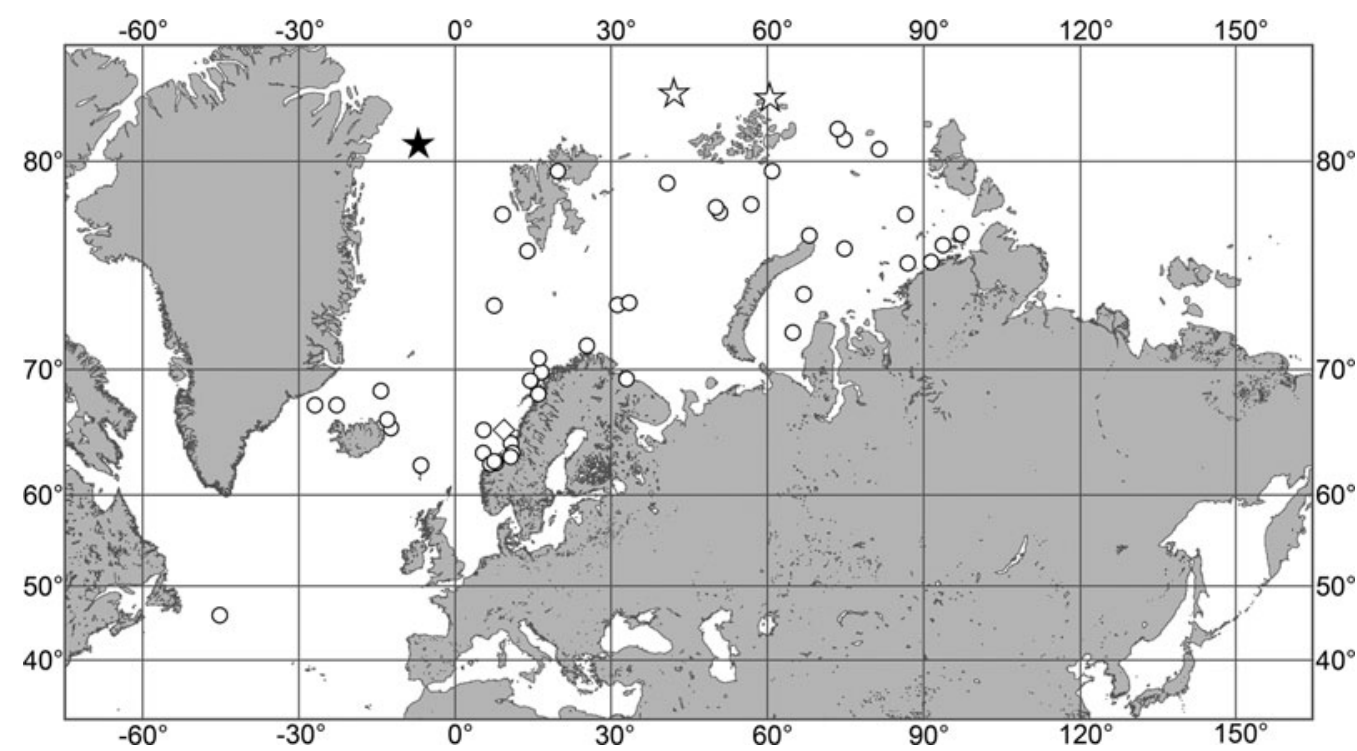

Fig. 16. Polymastia thielei, distribution: black star, locality of lectotype; white stars, localities of paralectotypes; white diamond, locality of MOM o4-0851 identified as P. uberrima by Topsent (1913) and re-identified as P. thielei herein; white circles, our data. 

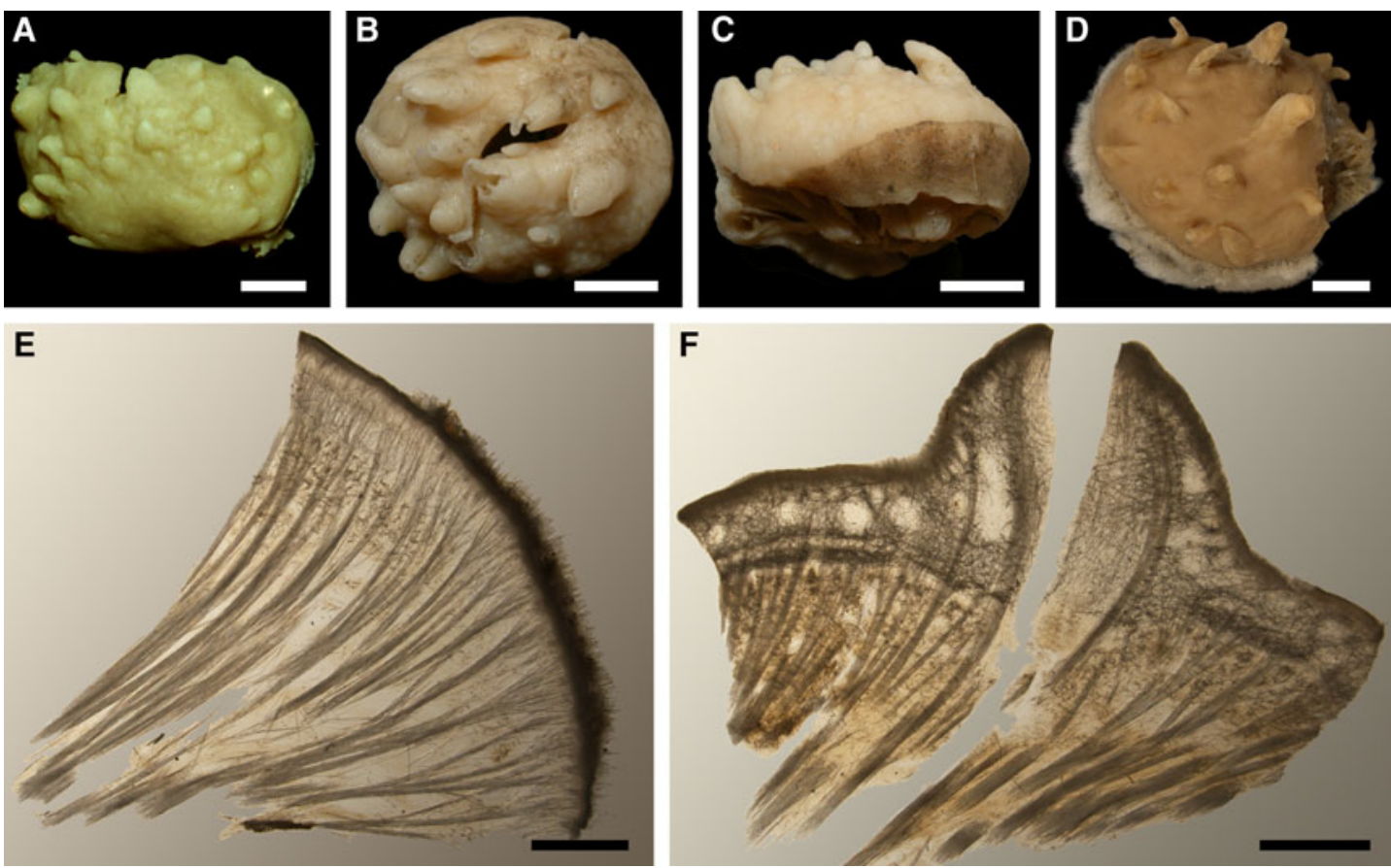

Fig. 17. Polymastia uberrima: (A) holotype of Rinalda uberrima, ZMUC-DEM-395, habitus; (B) lectotype of Polymastia infrapilosa (a synonym of $P$. uberrima), MOM 04-1449, habitus, view from above; (C) the same, side view; (D) ZIN RAS ocpuoo5, habitus; (E) holotype of Rinalda uberrima, ZMUC-DEM-395, longitudinal section through the body, peripheral area; (F) the same individual, longitudinal section through a papilla and adjacent area. Scale bars: A-D, $1 \mathrm{~cm}$; E, $3 \mathrm{~mm}$; F, $2 \mathrm{~mm}$.

relegated to a synonym of $P$. uberrima (see Discussion on this species below).

\section{COMPARATIVE MATERIAL}

(see Online resource 1 for details)

Canada: Nova Scotia: ZIN RAS ocpuoo4, ZIN RAS ocpuoo5 and ZIN RAS ocpuog4 (three specimens), Newfoundland: ZIN RAS ocpuoo2, ZIN RAS ocpuo15, ZIN RAS ocpuozo, ZIN RAS ocpuo22, ZIN RAS ocpuo23, ZIN RAS ocpuo24, ZIN RAS ocpuo26, ZIN RAS ocpuo27, ZIN RAS ocpuo31, ZIN RAS ocpuo33, ZIN RAS ocpuo34, ZIN RAS ocpuo43, ZIN RAS ocpuo44 and ZIN RAS ocpuo45 (17 specimens), Labrador: ZIN RAS ocpuoo3, ZIN RAS ocpuo16, ZIN RAS ocpuo17, ZIN RAS ocpuo21, ZIN RAS ocpuo25 and ZIN RAS ocpuo28 (six specimens), offshore areas of the NW Atlantic: ZIN RAS ocpuo46 (one specimen).

Greenland: SW Coast/Davis Strait: ZIN RAS ocpuo18, ZIN RAS ocpuo19, ZIN RAS ocpuo29 and ZIN RAS ocpuo32 (four specimens), SE Coast: ZIN RAS ocpuo42, ZIN RAS ocpuo49, ZIN RAS ocpuog7 and ZIN RAS ocpu1o2 (four specimens).

Iceland: ZIN RAS ocpuo35, ZIN RAS ocpuo39, ZIN RAS ocpuo41, ZIN RAS ocpuo48 and ZIN RAS ocpuo5o (11 specimens).

North-East Atlantic, offshore: ZIN RAS ocpuo36, ZIN RAS ocpuo40, ZIN RAS ocpuo38 and ZIN RAS ocpuog6 (four specimens).

Norwegian Sea, offshore: ZIN RAS ocpuoo6, ZIN RAS ocpuo07, ZIN RAS ocpuoo8, ZIN RAS ocpuoo9, ZIN RAS ocpuo10, ZIN RAS ocpuo13, ZIN RAS ocpuog9 and ZMBN 098066 (10 specimens).

Barents Sea, offshore: ZIN RAS ocpuo11, ZIN RAS ocpuo53, ZIN RAS ocpuo57, ZIN RAS ocpuo61, ZIN RAS ocpuo63, ZIN RAS ocpuo66, ZIN RAS ocpuo67, ZIN RAS ocpuo7o,
ZIN RAS ocpuo73, ZIN RAS ocpuo8o, ZIN RAS ocpuo81, ZIN RAS ocpuo82, ZIN RAS ocpuo85, ZIN RAS ocpu1oo, ZIN RAS ocpu101 and ZIN RAS ocpu104 (21 specimens).

Norway: Nordland: NTNU-VM-55002, NTNU-VM-72520 and NTNU-VM-72534 (three specimens), Troms: NTNUVM-72530, ZMBN 098073, ZMBN 107574 and ZMBN 107575 (four specimens), Finnmark: NTNU-VM-72503, NTNU-VM-72528, ZIN RAS ocpuo95 and ZMBN 107578 (five specimens), Svalbard: ZIN RAS ocpuo12 and ZIN RAS ocpuo14 (three specimens).

Russia: Murman Coast: ZIN RAS ocpuo51, ZIN RAS ocpuo56, ZIN RAS ocpuo62, ZIN RAS ocpuo64, ZIN RAS ocpuo71, ZIN RAS ocpuo74, ZIN RAS ocpuo75, ZIN RAS ocpuo76, ZIN RAS ocpuo77, ZIN RAS ocpuo83, ZIN RAS ocpuo84, ZIN RAS ocpuo88, ZIN RAS ocpuo89, ZIN RAS ocpuo9o, ZIN RAS ocpuo91, ZIN RAS ocpuo92 and ZIN RAS ocpu103 (21 specimens), White Sea: ZIN RAS ocpuo72 (one specimen), Franz Josef Land: ZIN RAS ocpuo107 (one specimen), Severnaya Zemlya: ZIN RAS ocpu105 and ZIN RAS ocpu1o6 (two specimens).

Arctic Ocean, offshore: ZIN RAS ocpu6o and ZIN RAS ocpu98 (three specimens).

\section{DESCRIPTION}

\section{External morphology}

Holotype of Rinalda uberrima massive, $\sim 46 \times 27 \times 29 \mathrm{~mm}$, removed from the substrate (Figure $17 \mathrm{~A}$ ). Surface, for the most part, smooth, cream-coloured, with about 20 papillae and a minutely hispid greyish edging, 5-6 $\mathrm{mm}$ wide, on the undamaged side. Most papillae wart-like, weakly developed, but some conical, up to $5 \mathrm{~mm}$ long and $7 \mathrm{~mm}$ wide at base, with visible oscula at the summits. Lectotype and paralectotypes of Polymastia infrapilosa massive, removed from the substrates. Surface, for the most part, smooth, cream- 
coloured, with a minute hispidation, $6-7 \mathrm{~mm}$ wide, along the undamaged edge and conical, occasionally cylindrical, papillae bearing oscula at the summits. Lectotype $\sim 42 \times 38 \times 21 \mathrm{~mm}$, split across, with 49 papillae, which are 2-12 $\mathrm{mm}$ long, 2$8 \mathrm{~mm}$ wide at base and $1-2 \mathrm{~mm}$ wide at summit (Figure $17 \mathrm{~B}, \mathrm{C}$ ). Paralectotypes $\sim 36 \times 30 \times 16 \mathrm{~mm}$, with 23 papillae, and $37 \times 29.5 \times 10 \mathrm{~mm}$, with 30 papillae. The latter with several surface protuberances, each bearing one to three buds, $2-3 \mathrm{~mm}$ in diameter. Other sponges massive or globular, occupying up to $100 \mathrm{~mm}^{2}$ of the substrate. Except for a marginal collar, the surface smooth or velvety, whitish in life, but often darkening in alcohol, with up to 150 conical or cylindrical papillae, in life all with visible oscula. The marginal collar is a rough, hispid or even shaggy area of various widths (Figure $17 \mathrm{D}$ ).

\section{Anatomy}

Choanosome yellowish in life, but may become dark brown in alcohol, dense. Main choanosomal skeleton composed of tracts $(207-571 \mu \mathrm{m}$ thick) of principal spicules radiating from the sponge base and occasionally ramifying under the cortex (Figure $17 \mathrm{E}, \mathrm{F}$ ). Most tracts end in the cortex except for the marginal area where they protrude above the surface. Some tracts ascend to the papillae (Figure ${ }_{17} \mathrm{~F}$ ). Auxiliary choanosomal skeleton comprises small bundles of intermediary spicules, especially abundant in a subcortical area (423$1484 \mu \mathrm{m}$ thick). Cortex in life cream-coloured, firm, not detachable. Cortical skeleton includes a superficial palisade (201-257 $\mu \mathrm{m}$ thick) of small spicules, a middle layer of loosely and confusedly lying bundles of intermediary spicules (672-1437 $\mu \mathrm{m}$ thick) and an internal layer (181-326 $\mu \mathrm{m}$ thick) with a high concentration of criss-cross intermediary spicules. In the areas under the papillae the middle layer contains aquiferous cavities connected with the surface ostia (Figure ${ }_{17} \mathrm{~F}$ ). The papillae walls reinforced with the ascending choanosomal tracts and covered with the superficial palisade and internal cortical layer. Several exhalant and inhalant canals running into the papillae are separated by bulkheads reinforced with the ascending tracts and free-scattered intermediary spicules.

Spicules

(Measurements based on nine specimens, individual variation presented in Table 6)

Principal spicules - styles to subtylostyles, straight, fusiform. Length 715-1409-1889 $\mu \mathrm{m}$, proximal diameter of shaft 7.9-13.1-17.2 $\mu \mathrm{m}$, maximum diameter of shaft 10.7-23.1$30.4 \mu \mathrm{m}, \mathrm{N}=270$.

Table 6. Individual variation of spicule dimensions of Polymastia uberrima (given in $\mu \mathrm{m}$ as minimum-mean-maximum). Parameters: length, proximal diameter of shaft, maximum diameter of shaft, number of spicules measured $(\mathrm{N})$.

\begin{tabular}{|c|c|c|c|}
\hline Specimen & Principal spicules & Intermediary spicules & Small spicules \\
\hline \multirow[t]{4}{*}{ Holotype of Rinalda uberrima, ZMUC } & $1228-1415-1649$ & $422-549-633$ & $175-202-239$ \\
\hline & $10.2-13.7-15.2$ & $6.4-7.6-11.4$ & $2.5-2.8-3.8$ \\
\hline & $20.3-24.6-29.2$ & $10.2-12.6-16.5$ & $5.1-6.9-8.9$ \\
\hline & $\mathrm{N}=30$ & $\mathrm{~N}=30$ & $\mathrm{~N}=30$ \\
\hline \multirow[t]{4}{*}{ Lectotype of Polymastia infrapilosa, MOM 04-1449a } & $1174-1609-1873$ & $441-552-690$ & $153-212-316$ \\
\hline & $9.8-13.8-16.4$ & $6.4-8.9-12.2$ & $2.2-3.3-4.5$ \\
\hline & $20.2-25.2-29.2$ & $8.2-11.4-15.1$ & $6.4-6.9-8.2$ \\
\hline & $\mathrm{N}=30$ & $\mathrm{~N}=30$ & $\mathrm{~N}=30$ \\
\hline \multirow[t]{4}{*}{ Paralectotype of Polymastia infrapilosa, MOM 04-1449b } & $1219-1685-1889$ & $453-581-699$ & $157-225-298$ \\
\hline & $10.1-14.1-17.2$ & $6.6-9.6-12.3$ & $2.3-3.3-4.2$ \\
\hline & $20.2-25.4-30.2$ & $8.4-12.2-15.8$ & $6.1-7.0-7.9$ \\
\hline & $\mathrm{N}=30$ & $\mathrm{~N}=30$ & $\mathrm{~N}=30$ \\
\hline \multirow[t]{4}{*}{ Paralectotype of Polymastia infrapilosa, MOM o4-1449c } & $1406-1630-1845$ & $438-563-706$ & $161-224-304$ \\
\hline & $12.9-14.7-16.6$ & $6.4-9.3-12.5$ & $2.4-2.9-4.2$ \\
\hline & $20.3-24.5-29.5$ & $8.2-11.8-16$ & $6.5-7.0-8.0$ \\
\hline & $\mathrm{N}=30$ & $\mathrm{~N}=30$ & $\mathrm{~N}=30$ \\
\hline \multirow[t]{4}{*}{ ZIN RAS puozo (Canada, Newfoundland) } & $1215-1607-1851$ & $381-538-686$ & $169-212-257$ \\
\hline & $10.1-14.1-16.7$ & $5.8-8.7-11.9$ & $2.4-3-3.8$ \\
\hline & $20.1-25.2-30.4$ & $7.2-11.4-15.4$ & $5.7-6.4-7.3$ \\
\hline & $\mathrm{N}=30$ & $\mathrm{~N}=30$ & $\mathrm{~N}=30$ \\
\hline \multirow[t]{4}{*}{ ZIN RAS puog6 (Faroes) } & $1102-1414-1670$ & $458-582-654$ & $263-276-307$ \\
\hline & $9.5-13-15.9$ & $6.5-9.4-11.6$ & $2.8-3.3-4.2$ \\
\hline & $19.4-22.2-24.8$ & $8.4-11.7-14.4$ & $3.3-4.6-6.5$ \\
\hline & $\mathrm{N}=30$ & $\mathrm{~N}=30$ & $\mathrm{~N}=30$ \\
\hline \multirow[t]{4}{*}{ ZMBN 098066 (Norwegian Sea) } & $973-1173-1611$ & $448-529-629$ & $167-225-293$ \\
\hline & $9.4-12-15$ & $6.4-8.7-11.3$ & $2.5-3.2-4.0$ \\
\hline & $17.7-20.3-23.4$ & $8.0-10.8-13.9$ & $3.7-4.7-6.0$ \\
\hline & $\mathrm{N}=30$ & $\mathrm{~N}=30$ & $\mathrm{~N}=30$ \\
\hline \multirow[t]{4}{*}{ ZMBN 107578 (Norway, Finnmark) } & $792-1176-1581$ & $487-567-612$ & $208-270-311$ \\
\hline & $8.2-11.2-14.7$ & $6.5-8.8-10.8$ & $2.4-3.5-4.3$ \\
\hline & $11.7-17.2-23.7$ & $9.0-11.4-13.5$ & $3.8-5.1-6.2$ \\
\hline & $\mathrm{N}=30$ & $\mathrm{~N}=30$ & $\mathrm{~N}=30$ \\
\hline \multirow[t]{4}{*}{ ZIN RAS puo51 (Barents Sea, Murman Coast) } & $715-1053-1446$ & $450-549-607$ & $282-307-327$ \\
\hline & $7.9-10.4-13.8$ & $6.2-8.5-10.5$ & $2.8-3.7-4.4$ \\
\hline & $10.7-16.4-22.5$ & $8.2-10.9-13.2$ & $4.4-5.3-6.7$ \\
\hline & $\mathrm{N}=30$ & $\mathrm{~N}=30$ & $\mathrm{~N}=30$ \\
\hline
\end{tabular}


Intermediary spicules - styles to subtylostyles, occasionally tylostyles, straight or occasionally gently curved, fusiform. Length 381-550-706 $\mu \mathrm{m}$, proximal diameter of shaft 5.88.5-12.5 $\mu \mathrm{m}$, maximum diameter of shaft 7.2-11.8$16.5 \mu \mathrm{m}, \mathrm{N}=270$.

Small spicules - subtylostyles to tylostyles, gently curved or straight, fusiform. Length 153-218-327 $\mu \mathrm{m}$, proximal diameter of shaft $2.2-3.1-4.5 \mu \mathrm{m}$, maximum diameter of shaft $3.3-6.4-8.9 \mu \mathrm{m}, \mathrm{N}=270$.

\section{Genetic data}

CO1 sequences obtained from two individuals of Polymastia uberrima are identical, but these sponges differ by one bp in $28 \mathrm{~S}$ rDNA (Matrix M34250 in TreeBase). In both $\mathrm{CO}_{1}$ and $28 \mathrm{~S}$ rDNA phylogenies $P$. uberrima falls in the clade with six other Polymastia spp. including the type species of this genus, P. mamillaris (Plotkin et al., 2016b). However, P. uberrima does not have sister relation to any of these species. It is distinguished by two autapomorphies in CO1 (Online resource 2, p. 2) and three autapomorphies in $28 \mathrm{~S}$ rDNA (Online resource 3, p. 2) from all other polymastiids. Apart from these autapomorphies, $P$. uberrima differs from $P$. mamillaris by 31 bps in CO1 (Matrix M34248 in TreeBase) and 15 bps in $28 \mathrm{~S}$ rDNA (Matrix M34250 in TreeBase).

\section{OCCURRENCE}

(Figure 18)

Our data (agree with the literature data): Canadian Atlantic Coast: Nova Scotia $(75-480 \mathrm{~m})$, Newfoundland and Labrador (135-700 m), offshore areas $(2070 \mathrm{~m})$. Davis Strait (110$350 \mathrm{~m})$. South-East Greenland (245-450 m). Denmark Strait $(132-345 \mathrm{~m})$. Iceland $(165-475 \mathrm{~m})$. North-East Atlantic, offshore areas (430-485 m). Norwegian Sea, offshore areas $(220-500 \mathrm{~m})$. Norwegian Coast: Nordland $(120-1100 \mathrm{~m})$, Troms $(35-220 \mathrm{~m})$, Finnmark $(130-286 \mathrm{~m})$. Barents Sea: Murman Coast $(31-270 \mathrm{~m})$, offshore areas $(80-350 \mathrm{~m})$. Svalbard $(100-230 \mathrm{~m})$. Franz Josef Land $(317 \mathrm{~m})$. White Sea (depth unknown). Laptev Sea/Severnaya Zemlya (108-139 m). Arctic Ocean (360-477 m).

\section{DISCUSSION}

Polymastia uberrima exhibits some similarity with $P$. thielei in external morphology, but is well-distinguished by the presence of a marginal more or less hispid collar. This collar may be destroyed during sampling, and that might be the reason why some early authors did not distinguish between P. uberrima and P. thielei (von Marenzeller, 1878; Hansen, 1885; Thiele, 1903; Lundbeck, 1909; Topsent, 1913; BouryEsnault, 1987). Furthermore, P. uberrima differs greatly from $P$. thielei by the architecture of the cortex and choanosomal skeleton (see Discussion on $P$. thielei above) and these morphological distinctions between the two species are confirmed by genetic data. At the same time $P$. infrapilosa established by Topsent $(1927 \mathrm{~b})$ for Polymastia possessing the marginal collar in fact has no differences from $P$. uberrima and hence is regarded as a junior synonym of $P$. uberrima.

\section{Polymastia sp.}

(Figure 19)

\section{MATERIAL EXAMINED}

ZMBN 098080 (one specimen), West off Marstein, Hordaland, Norway, $60^{\circ} 07.9^{\prime}-60^{\circ} 07.8^{\prime} \mathrm{N} \quad 04^{\circ} 50.5^{\prime}-$ $04^{\circ} 51.4^{\prime} \mathrm{E}, 312 \mathrm{~m}$, RV 'Hans Brattstrøm', station 2, coll. Plotkin, 03.07.2012.

\section{DESCRIPTION}

\section{External morphology}

Encrusting sponge, about $12 \mathrm{~mm}$ in diameter and $5 \mathrm{~mm}$ thick, removed from the substrate (Figure 19A). Surface strongly hispid, covered with sediment, bearing a conical papilla, $16.5 \mathrm{~mm}$ long and $4.6 \mathrm{~mm}$ wide at base, with a small osculum at the summit.

\section{Anatomy}

Choanosome in alcohol pale orange, firm. Main choanosomal skeleton composed of radiating tracts $(92-106 \mu \mathrm{m}$ thick) of principal spicules crossing the cortex and forming a surface hispidation reinforced with exotyles (Figure 19B). Auxiliary

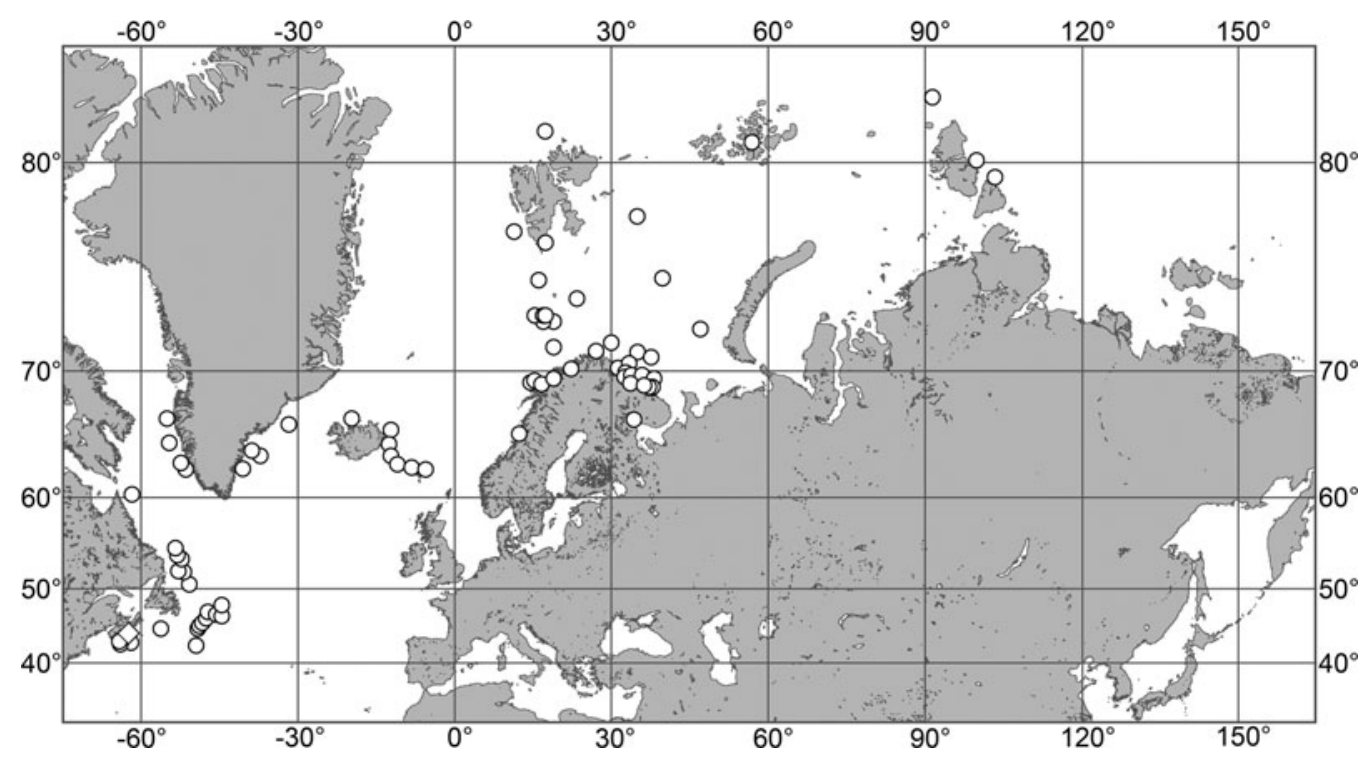

Fig. 18. Polymastia uberrima, distribution: white diamond, type locality of Polymastia infrapilosa (a synonym of $P$. uberrima); white circles, our data. Precise type locality of Rinalda uberrima is unknown. 

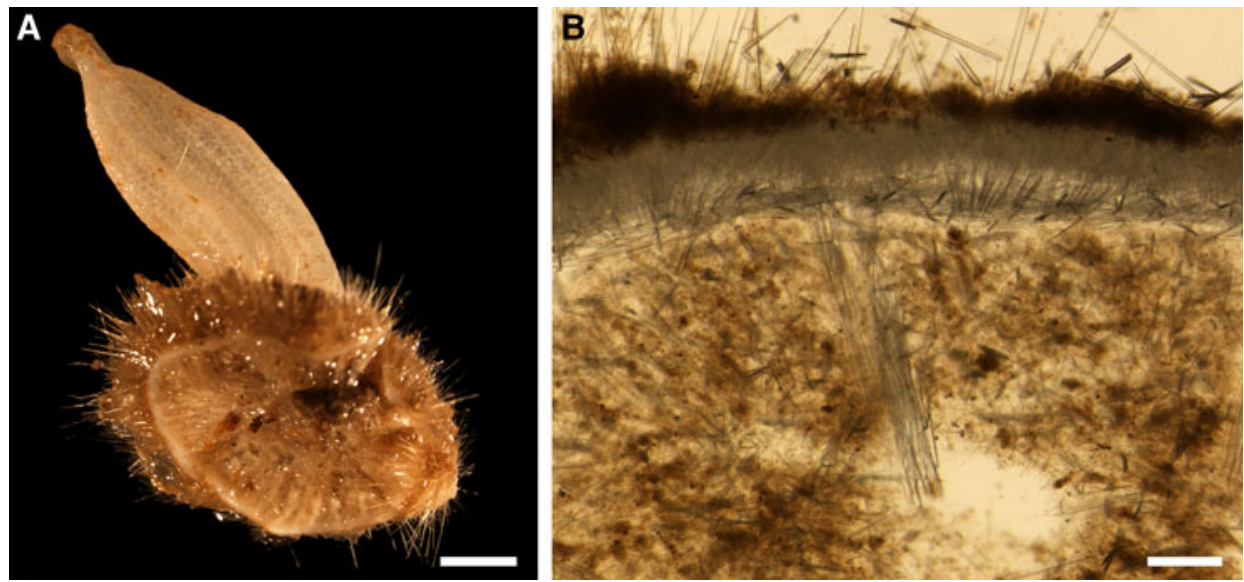

Fig. 19. Polymastia sp., ZMBN 098080: (A) habitus; (B) longitudinal section through the body. Scale bars: A, $3 \mathrm{~mm}$; B, o.2 mm.

choanosomal skeleton comprises bundles of free-scattered small spicules. Cortex in alcohol light-coloured, firm, not detachable. Cortical skeleton constituted by a superficial palisade $(170-200 \mu \mathrm{m}$ thick) of small spicules and an internal layer (139-184 $\mu \mathrm{m}$ thick) of criss-cross intermediary spicules (Figure 19B).

\section{Spicules}

Principal spicules - subtylostyles with slightly displaced tyles, occasionally polytylote, straight, fusiform. Length $880-1257-$ $2034 \mu \mathrm{m}$, diameter of tyle $8.1-12.2-17.8 \mu \mathrm{m}$, proximal diameter of shaft 6.4-9.7-11.4 $\mu \mathrm{m}$, maximum diameter $12.7-16.8-20.3 \mu \mathrm{m}, \mathrm{N}=30$.

Intermediary spicules - subtylostyles, straight, slender. Length 442-557-693 $\mu \mathrm{m}$, diameter of tyle 7.6-8.7-10.2 $\mu \mathrm{m}$, proximal diameter of shaft 5.1-6.7-8.9 $\mu \mathrm{m}$, maximum diameter $7.6-10.0-11.4 \mu \mathrm{m}, \mathrm{N}=30$.

Small spicules - tylostyles, often bent in the proximal part, stout. Length $132-162-183 \mu \mathrm{m}$, diameter of tyle $3.8-5.6-$ $7.6 \mu \mathrm{m}$, proximal diameter of shaft $2.5-3.7-5.1 \mu \mathrm{m}$, maximum diameter of shaft $2.5-5.0-6.4 \mu \mathrm{m}, \mathrm{N}=30$.

Exotyles - filiform subtylostyles. Length 1860-2590$3770 \mu \mathrm{m}$, diameter of tyle 12.7-14.1-16.5 $\mu \mathrm{m}$, proximal diameter of shaft 7.6-10.9-14.0 $\mu \mathrm{m}$, maximum diameter of shaft $10.2-13.8-17.8 \mu \mathrm{m}, \mathrm{N}=10$.

\section{Genetic data}

The Norwegian Polymastia sp. described above is genetically very close to $P$. svenseni and an unidentified Canadian Polymastia (Plotkin et al., 2016b). The relationships of this trio with other polymastiids and the synapomorphies between the Norwegian Polymastia sp. and P. svenseni are described in the Genetic data section for the latter species above. Three synapomorphies in $\mathrm{CO}_{1}$ distinguish the Norwegian Polymastia sp. and the Canadian Polymastia sp. from all other polymastiids (Online resource 2, p. 3, Matrix M34248 in TreeBase). At the same time the Norwegian Polymastia sp. is distinguished by two autapomorphies in this gene (Online resource 2, p. 3). Apart from them, it differs from the Canadian Polymastia sp. by four bps in $\mathrm{CO}_{1}$ (Matrix $\mathrm{M}_{34248}$ in TreeBase), from P. svenseni by 19 bps in $\mathrm{CO}_{1}$ (Matrix M34248 in TreeBase) and two bps in $28 \mathrm{~S}$ rDNA (Matrix M34250 in TreeBase) and from the type species of Polymastia, P. mamillaris, by $68 \mathrm{bps}$ in $\mathrm{CO}_{1}$
(Matrix M34248 in TreeBase) and 21 bps in $28 \mathrm{~S}$ rDNA (Matrix M34250 in TreeBase).

\section{OCCURRENCE}

(Figure 20)

Norwegian Coast: Hordaland (312 m).

\section{DISCUSSION}

The sponge described above is placed in Polymastia based on the $\mathrm{CO}_{1}$ and $28 \mathrm{~S}$ rDNA phylogenies. Meanwhile, it cannot be identified as any known Polymastia spp. It strongly resembles Polymastia andrica by the presence of four categories of spicules and a surface hispidation formed by the tracts of principal spicules crossing the cortex and reinforced with exotyles. However, in the molecular phylogenies Polymastia sp. is closely related to the morphologically quite distinct $P$. svenseni, while $P$. andrica falls in another subclade. We assume that Polymastia sp. may be a species new to science, but postpone the formal erection of this species until more material in addition to the single tiny individual becomes available.

Genus Quasillina Norman, 1869

Original description: Quasillina Norman, 1869, p. 329.

\section{SYNONYMS}

Bursalina Schmidt, 1875, p. 116.

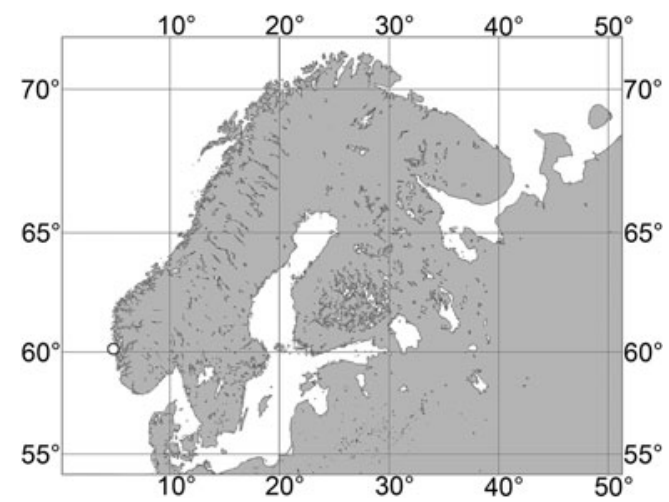

Fig. 20. Polymastia sp., ZMBN 098080: locality (white circle). 
TYPE SPECIES

Polymastia brevis Bowerbank, 1866 (by original designation).

\section{DIAGNOSIS}

Polymastiidae of pedunculate or columnar body shape with a smooth surface and a single osculum located either directly at the summit of the main body or at the summit of a short papilla. Choanosomal skeleton is a mass of small monactines. Cortex comprises a superficial palisade of small monactines, a middle layer of criss-cross large or intermediary monactines and an inner layer of longitudinal tracts of large monactines lying parallel to the surface.

\section{DISCUSSION}

Quasillina Norman, 1869 is very similar to Ridleia Dendy, 1888. Both genera lack one of the main morphological synapomorphies usually defined for Polymastiidae (BouryEsnault, 2002), the presence of main choanosomal skeleton composed of tracts of principal spicules. In Ridleia the choanosomal skeleton is restricted to a subcortical layer of crisscross small spicules, whereas in Quasillina it is an unordered mass of small spicules scattered over the choanosome that corresponds to the auxiliary choanosomal skeleton in other polymastiids. At the same time in both Quasillina and Ridleia longitudinal tracts of principal spicules are located in the inner part of the cortex making it very similar to the papilla wall in other polymastiids. Of the alternative phylogenies of Polymastiidae based on 25 morphological characters, one, suggesting the absence of papillae in Quasillina and Ridleia, displayed the position of these genera outside the clade of other polymastiids, whereas the other, interpreting their body as a single hyper-developed papilla with reduced choanosome, testified for the monophyly of Polymastiidae including Quasillina and Ridleia (Plotkin et al., 2012). Phylogenies based on $\mathrm{CO}_{1}$ and $28 \mathrm{~S}$ rDNA confirmed that Quasillina is a polymastiid (Plotkin et al., 2016b; Figure 1 in this study), but no molecular data on Ridleia are available so far.

\section{Quasillina brevis (Bowerbank, 1866)}

(Figure 21)

Original description: Polymastia brevis Bowerbank, 1866, p. 64 .

\section{SYNONYMS AND CITATIONS}

Bursalina muta (Schmidt, 1875, p. 116, pl. I figures 3 \& 4). Euplectella brevis (Bowerbank, 1861, p. 236 nomen nudum; 1861, p. 71 nomen nudum).

Polymastia brevis (Bowerbank \& Norman, 1882, p. 16 and 31; Fristedt, 1887 , p. 433; Topsent, 1888, p. 140).

Quasillina brevis (Norman, 1869, p. 329; Vosmaer, 1885, p. 20, 1887 , p. 330, pl. XXVI, figure 12; Ridley \& Dendy, 1886, p. 490, 1887 , p. 226, figure 10; Dendy, 1888, p. 520, figures 8-12; Topsent, 1892, p. 132, 1900, p. 158; Hanitsch, 1894, p. 175 and 203; Whiteaves, 1901, p. 14; Lundbeck, 1909, p. 452; Brøndsted, 1914, p. 522; 1932, p. 6, 1933, p. 14; Stephens, 1915, p. 30; Rezvoj, 1928, p. 81; Hentschel, 1929, p. 869; Burton, 1930a, p. 496; 1959a, p. 13; Alander, 1942, p. 76; Lévi, 1950, p. 9; Koltun, 1966, p. 89, text-figure 89, pl. XIX figures 9 \& 10, pl. XXVI figures 3-5); Boury-Esnault et al.,
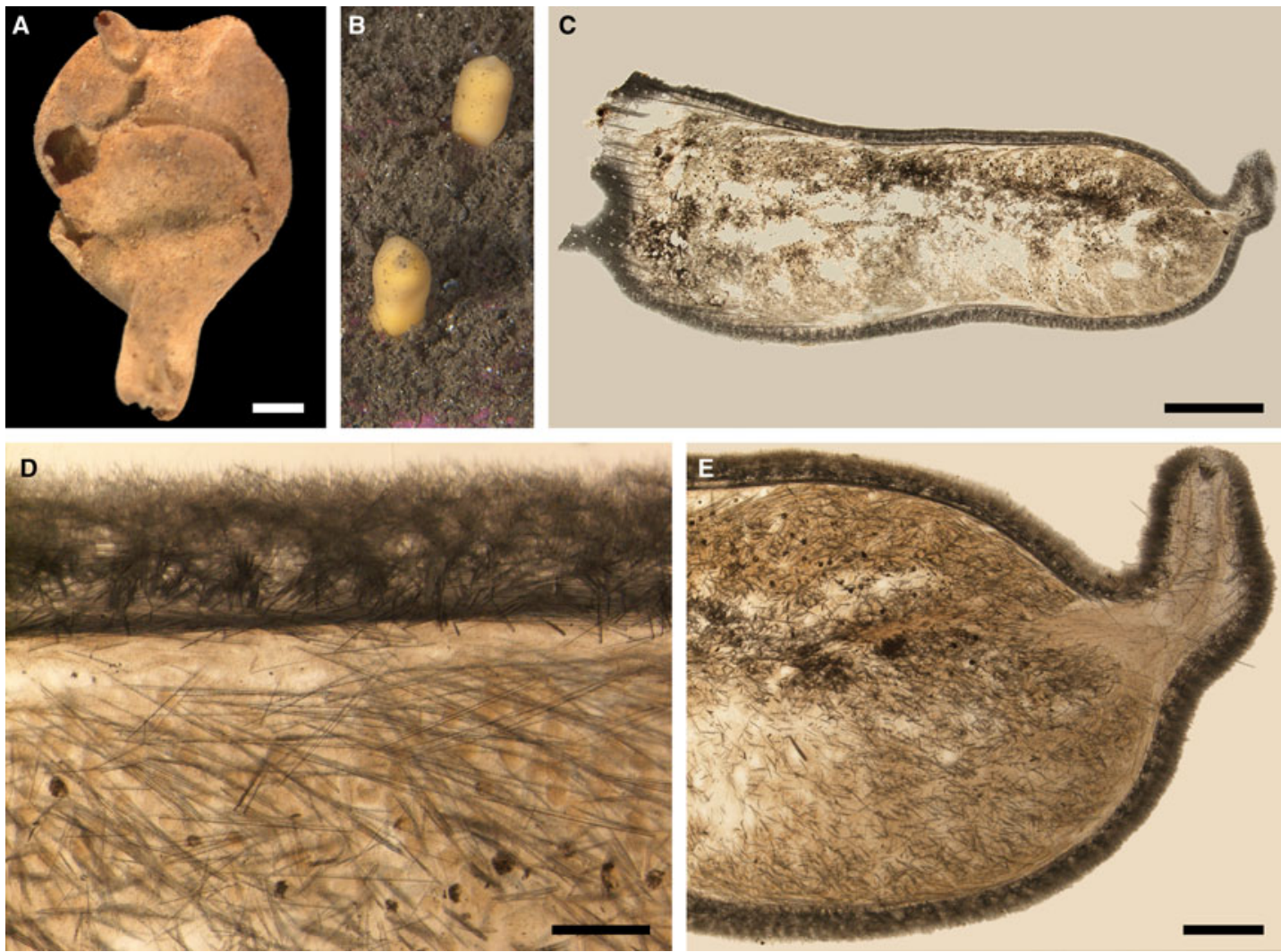

Fig. 21. Quasillina brevis: (A) lectotype BMNH 1910.1.1.5-6, habitus; (B) individuals in situ, Tingelsædet, Egersund, Norway (courtesy of E. Svensen, OceanPhoto/ Dalane Tidende AS, Egersund); (C) ZMBN 098084, longitudinal section through the body, general view; (D) the same section, detail of cortex; (E) ZMBN og8o84, longitudinal section through a papilla and adjacent area. Scale bars: A, $0.5 \mathrm{~cm}$;, $3 \mathrm{~mm}$;, $0.3 \mathrm{~mm}$;, $1 \mathrm{~mm}$. 
1994, p. 71, figure 46; Boury-Esnault, 2002, p. 211, figure 8; Plotkin, 2004, p. 545, figures 11 \& 2l; Plotkin et al., 2012, p. 25, figure $1 \mathrm{~h}$ ).

Quasillina richardi Topsent, 1913, p. 19, pl. III figure 7 and pl. V figure 14 (Alander, 1942, p. 76; Gorbunov, 1946, p. 37; Burton, 1959a, p. 13).

\section{TYPE MATERIAL}

Lectotype of Polymastia brevis (designated herein, Figure 21A): BMNH 1910.1.1.5-6 (dry specimen), Shetland, UK, precise locality unknown, 109-164 $\mathrm{m}$.

Paralectotypes of Polymastia brevis: BMNH 1910.1.1.5-6 (six intact specimens and several fragments, all dry), BMNH 1898.5.7.59 (two specimens in alcohol) and $\mathrm{BMNH}$ 1910.1.1.597A (two specimens in alcohol), from the same sample as the lectotype.

Syntypes of Quasillina richardi Topsent, 1913: MOM 04-0817 (two specimens in alcohol), between Bear Island and Norwegian Coast, $72^{\circ} 37^{\prime} \mathrm{N} 20^{\circ}$ oo' E, $394 \mathrm{~m}$, Campagnes scientifiques accomplies par le Prince Albert I de Monaco, RV 'Princesse-Alice', station 960, 29.07.1898. Herein Q. richardi is regarded as a synonym of Q. brevis.

\section{COMPARATIVE MATERIAL}

(see Online resource 1 for details)

Canada: offshore areas of NW Atlantic: ZIN RAS ocqboo7 (one specimen).

Iceland/Denmark Strait: ZMBN 098067 (one specimen).

North-East Atlantic, offshore: ZIN RAS ocqboo6 (one specimen).

Norwegian Sea, offshore: ZIN RAS ocqbo1o (one specimen). Barents Sea, offshore: ZIN RAS ocqboo1, ZIN RAS ocqboo2, ZIN RAS ocqboo4, ZIN RAS ocqboo9, ZIN RAS ocqbo12, ZIN RAS ocqbo13, ZIN RAS ocqbo14, ZIN RAS ocqbo15, ZIN RAS ocqbo16, ZIN RAS ocqbo17, ZIN RAS ocqbo18, ZIN RAS ocqbo19 and ZIN RAS ocqbo2o (13 specimens).

Norway: Vest-Agder: ZMBN 098084, ZMBN 098090 and ZMBN 107573 (three specimens), Rogaland: ZMBN 098082 (one specimen), Sogn and Fjordane: ZMBN 098049 (one specimen), Møre and Romsdal: ZMBN 107489 and ZMBN 107491 (two specimens), Nord-Trøndelag: NTNU-VM54600, NTNU-VM-54747, NTNU-VM-54751, NTNU-VM54754, NTNU-VM-54755 and NTNU-VM-72545 (15 specimens), Nordland: NTNU-VM-72516 (two specimens), Finnmark: NTNU-VM-72501 (two specimens). Svalbard: ZIN RAS ocqboo8 (one specimen).

Russia: Murman Coast: ZIN RAS ocqbo11 (one specimen), Novaya Zemlya: ZIN RAS ocqboo5 (one specimen).

Arctic Ocean, offshore: ZIN RAS ocqboo3 (one specimen).

\section{DESCRIPTION}

\section{External morphology}

Lectotype of Polymastia brevis has an irregularly ovoid main body, $\sim 25 \mathrm{~mm}$ in diameter and $28 \mathrm{~mm}$ high, sitting on a stalk, $\sim 11 \mathrm{~mm}$ high and $7 \mathrm{~mm}$ in diameter and bearing a well developed cylindrical papilla, $\sim 5 \mathrm{~mm}$ long and $3 \mathrm{~mm}$ in diameter, with an osculum at the summit (Figure $21 \mathrm{~A}$ ). Paralectotypes smaller, some with weakly developed papillae, others lacking papillae and bearing oscula directly on the body summits. Most other sponges columnar, up to $35 \mathrm{~mm}$ high and up to $8 \mathrm{~mm}$ in diameter, with no segregation between main body and stalk (Figure $21 \mathrm{~B}$ ). Few sponges with ovoid or pyriform main bodies sitting on stalks. Papillae, if present, are weakly developed. Colour in life pale orange or yellowish. Syntypes of Quasillina richardi are small fragments, one on a stalk lacking the major part of the main body, the other being a residual of the main body.

\section{Anatomy}

In life choanosome is an intensive yellow or orange, unstructured, semi-fluid mass without any spicule tracts. This mass is often washed away under preservation. Choanosomal skeleton comprises free-scattered bundles of small spicules (Figure $21 \mathrm{C}$ ). Cortex in life pale orange or pale yellow, leatherlike. Cortical skeleton comprises a superficial palisade (150$200 \mu \mathrm{m}$ thick) of bouquets of small spicules and two inner overlapping layers, a layer of criss-cross large spicules (270$300 \mu \mathrm{m}$ thick) located midst in the cortex and an internal layer (35-80 $\mu \mathrm{m}$ thick) of longitudinal tracts of large spicules (Figure $21 \mathrm{D}$ ). Skeleton of the papilla wall is the same as the cortical skeleton (Figure $21 \mathrm{E}$ ).

\section{Spicules}

(Measurements based on 15 specimens)

Principal spicules - subtylostyles to styles, straight, or occasionally gently curved, fusiform. Length $570-862-1098 \mu \mathrm{m}$, maximum diameter $11.2-17.8-25.5 \mu \mathrm{m}, \mathrm{N}=450$.

Small spicules - styles to subtylostyles, often bent in the distal part, slender. Length 140-227-306 $\mu \mathrm{m}$, maximum diameter of shaft $1.9-4.0-5.8 \mu \mathrm{m}, \mathrm{N}=450$.

\section{Genetic data}

Data obtained from five individuals of Quasillina brevis are identical in both genes studied. Quasillina brevis is closely related, especially in the $\mathrm{CO}_{1}$ phylogeny, to morphologically distinct Polymastia boletiformis (see the synapomorphies in the Genetic data section for the latter species above). At the same time Q. brevis possesses six autapomorphies in $28 \mathrm{~S}$ rDNA distinguishing it from all other polymastiids (Online resource 3, p. 4) and, apart from them, differs from P. boletiformis by 18 bps in this gene (Matrix M34250 in TreeBase).

\section{OCCURRENCE}

(Figure 22)

Literature data:

Canadian Atlantic Coast: Nova Scotia (155 m) (Ridley \& Dendy, 1886, 1887). Azores (318 m) (Topsent, 1892). West of Gibraltar (218-524 m) (Boury-Esnault et al., 1994). Mediterranean Sea: Moroccan Coast (144-145 m) (Boury-Esnault et al., 1994). Northern French Coast (Lévi, 1950). British Isles: Ireland (706 m) (Stephens, 1915), Shetland (73-309 m) (Bowerbank, 1866; Norman, 1869). Iceland $(83-557 \mathrm{~m}$ ) (as Q. brevis and Q. richardi - Burton, 1959a). South Greenland (120 m) (Brøndsted, 1933). East Greenland (231 m) (Lundbeck, 1909). Faroes (160 m) (Brøndsted, 1932). Swedish Western Coast (85-360 m) (as $Q$. brevis and Q. richardi - Alander, 1842). Norwegian Coast: Rogaland (193 m) (as Bursalina muta - Schmidt, 1875; as Q. brevis - Burton, 1930a), Hordaland (Burton, 1930a), Sør-Trøndelag (Burton, 1930a), Troms (Burton, 1930a), Finnmark (273 m) (Fristedt, 1887). Norwegian Sea (67-500 m) (as Q. brevis - Vosmaer, 1885; Hentschel, 1929; Koltun, 1966; as Q. richardi - Topsent, 1913). Barents Sea (67-500 m) (Vosmaer, 1885; Rezvoj, 1928; Koltun, 1966). Kara and Laptev Sea (67-500 m) (Gorbunov, 1946; Koltun, 1966). 


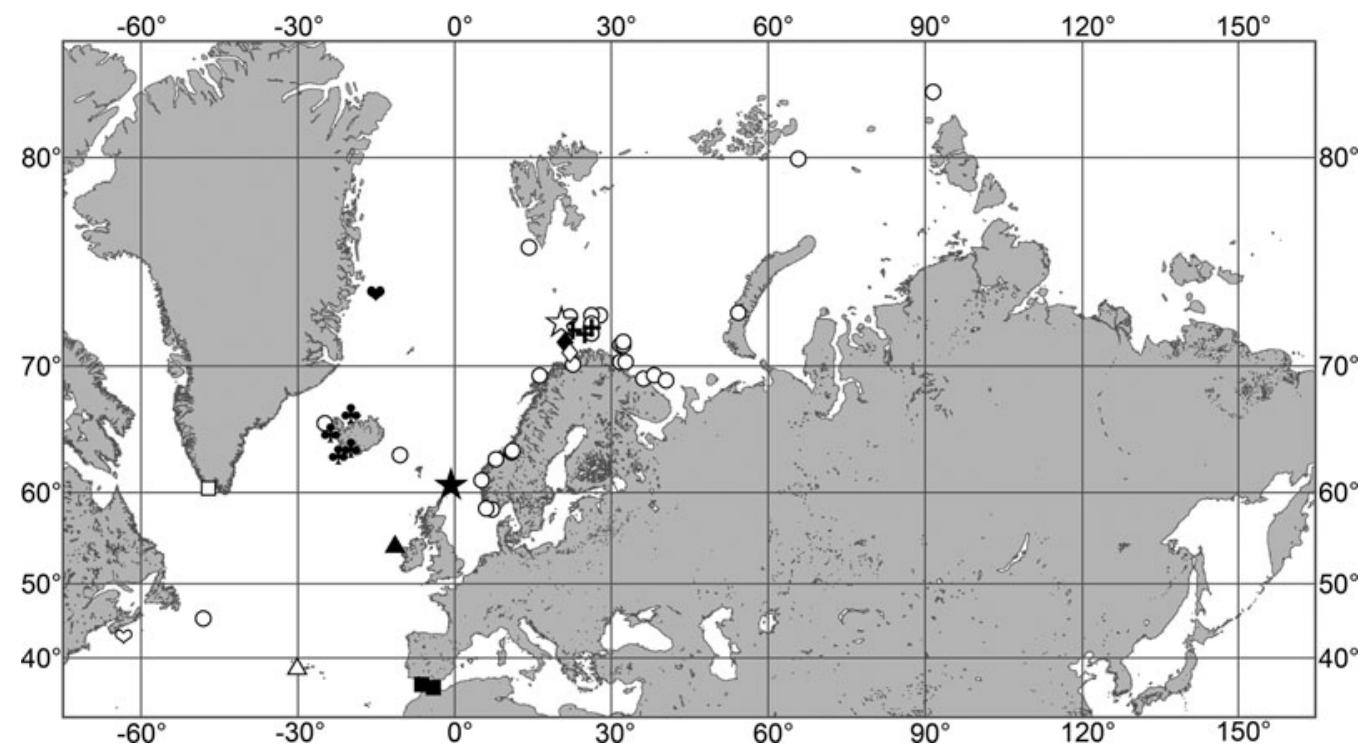

Fig. 22. Quasillina brevis, distribution: black star, type locality of Polymastia brevis; white star, type locality of Quasillina richardi (synonym of Q. brevis); black squares, data from Boury-Esnault et al. (1994); white square, data from Brøndsted (1933); black trefoils, data from Burton (1959a); black diamond, data from Hentschel (1929); white diamond, data from Fristedt (1887); black heart, data from Lundbeck (1909); white heart, data from Ridley \& Dendy (1886); black triangle, data from Stephens (1915), white triangle, data from Topsent (1892); white circles, our data.

Our data: Canadian Atlantic Coast: offshore areas (380$415 \mathrm{~m})$. Iceland/Denmark Strait $\quad(118 \mathrm{~m})$. North-East Atlantic (400 m). Norwegian Sea, offshore (394-500 m). Norwegian Coast: Vest-Agder $(30-45 \mathrm{~m})$, Rogaland (25$31)$, Sogn and Fjordane (241-254 m), Møre and Romsdal $(100-120 \mathrm{~m})$, Nord-Trøndelag $(15-110 \mathrm{~m})$, Nordland $(360 \mathrm{~m})$, Finnmark $(250 \mathrm{~m})$. Barents Sea: Murman Coast $(110-146 \mathrm{~m})$, offshore areas $(90-442 \mathrm{~m})$. Svalbard $(759 \mathrm{~m})$. Novaya Zemlya $(8 \mathrm{~m})$. Arctic Ocean, offshore $(360 \mathrm{~m})$.

\section{DISCUSSION}

Quasillina brevis is recorded in a wide geographic area, but there is some doubt whether all these records indicate the same species. Topsent (1913) established a new species of Quasillina, Q. richardi, for the sponges from the Northern Norwegian Sea based on their difference from Q. brevis from more southern areas (British Isles, French Coast, Azores). In the former species small spicules were bent in the distal part, while in the latter they were straight. However, the correlation of the spicule shape in Quasillina to geography was questioned by several records of both $Q$. brevis and Q. richardi from the same localities, e.g. from Iceland (Burton, 1959a) and the Swedish Western Coast (Alander, 1942). In our material from the Nordic Seas we have found both individuals with bent and straight small spicules, without any correlation to geography. Therefore, until molecular data on the British, South European and Azorean Quasillina become available and comparable with our data on the Nordic sponges, we follow Koltun (1966) and Plotkin (2004) and conclude that Q. richardi should be regarded as a junior synonym of $Q$. brevis.

Genus Sphaerotylus Topsent, 1898Original description: Sphaerotylus Topsent, 1898, p. 244.

TYPE SPECIES

Polymastia capitata Vosmaer, 1885 (by original designation).

\section{DIAGNOSIS}

Polymastiidae of hemispherical, dome, cushion-like or button-like body shape, always with papillae. Spicule assortment comprises smooth monactines in at least two size categories and exotyles with ornamented distal extremities, which may be rough, spined, granulated, tuberculated or wrinkled, often with knobs varying from spherical to hemispherical, fungiform, umbrelliform or lobate. Main choanosomal skeleton composed of radial or longitudinal tracts of principal monactines. Auxiliary choanosomal skeleton comprises free-scattered, small and/or intermediary monactines, and, occasionally exotyles. A superficial cortical palisade composed of either exotyles with sparse small monactines or small monactines reinforced with sparse exotyles. An inner layer of criss-cross intermediary monactines may also be present.

\section{DISCUSSION}

According to the $\mathrm{CO}_{1}$ and $28 \mathrm{~S}$ rDNA phylogenies Sphaerotylus Topsent, 1898 is not monophyletic (Plotkin et al., 2016b; Figure 1 in this study). The two species described below, the type species, S. capitatus (Vosmaer, 1885), and S. borealis (Swarczewsky, 1906) fall in remote clades. However, here we follow the traditional taxonomy of Sphaerotylus spp. (Boury-Esnault, 2002; Plotkin et al., 2016a), since no alternative classification is proposed for Polymastiidae so far (Plotkin et al., 2016b).

\section{Sphaerotylus borealis (Swarczewsky, 1906)}

(Figure 23)

Original description: Proteleia borealis Swarczewsky, 1906, p. 315, pl. X figure 1, pl. XIII figure 2. 

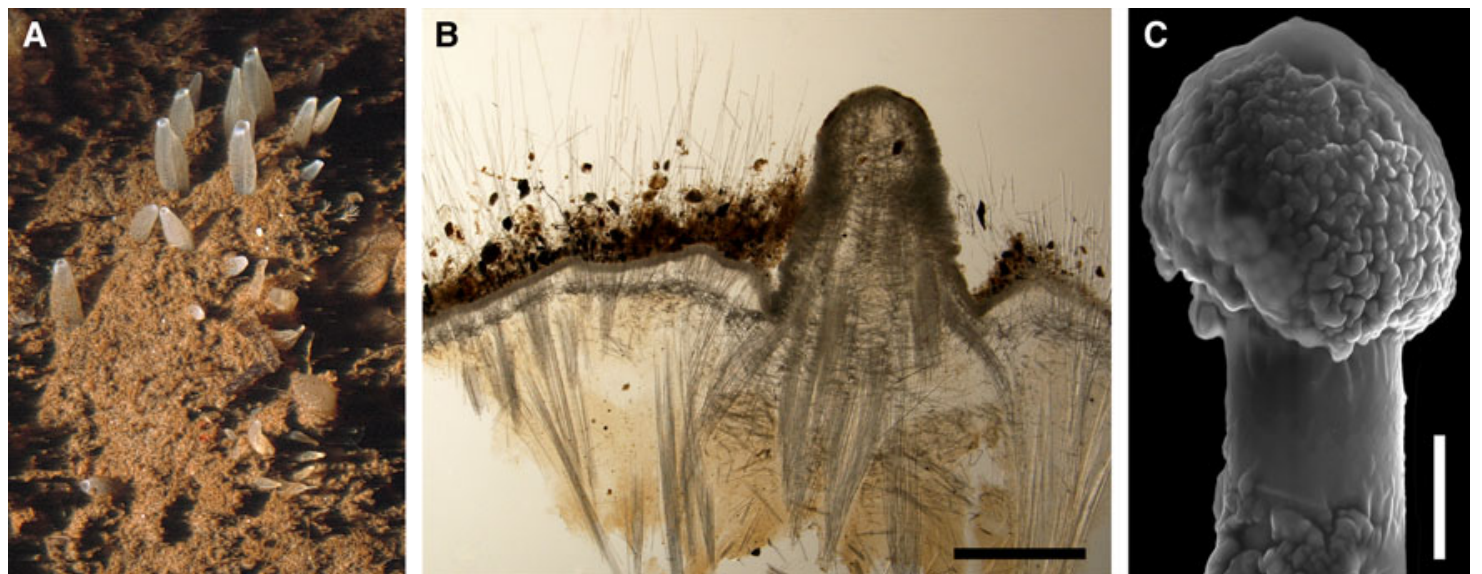

Fig. 23. Sphaerotylus borealis: (A) an individual in situ, Kandalaksha Bay, White Sea (courtesy of M. Fedyuk, St. Petersburg State University); (B) ZMBN o98059, longitudinal section through the body; (C) ZMBN 098036, proximal tip of exotyle. Scale bars: B, $2 \mathrm{~mm}$; C, $0.005 \mathrm{~mm}$.

Sphaerotylus borealis (Rezvoj, 1928, p. 78, figures 4 \& 5 Koltun, 1966, p. 83, pl. XXX figures 1-5, text-figure 55; Plotkin, 2004, p. 543, figures 1i, 2i \& 4b).

Sphaerotylus schoenus var. borealis (Hentschel, 1929, p. 925).

\section{TYPE MATERIAL}

Neotype: ZIN RAS 11194, Sredny Island, Keret' Inlet, Kandalaksha Bay, White Sea, $66^{\circ} 17.391^{\prime} \mathrm{N} 33^{\circ} 38.025^{\prime} \mathrm{E}, 10-$ $13 \mathrm{~m}, 12.07 .2000$, coll. Plotkin.

Designation and detailed description of the neotype was done by Plotkin et al. (2016a).

\section{COMPARATIVE MATERIAL}

(see Online resource 1 for details)

Iceland: ZIN RAS 11169 and ZIN RAS 11184 (two specimens). Norwegian Sea, offshore: ZIN RAS 11145 (one specimen). Barents Sea, offshore: ZIN RAS 11146, ZIN RAS 11156, ZIN RAS 11157, ZIN RAS 11158, ZIN RAS 11159, ZIN RAS 11160, ZIN RAS 11163, ZIN RAS 11165, ZIN RAS 11166, ZIN RAS 11167, ZIN RAS 11170, ZIN RAS 11171, ZIN RAS 11176, ZIN RAS 11177 and ZIN RAS 11181 (15 specimens).

Russia: Murman Coast: ZIN RAS 11164, ZIN RAS 11168, ZIN RAS 11174 and ZIN RAS 11183 (four specimens), White Sea: ZIN RAS 11144, ZIN RAS 11147, ZIN RAS 11148, ZIN RAS 11149, ZIN RAS 11150, ZIN RAS 11151, ZIN RAS 11155, ZIN RAS 11161, ZIN RAS 11162, ZIN RAS 11175, ZIN RAS 11180, ZIN RAS 11182, ZIN RAS 11195, ZMBN 098036, ZMBN 098059 and ZMBN 098061(31 specimens), Severnaya Zemlya: ZIN RAS 11179 (one specimen).

Arctic Ocean, offshore: ZIN RAS 11178 (one specimen).

\section{DESCRIPTION}

(according to Plotkin et al., 2016a)

\section{External morphology}

Sponges thickly encrusting or cushion-shaped, the largest up to $100 \mathrm{~cm}^{2}$. Surface shaggy, silted with sediment making it dirty greyish or brownish in colour. Up to 50 cylindrical or conical papillae, whitish in life, but usually becoming pale yellow, brownish or pinkish in alcohol. On soft bottoms living sponges are often completely covered by sediment with only erect papillae protruding above (Figure 23A). On hard bottoms the sponges may contract the papillae. After sampling and fixation the papillae always considerably contract and invaginate into the surface hispidation. Oscula not visible in preserved sponges.

\section{Skeleton}

Choanosome in life orange, dense. Main choanosomal skeleton composed of longitudinal tracts of principal spicules which cross the cortex and make up a dense and thick surface hispidation (Figure 23B). Auxiliary choanosomal skeleton comprises small, occasionally intermediary, spicules often arranged in bundles, 3-7 spicules each. Cortex in life whitish, dense, not detachable. Cortical skeleton composed of a $115-120 \mu \mathrm{m}$ thick superficial palisade of small spicules and an internal layer $\left(\sim_{210} \mu \mathrm{m}\right.$ thick $)$ of tangentially arranged intermediary spicules (Figure 23B). In areas around papillae these layers are separated by an intermediate, aspicular zone (about $100 \mu \mathrm{m}$ thick). Exotyles cross the cortex and join the surface hispidation. Walls of papillae lack the tangential cortical layer. Single intermediary spicules scattered both in the walls and in the bulkheads between canals.

\section{Spicules}

(Measurements based on 10 specimens)

Principal spicules - styles to subtylostyles, often polytylote straight, slender. Length $1100-2423-5000 \mu \mathrm{m}$, diameter of shaft 12.0-16.2-19.0 $\mu \mathrm{m}, \mathrm{N}=100$.

Intermediary spicules - tylostyles, usually straight, occasionally curved, slightly fusiform. Length 200-502-796 $\mu \mathrm{m}$, diameter of tyle 6.9-9.2-11.1 $\mu \mathrm{m}$, proximal diameter of shaft 5.0-7.1-9.0 $\mu \mathrm{m}$, maximum diameter of shaft 6.9$10.8-14.3 \mu \mathrm{m}, \mathrm{N}=100$.

Small spicules - tylostyles, straight or curved, usually slender. Length $94-125-160 \mu \mathrm{m}$, diameter of tyle 3.9-4.6-5.1 $\mu \mathrm{m}$, diameter of shaft $3.0-3.5-4.0 \mu \mathrm{m}, \mathrm{N}=100$.

Exotyles slender, 5100-6117-7520 $\mu \mathrm{m}$ long, usually with weakly developed or completely reduced proximal tyles. Shafts $13.8-17.2-20 \mu \mathrm{m}$ in maximum diameter. Distal knobs $(14.1-19.9-27.0 \mu \mathrm{m}$ in diameter) usually irregularly fungiform or umbrelliform (Figure ${ }_{23} \mathrm{C}$ ), more rarely hemispherical or spherical, occasionally with short protuberances on the edges, sometimes slightly displaced along the shaft or comprising several swellings. Surface of the knobs and the 
adjacent portions of the shafts rough, wrinkled, granulated or tuberculated.

\section{Genetic data}

Of the three individuals of Sphaerotylus borealis, from which genetic data were obtained, two sponges differ neither by $\mathrm{CO} 1$, nor by $28 \mathrm{~S}$ rDNA. The third individual is distinguished by two bps in $28 \mathrm{~S}$ rDNA (Matrix M34250 in TreeBase), but no CO1 was obtained from it. In both $\mathrm{CO}_{1}$ and $28 \mathrm{~S}$ rDNA phylogenies $S$. borealis does not group with any of the congeners (Plotkin et al., 2016b). The difference between $S$. borealis and the type species of Sphaerotylus, S. capitatus, is 26 bps in CO1 (Matrix $\mathrm{M}_{34248}$ in TreeBase) and $86 \mathrm{bps}$ in $28 \mathrm{~S}$ rDNA, excluding the intraspecific polymorphism in both species (Matrix M34250 in TreeBase). At the same time S. borealis possessing just one autapomorphy in $28 \mathrm{~S}$ rDNA (Online resource 3, p. 3) forms a clade with two morphologically quite distinct species, Polymastia cf. conigera Bowerbank, 1874 (a British species not covered by the present study) and Weberella bursa (the type species of Weberella Vosmaer, 1885 described below) in both $\mathrm{CO}_{1}$ and $28 \mathrm{~S}$ rDNA phylogenies (Plotkin et al., 2016b). However, the Bayesian support for this clade is weak (Plotkin et al., 2016b). These three species share just two synapomorphies in $28 \mathrm{~S}$ rDNA distinguishing them from all other polymastiids (Online resource 3, p. 3, Matrix M34250 in TreeBase), while the differences between them are large. Sphaerotylus borealis differs from $P$. cf. conigera by $17 \mathrm{bps}$ in CO1 (Matrix M34248 in TreeBase) and $35 \mathrm{bps}$ in $28 \mathrm{~S}$ rDNA (Matrix M34250 in TreeBase) and from $W$. bursa by 7 bps in CO1 (Matrix M34248 in TreeBase) and $33 \mathrm{bps}$ in $28 \mathrm{~S}$ rDNA (Matrix M34250 in TreeBase).

\section{OCCURRENCE}

(Figure 24)

Our data (agree with the literature data): Iceland (157$240 \mathrm{~m})$. Norwegian Sea, offshore areas $(342 \mathrm{~m})$. Barents Sea: Murman Coast (91-130 m), offshore areas (124-420 m). White Sea $(10-57 \mathrm{~m})$. Severnaya Zemlya (43 m). Arctic Ocean, offshore areas $(415 \mathrm{~m})$.

\section{DISCUSSION}

Sphaerotylus borealis (Swarczewsky, 1906) was originally assigned to Proteleia Dendy \& Ridley, 1886, but later (Koltun, 1966) transferred to Sphaerotylus. The large morphological differences between $S$. borealis and the type species of Proteleia, P. sollasi Dendy \& Ridley, 1886, were described by Plotkin et al. (2016a). At the same time S. borealis shares many features, e.g. the shaggy surface and the giant exotyles with umbrelliform or fungiform distal ornaments, with $S$. antarcticus Kirkpatrick, 1907. By these features both S. borealis and $S$. antarcticus are distinguished from the type species of Sphaerotylus, S. capitatus. Meanwhile, in CO1 and $28 \mathrm{~S}$ rDNA phylogenies $S$. borealis and $S$. capitatus fall in remote clades, while the relationships between $S$. antarcticus and S. capitatus are ambiguous (Plotkin et al., 2016b). Grouping of $S$. borealis with Polymastia cf. conigera and Weberella bursa in the molecular phylogenies has a weak Bayesian support, and no morphological synapomorphies can, for the moment, be defined for this grouping (Plotkin et al., 2016b). Thus, the taxonomic position of $S$. borealis remains unclear.

Sphaerotylus capitatus (Vosmaer, 1885)

(Figure 25)

Original description: Polymastia capitata Vosmaer, 1885, p. 16, pl. IV figures 25-29.

\section{SYNONYMS AND CITATIONS}

Polymastia capitata (Breitfuss, 1911, p. 218).

Polymastia schoenus (Dendy \& Ridley, 1886, p. 155, text-figure).

Radiella schoenus (Sollas, 1882, p. 162, considered as nomen nudum by Kirkpatrick, 1908, p. 18).

Sphaerotylus capitatus (Topsent, 1898, p. 244; Boury-Esnault, 2002, p. 206, figure 4; Plotkin, 2004, p. 543, figures $1 \mathrm{H}, 2 \mathrm{H} \&$ 4A; Plotkin et al., 2012, p. 27, figure 2d).

Sphaerotylus schoenus (Topsent, 1913, p. 23, pl. II figure 6, 1928 , p. 154; Koltun, 1966, p. 85, pl. XXX figures 6 \& 7, textfigure 56; Desqueyroux-Faúndez \& Van Soest, 1997, p. 421).

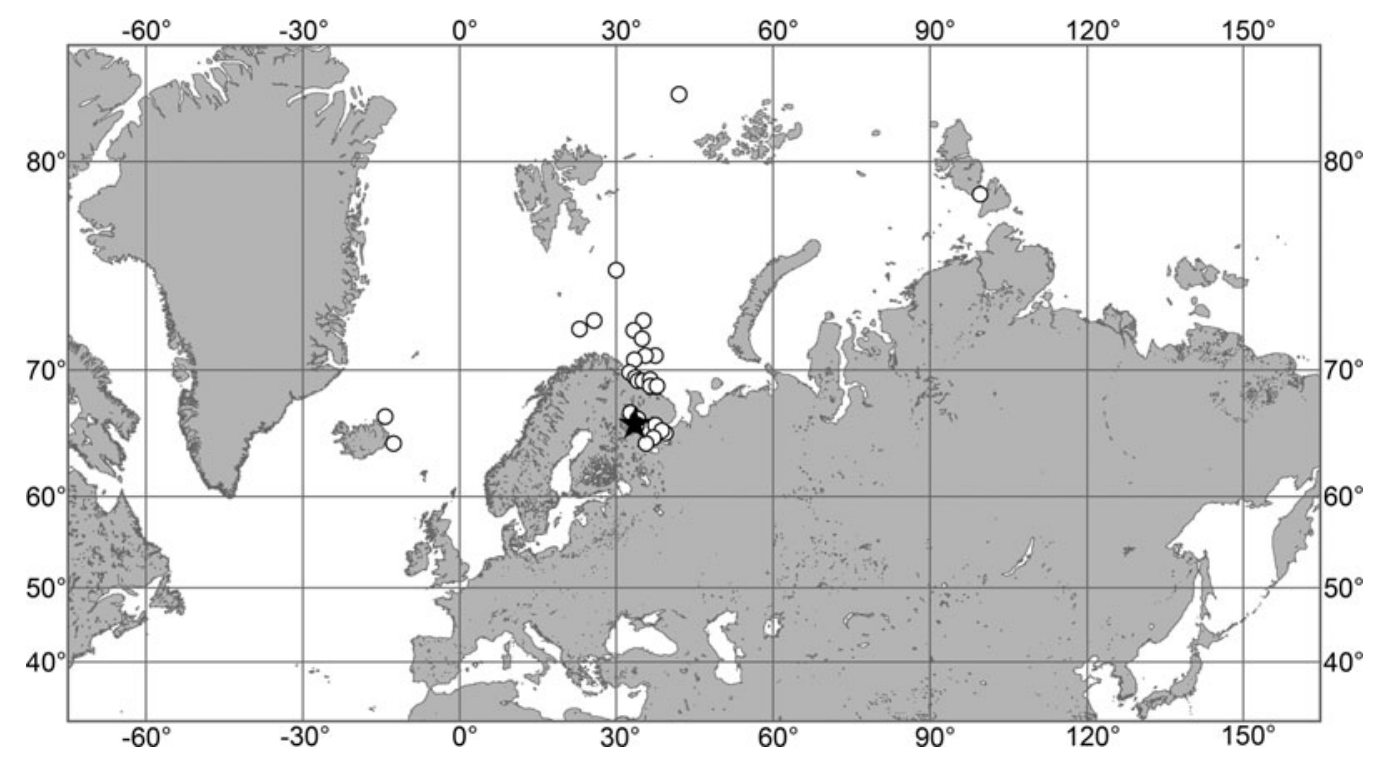

Fig. 24. Sphaerotylus borealis, distribution: black star, type locality; white circles, our data. 

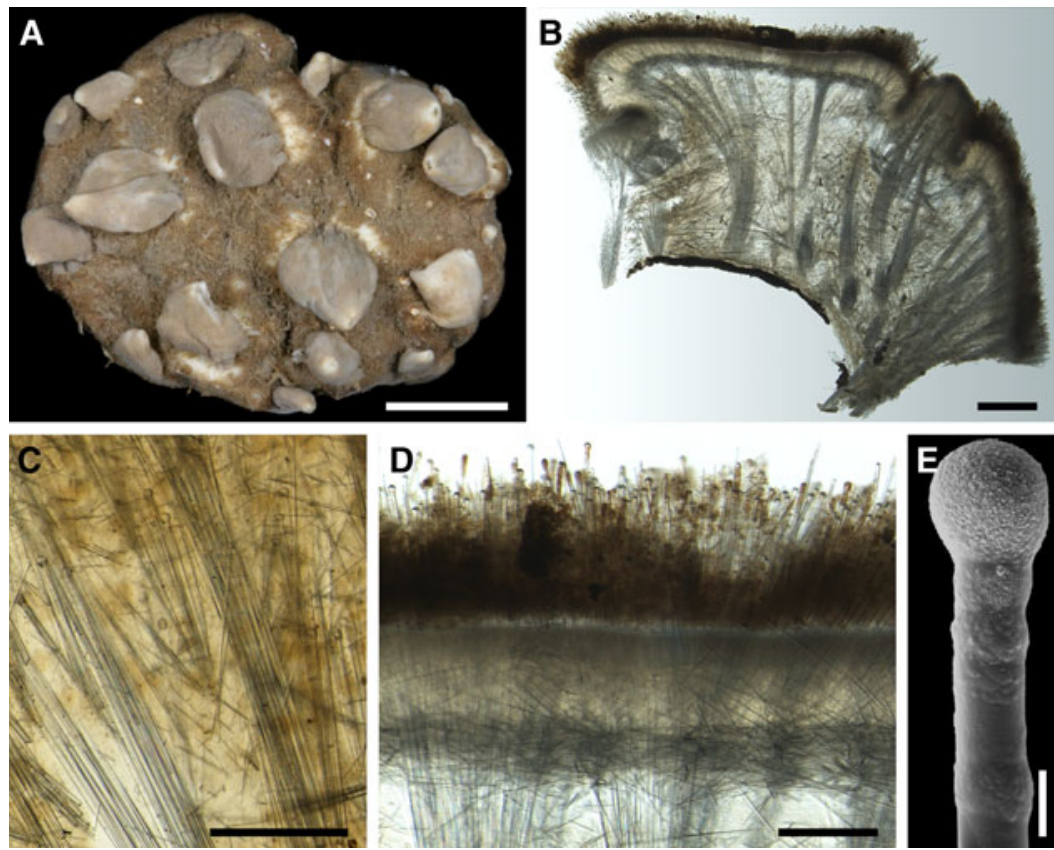

Fig. 25. Sphaerotylus capitatus: (A) GNM 899, habitus; (B) ZMBN 107485, longitudinal section through the body, general view; (C) paralectotype BMNH 1910.1.1.1199, detail of choanosome with exotyles; (D) ZMBN 107485, longitudinal section through the body, detail of cortex; (E) ZMB 10855, proximal tip of exotyle. Scale bars: A, $1 \mathrm{~cm}$; B, $1 \mathrm{~mm}$; C-D, $0.3 \mathrm{~mm}$; E, $0.02 \mathrm{~mm}$.

\section{TYPE MATERIAL}

Lectotype and one paralectotype: RMNH 704, Norwegian Sea, $72^{\circ} 14.8^{\prime} \mathrm{N} \quad 22^{\circ} 30.9^{\prime} \mathrm{E}$, about $300 \mathrm{~m}$, 'Willem Barentz' Expedition, station 28, 30.06.1881.

Paralectotype: BMNH 1910.1.1.612 (specimen in alcohol) and BMNH 1910.1.1.1196-1200 (slides), from the same sample as the lectotype.

Paralectotype: ZMA 1841 (specimen, not studied), from the same sample as the lectotype.

Detailed description of the type material was presented by Plotkin et al. (2016a).

\section{COMPARATIVE MATERIAL}

(see Online resource 1 for details)

Greenland: ZIN RAS 1193 (one specimen).

Sweden: Västra Götaland: GNM 899, GNM 900:1-2 and GNM 902 (four specimens).

Norway: Hordaland: ZMB 10855 and ZMBN 098042 (two specimens), Møre and Romsdal: |NTNU-VM-69133, ZMBN 107485, ZMBN 107487 and ZMBN 107490 (four specimens), Sør-Trøndelag: NTNU-VM-54686 and NTNU-VM-57267 (two specimens), Nord-Trøndelag: NTNU-VM-54629 and NTNU-VM-66578 (two specimens), Nordland: NTNU-VM55862 and NTNU-VM-72521 (three specimens), Troms: ZMBN 098075 (one specimen), Finnmark: ZIN RAS 1190 (one specimen), Svalbard: ZIN RAS 1185 and ZIN RAS 1192 (two specimens).

Russia: Murman Coast: ZIN RAS 1186, ZIN RAS 1187 and ZIN RAS 1188 (three specimens).

Barents Sea, offshore: ZIN RAS 1189 and ZIN RAS 1191 (two specimens).

\section{DESCRIPTION}

External morphology

Sponges thickly encrusting, cushion-shaped or massive, fistor dome-shaped, occupying up to $50 \mathrm{~cm}^{2}$ of the substrate.
Surface velvety, knobbly, dark brown in colour, with up to 30 papillae (Figure 25A). Papillae of living sponges whitish or pale yellow in colour, conical, with small, scarcely visible oscula at the summits. In alcohol-preserved specimens the papillae may be considerably contracted looking like tubercles, while their colour does not change much.

\section{Skeleton}

Choanosome in life yellowish or pale orange, dense. Main choanosomal skeleton composed of radial or longitudinal tracts of principal spicules which enter the cortex (Figure 25B). Auxiliary choanosomal skeleton comprises small and intermediary spicules usually scattered singly or sometimes arranged in small groups. Besides these spicules some individuals possess exotyles between the choanosomal tracts (Figure 25C). Cortex in life whitish, firm, not detachable. Cortical skeleton composed of a superficial palisade $(\sim 110 \mu \mathrm{m}$ thick) of small spicules, an internal layer (about $170 \mu \mathrm{m}$ thick) of tangentially arranged intermediary spicules and a middle layer (180-190 $\mu \mathrm{m}$ thick) with a low concentration of spicules (Figure 25D). Exotyles cross the cortex forming a dense superficial layer with their distal knobs rising above the palisade. Papillae walls without internal cortical layer. Single intermediary spicules scattered both in the papillae walls and in the bulkheads between the canals.

\section{Spicules}

(Measurements based on five specimens)

Principal spicules - subtylostyles to styles, often polytylote, straight, slightly fusiform or slender. Length 650-998$1505 \mu \mathrm{m}$, diameter of tyle, if present, $10.0-12.8-16.0 \mu \mathrm{m}$, proximal diameter of shaft $8.9-11.5-15.1 \mu \mathrm{m}$, maximum diameter of shaft $14.0-19.5-26.0 \mu \mathrm{m}, \mathrm{N}=50$.

Intermediary spicules - tylostyles, straight or gently curved, slender or slightly fusiform. Length 314-484-650 $\mu \mathrm{m}$, 
diameter of tyle 9.1-11.4-14.0 $\mu \mathrm{m}$, proximal diameter of shaft $6.9-8.8-11.0 \mu \mathrm{m}$, maximum diameter of shaft 9.0$13.0-16.5 \mu \mathrm{m}, \mathrm{N}=50$.

Small spicules - tylostyles, straight or curved, usually slender. Length 96-155-221 $\mu \mathrm{m}$, diameter of tyle 2.9-4.6-6.1 $\mu \mathrm{m}$, proximal diameter of shaft 1.1-2.3-3.2 $\mu \mathrm{m}$, maximum diameter of shaft 2.0-5.0-7.0 $\mu \mathrm{m}, \mathrm{N}=50$.

Exotyles straight or gently curved, slender, 650-974$1250 \mu \mathrm{m}$ long. Proximal tyles varying from well-developed $(6.8-11.0-14.0 \mu \mathrm{m}$ in diameter) to reduced. Distal knobs usually regularly spherical (Figure $25 \mathrm{E}$ ), occasionally hemispherical or elongated, $18.0-22.8-30.0 \mu \mathrm{m}$ in diameter. Surface of the knobs and the adjacent portions of the shafts usually rough, spined or granulated. Shafts gradually expanding towards the distal knobs, $\mathrm{N}=50$.

\section{Genetic data}

$\mathrm{CO}_{1}$ sequences obtained from three individuals of Sphaerotylus capitatus are identical (Matrix M34248 in TreeBase). 28S rDNA sequences obtained only from two of these sponges differ by two bps (Matrix M34250 in TreeBase) and exhibit one synapomorphy distinguishing S. capitatus from other polymastiids (Online resource 3, p. $4)$. In the $\mathrm{CO}_{1}$ and $28 \mathrm{~S}$ rDNA phylogenies $S$. capitatus forms a clade with two British unidentified species, Sphaerotylus sp. 1 and Sphaerotylus sp. 2, not covered by the present study (Plotkin et al., 2016b). These three species share three synapomorphies in $\mathrm{CO}_{1}$ (Online resource 2, p. 4, Matrix M34248 in TreeBase) and three synapomorphies in $28 \mathrm{~S}$ rDNA (Online resource 3, p. 4, Matrix M34250 in TreeBase) distinguishing them from all other polymastiids. One more synapomorphy in $28 \mathrm{~S}$ rDNA is shared only by $S$. capitatus and Sphaerotylus sp. 1 (Online resource 3, p. 4, Matrix M34250 in TreeBase). Meanwhile, S. borealis, a Nordic species described above, does not fall in this clade (see the differences between $S$. borealis and $S$. capitatus in the Genetic data section for the former species).

\section{OCCURRENCE}

(Figure 26)

Literature data (only the locality distinct from our data is given): Canadian Atlantic Coast: Nova Scotia (75 m) (as Sphaerotylus schoenus - Topsent, 1928).

Our data (agree with most literature data): Greenland (420-450 m). Norwegian Sea, offshore areas (300 m), Skagerrak: Swedish Western Coast $(239-317 \mathrm{~m})$. Norwegian Coast: Hordaland (200-500 m), Møre and Romsdal (130$250 \mathrm{~m}$ ), Sør-Trøndelag (45-100 m), Nord-Trøndelag (20$130 \mathrm{~m})$, Nordland (150-800 m), Troms $(25 \mathrm{~m})$, Finnmark $(275 \mathrm{~m})$. Barents Sea: Murman Coast $(31-235 \mathrm{~m})$, offshore areas $(142-309 \mathrm{~m})$. Svalbard $(819 \mathrm{~m})$.

\section{DISCUSSION}

Sphaerotylus capitatus is a well-defined species and identification of it usually causes no difficulties. Meanwhile, molecular data on a larger set of species are required for reconstruction of the relationships between $S$. capitatus and its congeners.

Genus Spinularia Gray, 1867

Original description: Spinularia Gray, 1867, p. 524.

\section{SYNONYMS}

Radiella Schmidt, 1870 , p. 48 pars.

Rhaphidorus Topsent, 1898, p. 244.

\section{TYPE SPECIES}

Tethea spinularia Bowerbank, 1866 (by original designation).

\section{DIAGNOSIS}

Polymastiidae of discoid, hemispherical, lenticular or cushionlike body shape with a shaggy or minutely hispid surface and one to 15 weakly developed exhalant papillae. Main choanosomal skeleton composed of longitudinal or radial tracts of principal monactines crossing the cortex. Auxiliary choanosomal skeleton comprises free-scattered small and/or intermediary

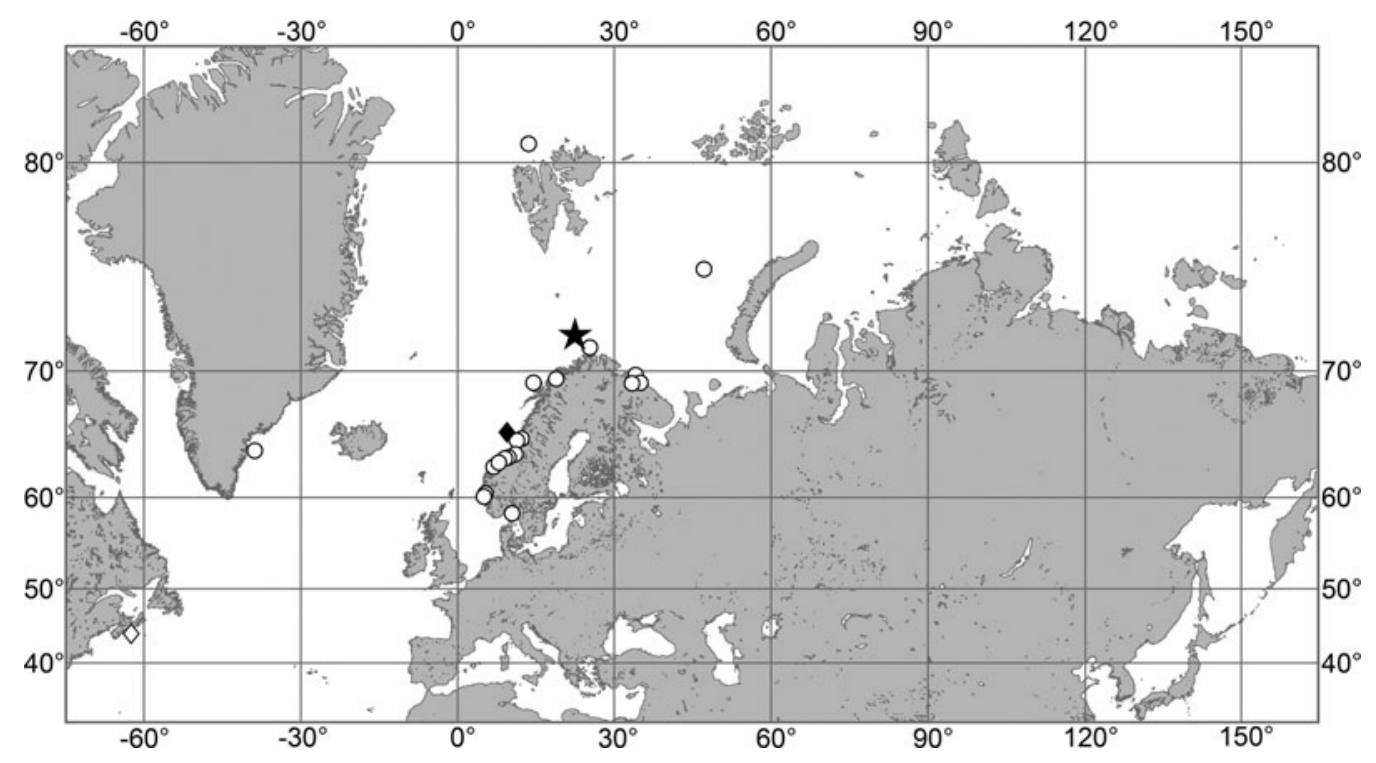

Fig. 26. Sphaerotylus capitatus, distribution: black star, type locality; black diamond, data from Topsent (1913); white diamond, data from Topsent (1928); white circles, our data. 
(sub)tylostyles and may also include raphides in trichodragmata. Cortical skeleton may, in addition to the superficial palisade of small tylostyles, include extra spicule layers. Basal cortex, if present, reinforced with the peripheral tracts of principal spicules lying parallel to the surface. A spicule fringe is always present at the edge of the body.

\section{GENETIC SYNAPOMORPHIES}

Spinularia spp. are distinguished from other polymastiids by two synapomorphies in $\mathrm{CO}_{1}$ (Online resource 2, p. 5) and one synapomorphy in $28 \mathrm{~S}$ rDNA (Online resource 3, p. 5).

\section{DISCUSSION}

Taxonomic history of Spinularia is closely related to Radiella and Trichostemma. Spinularia was established by Gray (1867) for a new species name Spinularia tetheoides Gray, 1867 for unknown reasons proposed as a replacement for Tethea spinularia Bowerbank, 1866. This replacement was, however, not acknowledged by the subsequent authors. Radiella was established by Schmidt (1870) for two species, his new species Radiella sol Schmidt, 1870 and Tethea spinularia, without designation of the type species. In that way Spinularia was consequently regarded as a synonym of Radiella, although the former had precedence over the latter. But three years later Schmidt (1880) reconsidered the status of Radiella spinularia (ex Tethea spinularia) acknowledging that it was conspecific with Halicnemia patera Bowerbank, 1864. Moreover, he admitted that Radiella might be a synonym of Halicnemia Bowerbank, 1864. However, Fristedt $(1885,1887)$ preferred to retain Tethea spinularia in Radiella as $R$. spinularia, while Hanitsch (1894) transferred it to Polymastia Bowerbank, 1862, although with some doubt. Spinularia was resurrected by Stephens (1915) who defined the main feature distinguishing this genus from Polymastia, Halicnemia and Radiella, the presence of raphides (filiform oxea-like spicules) packed in trichodragmata. In the same paper Stephens stated that the type species of Rhaphidorus Topsent, 1898, R. setosus Topsent, 1898 , which also possessed raphides in trichodramata, is synonymous with S. spinularia, and, consequently, Rhaphidorus was synonymized with Spinularia. The actions performed by Stephens were acknowledged by most subsequent authors (Topsent, 1928; Burton, 1930a; Alander, 1942; Lévi, 1993; Boury-Esnault, 2002; Plotkin et al., 2012). Since Tethea spinularia was the type species of Spinularia, Radiella sol was designated as the type species of Radiella (Boury-Esnault, 2002).

Trichostemma was established by Sars (1872) for his new species T. hemisphaericum Sars, 1872, although these names first appeared in a faunistic list three years earlier (Sars, 1869). Schmidt (1880) considered T. hemisphaericum to be a synonym of Radiella sol and, consequently, Trichostemma to be a synonym of Radiella. However, most subsequent authors recognized T. hemisphaericum and $R$. sol as different species, although they agreed that Trichostemma and Radiella were synonymous, and there were debates on which of these names preceded until Boury-Esnault (2002) acknowledged the synonymization of Trichostemma with Radiella based on the principle of priority (for references and other details see Discussion on Polymastia hemisphaerica above).

The relationships between Polymastia, Spinularia, Radiella and Trichostemma were re-considered by Plotkin et al. (2016b). Based on the $\mathrm{CO}_{1}$ and $28 \mathrm{~S}$ rDNA phylogenies Radiella sarsii and Radiella sp. (here described as Spinularia njordi sp. nov., see below) forming a strongly supported clade with Spinularia spinularia (Figure 1) were transferred to Spinularia. Conversely, Trichostemma hemisphaericum, falling into a clade with the type species of Polymastia ( $P$. mamillaris), was transferred to Polymastia. Consequently, Trichostemma Sars, 1872 was regarded as a junior synonym of Polymastia Bowerbank, 1862 (Plotkin et al., 2016b). These actions are followed in the present study, and the definition of Spinularia is extended to cover the species lacking raphides in trichodragmata (see Diagnosis above). Spinularia australis Lévi, 1993, a species from New Caledonia originally placed in Spinularia, perfectly fits with this diagnosis. It possesses raphides like S. spinularia and, at the same time, resembles $S$. sarsii by body shape and the presence of basal cortex. We also agree that Rhaphidorus is a synonym of Spinularia, although we question the synonymization of $R$. setosus with $S$. spinularia (for details see Discussion on S. spinularia below).

Meanwhile, the status of the type species of Radiella, R. sol, remains uncertain. Its type material is lost (Plotkin et al., 2012) and no fresh material is available. The age-old non-type specimen identified as $R$. sol by Schmidt (1880) and re-described by Boury-Esnault (2002) resembles Polymastia hemisphaerica by its relatively narrow marginal spicule fringe (Plotkin \& Janussen, 2008; Plotkin et al., 2012). But it does not match the drawing in the original description of R. sol (Schmidt, 1870: pl. 4, figure 6), which displays a wider marginal fringe rather resembling Spinularia sarsii (Plotkin \& Janussen, 2008; Plotkin et al., 2012). However, regardless of the relationships of $R$. sol with P. hemisphaerica and S. sarsii, Radiella is abandoned since both Polymastia and Spinularia are older names (Plotkin et al., 2016b).

\section{Spinularia njordi sp. nov.}

(Figure 27)

\section{TYPE MATERIAL}

Holotype: ZMBN 098040 (specimen), Low-angle fault to the west of Loki's Castle, North Norwegian Sea, $73^{\circ} 34.738^{\prime}-$ $73^{\circ} 35.005^{\prime} \mathrm{N} \quad 08^{\circ} 03.034^{\prime}-08^{\circ} 01.085^{\prime} \mathrm{E}, \quad 2457-1997 \mathrm{~m}, \quad \mathrm{RV}$ 'G.O. Sars', expedition $\mathrm{H}_{2}$ DEEP, station 09-40-DR 03, 09.08.2009.

Paratype: ZMBN 098041 (specimen), from the same sample as the holotype.

Paratype: ZMBN 098038 (sections and spicule slides; the specimen was completely used for the preparations), Schultz Massive, North Norwegian Sea, $73^{\circ} 47.385^{\prime} \mathrm{N} 07^{\circ} 40.413^{\prime} \mathrm{E}$, 1997 m, RV 'G.O. Sars', expedition BIODEEP, 07-90-ROV 10 rock 2, 14.07.2007, coll. Augustin.

\section{COMPARATIVE MATERIAL}

(see Online resource 1 for details)

Norwegian Sea: Southern part, Storegga: ZMBN 107497, ZMBN 107498 and ZMBN 107499 (three specimens), Eastern part, $\sim 160 \mathrm{~km}$ North from Andenes: NTNU-VM72525 (10 specimens), Northern part, Schultz Massive Loki's Castle: 58 specimens deposited in ZMBN.

\section{ETYMOLOGY}

Named after Njord, the god of ocean, seafaring and fishing in Norse mythology. Referring to the occurrence of this species in the offshore areas of the Norwegian Sea. 

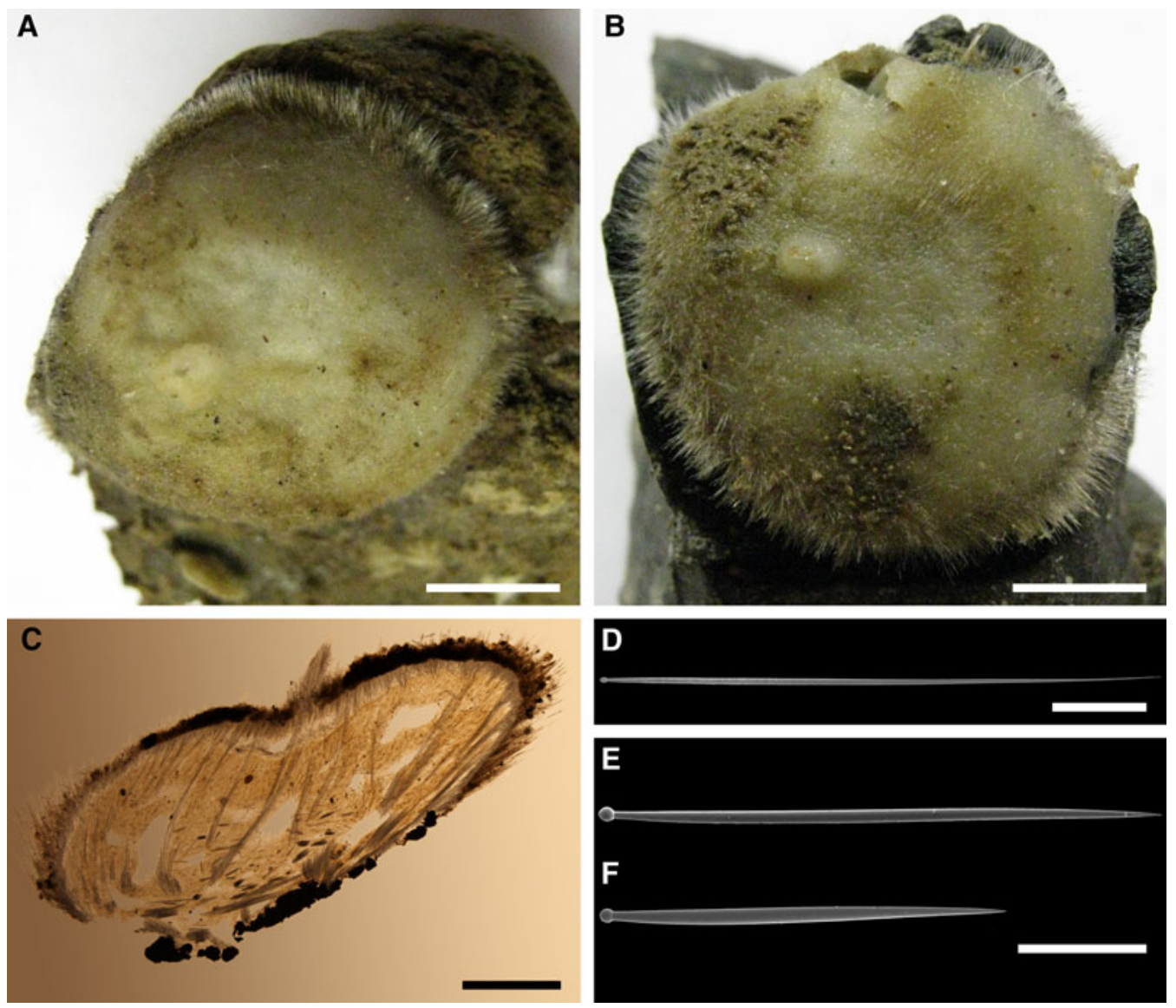

Fig. 27. Spinularia njordi: (A) holotype ZMBN 098040, habitus; (B) paratype ZMBN 098041, habitus; (C) paratype ZMBN 098038, longitudinal section through the body; (D) the same individual, principal subtylostyle; (E) the same individual, intermediary tylostyle; (F) the same individual, small tylostyle. Scale bars: A-B, $0.5 \mathrm{~cm} ; \mathrm{C}, 2 \mathrm{~mm}$; D, $0.2 \mathrm{~mm}$; E-F, $0.1 \mathrm{~mm}$.

\section{DESCRIPTION}

\section{External morphology}

Holotype and both paratypes hemispherical, with a minutely and unevenly hispid surface edged with a narrow spicule fringe and bearing a single weakly developed papilla with an osculum at the summit. Holotype $16-17 \mathrm{~mm}$ in diameter and $\sim_{9} \mathrm{~mm}$ in height, attached to a volcanic porous concretion (Figure $27 \mathrm{~A}$ ). Surface dirty grey, with a whitish papilla. Paralectotype ZMBN 098041 17-18 $\mathrm{mm}$ in diameter and $\sim 6 \mathrm{~mm}$ in height, attached to a basalt piece (Figure $27 \mathrm{~B}$ ). Surface dirty grey, with a whitish papilla. Paratype ZMBN 098038 was, before dissection, $11 \mathrm{~mm}$ in diameter and $4 \mathrm{~mm}$ in height, attached to small gravels. Surface was brownish, with a yellowish papilla located in a small depression. Other sponges hemispherical, lenticular or irregular, up to $24 \mathrm{~mm}$ in diameter. Surface, for the most part, hispid, occasionally shaggy, dark brown or dark grey because of the covering sediment. A single papilla and the surrounding area on the body top, which may be gently depressed, are smooth and pale in colour. Marginal spicule fringe up to $3 \mathrm{~mm}$ wide in the largest individuals.

\section{Anatomy}

Choanosome in alcohol light or dark brown, dense. Main choanosomal skeleton composed of tracts $(96-310 \mu \mathrm{m}$ thick) of principal spicules radiating from the basal area, where the sponge is attached to the substrate, occasionally ramifying, crossing the cortex and protruding above the surface (Figure $27 \mathrm{C}$ ). At the body edge the protruding tracts form a prominent fringe. Some tracts ascend to the papilla walls. Auxiliary choanosomal skeleton comprises freescattered small and intermediary spicules, the latter occasionally gathered in small bundles. Cortex in alcohol whitish or pale brown, firm, not detachable. Cortical skeleton comprises a superficial palisade $(217-300 \mu \mathrm{m}$ thick) of small spicules. In the central area of the upper cortex there is also an internal layer (116-494 $\mu \mathrm{m}$ thick) of criss-cross intermediary spicules. Under the papilla the palisade and the internal layer are separated by an aquiferous cavity $(\sim 268-810 \mu \mathrm{m}$ in diameter).

\section{Spicules}

(Measurements based on seven specimens, individual variation presented in Table 7)

Principal spicules (Figure $27 \mathrm{D}$ ) - subtylostyles to tylostyles, usually straight and slender. Length 1116-1492-2579 $\mu \mathrm{m}$, diameter of tyle (if present) $8.9-13.3-16.5 \mu \mathrm{m}$, proximal diameter of shaft $6.4-9.1-14.0 \mu \mathrm{m}$, maximum diameter of shaft 8.9-14.9-21.6 $\mu \mathrm{m}, \mathrm{N}=284$.

Intermediary spicules (Figure $27 \mathrm{E}$ ) - tylostyles to subtylostyles, usually straight, occasionally gently curved, slender. Length 422-685-1128 $\mu \mathrm{m}$, diameter of tyle (if present) 8.9-13.0-16.5 $\mu \mathrm{m}$, proximal diameter of shaft 5.1-7.9$11.4 \mu \mathrm{m}$, maximum diameter of shaft $8.9-13.3-17.8 \mu \mathrm{m}$, $\mathrm{N}=254$. 
Table 7. Individual variation of spicule dimensions of Spinularia njordi (given in $\mu \mathrm{m}$ as minimum-mean-maximum). Parameters: length, diameter of tyle, proximal diameter of shaft, maximum diameter of shaft, number of spicules measured $(\mathrm{N})$.

\begin{tabular}{|c|c|c|c|}
\hline Specimen & Principal spicules & Intermediary spicules & Small spicules \\
\hline \multirow[t]{5}{*}{ Holotype ZMBN 98038} & $1166-1460-1823$ & $422-713-1128$ & $251-328-402$ \\
\hline & $10.2-13.2-16.5$ & $10.2-12.2-14$ & $10.2-12.3-15.2$ \\
\hline & $7.6-9-12.7$ & $5.1-7.4-8.9$ & $5.1-7.6-10.2$ \\
\hline & $12.7-15-20.3$ & $8.9-12.3-15.2$ & $10.2-12.9-16.5$ \\
\hline & $\mathrm{N}=104$ & $\mathrm{~N}=91$ & $\mathrm{~N}=73$ \\
\hline \multirow[t]{5}{*}{ Paratype ZMBN 98040} & $1141-1628-2108$ & $422-572-942$ & $231-338-422$ \\
\hline & $8.9-14-15.2$ & $12.7-13.6-15.2$ & $12.7-13.3-15.2$ \\
\hline & $7.6-9.8-11.4$ & $7.6-8-8.9$ & $7.6-8.3-10.2$ \\
\hline & $10.2-17-20.3$ & $12.7-14.6-17.8$ & $12.7-14.5-17.8$ \\
\hline & $\mathrm{N}=35$ & $\mathrm{~N}=19$ & $\mathrm{~N}=30$ \\
\hline \multirow[t]{5}{*}{ ZMBN 107498} & $1116-1754-2579$ & $422-547-1116$ & $286-327-392$ \\
\hline & $8.9-12.3-16.5$ & $8.9-12.8-15.2$ & $10.2-12.2-14$ \\
\hline & $7.6-10.2-14$ & $7.6-8.8-11.4$ & $5.1-7.4-8.9$ \\
\hline & $8.9-14.2-21.6$ & $10.2-14.4-16.5$ & $10.2-13.7-17.8$ \\
\hline & $\mathrm{N}=41$ & $\mathrm{~N}=30$ & $\mathrm{~N}=30$ \\
\hline \multirow[t]{5}{*}{ ZMBN 107499} & $1166-1267-1364$ & $427-775-1116$ & $201-292-382$ \\
\hline & $10.2-13.1-15.2$ & $10.2-12.5-14$ & $8.9-11.8-14$ \\
\hline & $6.4-8.1-10.2$ & $6.4-7.5-7.6$ & $3.8-6.8-8.9$ \\
\hline & $10.2-14.9-17.8$ & $11.4-13.7-15.2$ & $8.9-12.6-14$ \\
\hline & $\mathrm{N}=12$ & $\mathrm{~N}=24$ & $\mathrm{~N}=30$ \\
\hline \multirow[t]{5}{*}{ ZMBN 107500} & $1166-1607-2058$ & $422-581-1005$ & $261-331-412$ \\
\hline & $12.7-13.5-15.2$ & $10.2-12.7-15.2$ & $12.7-12.8-14$ \\
\hline & $7.6-8.8-10.2$ & $5.1-6.7-7.6$ & $6.4-7-7.6$ \\
\hline & $12.7-14.6-16.5$ & $10.2-11.9-12.7$ & $11.4-12.8-15.2$ \\
\hline & $\mathrm{N}=32$ & $\mathrm{~N}=30$ & $\mathrm{~N}=30$ \\
\hline \multirow[t]{5}{*}{ ZMBN 107504} & $1141-1266-1488$ & $422-730-1128$ & $221-342-412$ \\
\hline & $11.4-13.6-15.2$ & $12.7-14.2-16.5$ & $12.7-14-16.5$ \\
\hline & $7.6-8.9-10.2$ & $7.6-9-10.2$ & $7.6-9.1-12.7$ \\
\hline & $12.7-13.8-15.2$ & $12.7-13.7-15.2$ & $12.7-14.4-20.3$ \\
\hline & $\mathrm{N}=30$ & $\mathrm{~N}=30$ & $\mathrm{~N}=30$ \\
\hline \multirow[t]{5}{*}{ ZMBN 107505} & $1141-1282-1401$ & $437-794-1116$ & $251-336-412$ \\
\hline & $11.4-13.8-15.2$ & $10.2-13.2-15.2$ & $12.7-13.8-15.2$ \\
\hline & $7.6-9.1-10.2$ & $6.4-7.9-8.9$ & $7.6-9.4-10.2$ \\
\hline & $12.7-14-15.2$ & $8.9-12.7-15.2$ & $12.7-14.4-16.5$ \\
\hline & $\mathrm{N}=30$ & $\mathrm{~N}=30$ & $\mathrm{~N}=30$ \\
\hline
\end{tabular}

Small spicules (Figure $27 \mathrm{~F}$ ) - tylostyles, often gently bent at the proximal part, occasionally straight, usually slightly fusiform. Length 201-328-422 $\mu \mathrm{m}$, diameter of tyle 8.9$12.6-16.5 \mu \mathrm{m}$, proximal diameter of shaft $3.8-7.8-$ $12.7 \mu \mathrm{m}$, maximum diameter of shaft $8.9-13.3-20.3 \mu \mathrm{m}$, $\mathrm{N}=253$.

\section{Genetic data}

Data obtained from three individuals of Spinularia njordi are identical in both genes studied. Moreover, the $\mathrm{CO}_{1}$ sequences from $S$. njordi are identical to those from the type species of Spinularia, S. spinularia, and the Norwegian individuals of S. sarsii, but not the Mozambican S. cf. sarsii (Online resource 2, p. 5). At the same time $S$. njordi displays seven autapomorphies in $28 \mathrm{~S}$ rDNA distinguishing it from the congeners (Matrix M34250 in TreeBase). Of these autapomorphies one is unique among all polymastiid species from which $28 \mathrm{~S}$ rDNA has ever been obtained (Online resource 3, p. 5).

\section{OCCURRENCE}

(Figure 28)

Norwegian Sea, offshore: southern areas $(733-790 \mathrm{~m})$, eastern areas $(1580 \mathrm{~m})$, northern areas $(1262-2457 \mathrm{~m})$.

\section{DISCUSSION}

Spinularia njordi resembles the type species of Spinularia, S. spinularia, by the encrusting growth pattern, the consequent absence of the basal cortex and the relatively small marginal fringe composed of the spicules of the same category as those forming the main choanosomal tracts. These features distinguish S. njordi and S. spinularia from other Spinularia spp. At the same time $S$. njordi differs from S. spinularia by the shaggy surface, the presence of an additional cortical layer made of intermediary monactines and the absence of raphides in trichodragmata in the choanosome. These features rather resemble $S$. sarsii. Based on the absence of raphides $S$. njordi and S. sarsii were provisionally allocated to Radiella, as Radiella sp. and $R$. sarsii respectively (Plotkin et al., $2016 \mathrm{~b}$ ). However, based on the $28 \mathrm{~S}$ rDNA phylogeny and the identity of the $\mathrm{CO}_{1} 5^{\prime}$-end barcodes from these species and S. spinularia, they were transferred to Spinularia (Plotkin et al., 2016b). Spinularia njordi is established as a new species primarily based on its autapomorphies in $28 \mathrm{~S}$ rDNA (see the Genetic data above).

\section{Spinularia sarsii (Ridley \& Dendy, 1886)}

(Figure 29) 


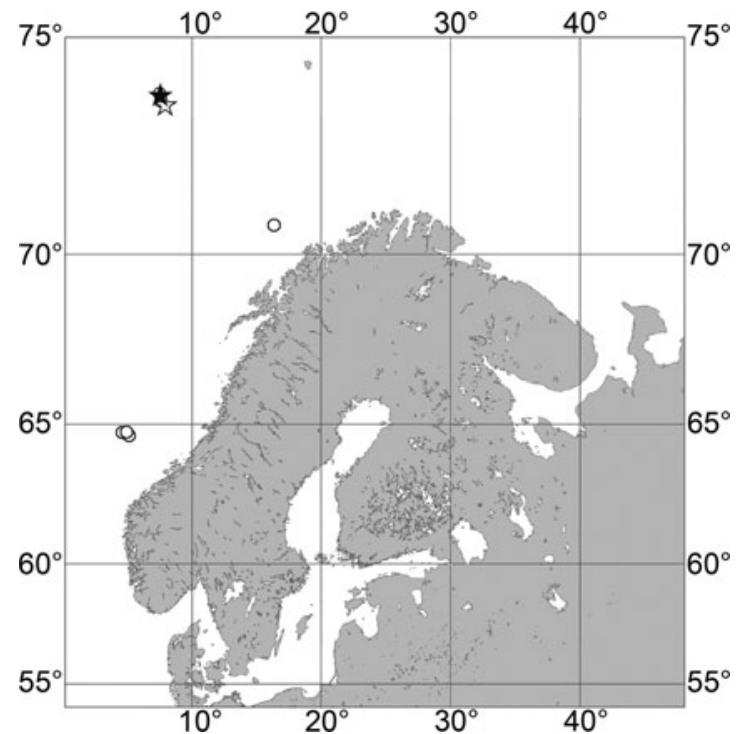

Fig. 28. Spinularia njordi, distribution: black star, locality of holotype and paratype ZMBN 098041; white star, locality of paratype ZMBN 098038; white circles, other data.

Original description: Trichostemma sarsii Ridley \& Dendy, 1886, p. 488.

\section{SYNONYMS AND CITATIONS}

Radiella sarsii (Gorbunov, 1946, p. 37; Plotkin, 2004, p. 543, figures $1 \mathrm{~g} \&$ 2g; Plotkin et al., 2012, p. 27, figure 2j).

Radiella sol (Koltun, 1964, p. 149, figure 3).

Polymastia sol sol (Koltun, 1966, p. 81, text-figure 52, pl. XXX figures 8 \& 9, pl. XXXI figures 10 \& 11).

Trichostemma sarsii (Ridley \& Dendy, 1887, p. 218, pl. XLIII figures 1, la, 2, 2a, 3 \& 3a; Topsent, 1892, p. 132, 1904, p. 120,1928 , p. 154; Uriz \& Rosell, 1990, p. 380, figures 3, 5e \& 6; Boury-Esnault et al., 1994, p. 73, figure 49).

Trichostemma sol (Barthel \& Tendal, 1993, p. 88, figure 5).

Non Radiella sarsii (Burton, 1959b, p. 208).

Non Trichostemma sarsii (Dendy, 1922, p. 151).

\section{TYPE MATERIAL}

Lectotype (designated herein, Figure 29A, B): BMNH 1887.5.2.38.1, off Azores, $38^{\circ} 30^{\prime} \mathrm{N} 31^{\circ} 14^{\prime} \mathrm{W}, \mathrm{RV}$ 'Challenger', $1820 \mathrm{~m}$, station $73,30.06 .1873$.

Paralectotypes: BMNH 1887.5.2.38.2 (small fragment), BMNH 1887.5.2.61 (two specimens) and BMNH 1887.5.2.66 (one specimen, Figure $29 \mathrm{C}, \mathrm{D}$ ), from the same sample as the lectotype.

Paralectotype: BMNH 1887.5.2.40 (one specimen, Figure 29E, F), SE off Cape York, Australia, $12^{\circ} 08^{\prime} \mathrm{S} 145^{\circ} 10^{\prime} \mathrm{E}, 2548 \mathrm{~m}, \mathrm{RV}$ 'Challenger', station 184, 29.08.1874.

\section{COMPARATIVE MATERIAL}

(see Online resource 1 for details)

Greenland: East Coast: ZIN RAS ocrsoo2 (one specimen), NE

Coast: ZIN RAS ocrsoo3 (one specimen).

Greenland Sea: ZIN RAS ocrsoo1 and ZIN RAS ocrsoo4 (two specimens).
Norwegian Sea, offshore: NTNU-VM-72506, ZMBN 098039, ZMBN 098098, ZMBN 107582 and ZMBN 107583 (five specimens).

Indian Ocean: Mozambican Coast: ZMBN 098103 (one specimen identified as Radiella cf. sarsii by Plotkin et al., 2016b).

\section{DESCRIPTION}

\section{External morphology}

Lectotype discoid, flattened, with hispid, grey upper and basal surfaces and a marginal spicule fringe (Figure $29 \mathrm{~A}, \mathrm{~B}$ ). Body $\sim 9 \mathrm{~mm}$ in diameter (excluding the fringe) and $\sim 6 \mathrm{~mm}$ thick. Upper surface bears four tiny papillae with oscula at the summits (Figure 29A). Basal surface without any trace of the substrate (Figure 29B). Fringe 1.5-4 mm wide. All paralectotypes externally resemble the lectotype. Paralectotype BMNH 1887.5 .2 .38 .2 is a body sector with a $3.0-3.5 \mathrm{~mm}$ wide fringe and without papillae. Paralectotype BMNH 1887.5 .2 .40 discoid, $\sim 9 \mathrm{~mm}$ in diameter, with a convex, smooth basal surface and a flattened, hispid upper surface bearing a single papilla damaged at the summit (Figure 29E, F). Fringe 1.5-2.5 mm wide. One of the paralectotypes BMNH 1887.5.2.61 flattened, irregular, $\sim 6 \times 8 \mathrm{~mm}$, with hispid upper and basal surfaces and without visible papillae. Fringe 1-2 mm wide. The other paralectotype BMNH 1887.5.2.61 discoid, flattened, $\sim_{4} \mathrm{~mm}$ in diameter, with an almost smooth basal surface and a hispid upper surface bearing a single papilla. Fringe $0.7-3.0 \mathrm{~mm}$ wide. Paralectotype BMNH 1887.5.2.66 discoid, $\sim 5.0-5.5 \mathrm{~mm}$ in diameter, with a convex, almost smooth basal surface and a flattened, strongly hispid upper surface lacking visible papillae (Figure $29 \mathrm{C}, \mathrm{D}$ ). Fringe $1.3-2.6 \mathrm{~mm}$ wide. Other sponges discoid, lenticular, hemispherical, occasionally irregular, up to $13 \mathrm{~mm}$ in diameter (Figure $29 \mathrm{G}, \mathrm{H}$ ). Upper surface flattened, hispid or shaggy, covered with sediment, bearing a single papilla, more rarely few, small papillae with oscula at the summits (Figure $29 \mathrm{G}$ ). Basal surface often convex, smooth, attached to the substrate with a central point (Figure $29 \mathrm{H}$ ). A small substrate may be plunged into the basal cortex. Some individuals are free of any substrates. Width of the marginal fringe may reach half of body diameter.

\section{Anatomy}

Choanosome in alcohol light or dark brown, dense. Main choanosomal skeleton composed of tracts $(119-283 \mu \mathrm{m}$ thick) of principal spicules radiating from the central basal point, crossing the upper cortex and protruding above the surface (Figure 29I). Some tracts ascend to the papilla walls. Auxiliary choanosomal skeleton comprises free-scattered bundles of intermediary spicules. Cortex in alcohol whitish, firm, not detachable. Skeleton of the upper cortex comprises a superficial palisade (about $300 \mu \mathrm{m}$ thick) of small spicules, a middle space $(340-405 \mu \mathrm{m}$ thick) with low concentration of spicules except for ascending choanosomal tracts and an internal layer (100-110 $\mu \mathrm{m}$ thick) of criss-cross intermediary spicules. Skeleton of the basal cortex formed of peripheral tracts of principal spicules running parallel to the surface and free-scattered single small spicules. Extra-long spicules (exotyles) composing the marginal fringe are embedded in the tracts.

\section{Spicules}

(Measurements based on 13 specimens) 

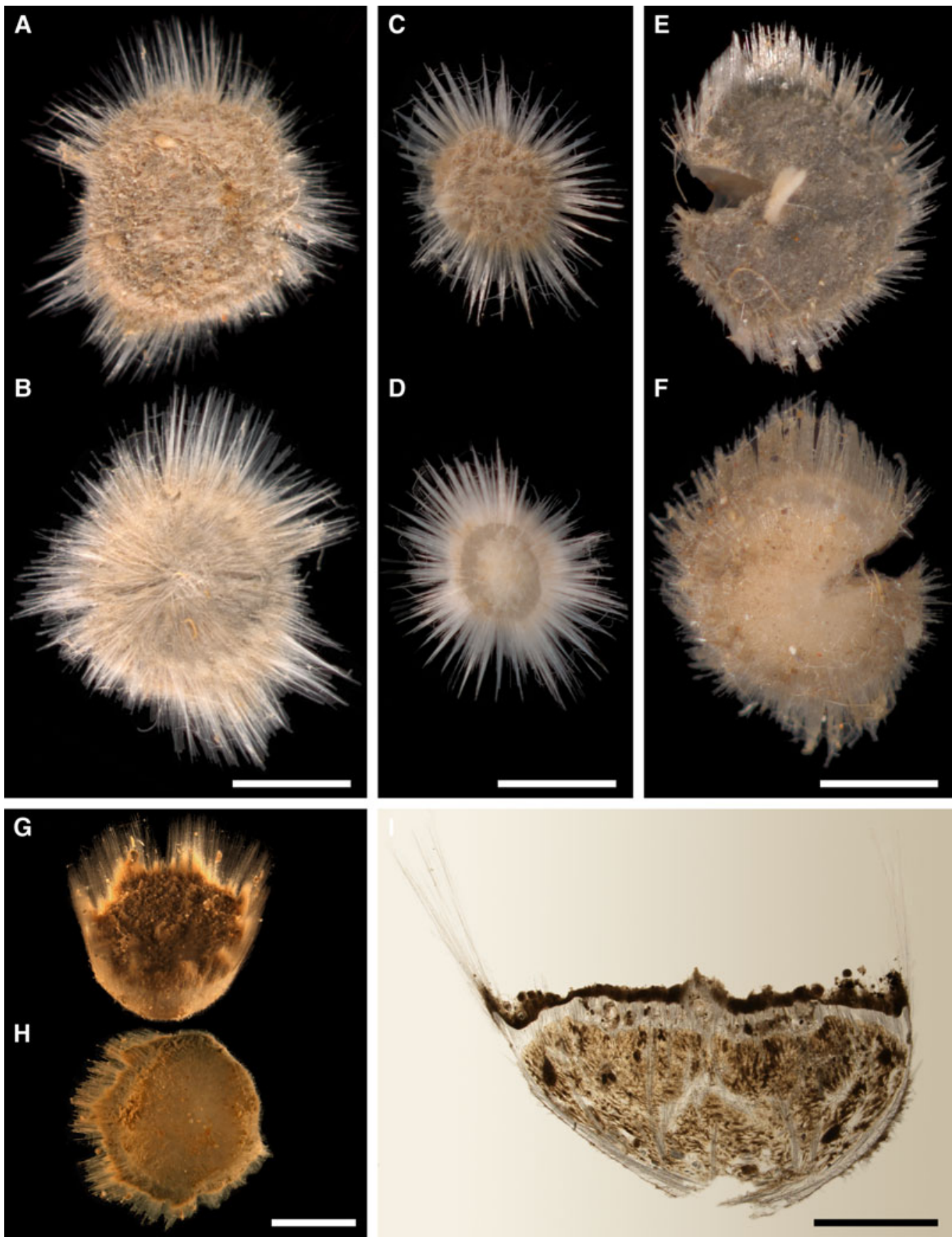

Fig. 29. Spinularia sarsii, type series, habitus: (A) lectotype BMNH 1887.5.2.38.1, view from above; (B) the same, bottom view; (C) paralectotype BMNH 1887.5.2.66, view from above; (D) the same, bottom view; (E) paralectotype BMNH 1887.5.2.40, view from above; (F) the same, bottom view; (G) ZMBN 107582, habitus, side view; $(\mathrm{H})$ the same, bottom view; (I) the same individual, longitudinal section through the body. Scale bars: A-H, $5 \mathrm{~mm}$; I, $3 \mathrm{~mm}$.

Principal spicules - styles, occasionally subtylostyles, usually straight and fusiform. Length 871-1787-2900 $\mu \mathrm{m}$, maximum diameter of shaft $13.0-19.3-26.6 \mu \mathrm{m}, \mathrm{N}=130$. Intermediary spicules - subtylostyles to tylostyles, usually straight, slightly fusiform. Length 250-471-632 $\mu \mathrm{m}$, maximum diameter of shaft $6.1-7.6-8.7 \mu \mathrm{m}, \mathrm{N}=390$.

Small spicules - tylostyles, often gently bent at the proximal part, fusiform. Length 152-232-298 $\mu \mathrm{m}$, maximum diameter of shaft 8.1-9.8-10.4, N=390.

Exotyles (spicules of the marginal fringe) - styles, occasionally subtylostyles, straight or slightly curved, fusiform. Length 3890-5010-6030, $\mu \mathrm{m}$, maximum diameter of shaft 24.5$27.3-29.8 \mu \mathrm{m}, \mathrm{N}=70$.

\section{Genetic data}

Certain genetic differences are revealed between the morphologically very similar Spinularia sarsii from Norway and Spinularia cf. sarsii from Mozambique. Data obtained from two Norwegian individuals are identical in both genes studied. Moreover, the $\mathrm{CO}_{1}$ sequences from these individuals are identical to those from the type species of Spinularia, S. spinularia, and S. njordi and display one synapomorphy distinguishing them from other polymastiids including the Mozambican S. cf. sarsii (Online resource 2, p. 5). In $28 \mathrm{~S}$ rDNA the Norwegian $S$. sarsii differs from $S$. spinularia by 6 bps and from S. njordi by 12 bps (Matrix M34250 in TreeBase) and shares with them two synapomorphies 
(Online resource 3, p. 5). At the same time the Mozambican $S$. cf. sarsii is distinguished from all polymastiids by three autapomorphies in $\mathrm{CO}_{1}$ (Online resource 2, p. 5). Apart from these autapomorphies, it differs from the congeners by five bps in $\mathrm{CO}_{1}$ (Matrix M34248 in TreeBase). In $28 \mathrm{~S}$ rDNA the Mozambican $S$. cf. sarsii differs from the Norwegian $S$. sarsii by $13 \mathrm{bps}$, from $S$. njordi by 18 bps and from $S$. spinularia by 14 bps (Matrix M34250 in TreeBase).

\section{OCCURRENCE}

\section{(Figure 30)}

Type locality: North-East Atlantic: Azores $(1820 \mathrm{~m})$. The other type locality (Coral Sea near Australia, $2548 \mathrm{~m}$ ) probably represents another species (see Discussion below).

Other literature data: Canadian Atlantic Coast: off Newfoundland (1267 m) (Topsent, 1892). North-East Atlantic: Azores (861-2102 m) (Topsent, 1892, 1904), Cape Verde (1209-1417 m) (Topsent, 1928), Madeira (23803118) (Topsent, 1928), Moroccan Coast/Saharan Upwelling (851-2142 m) (Topsent, 1928; Boury-Esnault et al., 1994). Mediterranean Sea: Iberian Sea (1020-1580 m) (Uriz \& Rosell, 1990). Arctic Ocean, Greenland Sea and Norwegian Sea (800-2892 m) (Gorbunov, 1946; Koltun, 1964, 1966; Plotkin, 2004). Barents Sea, Kara Sea and Laptev Sea (from $145 \mathrm{~m}$ and deeper) (Koltun, 1966).

Our data: Greenland, East and NE Coast $(368-2581 \mathrm{~m})$ Greenland Sea, offshore (1447-2754 m). Norwegian Sea, offshore $(2387-2463 \mathrm{~m})$.

\section{DISCUSSION}

Spinularia sarsii was originally described as Trichostemma sarsii Ridley \& Dendy, 1886, despite Trichostemma having been synonymized earlier with Radiella (Schmidt, 1880). After long debates on which of the names, Trichostemma or Radiella, preceded, Boury-Esnault (2002) finally proved the action by Schmidt (1880) (for details see Discussion on the genus Spinularia above). Radiella was defined as sponges with the upper and basal cortex of different architecture and a spicule fringe developed at the boundary between the upper and basal surface (Boury-Esnault, 2002). Radiella sarsii perfectly fitted with this definition (Plotkin, 2004; Plotkin et al., 2012). The marginal spicule fringe was also typical of another genus, Spinularia, but the latter was distinguished from Radiella by the presence of raphides in trichodragmata (Boury-Esnault, 2002). However, based on the CO1 and 28S rDNA phylogenies, Plotkin et al. (2016b) transferred R. sarsii to Spinularia (for details see Discussion on the genus Spinularia and S. njordi above).

The other problem with Spinularia sarsii is the allegedly cosmopolitan distribution reported for this species. Its type localities are such remote regions as Azores and Australia (Ridley \& Dendy, 1886). Besides these S. sarsii is recorded from quite remote localities in the North Atlantic (Newfoundland (Topsent, 1892), Azores (Topsent, 1892, 1904), Cape Verdi (Topsent, 1928), Madeira (Topsent, 1928), Moroccan Coast (Topsent, 1928; Boury-Esnault et al., 1994), West Mediterranean Sea (Uriz \& Rosell, 1990)),

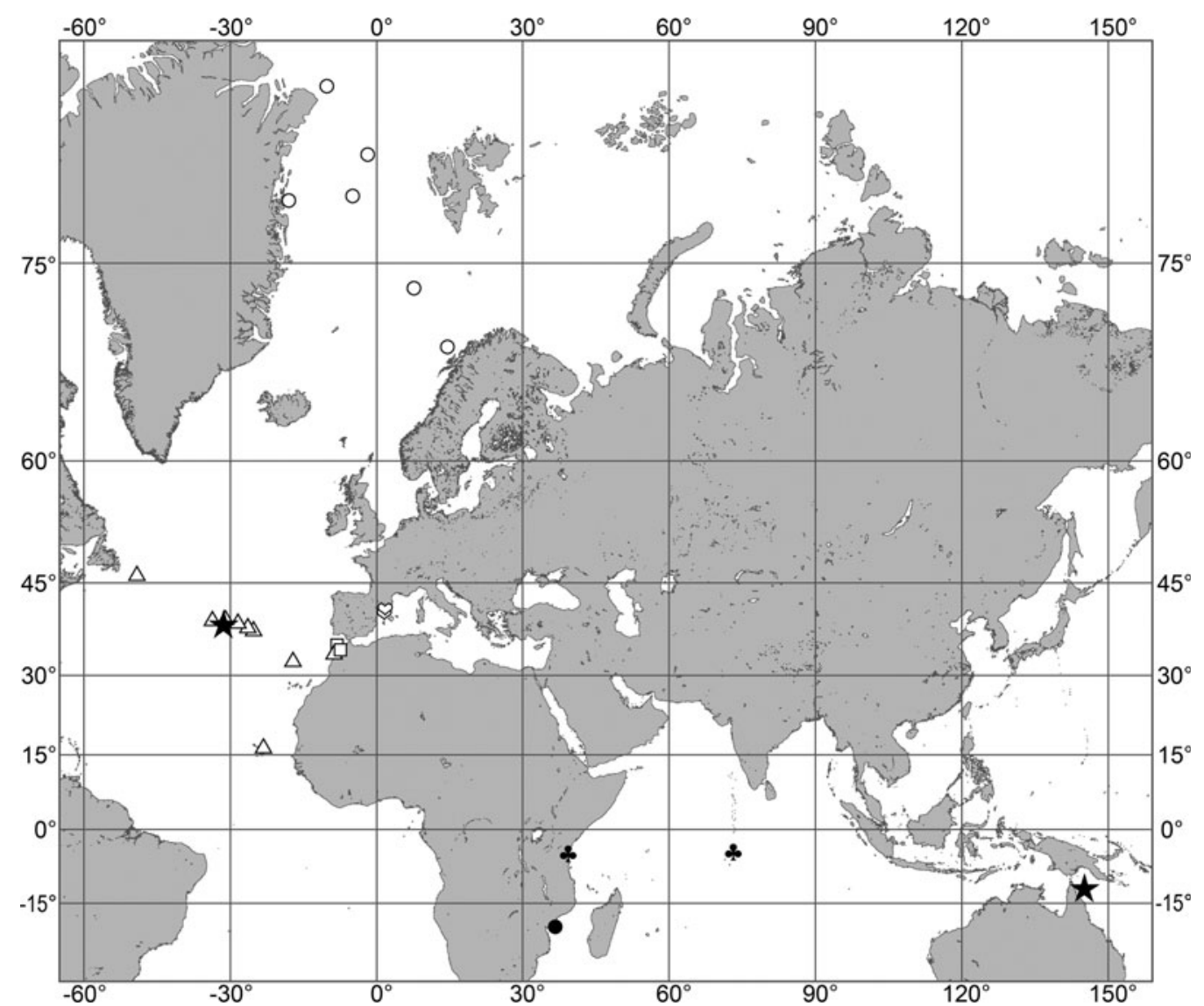

Fig. 3o. Spinularia sarsii, distribution: black stars, type localities; white squares, data from Boury-Esnault et al. (1994); black trefoils, data from Burton (1959b); white triangles, data from Topsent $(1892,1904,1928)$; white hearts, data from Uriz \& Rosell (1990); white circles, our data from the Nordic Seas; black circle, our data from Mozambique. 
Arctic Ocean, Greenland and Norwegian Sea (Gorbunov, 1946; Plotkin, 2004) and Indian Ocean (Mozambique (Plotkin et al., 2016b), Zanzibar (Burton, 1959b), Saya de Malha (Dendy, 1922), South off Maldives (Burton, 1959b)). This list may also be appended with the records of Radiella sol from the Barents, Kara and Laptev Sea by Koltun (1964, 1966) and Trichostemma sol from the NorwegianGreenland Sea by Barthel \& Tendal (1993), who at that time regarded Radiella sarsii to be a synonym of Radiella sol, which was in fact originally described from the Mexican Gulf (Schmidt, 1870). Furthermore, Van Soest et al. (2016) assumed that Suberites alveus Hansen, 1885 and Suberites conica Hansen, 1885 from the Norwegian Sea were very probably conspecific with Spinularia sarsii, just displaying variation of the body shape resembling a hive-like cone in $S$. alveus and a flattened cone in S. conica.

The cosmopolitan distribution of Spinularia sarsii is questioned by Plotkin et al. (2016b) and the present study based on genetic data. In the $28 \mathrm{~S}$ rDNA phylogeny morphologically very similar $S$. sarsii (former Radiella sarsii) from the Norwegian Sea and S. cf. sarsii from the Mozambican Coast (former Radiella cf. sarsii) do not group together, although they fall in the same clade (Plotkin et al., 2016b). Furthermore, the Mozambican sponge is distinguished from the congeners in $\mathrm{CO}_{1}$, whereas the sequences of this phylogenetic marker obtained from the Norwegian S. sarsii, S. spinularia and $S$. njordi are identical. Based on these data the records of $S$. sarsii from the northern and southern hemisphere are assumed to represent two different species. However, herein we do not formally establish a new species for the Mozambican individual because the locality is outside our study area and more material is required for a careful morphological description. At the same time there are no genetic data on $S$. sarsii from North Atlantic regions other than the Norwegian Sea, while the comparison of the Norwegian S. sarsii with the type material from Azores reveals no morphological differences. Neither can we check whether Suberites alveus and Suberites conica from the Norwegian Sea are indeed conspecific with Spinularia sarsii because the type material of the first two species is unfortunately lost. Therefore, for the moment we consider all records of Spinularia sarsii from the northern hemisphere as one species.

\section{Spinularia spinularia (Bowerbank, 1866)}

(Figures $31 \& 32$ )

Original description: Tethea spinularia Bowerbank, 1866 , p. 94 .

\section{SYNONYMS AND CITATIONS}

Polymastia spinularia (Hanitsch, 1894, p. 202).

Radiella spinularia (Schmidt, 1870, p. 48, pl. IV figures 7 \& 8; Fristedt, 1885 , p. 16, 1887, p. 435).

Spinularia spinularia (Stephens, 1915, p. 31, pl. III figure 5, pl. V figure 3; Burton, 1930a, p. 496; Alander, 1942, p. 76; Boury-Esnault, 2002, p. 216, figure 13; Plotkin et al., 2012, p. 27, figure 2i).

Spinularia tetheoides (Gray, 1867, p. 524).

Tethea spinularia (Bowerbank, 1874: pl. XV figures 23-30). Non Spinularia spinularia (Topsent, 1928, p. 150).

\section{TYPE MATERIAL}

Lectotype of Tethea spinularia (designated herein, dry specimen (Figure 31A) and seven slides labelled BR 393): $\mathrm{BMNH}$ 1910.1.1.34A, Shetland, UK, precise locality unknown, coll. Alfred M. Norman.

Paralectotypes of Tethea spinularia: BMNH 1910.1.1.34B (one dry specimen and three fragments): from the same sample as the lectotype.

Slides from the paralectotypes of Tethea spinularia: $\mathrm{BMNH}$ 10.1.1.1820, BMNH 10.1.1.1821 and 10.1.1.1822.

Holotype of Rhaphidorus setosus Topsent, 1898 (in alcohol): MOM 04-0303, East off Sao Miguel, Azores, $38^{\circ} 09^{\prime} \mathrm{N}$ $23^{\circ} 15.75^{\prime} \mathrm{W}-38^{\circ} 08^{\prime} \mathrm{N} 23^{\circ} 18.75^{\prime} \mathrm{W}, 4020 \mathrm{~m}$, Campagnes
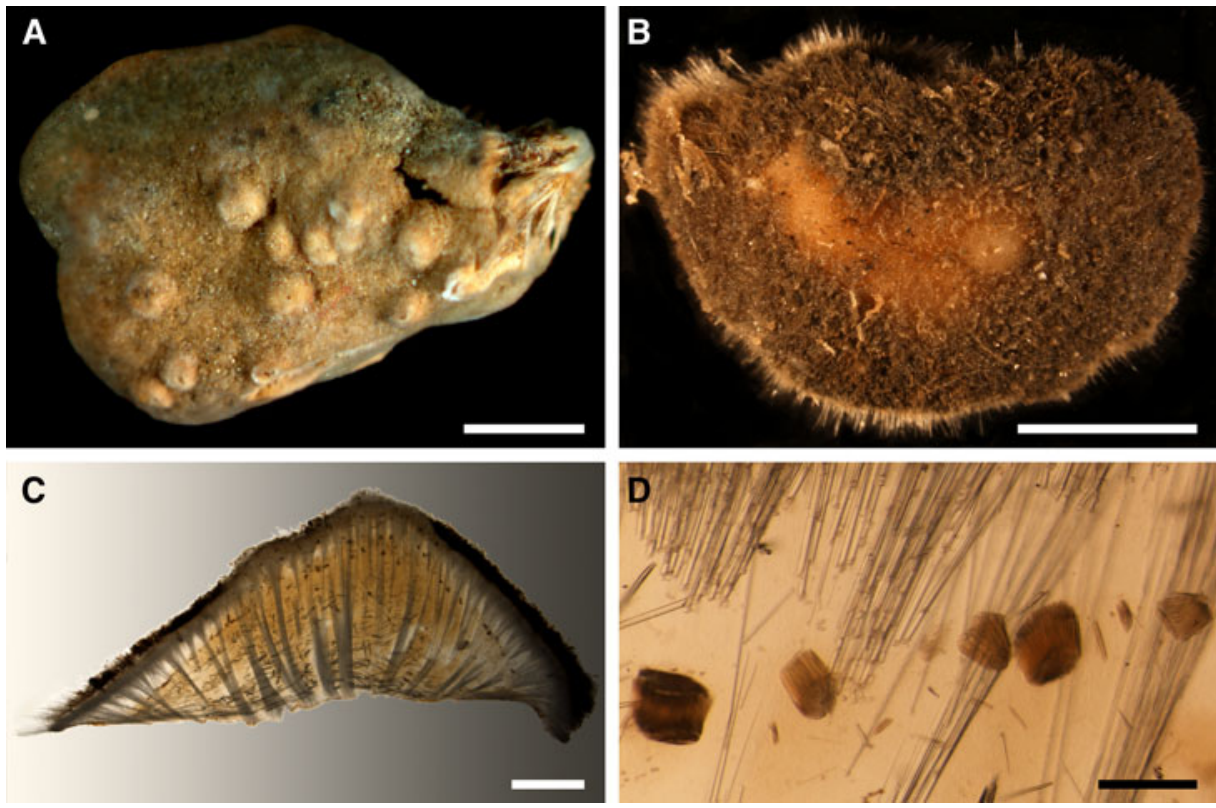

Fig. 31. Spinularia spinularia: (A) lectotype BMNH 1910.1.1.34A, habitus; (B) an individual from Hardangerfjorden, Norway, habitus; (C) the same individual, longitudinal section through the body, general view; (D) the same section, detail of subcortical area with trichodragmata. Scale bars: A-B, o.5 cm; C, 2 mm; D, $0.2 \mathrm{~mm}$. 

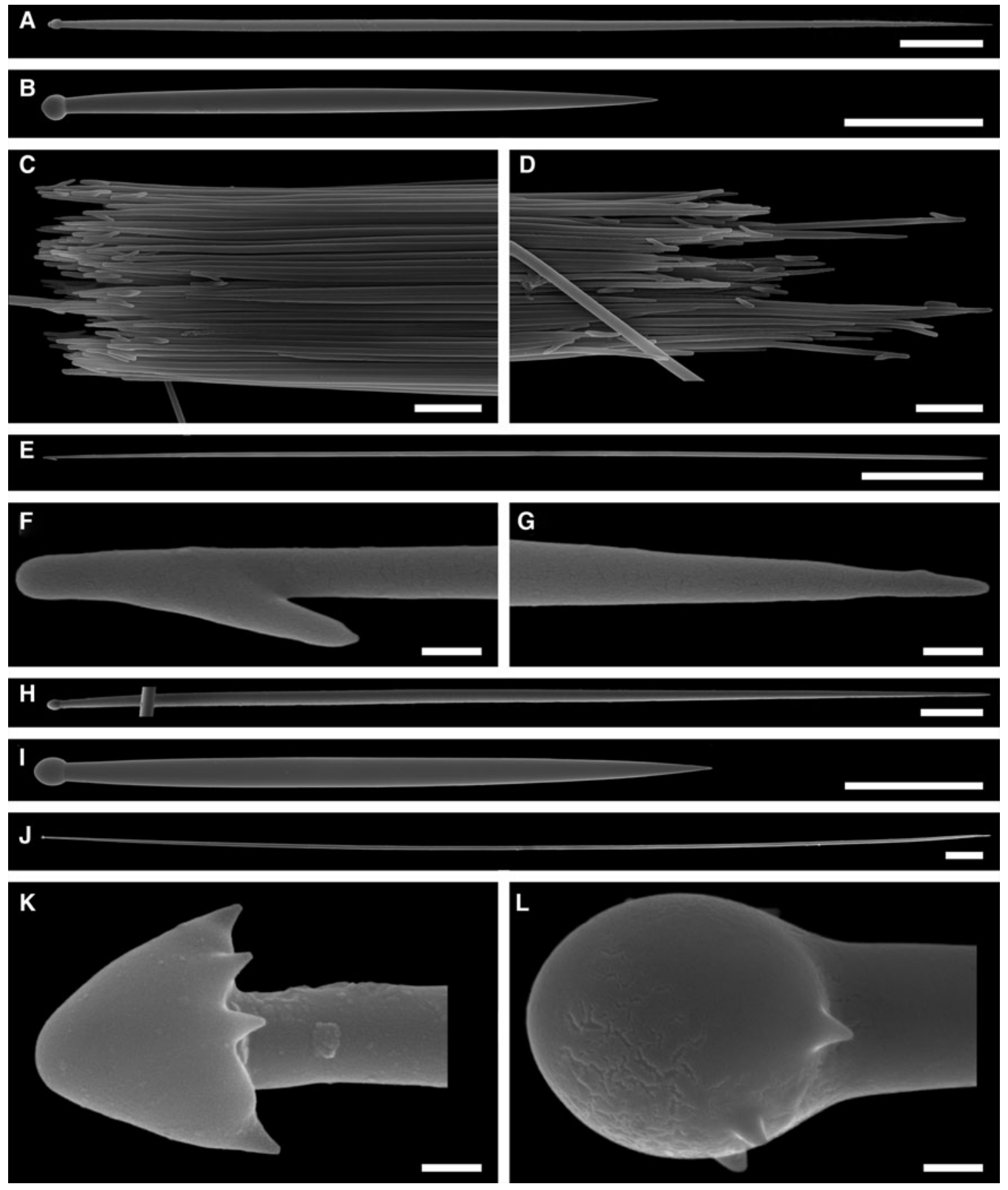

Fig. 32. Spinularia spinularia and S. setosa, spicules: (A) S. spinularia, principal tylostyle; (B) S. spinularia, small tylostyle; (C) and (D) S. spinularia, details of a trichodragma of raphides, (E) S. spinularia, raphide, general view; (F) the same spicule, detail of harpoon-shaped tip; (G) the same spicule, detail of the opposite tip; (H) S. setosa, principal tylostyle; (I) S. setosa, small tylostyle; (J) S. setosa, raphide, general view; (K) the same spicule, detail of umbrelliform tip; (L) another raphide of the same sponge, detail of subspherical tip. Scale bars: A, $0.1 \mathrm{~mm} ; \mathrm{B}, 0.05 \mathrm{~mm}$; C and D, $0.002 \mathrm{~mm}$; $0.01 \mathrm{~mm}$; F and G, $0.2 \mu \mathrm{m}$; H, $0.1 \mathrm{~mm}$; $0.05 \mathrm{~mm}$; J, $0.01 \mathrm{~mm} ; \mathrm{K}$ and $\mathrm{L}, 0.2 \mu \mathrm{m}$.

scientifiques accomplies par le Prince Albert I de Monaco, RV 'Princesse-Alice', station 527, 25.06.1895. Rhaphidorus setosus was relegated to a synonym of Spinularia spinularia by Stephens (1915), but herein it is assumed to be a separate species Spinularia setosa (see Discussion below).

\section{COMPARATIVE MATERIAL}

(see Online resource 1 for details)

Sweden: Västra Götaland: GNM 792:1 (one specimen).
Norway: Aust-Agder: ZMBN 107587 (one specimen), Hordaland: ZMBN 098037, ZMBN 098076 and ZMBN 098079 (three specimens), Sogn and Fjordane: ZMBN 098050 (one specimen), Møre and Romsdal: ZMBN 107488 and ZMBN 107494 (two specimens), Sør-Trøndelag: NTNU-VM-54615 (one specimen), Nord-Trøndelag: NTNU-VM-54669, NTNU-VM-56952, NTNU-VM-72538 and NTNU-VM-72546 (seven specimens).

Norwegian Sea, offshore: ZMBN 107586 (one specimen). 


\section{DESCRIPTION}

External morphology

Lectotype of Tethea spinularia cushion-shaped, $\sim 23 \times 15 \times$ $12 \mathrm{~mm}$, removed from the substrate (Figure 31A). Surface rough, beige in the central area and grey in the periphery, bearing 11 wart-like papillae, most with oscula at the summits. The most intact paralectotype cushion-shaped, $\sim_{9} \times 8 \times 5 \mathrm{~mm}$, removed from the substrate. Surface minutely hispid, covered with grey sediment in the periphery and clean, pale orange in the central area around a single wart-like papilla. Two paralectotypes are fragments of cushion-shaped sponges with minutely hispid surface, without papillae, removed from the substrates. The smallest paralectotype is a tiny encrust on a stone. Holotype of Rhaphidorus setosus cushion-shaped, about $12 \mathrm{~mm}$ in diameter, considerably damaged, attached to a stone. Scandinavian sponges cushion-shaped, occupying up to $9 \mathrm{~cm}^{2}$ of the substrate (Figure $31 \mathrm{~B}$ ). Surface minutely hispid, occasionally smooth and free of sediment in the central area and more hispid and covered with sediment in the periphery, bearing up to 15 papillae. Many individuals with tiny spicule fringes at the body edges. Papillae small, usually wart-like, with oscula at the summits.

\section{Anatomy}

Description is based on the lectotype of Tethea spinularia and Scandinavian individuals. Anatomy of the holotype of Rhaphidorus setosus is not studied because of its considerable damage. Choanosome in life pale orange, dense. Main choanosomal skeleton composed of tracts $(72-380 \mu \mathrm{m}$ thick) of principal spicules radiating from the base, crossing the cortex and protruding above the surface (Figure $31 \mathrm{C}$ ). Some tracts ascend to the papilla walls. Auxiliary choanosomal skeleton comprises free-scattered bundles of small spicules spread all over the body, bundles of principal spicules concentrated in the basal area and lying perpendicular to the main tracts, and trichodragmata (dense packs, 69-391 long and 56-453 $\mu \mathrm{m}$ wide) of raphides concentrated in the subcortical area (Figures $31 \mathrm{D} \& 32 \mathrm{C}-\mathrm{D}$ ). Cortex in life whitish, creamcoloured or pale brown, firm, not detachable. Cortical skeleton comprises a superficial palisade $(368-643 \mu \mathrm{m}$ thick) of small spicules and an inner space (256-1128 $\mu \mathrm{m}$ thick) with low concentration of spicules, both reinforced with the ascending choanosomal tracts. Papilla wall covered with a superficial palisade.

\section{Spicules}

Lectotype of Tethea spinularia, two Swedish individuals and seven Norwegian individuals:

Principal spicules (Figure 32A) - tylostyles with roundish, occasionally oval, tyles, usually straight and slender. Length $404-758-1355 \mu \mathrm{m}$, diameter of tyle $6.8-9.3-14.4 \mu \mathrm{m}$, proximal diameter of shaft 3.2-6.0-10.0 $\mu \mathrm{m}$, maximum diameter of shaft $5.8-10.0-14.6 \mu \mathrm{m}, \mathrm{N}=300$.

Small spicules (Figure $32 \mathrm{~B}$ ) - tylostyles, straight or occasionally gently bent, slightly fusiform. Length $161-290-373 \mu \mathrm{m}$, diameter of tyle $6.6-8.8-11.5 \mu \mathrm{m}$, proximal diameter of shaft 2.8-5.6-7.8 $\mu \mathrm{m}$, maximum diameter of shaft 5.4$8.8-13.4 \mu \mathrm{m}, \mathrm{N}=300$.

Raphides (Figure $32 \mathrm{C}-\mathrm{G}$ ) - thin monactines with one tip acerated (Figure $32 \mathrm{G}$ ) and the other harpoon-shaped, with a blunt point and a lateral barb (Figure 32F). Length 65-79-
$85 \mu \mathrm{m}$, maximum diameter of shaft $0.3-0.4-0.4 \mu \mathrm{m}, \mathrm{N}=$ 200.

Holotype of Rhaphidorus setosus:

Principal spicules (Figure $32 \mathrm{H}$ ) - tylostyles with roundish, occasionally oval, tyles, usually straight and slightly fusiform. Length 548-1458-2185 $\mu \mathrm{m}$, diameter of tyle 10.5-16.2$20.2 \mu \mathrm{m}$, proximal diameter of shaft 7.4-14.1-19.5 $\mu \mathrm{m}$, maximum diameter of shaft 11.9-17.5-22.8 $\mu \mathrm{m}, \mathrm{N}=30$.

Small spicules (Figure 32I) - tylostyles, usually straight and slender. Length 216-252-330 $\mu \mathrm{m}$, diameter of tyle 11.111.7-12.5 $\mu \mathrm{m}$, proximal diameter of shaft 7.2-7.7-8.4 $\mu \mathrm{m}$, maximum diameter of shaft 10.9-12.0-12.7 $\mu \mathrm{m}, \mathrm{N}=30$.

Raphides (Figure 32J) - thin monactines with one tip acerated and the other bearing an umbrelliform (Figure $32 \mathrm{~K}$ ) or subspherical ornamentation (Figure $32 \mathrm{~L}$ ) with tiny jags along the edge. Length 233-245-260 $\mu \mathrm{m}$, maximum diameter of shaft $1.0-1.2-1.3 \mu \mathrm{m}, \mathrm{N}=20$.

\section{Genetic data}

28S rDNA was obtained from five individuals of Spinularia spinularia, while $\mathrm{CO}_{1}$ was sequenced only from four of them. The $\mathrm{CO}_{1}$ sequences are identical, but a polymorphism is revealed in $28 \mathrm{~S}$ rDNA. Two subspecies groups, one comprising three individuals and the other two individuals, differ by two bps in this gene (Matrix M34250 in TreeBase). The synapomorphies and distinctions of S. spinularia from the congeners are described in the Genetic data sections for S. njordi and S. sarsii.

\section{OCCURRENCE}

(Figure 33)

Literature data: East Greenland (237 m) (Fristedt, 1887), Ireland (1001 m) (Stephens, 1915). Shetland (Bowerbank, 1866, 1874). Swedish Western Coast (50 m) (Fristedt, 1885; Alander, 1942). Norwegian Coast: Rogaland, Hordaland (70 $\mathrm{m}$ and deeper) (Burton, 1930a; Alander, 1942).

Our data: Skagerrak: Swedish Western Coast (45-60 m), Southern Norwegian Coast (Aust-Agder) (137-149 m). Norwegian Coast: Hordaland $(30-310 \mathrm{~m})$, Sogn and Fjordane (240-243 m), Møre and Romsdal (depth unknown), Sør-Trøndelag $(14-35 \mathrm{~m})$, Nord-Trøndelag $(25-400 \mathrm{~m})$. Norwegian Sea, offshore areas $(272-311 \mathrm{~m})$.

\section{DISCUSSION}

Since Bowerbank (1866) established Tethea spinularia for several sponges from Shetland the validity of this species was not disputed except for the proposal by Schmidt (1880) to synonymize it with Halicnemia patera not supported by the subsequent authors. Meanwhile, there was some disagreement on what genus it should be placed in. Gray (1867) established for $T$. spinularia a new genus Spinularia. However, Schmidt $(1870)$ and Fristedt $(1885,1887)$ proposed to place T. spinularia in Radiella, while Hanitsch (1894) allocated it to Polymastia. Spinularia was resurrected by Stephens (1915) defining the main distinguishing feature of its type species, the presence of raphides in trichodragmata. Based on this feature she also synonymized an Azorean species Rhaphidorus setosus Topsent, 1898 with S. spinularia. Both actions were encouraged by most subsequent authors (Topsent, 1928; Burton, 1930a; Alander, 1942; BouryEsnault, 2002; Plotkin et al., 2012). However, examination of the type and comparative material of S. spinularia and the holotype of $R$. setosus has revealed that in the latter both the 


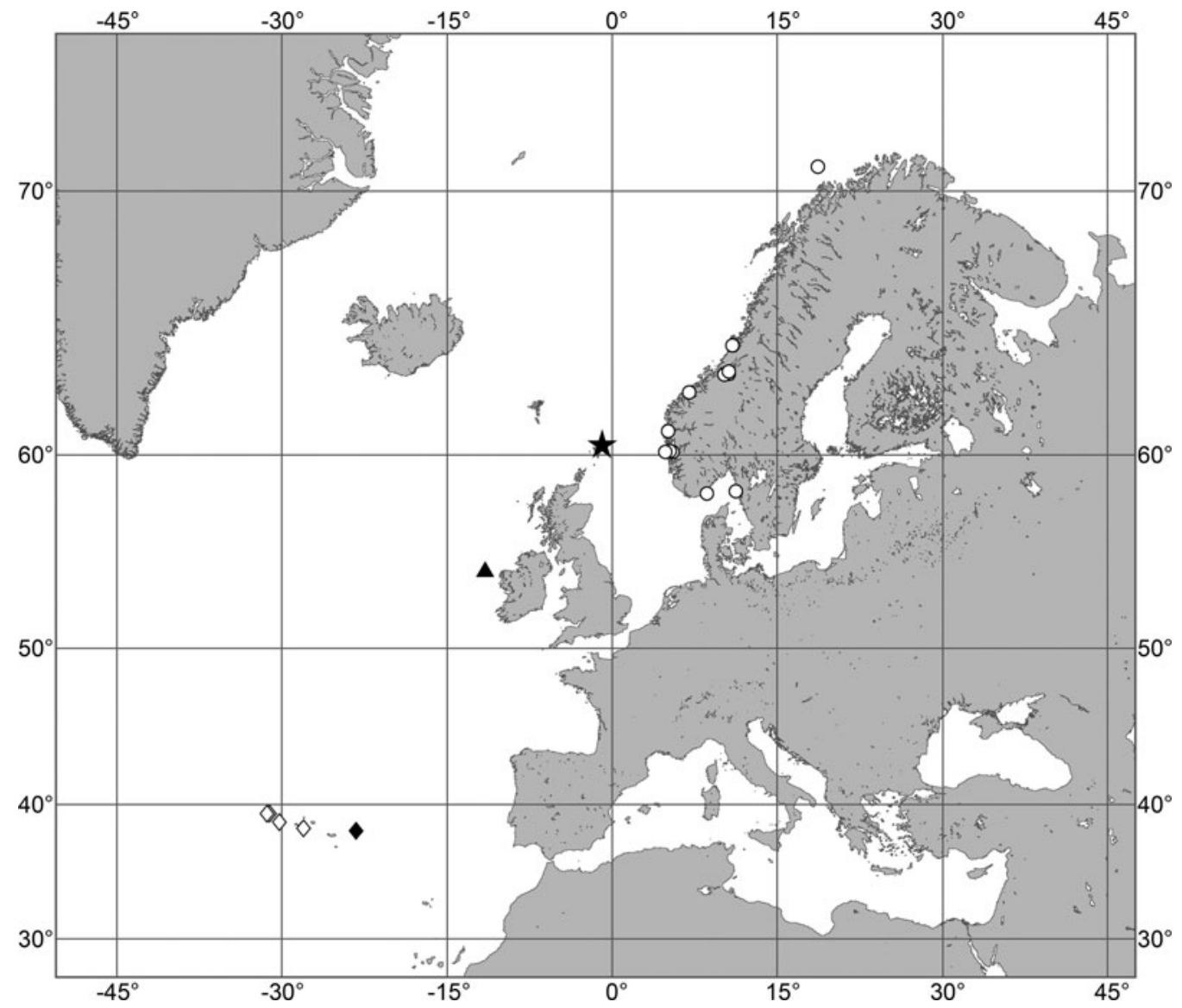

Fig. 33. Spinularia spinularia and S. setosa, distribution: black star, type locality of S. spinularia; black triangle, data on S. spinularia from Stephens (1915); white circles, our data on S. spinularia; black diamond, type locality of S. setosa, white diamonds, other records of S. setosa (Topsent, 1904, 1928).

principal spicules and the raphides are longer than in S. spinularia. Moreover, the raphides in $R$. setosus bear umbrelliform or subspherical distal ornaments, whereas in S. spinularia they are harpoon-shaped. Based on these differences we assume that $R$. setosus may be accepted as a separate species of Spinularia, S. setosa, although this should preferably be tested further with molecular data.

Genus Tentorium Vosmaer, 1887

Original description: Tentorium Vosmaer, 1887, p. 329, pl. II figure 4, pl. 21 figure 19.

\section{SYNONYMS}

Thecophora Schmidt, 1870, p. 50 (preoccupied by Thecophora Róndani, 1845 , a genus of flies).

\section{TYPE SPECIES}

Thecophora semisuberites Schmidt, 1870 (by original designation).

\section{DIAGNOSIS}

Polymastiidae of columnar or globular body shape, always with papillae. Main choanosomal skeleton constituted by longitudinal or radial tracts of principal monactines. Skeleton of the upper cortex comprises a palisade of small monactines. Skeleton of the lateral cortex may be either the same palisade or a dense layer of criss-cross principal or intermediary spicules.

\section{DISCUSSION}

In the $\mathrm{CO}_{1}$ and $28 \mathrm{~S}$ rDNA phylogenies Tentorium Vosmaer, 1887 is not monophyletic (Plotkin et al., 2016b; Figure 1 in this study). The type species, T. semisuberites and T. papillatum Kirkpatrick, 1908 do not group together and, moreover, in the $28 \mathrm{~S}$ rDNA tree the Arctic T. semisuberites and the Antarctic T. cf. semisuberites are not sisters. At the same time these phylogenies are unable to reconstruct the relationships between Tentorium spp. and other polymastiids, and therefore no alternative classification is proposed. Until more molecular data on a larger set of species become available, we recognize Tentorium as a valid genus, but emend its diagnosis proposed by Boury-Esnault (2002) so that all species currently allocated to Tentorium (Van Soest et al., 2016) fit with it.

\section{Tentorium semisuberites (Schmidt, 1870)}

(Figure 34)

Original description: Thecophora semisuberites Schmidt, 1870, p. 50, pl. VI figure 2 .

\section{SYNONYMS AND CITATIONS}

Tecophora semisuberites (Fristedt, 1885, p. 17, 1887, p. 433). Thecophora elongata von Marenzeller, 1878, p. 368, pl. II figure 4 .

Thecophora ibla Thompson, 1873, p. 147, figure 24 (Verrill, 1874, p. 500, 505, pl. VIII figure 8; Whiteaves, 1874, p. 184). 
Thecophora semisuberites (Thompson, 1873, p. 147, figure 23; Whiteaves, 1874 , p. 184; von Marenzeller, 1878, p. 368; Vosmaer, 1882 , p. 30,1885 , p. 18, text-figure 9, pl. I figures 23 \& 24 and pl. III figures 22-26; Hansen, 1885, p. 8).

Tentorium semisuberites (Vosmaer, 1887, p. 329, pl. II figure 4 and pl. XXI figure 19; Ridley \& Dendy, 1887, p. 221; Lambe, 1896, p. 198, pl. III figures 2, 2a-c; Topsent, 1892, p. 132; Lambe, 1900, p. 25; Whiteaves, 1901, p. 14; Topsent, 1904, p. $124,252-253$; 1913 , p. 25,1928 , p. 151 , pl. VI, figure 10 ; Lundbeck, 1909, p. 452; Gorbunov, 1946, p. 37; Koltun, 1966, p. 85, text-figure 57, pl. XIX figures 4-8, pl. XXXI figure 12; Barthel \& Tendal, 1993, p. 88, figure 8; Boury-Esnault, 2002, p. 215, figure 12; Plotkin, 2004, p. 544, figures 1j \& 2j; Plotkin et al., 2012, p. 25, figure 1g).

TYPE MATERIAL

Holotype: ZMUC-DEM-396, Greenland, precise locality unknown.

\section{COMPARATIVE MATERIAL}

(see Online resource 1 for details)

Canada: Newfoundland and Labrador: ZIN RAS octs140, ZIN RAS octs142, ZIN RAS octs143 and ZIN RAS octs150 (four specimens).

Greenland: South-East Coast: ZIN RAS octs101, ZIN RAS octs138, ZIN RAS octs197, ZIN RAS octs199 and ZIN RAS octs201 (six specimens), East Coast: ZIN RAS octso92, ZIN RAS octs173 and ZIN RAS octs176 (six specimens), North-East Coast: ZIN RAS octs174 (one specimen).

Icelandic Coast and Iceland Sea: ZIN RAS octso88, ZIN RAS octs132, ZIN RAS octs141, ZIN RAS octs151 and ZIN RAS octs193 (27 specimens).

Denmark Strait: ZIN RAS octs139 (four specimens).

North-East Atlantic, offshore: ZIN RAS octs146, ZIN RAS octs147, ZIN RAS octs148 and ZIN RAS octs20o (four specimens).

Greenland Sea, offshore: ZIN RAS octso9o, ZIN RAS octso91, ZIN RAS octso93, ZIN RAS octso94, ZIN RAS octso95, ZIN RAS octso96, ZIN RAS octs175, ZIN RAS octs178, ZIN RAS octs179, ZIN RAS octs18o, ZIN RAS octs181, ZIN RAS octs182, ZIN RAS octs204, ZIN RAS octs209 and ZIN RAS octs216 (26 specimens).

Norwegian Sea, offshore: NTNU-VM-72502, NTNUVM-72512, NTNU-VM-72526, ZIN RAS octso23, ZIN RAS octso34, ZIN RAS octso67, ZIN RAS octso68, ZIN RAS octso87, ZIN RAS octs104, ZIN RAS octs105, ZIN RAS octs126, ZIN RAS octs152, ZIN RAS octs161 and ZIN RAS octs203 (69 specimens).

Barents Sea, offshore: 141 specimens deposited in ZIN RAS. Norway: Hordaland: ZMBN 098099 (one specimen), Møre and Romsdal: ZMBN 107492 (one specimen), NordTrøndelag: NTNU-VM-72539 and NTNU-VM-72547 (two specimens), Nordland: NTNU-VM-72517 (one specimen), Troms: NTNU-VM-72531 (one specimen), Svalbard: ZIN RAS octso84, ZIN RAS octso99, ZIN RAS octs106 and ZMBN 098054 (17 specimens).

Russia: Murman Coast: ZIN RAS octso54, ZIN RAS octso58, ZIN RAS octs10o, ZIN RAS octs130, ZIN RAS octs135, ZIN RAS octs156, ZIN RAS octs157, ZIN RAS octs158, ZIN RAS octs159, ZIN RAS octs191, ZIN RAS octs194 and ZIN RAS octs211 (51 specimens), Kanin Peninsula: ZIN RAS octso53 (six specimens), Pechora Sea: ZIN RAS octso28 (five specimens), Franz Josef Land: ZIN RAS octso14, ZIN RAS octs113, ZIN RAS octs122, ZIN RAS octs145, ZIN RAS octs153, ZIN RAS octs188 and ZIN RAS octs189 (21 specimens), Novaya Zemlya: ZIN RAS octsoo1, ZIN RAS octsoo6 and ZIN RAS octs206 (four specimens), Taymyr Peninsula: ZIN RAS octso79 and ZIN RAS octs215 (four specimens), Nordenskjold Archipelago: ZIN RAS octso89, ZIN RAS octs123, ZIN RAS octs124 and ZIN RAS octs214 (92 specimens), Severnaya Zemlya: ZIN RAS octso11, ZIN RAS octso13, ZIN RAS octso15, ZIN RAS octso16, ZIN RAS octso82, ZIN RAS octs108, ZIN RAS octs109, ZIN RAS octs115, ZIN RAS octs116 and ZIN RAS octs117 (144 specimens).

Kara Sea: ZIN RAS octsoo2, ZIN RAS octsoo3, ZIN RAS octsoo4, ZIN RAS octsoo8, ZIN RAS octsoo9, ZIN RAS octso85, ZIN RAS octs102, ZIN RAS octs103, ZIN RAS octs154, ZIN RAS octs198, ZIN RAS octs205, ZIN RAS octs207, ZIN RAS octs208, ZIN RAS octs210, ZIN RAS octs213 and ZIN RAS octs219 (43 specimens).

Laptev Sea: ZIN RAS octsoo7 and ZIN RAS octs110 (three specimens).

East Siberian Sea: ZIN RAS octso86, ZIN RAS octso98, ZIN RAS octs171 and ZIN RAS octs172 (27 specimens).

Arctic Ocean, offshore: ZIN RAS octso81, ZIN RAS octso97, ZIN RAS octs107, ZIN RAS octs111, ZIN RAS octs112, ZIN RAS octs128, ZIN RAS octs149, ZIN RAS octs177, ZIN RAS
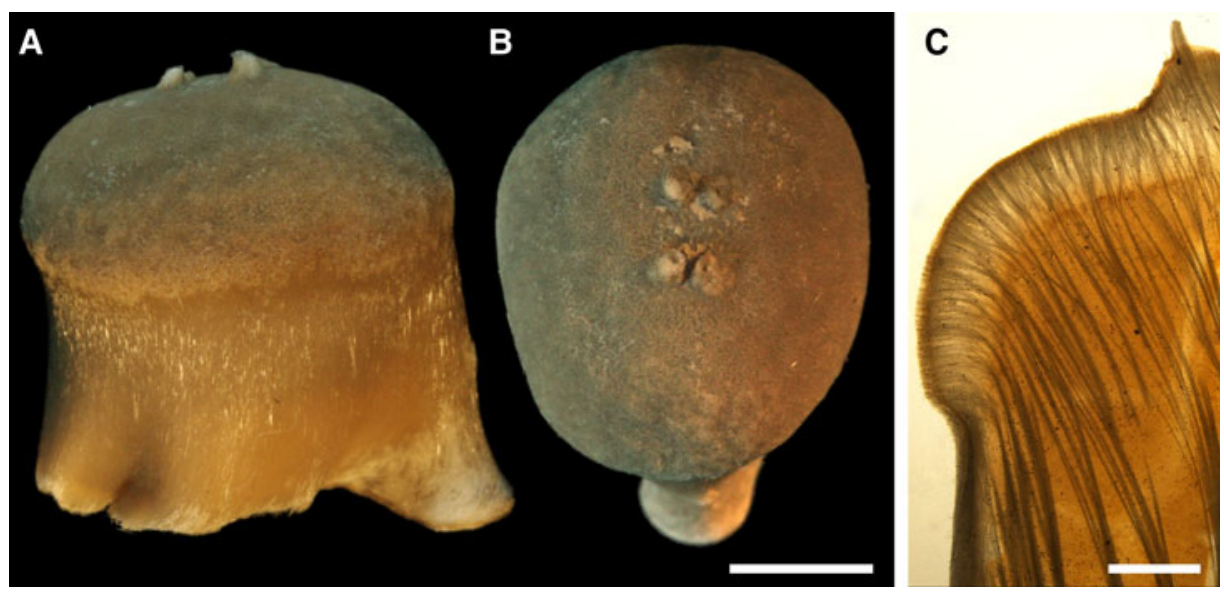

Fig. 34. Tentorium semisuberites: (A) holotype ZMUC-DEM-396, habitus, side view; (B) the same, view from above; (C) ZIN RAS octso59, longitudinal section through the body. Scale bars: A-B, $0.5 \mathrm{~cm} ; \mathrm{C}, 2 \mathrm{~mm}$. 
octs184, ZIN RAS octs185, ZIN RAS octs186, ZIN RAS octs187 and ZIN RAS octs19o (69 specimens).

\section{DESCRIPTION}

\section{External morphology}

Holotype fungiform, $\sim 16 \mathrm{~mm}$ high and $13-15 \mathrm{~mm}$ in diameter, removed from the substrate (Figure $34 \mathrm{~A}, \mathrm{~B}$ ). Lateral surface smooth, pale beige (Figure $34 \mathrm{~A}$ ). Upper surface minutely hispid, beige, with four small exhalant papillae at the summit (Figure 34B). Other sponges columnar, fungiform, occasionally drum-shaped, up to $35 \mathrm{~mm}$ high and $30 \mathrm{~mm}$ in diameter, with distinct difference between the smooth, palely coloured lateral surface and the more or less hispid, phaeochrous upper surface bearing one to 20 exhalant papillae. In some individuals the papillae considerably stretched, thread like, with the length exceeding the height of the main body by several times. When growing on soft sediments, the sponges often form long root-like structures made of spicule bundles.

\section{Anatomy}

Choanosome in life pale orange, pale yellow or light brown, dense. Main choanosomal skeleton composed of longitudinal tracts $(430-1000 \mu \mathrm{m}$ thick) of principal spicules running from the base, branching and entering the cortex (Figure $34 \mathrm{C}$ ). Some tracts ascend to the papilla walls. No auxiliary choanosomal skeleton observed. Cortex in life whitish or light beige, firm, not detachable. Skeleton of the lateral cortex $(500-780 \mu \mathrm{m}$ thick) is a dense layer of criss-crossed intermediary spicules. Skeleton of the upper cortex (1000$1600 \mu \mathrm{m}$ thick) comprises radiating tracts of principal spicules ascending from the choanosome perpendicular to the surface and a superficial palisade $(450-650 \mu \mathrm{m}$ thick) of small spicules.

\section{Spicules}

(Measurements based on 15 individuals)
Principal spicules - subtylostyles to tylostyles, usually straight and slender. Length 956-1642-2400 $\mu \mathrm{m}$, maximum diameter of shaft $13.2-20.8-25.2 \mu \mathrm{m}, \mathrm{N}=450$.

Intermediary spicules - tylostyles, straight, fusiform. Length 810-955-1138 $\mu \mathrm{m}$, maximum diameter of shaft 20.5$24.7-31.2 \mu \mathrm{m}, \mathrm{N}=450$.

Small spicules - tylostyles, straight, fusiform. Length 274467-670 $\mu \mathrm{m}$, maximum diameter of shaft 12.8-16.8$19.8 \mu \mathrm{m}, \mathrm{N}=450$.

\section{Genetic data}

In the $\mathrm{CO}_{1}$ phylogeny Tentorium semisuberites is the sister to the clade of Spinularia spp., but in the $28 \mathrm{~S}$ rDNA it has no close relations (Plotkin et al., 2016b). At the same time T. semisuberites possesses just one autapomorphy in $\mathrm{CO}_{1}$ distinguishing it from all other polymastiids (Online resource 2, p. 5). Moreover, an intraspecific polymorphism in both genes is observed in this species. The two individuals, from which the data were obtained, differ by two bps in $\mathrm{CO}_{1}$ (Matrix $\mathrm{M}_{34248}$ in TreeBase) and four bps in $28 \mathrm{~S}$ rDNA (Matrix M34250 in TreeBase).

\section{OCCURRENCE}

(Figure 35)

Literature data (only the localities distinct from our data are given): US Atlantic Coast: Gulf of Maine (Verrill, 1874). Canadian Atlantic Coast: Nova Scotia (1458 m) (Topsent, 1928), Gulf of St. Lawrence (91-175 m) (as Thecophora semisuberites and T. ibla - Whiteaves, 1874; as Tentorium semisuberites - Lambe, 1896; Whiteaves, 1901). Davis Strait (273 m) (Lambe, 1900; Whiteaves, 1901). West Greenland: Uummannaq Fjord (211-746 m) (Fristedt, 1887). North Atlantic: Azores (200-3018 m) (Topsent, 1892, 1904, 1928), Bay of Biscay (248 m) (Topsent, 1892).

Our data (agree with most literature data): Canadian Atlantic Coast: Newfoundland and Labrador $(208-375 \mathrm{~m})$. Greenland: South-East Coast $(180-400 \mathrm{~m})$, East Coast $(56-165 \mathrm{~m})$, North-East Coast $(83 \mathrm{~m})$. Icelandic Coast and Iceland Sea

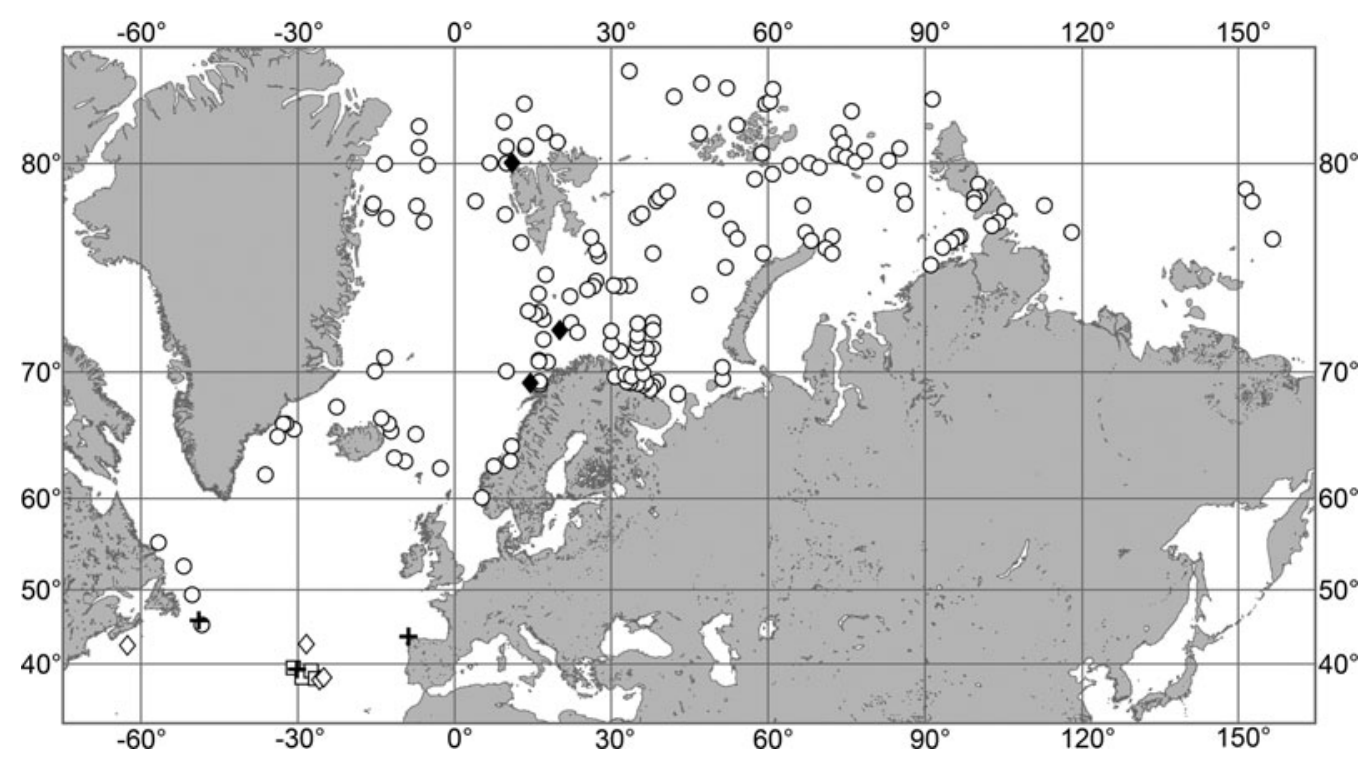

Fig. 35. Tentorium semisuberites, distribution: black crosses, data from Topsent (1892); white squares, data from Topsent (1904); black diamonds, data from Topsent (1913); white diamonds, data from Topsent (1928); white circles, our data. Precise type locality is unknown. 
(165-1075 m). Denmark Strait (650 m). North-East Atlantic, offshore areas $(385-485 \mathrm{~m})$. Greenland Sea, offshore areas $(136-2800 \mathrm{~m})$. Norwegian Sea, offshore areas (180$1820 \mathrm{~m})$. Norwegian Coast: Hordaland (100-500 m), Møre and Romsdal (108-109 m), Nord-Trøndelag (40-400 m), Nordland $(360 \mathrm{~m})$, Troms $(200-220 \mathrm{~m})$. Barents Sea: Murman Coast (75-271 m), Kanin Peninsula (228 m), Pechora Sea $(64 \mathrm{~m})$, offshore areas $(66-395 \mathrm{~m})$. Svalbard $(81-550 \mathrm{~m})$. Franz Josef Land $(124-285 \mathrm{~m})$, Novaya Zemlya (307-368 m), Taymyr Peninsula (53 m), Nordenskjold Archipelago (53-82 m), Severnaya Zemlya (43-257 m). Kara Sea $(41-580 \mathrm{~m})$. Laptev Sea $(86-459 \mathrm{~m})$ East Siberian Sea $(65-81 \mathrm{~m})$. Arctic Ocean, offshore areas $(165-2899 \mathrm{~m})$

\section{DISCUSSION}

Taxonomic identification of Tentorium semisuberites usually causes no difficulties. Thecophora ibla Thomson, 1873 and Thecophora elongata von Marenzeller, 1878 represent in fact just varieties of body shapes in T. semisuberites. Meanwhile, the phylogenetic relationships of $T$. semisuberites are unresolved (see Genetic data for this species and Discussion on the genus Tentorium above).

\section{Genus Weberella Vosmaer, 1885}

Original description: Weberella Vosmaer, 1885 , p. 16, textfigures $6 \& 8$, pl. III figures $16-19$

\section{TYPE SPECIES}

Alcyonium bursa Müller, 1806 (by original designation).

\section{DIAGNOSIS}

Polymastiidae of massive or globular body shape, with a smooth surface always bearing papillae. Spicule assortment restricted to two size categories of smooth monactines. Main choanosomal skeleton is a reticulation formed by tracts of principal monactines. Auxiliary choanosomal skeleton comprises free-scattered small monactines. Cortical skeleton composed of a palisade of small tylostyles or subtylostyles and an internal layer of criss-cross principal monactines separated by a middle layer with aquiferous cavities.

\section{DISCUSSION}

Weberella is morphologically well-defined, but the relationships between Weberella spp. are unclear because for the moment the genetic data are only available from the type species, $W$. bursa.

\section{Weberella bursa (Müller, 1806)}

(Figure 36)

Original description: Alcyonium bursa Müller, 1806, p. 43, pl CLVIII figures $1 \& 2$.

\section{SYNONYMS AND CITATIONS}

Polymastia bursa (Koltun, 1964, p. 149, 1966, p. 76, textfigure 49 , pl. IX figure 2; pl. XXIII figure 1-2, pl. XXIV figures 1 \& 2).

Polymastia uberrima (Burton, 1959a: 12 pars.).

Weberella bursa (Vosmaer, 1885, p. 16, text-figures $6 \& 8$, pl III figures $16-19,1887$, p. 329 pl. XXVI figure 10; Topsent, 1928, p. 149, pl. II, figure 19; Boury-Esnault et al., 1994, p.
76, figure 51, 2002, p. 214, figure 11; Plotkin, 2004, p. 544,

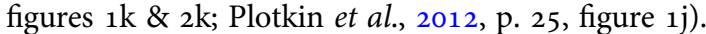

Non Polymastia bursa (von Lendenfeld, 1898, p. 117, pl. VI figure 79).

\section{TYPE MATERIAL}

Unknown.

\section{COMPARATIVE MATERIAL}

(see Online resource 1 for details)

Canada: Newfoundland: ZIN RAS ocwboo4 (one specimen), offshore areas of the NW Atlantic: ZIN RAS ocwbo1o (one specimen).

Greenland: SW Coast/Davis Strait: ZIN RAS ocwbo33 and ZIN RAS ocwbo35 (two specimens), SE Coast: ZIN RAS ocwboo3 and ZIN RAS ocwbo31 (two specimens).

Denmark Strait: ZIN RAS ocwbo25 (one specimen).

Iceland: ZIN RAS ocwboo5, ZIN RAS ocwbo15, ZIN RAS ocwbo18 and ZIN RAS ocwbo36 (four specimens).

Faroes: ZIN RAS ocwbo11 (one specimen).

Norwegian Sea, offshore: ZIN RAS ocwbo12 and ZIN RAS ocwbo2o (two specimens).

Barents Sea, offshore: ZIN RAS ocwboo1, ZIN RAS ocwboo2, ZIN RAS ocwboo6, ZIN RAS ocwboo7, ZIN RAS ocwboo8, ZIN RAS ocwboo9, ZIN RAS ocwbo13, ZIN RAS ocwbo16, ZIN RAS ocwbo19, ZIN RAS ocwbo21, ZIN RAS ocwbo23, ZIN RAS ocwbo26, ZIN RAS ocwbo27, ZIN RAS ocwbo28, ZIN RAS ocwbo29, ZIN RAS ocwbo3o and ZIN RAS ocwbo32 (17 specimens).

Norway: Sør-Trøndelag: NTNU-VM-56951 (one specimen), Nord-Trøndelag: NTNU-VM-54951 (one specimen), Nordland: NTNU-VM-72522 (one specimen), Troms: NTNU-VM-72532 and ZMBN 098072 (two specimens), Finnmark: NTNU-VM-72504 and ZIN RAS ocwbo24 (two specimens), Svalbard: ZIN RAS ocwbo22 and ZMBN 098051 (two specimens).

Russia: Franz Josef Land: ZIN RAS ocwbo17 (one specimen), Novaya Zemlya: ZIN RAS ocwbo14 and ZIN RAS ocwbo34 (two specimens).

\section{DESCRIPTION}

External morphology

Massive, fist-shape, or occasionally globular sponges occupying up to $100 \mathrm{~cm}^{2}$ of the substrate (Figure $36 \mathrm{~A}, \mathrm{~B}$ ). Surface smooth, white or pale cream both in life and alcohol, with up to 200 papillae, all with oscula at the summits. The papillae conical, 2-8 $\mathrm{mm}$ long, up to $8 \mathrm{~mm}$ wide at base and $2 \mathrm{~mm}$ wide at summit.

\section{Anatomy}

Choanosome crumbly, pale yellow in life, but becoming slightly darker in alcohol. Main choanosomal skeleton composed of reticulating tracts $(47-254 \mu \mathrm{m}$ thick) of principal spicules (Figure 36C). Some tracts ascend to the cortex and the papillae. Auxiliary choanosomal skeleton comprises freescattered small spicules. Cortex both in life and alcohol whitish, firm, but detachable. Cortical skeleton includes a superficial palisade $(246-337 \mu \mathrm{m}$ thick) composed of tufts of small spicules, a middle layer (513-1011 $\mu \mathrm{m}$ thick) with aquiferous cavities separated by the ascending and radiating choanosomal tracts and an internal layer $(100-233 \mu \mathrm{m}$ thick) of obliquely lying small spicules (Figure $36 \mathrm{D}$ ). The cortical palisade and the internal layer stretch to the papillae 

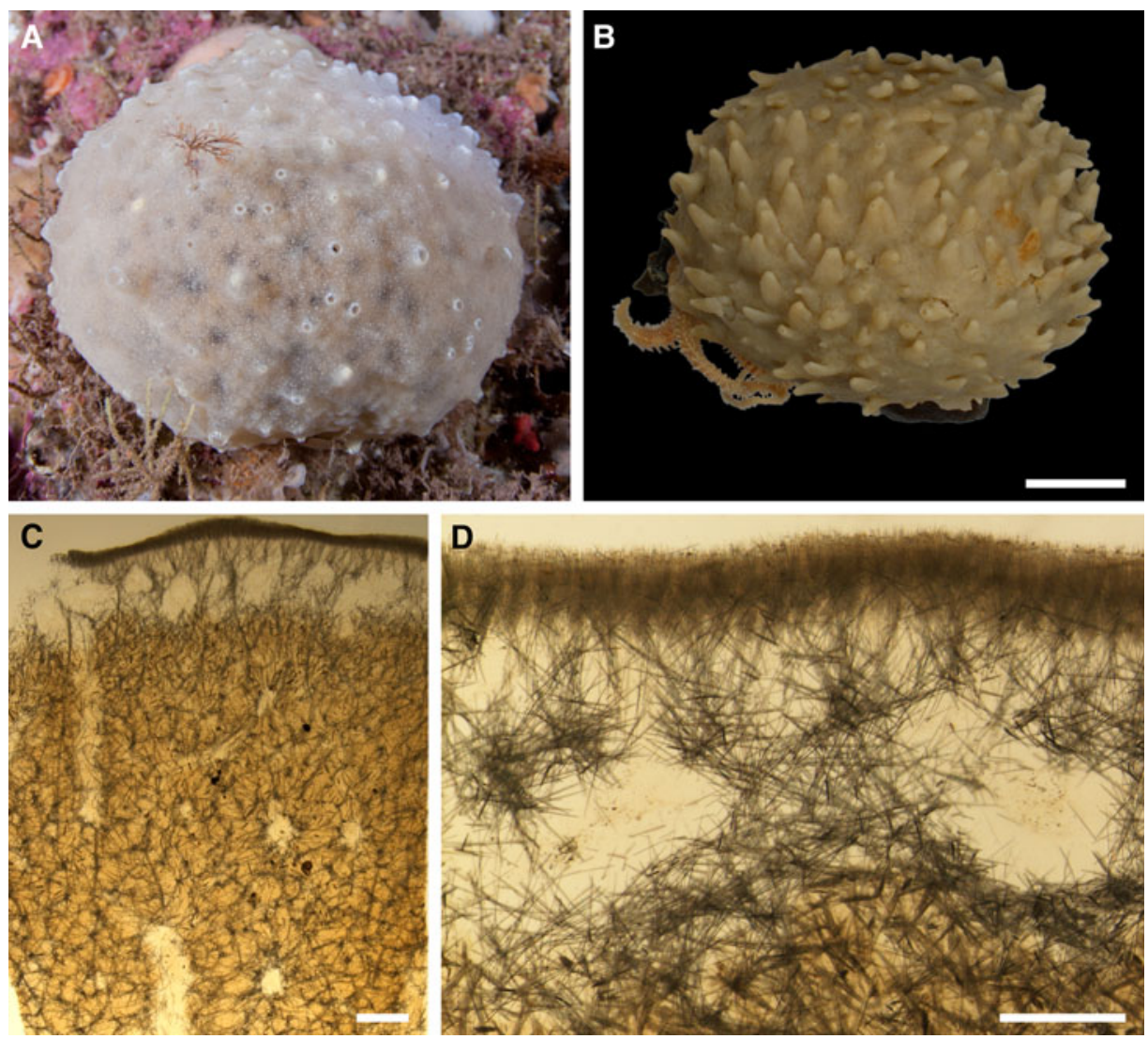

Fig. 36. Weberella bursa: (A) ZMBN 098051 in situ, Hinlopenstretet, Svalbard, Norway (courtesy P. Leopold, University of Tromsø); (B) ZIN RAS ocwbo16, habitus; (C) the same, longitudinal section through the body, general view; (D) the same section, detail of cortex. Scale bars: $\mathrm{B}, 2 \mathrm{~cm}$; $\mathrm{C}, 1 \mathrm{~mm}$; $\mathrm{D}$, o.5 mm.

walls. Each papilla has a large central exhalant canal and numerous small inhalant canals in the periphery. Bulkheads separating the canals reinforced with the ascending tracts of principal spicules and free-scattered small spicules.

\section{Spicules}

(Measurements based on 12 individuals)

Principal spicules - subtylostyles, occasionally styles, usually straight and slender. Length $407-538-700 \mu \mathrm{m}$, diameter of tyle 8.8-11.0-13.0 $\mu \mathrm{m}$, proximal diameter of shaft 7.49.6-12.5 $\mu \mathrm{m}$, maximum diameter of shaft 8.8-11.0-12.6, $\mathrm{N}=360$.

Small spicules - tylostyles, occasionally subtylostyles, usually straight and slender. Length $90-201-273 \mu \mathrm{m}$, diameter of tyle 2.5-4.8-7.7 $\mu \mathrm{m}$, proximal diameter of shaft 1.9-3.3$5.0 \mu \mathrm{m}$, maximum diameter of shaft $1.9-3.6-5.3, \mathrm{~N}=360$.

\section{Genetic data}

Two individuals of Weberella bursa, from which the genetic data were obtained, differ neither by $\mathrm{CO}_{1}$, nor by $28 \mathrm{~S}$ rDNA. In the phylogenies based on these genes $W$. bursa is the sister to morphologically quite distinct Polymastia cf. conigera (a British species not covered by the present study), although the Bayesian support for this relationship is weak (Plotkin et al., 2016b). These species share two unique synapomorphies in $\mathrm{CO}_{1}$ (Online resource 2, p. 3, Matrix M34248 in TreeBase) and three synapomorphies in $28 \mathrm{~S} \mathrm{rDNA}$, of which one is unique and two are also shared by Sphaerotylus borealis (Online resource 3, p. 3, Matrix M34250 in TreeBase). The difference between $W$. bursa and $P$. cf. conigera is 13 bps in CO1
(Matrix M34248 in TreeBase) and five bps in $28 \mathrm{~S}$ rDNA (Matrix M34250 in TreeBase). The distinctions between $W$. bursa and $S$. borealis are described in the Genetic data section for the latter species.

\section{OCCURRENCE}

(Figure 37)

Literature data: North-East Atlantic: North off Azores (150$932 \mathrm{~m}$ ) (Topsent, 1928), West off Strait of Gibraltar (133$137 \mathrm{~m}$ ) (Boury-Esnault et al., 1994). Norwegian and Barents Sea: off Finnmark Coast in Norway (255-282 m) (Vosmaer, 1885). Norwegian and Barents Sea (elsewhere), Svalbard $(62-485$ m) (Koltun, 1964, 1966).

Our data: Canadian Atlantic Coast: Newfoundland (415 m), offshore areas (410-430 m). Davis Strait (75-195 m). South Greenland $(184-300 \mathrm{~m})$. Denmark Strait $(348 \mathrm{~m})$. Iceland (125-490 m). Faroes $(525 \mathrm{~m})$. Norwegian Sea, offshore areas $(500-525 \mathrm{~m})$. Barents Sea, offshore areas $(130-$ $250 \mathrm{~m})$. Norwegian Coast: Sør-Trøndelag (50-200 m), Nord-Trøndelag (30-100 m), Nordland (750-800 m), Troms: $(16-220 \mathrm{~m})$, Finnmark: $(200-260 \mathrm{~m})$. Svalbard $(40-215 \mathrm{~m})$. Franz Josef Land $(246 \mathrm{~m})$. Novaya Zemlya $(110-133 \mathrm{~m})$.

\section{DISCUSSION}

Weberella bursa exhibits some external similarities with Polymastia thielei and P. uberrima, but is distinguished from these two by the reticulate choanosomal skeleton, the presence of only two size categories of spicules and some other features (see more in Discussions on P. thielei and P. uberrima). These 


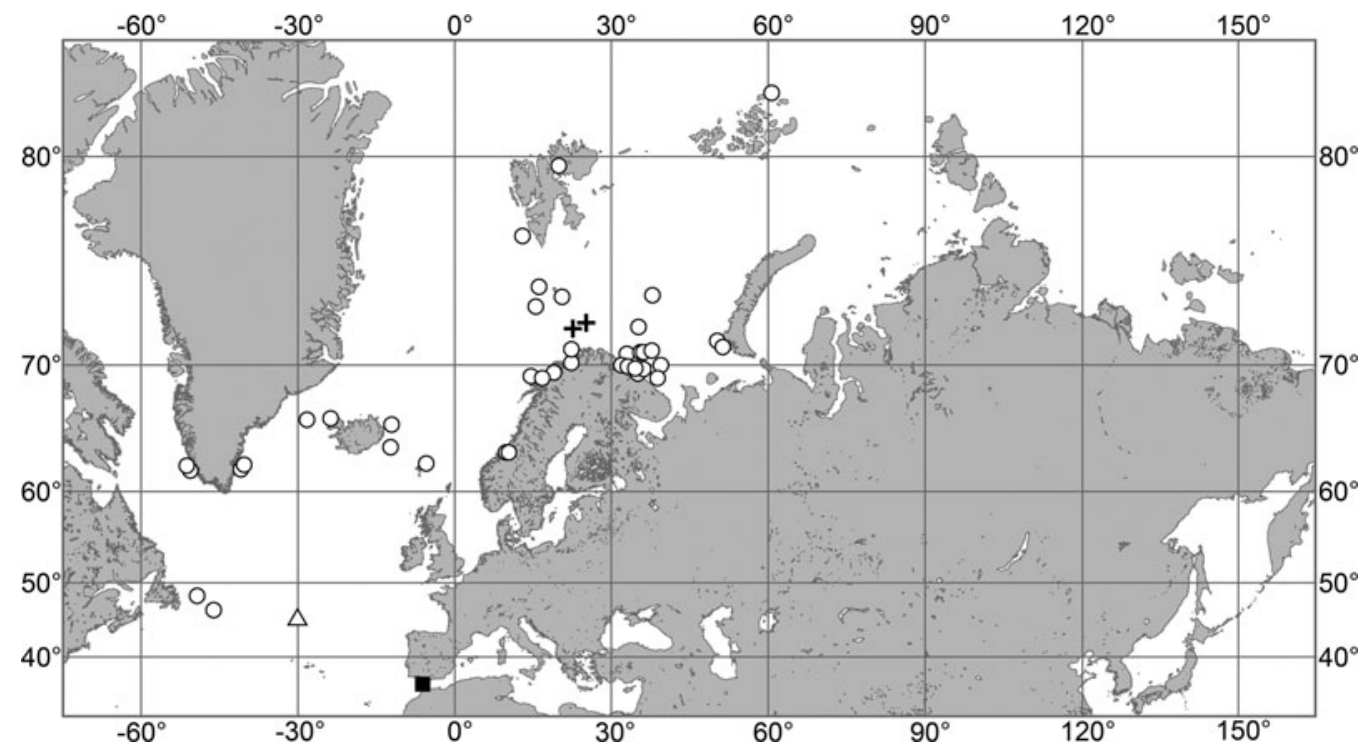

Fig. 37. Weberella bursa, distribution: black square, data from Boury-Esnault et al. (1994); white triangle, data from Topsent (1928); black crosses, data from Vosmaer (1885); white circles, our data. Type locality is unknown.

morphological differences are confirmed by the molecular phylogenies. At the same time the sister relationships between $W$. bursa and Polymastia cf. conigera as well as the sister relationships between this pair and $S$. borealis revealed in the molecular phylogenies, but insufficiently supported, need more studies on a larger set of species.

Koltun $(1964,1966)$ put Weberella in synonymy with Polymastia, that was not accepted further (Boury-Esnault, 2002). Polymastia bursa (Müller, 1806) sensu Koltun should not be mixed with Polymastia bursa (Schmidt, 1862) sensu von Lendenfeld (1898). The latter is taxon inquirendum originally described as Suberites bursa Schmidt, 1862 from the Adriatic Sea (see Van Soest et al., 2016).

\section{CONCLUDING REMARKS}

\section{Diversity of species}

Altogether 20 species from six polymastiid genera were recorded in the Nordic and Siberian Seas (Table 8). Of these two species, Polymastia svenseni and Spinularia njordi, are new to science, one species, Polymastia andrica, is new to the Nordic Seas and two species, $P$. cf. bartletti and $P$. penicillus, are new to the Scandinavian Coast. The sponge from Western Norway herein identified as Polymastia sp. may potentially be another new species, but more material is required to check this. The new findings listed above were mainly done based on molecular data. Polymastia svenseni and $S$. njordi are distinguished by genetic autapomorphies, but exhibit no clear morphological autapomorphies. Polymastia cf. bartletti is morphologically very similar to $P$. nivea and therefore these species can be separated only based on their considerable genetic distinctions. Polymastia andrica exhibits just one clear morphological distinction, the presence of exotyles, and several distinctions in $\mathrm{CO}_{1}$ from the sibling species $P$. arctica, although the relationship between these two needs more studies taking into account the intragenomic polymorphism of their $28 \mathrm{~S}$ rDNA, which probably may indicate a gene flow through hybridization between these species (Plotkin et al., 2016b). Polymastia penicillus was identified based on its both morphological and genetic distinctions from the congeners. Polymastia sp. is morphologically very similar to $P$. andrica, but considerably differs from the latter by both $\mathrm{CO}_{1}$ and $28 \mathrm{~S}$ rDNA. Moreover, based on the $28 \mathrm{~S}$ rDNA phylogeny Polymastia sp. is a sibling of morphologically distinct $P$. svenseni.

In addition to the species described in our study, one more polymastiid was recorded in the Nordic Seas - Polymastia paupera Fristedt, 1887 found east off South Greenland. However, Boury-Esnault (1987) suggested that this was a suberitid. We agree with her opinion after examining the holotype of this species (Swedish Museum of Natural History, Stockholm, Type-1207). It is a sponge piece without papillae. The skeleton is made of tylostyles with lobate tyles (one size category) located obliquely to the surface. Cortex is not differentiated. None of these traits are found in the polymastiids.

\section{PATTERNS OF DISTRIBUTION}

Of all the species studied, 10 species, Polymastia andrica, $P$. grimaldii, $P$. hemisphaerica, $P$. thielei, $P$. uberrima, Quasillina brevis, Sphaerotylus capitatus, Spinularia sarsii, Tentorium semisuberites and $W$. bursa, have an amphi-Atlantic boreoarctic distribution ranging from Nova Scotia, Newfoundland and Labrador at the Canadian Atlantic Coast and north-eastwards over the Nordic Seas and along the coasts of Greenland, Iceland, Scandinavia and Russia up to the Arctic Ocean and the Siberian Seas (Table 8). In the south-western parts of this area the occurrence of these species is usually limited to the depths below $100-200 \mathrm{~m}$, while in the north-east most of them spread to shallow waters (Figure 38). The distribution of two species, $P$. hemisphaerica and S. sarsii, is limited to the deep-sea (to $150 \mathrm{~m}$ for the former species and to $300 \mathrm{~m}$ for the latter) in all regions. The prevalence of the amphi-Atlantic boreoarctic species in the Nordic and Arctic faunas was earlier demonstrated on several demosponge genera, e.g. Geodia Lamarck, 1815 from the family Geodiidae Gray, 1867 (Cárdenas et al., 
Table 8. Geographic distribution of Polymastiidae in the Nordic and Siberian Seas. + our and literature data, $x$ only literature data. Numeration of species: 1 - Polymastia andrica, 2 - Polymastia arctica, 3 - Polymastia cf. bartletti, 4 - Polymastia boletiformis, 5 - Polymastia grimaldii, 6 Polymastia hemisphaerica, 7 - Polymastia mamillaris, 8 - Polymastia nivea, 9 - Polymastia penicillus, 10 - Polymastia svenseni, 11 - Polymastia thielei, 12 - Polymastia uberrima, 13 - Polymastia sp., 14 - Quasillina brevis, 15 - Sphaerotylus borealis, 16 - Sphaerotylus capitatus, 17 Spinularia njordi, 18 - Spinularia sarsii, 19 - Spinularia spinularia, 20 - Tentorium semisuberites, 21 - Weberella bursa.

\begin{tabular}{|c|c|c|c|c|c|c|c|c|c|c|c|c|c|c|c|c|c|c|c|c|c|}
\hline \multirow[b]{2}{*}{ Region } & \multicolumn{21}{|c|}{ Species } \\
\hline & $\mathbf{1}$ & 2 & 3 & 4 & 5 & 6 & 7 & 8 & 9 & 10 & 11 & 12 & 13 & 14 & 15 & 16 & 17 & 18 & 19 & 20 & 21 \\
\hline Greenland Sea, offshore & & & & & & & & & & & + & & & & & & & + & & + & \\
\hline Greenland & & & & & + & + & & & & & & + & & $\mathrm{x}$ & & + & & + & $\mathrm{x}$ & + & + \\
\hline Denmark Strait & & & & & + & & & & & & + & & & + & & & & & & + & + \\
\hline Icelandic Coast and Iceland Sea & & & & & + & + & & & & & + & + & & $\mathrm{x}$ & + & & & & & + & + \\
\hline Faroes & & & & & & & & & & & + & & & $\mathrm{x}$ & & & & & & & + \\
\hline NE Atlantic, offshore & & & & & & & & & & & & + & & + & & & & & & + & \\
\hline Norwegian Sea, offshore & + & & & & + & + & & & & & + & + & & + & + & + & + & + & + & + & + \\
\hline Barents Sea, offshore & & & & & + & + & & + & & & + & + & & + & + & + & & $\mathrm{x}$ & & + & + \\
\hline Swedish Western Coast & & & + & + & & & + & & + & & & & & $\mathrm{x}$ & & + & & & + & & \\
\hline \multicolumn{22}{|c|}{ Norwegian Coast and offshore islands } \\
\hline Aust-Agder & & & & & & & & & & & & & & & & & & + & & & \\
\hline Vest-Agder & & & & + & & & + & + & & & & & & + & & & & & & & \\
\hline Rogaland & & & & & & & & & & + & & & & + & & & & & $\mathrm{x}$ & & \\
\hline Hordaland & + & & & + & & + & + & + & & & & & + & $\mathrm{x}$ & & + & & & + & + & \\
\hline Sogn og Fjordane & & & & & & & & & & & & & & + & & & & & + & & \\
\hline Møre og Romsdal & & & & + & & + & & + & & & + & & & + & & + & & & + & + & \\
\hline Sør-Trøndelag & & + & & & & & & + & & & & & & $\mathrm{x}$ & & + & & & + & & + \\
\hline Nord-Trøndelag & & & & & & + & & & & & + & & & + & & + & & & + & + & + \\
\hline Nordland & + & & & & & + & & + & & & + & + & & + & & + & & & & + & + \\
\hline Troms & + & $\mathrm{x}$ & & & + & & & & & & + & + & & $\mathrm{x}$ & & + & & & & + & + \\
\hline Finnmark & + & + & & & + & & & + & & & + & + & & + & & + & & & & & + \\
\hline Svalbard & + & & & & + & & & & & & + & + & & + & & + & & & & + & + \\
\hline \multicolumn{22}{|l|}{ Russian coasts and offshore islands } \\
\hline Murman Coast & & + & & & + & & & + & & & + & + & & + & + & + & & & & + & \\
\hline White Sea & & + & & & + & & & + & & & & + & & & + & & & & & & \\
\hline Kanin Peninsula & & & & & + & & & & & & & & & & & & & & & + & \\
\hline Chyosha Bay & & + & & & & & & & & & & & & & & & & & & & \\
\hline Pechora Sea & & & & & & & & & & & & & & & & & & & & + & \\
\hline Franz Josef Land & & & & & & & & & & & + & + & & & & & & & & + & + \\
\hline Novaya Zemlya & & & & & + & + & & & & & + & & & + & & & & & & + & + \\
\hline Taymyr Peninsula & & & & & + & & & & & & + & & & & & & & & & + & \\
\hline Norden-skjold & & & & & & & & & & & + & & & & & & & & & + & \\
\hline Severnaya Zemlya & & & & & + & & & & & & & + & & & + & & & & & + & \\
\hline Kara Sea & & & & & + & + & & & & & + & & & & & & & $\mathrm{x}$ & & + & \\
\hline Laptev Sea & & & & & + & & & & & & & & & & & & & $\mathrm{x}$ & & + & \\
\hline East-Siberian Sea & & & & & + & & & & & & & & & & & & & & & + & \\
\hline Arctic Ocean, offshore & & & & & + & & & & & & + & + & & + & + & & & & & + & \\
\hline
\end{tabular}

2013) and Thenea Gray, 1867 (Cárdenas \& Rapp, 2012) from Theneidae Carter, 1883, and on hexactinellids, e.g. Asconema Kent, 1870 from Rossellidae Schulze, 1885 (Tabachnick \& Menshenina, 2007).

Meanwhile, it is still unclear how far southwards in the central North Atlantic and along the European and African coasts the amphi-Atlantic boreoarctic polymastiids may be found. The records of Q. brevis and W. bursa from Azores (Topsent, 1892, 1928), the entrance to the Gibraltar Strait and the Mediterranean Sea (Uriz \& Rosell, 1990; BouryEsnault et al., 1994) as well as the records of T. semisuberites from Azores (Topsent, 1892, 1904, 1928) and the Bay of Biscay (Topsent, 1892) need verification with molecular data. The allegedly cosmopolitan distribution of $S$. sarsii is already questioned based on the observed genetic differences between the Norwegian and Mozambican sponges, but a thorough comparison between the Norwegian, Azorean and NW African individuals is still required.
The distribution of other polymastiid species studied is narrower (Table 8). Four species, Polymastia arctica, $P$. nivea, Sphaerotylus borealis and Spinularia spinularia may be regarded as NE Atlantic high-boreoarctic. The known occurrence of Sphaerotylus borealis is limited to Iceland in the south-west and the eastern Kara Sea in the north-east. The distribution of Polymastia arctica and $P$. nivea is limited to the Norwegian Coast and Russian Coast of the Barents and White Sea. The former species has never been recorded to the south-west from Central Norway (Sør-Trøndelag), while the latter has been found up to Southern Norway (Vest-Agder). Spinularia spinularia is widely distributed along the Scandinavian Coast, East Greenland Coast and around the British Isles, while its records from Azores (Topsent, 1898, 1904, 1928) are considered as a separate species, $S$. setosa, based on distinct differences in morphology. Atlantic high-boreoarctic species were earlier recorded among other demosponge families, e.g. 


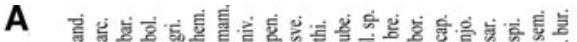

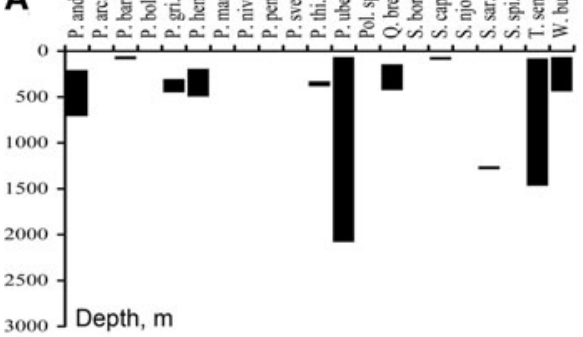

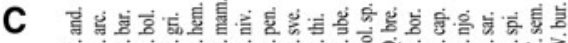

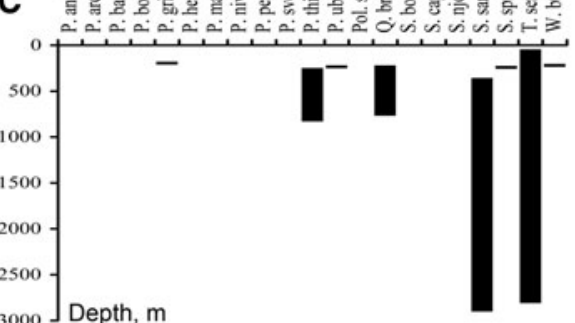

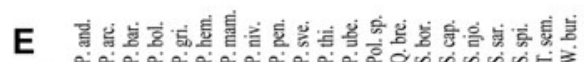

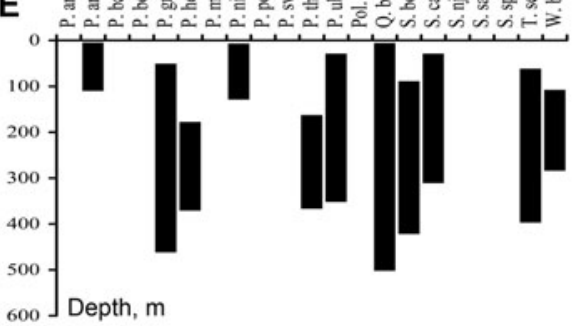

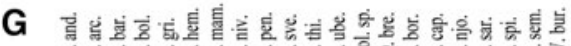

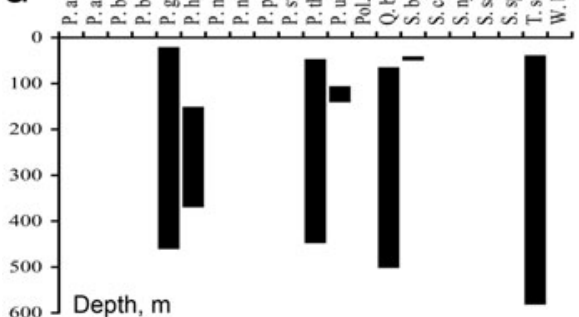

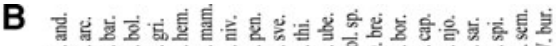

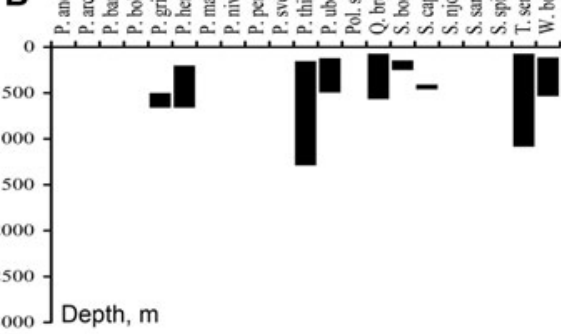

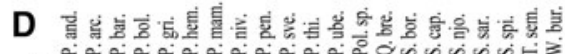

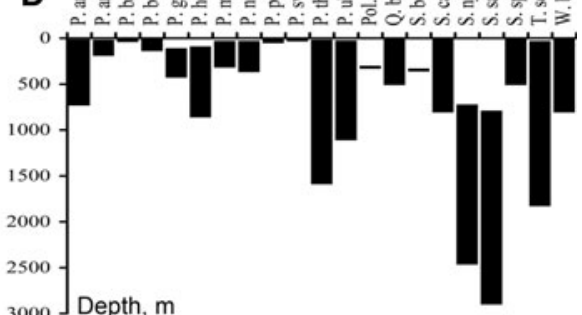

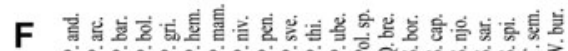

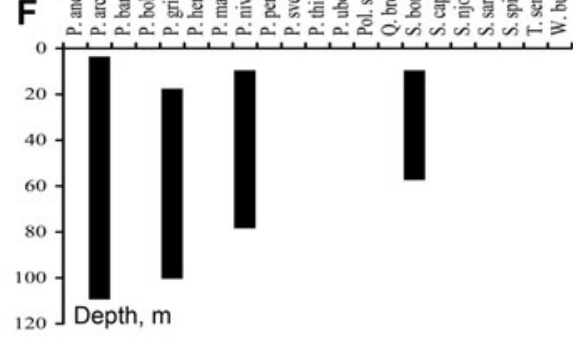

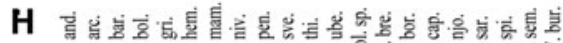

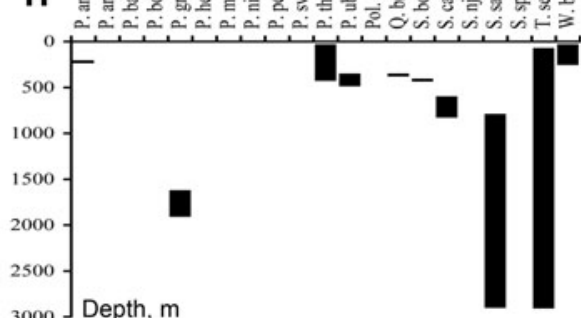

Fig. 38. Vertical distribution of Polymastiidae in the Nordic and Siberian Seas (our and literature data): (A) NW Atlantic (offshore areas, Canadian Coast and Davis Strait); (B) NE Atlantic (offshore areas), Southern Greenland Coast, Denmark Strait, Iceland Sea, Icelandic Coast and Faroes; (C) Greenland Sea (offshore areas and Eastern Greenland Coast); (D) Norwegian Sea (offshore areas) and Scandinavian Coast from Western Sweden to Northern Norway; (E) Barents Sea (offshore areas, archipelagos and Russian Coast); (F) White Sea; (G) Siberian Seas (offshore areas, archipelagos and Russian Coast); (H) Arctic Ocean. Labelling species: P. and., Polymastia andrica, P. arc., Polymastia arctica, P. bar., Polymastia bartletti and P. cf. bartletti, P. bol., Polymastia boletiformis, P. gri., Polymastia grimaldii, P. hem., Polymastia hemisphaerica, P. mam., Polymastia mamillaris, P. niv., Polymastia nivea, P. pen., Polymastia penicillus, P. sve., Polymastia svenseni, P. thi., Polymastia thielei, P. ube., Polymastia uberrima, Pol. sp., Polymastia sp., Q. bre., Quasillina brevis, S. bor., Sphaerotylus borealis, S. cap., Sphaerotylus capitatus, S. njo., Spinularia njordi, S. sar., Spinularia sarsii, S. spi., Spinularia spinularia, T. sem., Tentorium semisuberites, W. bur., Weberella bursa.

Geodia hentscheli Cárdenas et al., 2010 and G. parva Hansen, 1885 from Geodiidae (Cárdenas et al., 2013), Tetilla sibirica (Fristedt, 1887) from Tetillidae Sollas, 1886 (Koltun, 1966), and Thenea abyssorum Koltun, 1964 from Theneidae (Cárdenas \& Rapp, 2012). A few records of the sponge species distribution limited to the Arctic Ocean and Siberian Seas, e.g. demosponges Hemimycale rhodus (Hentschel, 1929), Cladorhiza arctica Koltun, 1959 and Pseudosuberites sadko Koltun, 1966, should be verified on the additional material. It seems that the Arctic sponge fauna is predominantly composed of the species dispersed from the Atlantic.

Two species studied, Polymastia boletiformis and P. penicillus, represent the southern boreal component in the Scandinavian sponge fauna. They are quite common in the shallow depths along the European coasts (Figure 38), with their northernmost records from Møre and Romsdal in Norway for P. boletiformis and the British Isles and the Swedish Western Coast for $P$. penicillus. The occurrence of the southern boreal species along the Scandinavian Coast was earlier recorded for other sponge families, e.g. a calcarean Clathrina coriacea (Montagu, 1814) from Clathrinidae Minchin, 1900 (Rapp, 2006), demosponges Characella pachastrelloides (Carter, 1876) and Poecillastra compressa (Bowerbank, 1866) from Pachastrellidae Carter, 1875 and Thenea muricata (Bowerbank, 1858) from Theneidae (Cárdenas \& Rapp, 2012).

Even though we have got numerous and well-documented records for most species studied, our knowledge of the distribution of other species is still poor. Particularly, more data on the rare species Polymastia bartletti and two new species, $P$. svenseni and Spinularia njordi, are required. The observed distribution patterns of the polymastiids in the area of study should therefore be considered as preliminary until more 
comprehensive material from adjacent waters can be included. It is recommended that further research on the biogeography of polymastiids should be based on an integrative approach including detailed morphological studies and analyses of a larger set of phylogenetic markers.

\section{SUPPLEMENTARY MATERIAL}

The supplementary material for this article can be found at https://doi.org/10.1017/So025315417000285

\section{ACKNDWLEDGEMENTS}

We would like to express our gratitude to all colleagues, who kindly provided the access to the sponge collections of their institutions: Jean-Marc Gagnon (Canadian Museum of Nature, Ottawa), Erica Mejlon (Museum of Evolution, University of Uppsala), Kennet Lundin and Carola Azurduy Högström (Gothenburg Natural History Museum), Michèle Bruni (Musée Océanographique de Monaco), Carsten Lüter (Museum für Naturkunde, Berlin), Isabelle Domart-Coulon (Muséum National d'Histoire Naturelle, Paris), Clare Valentine, Andrew Cabrinovic and Emma Sherlock (Natural History Museum, London), Nicole de Voogd and J. Koos van Egmond (Naturalis Biodiversity center, Leiden), Lutz Bachmann and Åse Ingvild Wilhelmsen (Natural History Museum, University of Oslo), Ole Secher Tendal (Natural History Museum of Denmark, University of Copenhagen), Bernard E. Picton (Ulster Museum, National Museums of Northern Ireland, Belfast), Jon Anders Kongsrud (University Museum of Bergen, Natural History Collections), Torkild Bakken (University Museum of the Norwegian University of Science and Technology, Trondheim), Olga Bozhenova (Zoological Institute of Russian Academy of Sciences, Saint-Petersburg). We are also thankful to Bjørn Gulliksen (University of Tromsø), Bjørn Tore Dragnes (OMNIMAR Dragnes, Troms $\varnothing$ ), Peter Leopold (University Centre in Svalbard) and Erling Svensen (OceanPhoto/Dalane Tidende AS, Egersund), who arranged the sampling of fresh material along the Norwegian Coast and on Svalbard and provided us with high-quality underwater images. The colleagues, who granted us fresh samples from other regions, are also greatly acknowledged: Christine Morrow (Department of Zoology, Ryan Institute, National University of Ireland, Galway) and Bernard E. Picton (Ulster Museum, National Museums of Northern Ireland, Belfast) for the samples and photos of sponges from the British Isles, Javier Cristobo and Pilar Rios (Spanish Institute of Oceanography, Madrid) for the samples from Mozambique, and Natalia Chervyakova (Moscow State University) for the material from the White Sea. Paco Cárdenas (BioMedical Centre, Uppsala) is acknowledged for the photos of sponges from Museum of Evolution, University of Uppsala. Thanks also come to Egil Severin Erichsen and Irene Heggstad (University of Bergen, Laboratory for Electron Microscopy) for their careful assistance at SEM, to Kenneth Meland, Solveig Thorkildsen and Louise Lindblom (University of Bergen, BioDiversity Laboratories at the Department of Biology) for their great assistance under the obtaining and treatment of molecular data and to Endre Willassen (University Museum of Bergen, Natural History Collections) and Oliver Voigt
(Ludwig-Maximilians-Universität München, Palaeontology and Geobiology) for their inestimable help with the phylogenetic computing. Last but not least, we would like to thank the two reviewers for the great work they have done when reading our manuscript.

\section{FINANCIAL SUPPDRT}

This study was supported by the Norwegian Biodiversity Information Centre, Artsdatabanken (project No. 70184219), the Norwegian Academy of Science and Letters (grant to HTR), the Research Council of Norway (through contract No. 179560) and the European Union's Horizon 2020 research and innovation programme under grant agreement No. 679849 (the SponGES project). The visit of AP to the Natural History Museum (London) in 2010 received funding from the SYNTHESYS Project (http://www. synthesys.info/) financed by European Community Research Infrastructure Action under the $\mathrm{FP}_{7}$ Integrating Activities Programme.

\section{REFERENCES}

Alander H. (1942) Sponges from the Swedish west-coast and adjacent waters. PhD thesis. Lund University. Göteborg: Henrik Struves.

Alex A., Silva V., Vasconcelos V. and Antunes A. (2013) Evidence of unique and generalist microbes in distantly related sympatric intertidal marine sponges (Porifera: Demospongiae). PLoS ONE 8, e80653. doi: 10.1371/journal.pone.0080653.

Anisimova N.A., Jørgensen L.L., Lyubin P.A. and Manushin I.E. (2010) Mapping and monitoring of benthos in the Barents Sea and Svalbard waters: results from the joint Russian-Norwegian benthic programme 2006-2008. IMR-PINRO Joint Report Series, 1.

Anonymous (1999) International code of zoological nomenclature, 4th edition. International Trust for Zoological Nomenclature. London: The Natural History Museum.

Arndt W. (1928) Porifera, Schwämme, Spongien. In Arndt W., Broch H., Krumbach T., Pax F. and Lieberkind I. (eds) Porifera, Hydrozoa, Coelenterata, Echinodermata. Die Tierwelt Deutschlands und der angrenzenden Meeresteile nach ihren Merkmalen und nach ihrer Lebensweise, Volume 4. pp. 1-94.

Arndt W. (1935) Porifera. In Grimpe G. and Wagler E. (eds) Die Tierwelt der Nord- und Ostsee, Teil IIIa. Leipzig: Academische Verlagsgesellshaft m.b.H., pp. $1-140$.

Arnesen E. (1900) Spongier fra den norske kyst. I. Calcarea. Bergens Museums Aarbog 5, 1-46.

Arnesen E. (1903) Spongien von der norwegischen Küste. ii, Monaxonida: Halichondrina. Bergens Museums Aarbog 1, 1-30.

Arnesen E. (1918) Brutknospenbildung bei Polymastia mammilaris (O.F. Müller). Bow. (Rinalda arctica Merej.). Det Kongelige Norske Videnskabers selskabs skrifter 1, 1-24.

Arnesen E. (1920) Spongia. Report on the Scientific Results of the 'Michael Sars' North Atlantic Deep-Sea Expedition in 1910 3, 1-29.

Babkov A.I. and Golikov A.N. (1984) Hydrobiocomplexes of the White Sea. Leningrad: Publications of the Zoological Institute, Academy of Sciences of USSR. [In Russian]

Barthel D. and Tendal O.S. (1993) The sponge association of the abyssal Norwegian-Greenland Sea - species composition, substrate relationships and distribution. Sarsia 78, 83-96. 
Blindheim J. and Østerhus S. (2005) The Nordic Seas, main oceanographic features. In Drange H., Dokken T., Furevik T., Gerdes R. and Berger W. (eds) The Nordic Seas, main oceanographic features, in the Nordic Seas: an integrated perspective. AGU Monograph 158, Washington, DC: American Geophysical Union, pp. 11-37.

Borojevic R. (1967) La ponte et le développement de Polymastia robusta (Démosponges). Cahiers de Biologie Marine 8, 1-6.

Boury-Esnault N. (1987) The Polymastia species (Demosponges, Hadromerida) of the Atlantic area. In Vacelet J. and Boury-Esnault N. (eds) Taxonomy of Porifera from the N.E. Atlantic and Mediterranean Sea. NATO ASI Series, G 13. Berlin-Heidelberg: Springer, pp. 29-66.

Boury-Esnault N. (2002) Family Polymastiidae Gray, 1867. In Hooper J.N.A. and Van Soest R.W.M. (eds) Systema Porifera. a guide to the classification of sponges, Volume 1. New York, NY: Kluwer Academic/Plenum Publishers, pp. 201-219.

Boury-Esnault N. and Bézac C. (2007) Morphological and cytological descriptions of a new Polymastia species (Hadromerida, Demospongiae) from the North-West Mediterranean Sea. In Custódio M.R., Lôbo-Hajdu G., Hajdu E. and Muricy G. (eds) Porifera research: biodiversity, innovation and sustainability. Rio de Janeiro: Museu Nacional, Série Livros 28, pp. 23-30.

Boury-Esnault N., Marschal C., Kornprobst J.-M. and Barnathan G. (2002) A new species of Axinyssa Lendenfeld, 1897 (Porifera, Demospongiae, Halichondrida) from the Senegalese coast. Zootaxa $117,1-8$.

Boury-Esnault N., Pansini M. and Uriz M.-J. (1994) Spongiaires bathyaux de la mer d'Alboran et du golfe ibéro-marocain. Mémoires $d u$ Muséum national d'Histoire naturelle 160, 1-174.

Bowerbank J.S. (1858) On the anatomy and physiology of the Spongiadae. Part I. On the spicula. Philosophical Transactions of the Royal Society 148, 279-332.

Bowerbank J.S. (1861) List of British sponges. In McAndrew R. (ed.) List of the British marine invertebrate fauna. Report of the British Association for the advancement of science, Volume 30. London: Taylor \& Francis, pp. $235-236,830-836$.

Bowerbank J.S. (1862) On the anatomy and physiology of the Spongiadae. Part III. On the generic characters, the specific characters, and on the method of examination. Philosophical Transactions of the Royal Society 152, 1087-1135.

Bowerbank J.S. (1864) A monograph of the British Spongiadae, Volume 1. London: The Ray Society.

Bowerbank J.S. (1866) A monograph of the British Spongiadae, Volume 2. London: The Ray Society.

Bowerbank J.S. (1874) A monograph of the British Spongiadae, Volume 3 London: The Ray Society.

Bowerbank J.S. and Norman A.M. (1882) A monograph of the British Spongiadae, Volume 4 (Supplement). London: The Ray Society.

Breitfuss L.L. (1911) Zur Kenntnis der Spongio-Fauna des Kola-Fjords. Travaux de la Société Impériale des Naturalistes de St. -Pétersbourg Section Zoologie, 42, 209-226.

Breitfuss L.L. (1912) Zur Kenntnis der Spongio-Fauna des Kola Fjords. II. Travaux de la Societé Impériale des Naturalistes de St. Petersbourg Section Zoologie, 41, 61-80.

Breitfuss L.L. (1930) Biogeographischer Beitrag zur Kenntniss der Spongienfauna der Arktis. Sitzungsberichte der Gesellschaft Naturforschender Freunde zu Berlin 1929, 274-282.

Brøndsted H.V. (1914) Conspectus faunæ groenlandicæ. Porifera. Meddelelser om Grønland 23, 457-544.
Brøndsted H.V. (1932) Marine Spongia. III. In Jensen A.S., Lundbeck W. and Ragnar Spärck M.T. (eds) The zoology of the Faroes. Copenhagen: A.F. Høst \& Son, pp. 1-34.

Brøndsted H.V. (1933) Porifera. Meddelelser om Grønland 104, 1-10.

Burton M. (1930a) Norwegian sponges from the Norman collection. Proceedings of the Zoological Society of London 1930, 487-546.

Burton M. (1930b) Additions to the Sponge fauna of the Gulf of Manaar. Annals and Magazine of Natural History 5, 665-676.

Burton M. (1959a) Spongia. In Fridriksson A. and Tuxen S.L. (eds) The zoology of Iceland. Copenhagen: Ejnar Munksgaard, pp. 1-71.

Burton M. (1959b) Sponges. In Scientific Reports. John Murray Expedition 1933-34, Volume 10, issue 5. London: British Museum (Natural History), pp. 151-281.

Cabioch L. (1968) Contribution à la connaissance de la faune des Spongiaires de la Manche Occidentale. Démosponges de la région de Roscoff. Cahiers de Biologie Marine 9, 211-246.

Cárdenas P., Perez T. and Boury-Esnault N. (2012) Sponge systematics facing new challenges. Advances in Marine Biology 61, 79-209.

Cárdenas P. and Rapp H.T. (2012) A review of Norwegian streptasterbearing Astrophorida (Porifera: Demospongiae: Tetractinellida), new records and a new species. Zootaxa 3253, 1-52.

Cárdenas P., Rapp H.T., Klitgaard A.B., Best M., Thollesson M. and Tendal O.S. (2013) Taxonomy, biogeography and DNA barcodes of Geodia species (Porifera, Demospongiae, Tetractinellida) in the Atlantic boreo-arctic region. Zoological Journal of the Linnean Society 169, 251-311.

Cárdenas P., Rapp H.T., Schander C. and Tendal O.S. (2010) Molecular taxonomy and phylogeny of the Geodiidae (Porifera, Demospongiae, Astrophorida) - combining phylogenetic and Linnaean classification. Zoologica Scripta 39, 89-106.

Carter H.J. (1875) Notes introductory to the study and classification of the Spongida. Part II. Proposed classification of the Spongida. Annals and Magazine of Natural History 4, 126-145.

Carter H.J. (1876) Descriptions and figures of deep-sea sponges and their spicules, from the Atlantic Ocean, dredged up on board H.M.S. 'Porcupine', chiefly in 1869 (concluded). Annals and Magazine of Natural History 18, 388-410.

Carter H.J. (1883) Contributions to our knowledge of the Spongida. Annals and Magazine of Natural History 12, 308-329.

Coachman L.K. and Aagaard K. (1974) Physical oceanography of Arctic and Subarctic waters. In Herman Y. (ed.) Marine geology and oceanography of the Arctic Seas. New York, NY: Springer-Verlag, pp. 1-72.

de Laubenfels M.W. (1942) Porifera from Greenland and Baffinland collected by Capt. Robert A. Bartlett. Journal of the Washington Academy of Sciences 32, 263-269.

de Laubenfels M.W. (1949) The sponges of Woods Hole and adjacent waters. Bulletin of the Museum of Comparative Zoology at Harvard College 103, 1-55.

Dendy A. (1888) Studies on the comparative anatomy of sponges. I. On the genera Ridleia, n. gen., and Quasillina, Norman. Quarterly Journal of Microscopical Science 282, 513-529.

Dendy A. (1922) Report on the Sigmatotetraxonida collected by H.M.S. 'Sealark' in the Indian Ocean. Reports of the Percy Sladen Trust Expedition to the Indian Ocean in 1905, Volume 7. Transactions of the Linnean Society of London 18, 1-164.

Dendy A. and Ridley S.O. (1886) On Proteleia sollasi, a new genus and species of monaxonid sponges allied to Polymastia. Annals and Magazine of Natural History 18, 152-159. 
Desqueyroux-Faúndez R. and Van Soest R.W.M. (1997) Shallow water Demosponges of the Galápagos Islands. Revue Suisse de Zoologie 104, 379-467.

Drange H., Dokken T., Furevik T., Gerdes R., Berger W., Nesje A., Orvik K.A., Skagseth Ø., Skjelvan I. and Østerhus S. (2005) The Nordic Seas: an overview. In Drange H., Dokken T., Furevik T., Gerdes R. and Berger W. (eds) The Nordic Seas, main oceanographic features, in the Nordic Seas: an integrated perspective. AGU Monograph 158. Washington, DC: American Geophysical Union, pp. $1-10$.

Ereskovsky A.V. (1993a) Materials to the faunistic study of the White and Barents Seas sponges. 1. Taxonomic composition. Bulletin of St. Petersburg State University Series 3 3, 19-28. [In Russian]

Ereskovsky A.V. (1993b) Addition to the fauna of sponges (Porifera) of the White Sea. Bulletin of St. Petersburg State University Series 32 , 3-12. [In Russian]

Ereskovsky A.V. (1994a) Materials to the faunistic study of the White Sea and Barents Sea sponges. 2. Biogeographical and comparative-faunistic analysis. Bulletin of St. Petersburg State University Series 3 1, 13-26. [In Russian]

Ereskovsky A.V. (1994b) Materials to the faunistic study of the White Sea and Barents Sea sponges. 3. Dependence of sponge distribution on the temperature and salinity. Bulletin of St. Petersburg State University Series 3 3, 3-10. [In Russian]

Ereskovsky A.V. (1995a) Materials to the faunistic study of the White Sea and Barents Sea sponges. 4. Vertical distribution. Bulletin of St. Petersburg State University Series 3 1, 3-17. [In Russian]

Ereskovsky A.V. (1995b) Materials to the faunistic study of the White Sea and Barents Sea sponges 5. Quantitative distribution. Berliner Geowissenschaftliche Abhandlungen Reihe E: Paleobiologie 16, 709-714.

Ereskovsky A.V. (1995c) Materials to the faunistic study of the White Sea and Barents Sea sponges 6. The origin of the White and Barents seas sponge faunas. Berliner Geowissenschaftliche Abhandlungen Reihe E: Paleobiologie 16, 715-730.

Fleming J. (1828) A history of British animals, exhibiting the descriptive characters and systematical arrangement of the genera and species of quadrupeds, birds, reptiles, fishes, Mollusca, and Radiata of the United Kingdom; including the indigenous, extirpated, and extinct kinds, together with periodical and occasional visitants. Edinburgh: Bell and Bradfute.

Fristedt K. (1885) Bidrag till Kännedomen om de vid Sveriges vestra Kust lefvande Spongiae. Kungliga Svenska vetenskapsakademiens handlingar 21, 1-56.

Fristedt K. (1887) Sponges from the Atlantic and Arctic Oceans and the Behring Sea. Vega-Expeditionens Vetenskapelige Iakttagelser (Nordenskiöld) 4, 401-471.

Golikov A.N. and Scarlato O.A. (1989) Evolution of Arctic ecosystems during the Neogene period. In Herman Y. (ed.) The Arctic Seas. Climatology, oceanography, geology, and biology. New York, NY: Springer, pp. 257-279.

Golikov A.N., Scarlato O.A., Averincev V.G., Menshutkina T.V., Novikov O.K. and Sheremetevsky A.M. (1990) Ecosystems of the New Siberian shoals, their distribution and functioning. In Golikov A.N. (ed.) Ecosystems of the New Siberian shoal and the fauna of the Laptev Sea and adjacent waters, Explorations of the fauna of the seas, Volume 37. Leningrad: Nauka, pp. 4-79. [In Russian]

Gorbunov G.P. (1946) Bottom life of the Novosiberian shoalwaters and central part of the Arctic Ocean. Transactions of the Glavsevmorput drifting expedition onboard ice-breaker "G. Sedov" in 1937-1940 III, 30-136. [In Russian]
Gray J.E. (1867) Notes on the arrangement of sponges, with the descriptions of some new genera. Proceedings of the Zoological Society of London $1867,492-558$.

Hanitsch R. (1894) Revision of the generic nomenclature and classification in Bowerbank's 'British Spongiadae'. Proceedings and Transactions of the Liverpool Biological Society 8, 173-206.

Hansen B. and Østerhus S. (2000) North Atlantic-Nordic Seas exchanges. Progress in Oceanography 45, 109-208.

Hansen G.A. (1885) Spongiadae. The Norwegian North-Atlantic Expedition 1876-1878. Zoologi 13, 1-26.

Hentschel E. (1916) Die Spongien des Eisfords. In Théel H.J. and Lönnberg E. (eds) Zoologische Ergebnisse der Schwedischen Expedition nach Spitzbergen, 1908, Volume 54(3). Teil II(3). Stockholm: Kungliga Svenska vetenskapsakademiens Handlingar, pp. 1-18.

Hentschel E. (1929) Die Kiesel- und Hornschwämme des Nördlichen Eismeers. In Römer F., Schaudinn F., Brauer A. and Arndt W. (eds) Fauna Arctica. Eine Zusammenstellung der arktischen Tierformen mit besonderer Berücksichtigung des Spitzbergen-Gebietes auf Grund der Ergebnisse der Deutschen Expedition in das Nördliche Eismeer im Jahre 1898, Volume 5(4). Jena: G. Fischer, pp. 857-1042.

Herman Y. (1974) Topography of the Arctic Ocean. In Herman Y. (ed.) Marine geology and oceanography of the Arctic Seas. New York, NY: Springer-Verlag, pp. 73-81.

Hooper J.N.A. and Van Soest R.W.M. (eds) (2002) Order Hadromerida Topsent, 1894. In Systema Porifera. A guide to the classification of Sponges, Volume 1. New York, NY: Kluwer Academic/Plenum Publishers, pp. $169-172$.

Johnston G. (1842) A history of British Sponges and Lithophytes. Edinburgh: W.H. Lizars.

Kędra M., Renaud P.E., Andrade H., Goszczko I. and Ambrose W.G. (2013) Benthic community structure, diversity, and productivity in the shallow Barents Sea bank (Svalbard Bank). Marine Biology 160, $805-819$.

Kent W.S. (1870) On the 'Hexactinellidae' or hexradiate spiculed silicious sponges taken in the 'Norna' Expedition off the coast of Spain and Portugal. With description of new species, and revision of the order. Monthly Microscopical Journal 4, 241-252.

Kirkpatrick R. (1907) Preliminary report on the Monaxonellida of the National Antarctic Expedition. Annals and Magazine of Natural History 20, 271-291.

Kirkpatrick R. (1908) Porifera (Sponges). II. Tetraxonida, Dendy. National Antarctic Expedition, 1901-1904. Natural History, series 4, Zoology, pp. 1-56.

Klitgaard A.B. and Tendal O.S. (2004) Distribution and species composition of mass occurrences of large-sized sponges in the northeast Atlantic. Progress in Oceanography 61, 57-98.

Klitgaard A.B., Tendal O.S. and Westerberg H. (1997) Mass occurrences of large sized sponges (Porifera) in Faroe Island (NE-Atlantic) shelf and slope areas: characteristics, distribution and possible causes. In Hawkins L.E., Hutchinson S., Jensen A.C., Sheader M. and Williams J.A. (eds) The responses of marine organisms to their environments. Proceedings of the 3oth European Marine Biology Symposium. Southampton: University of Southampton, pp. 129-142.

Koltun V.M. (1959) Siliceous horny sponges of the Northern and Far Eastern Seas of the USSR. Identifiers of the USSR fauna issued by the Zoological Institute of the Academy of Sciences of the USSR. Moscow-Leningrad: Nauka, Academy of Sciences of the USSR, p. 67. [In Russian]

Koltun V.M. (1964) Sponges (Porifera) collected in the Greenland Sea and in the North area off Spitzbergen and Frantz Josef Land by the icebreaker "F. Litke" in 1955, the steamer "Ob" in 1956 and the steamer 
"Lena" in 1957-1958. Proceeding of the Arctic and Antarctic Research Institute 259, 143-166. [In Russian]

Koltun V.M. (1966) Four-rayed sponges (order Tetraxonida) of the Northern and Far Eastern Seas of the USSR. Identifiers of the USSR fauna issued by the Zoological Institute of the Academy of Sciences of the USSR. Moscow-Leningrad: Nauka, Academy of Sciences of the USSR, p. 90. [In Russian]

Korablev A., Smirnov A. and Baranova O.K. (2014) Climatological atlas of the Nordic Seas and Northern North Atlantic. In Seidov D. and Parsons A.R. (eds) NOAA Atlas NESDIS, Volume 77. Silver Spring, MD: NESDIS. doi: $10.7289 / \mathrm{V}_{54} \mathrm{~B}_{2} \mathrm{Z}_{7} 8$.

Lamarck J.B.P. (1815) Suite des polypiers empâtés. Mémoires du Muséum d'Histoire naturelle 1, Paris, 69-80, 162-168, 331-340.

Lambe L.M. (1896) Sponges from the Atlantic coast of Canada Transactions of the Royal Society of Canada 2, 181-211.

Lambe L.M. (1900) Sponges from the coasts of north-eastern Canada and Greenland. Transactions of the Royal Society of Canada 6, 19-49.

Lévi C. (1950) Spongiaires. Travaux de la Station biologique de Roscoff Supplement 2, 1-28.

Lévi C. (1993) Porifera Demospongiae: Spongiaires bathyaux de Nouvelle-Calédonie, récoltés par le 'Jean Charcot'. Campagne BIOCAL, 1985. In Crosnier A. (ed.) Résultats des campagnes MUSORSTOM, Volume 11. Mémoires du Muséum national d'Histoire naturelle (A, Zoologie) 158, 9-87.

Levinsen G.M.R. (1887) Kara-Havets Svampe (Porifera). In Lütken C.F. (ed.) Dijmphna-Togtets zoologisk-botaniske Udbytte. København: Komission hos H. Hagerup, pp. 339-372.

Loeng H. and Drinkwater K. (2007) An overview of the ecosystems of the Barents and Norwegian Seas and their response to climate variability. Deep Sea Research Part II: Topical Studies in Oceanography 54, 2478 2500.

Lundbeck W. (1902) Porifera. Part I. Homorrhaphidae and Heterorrhaphidae. In The Danish Ingolf-Expedition, Volume 6(1). Copenhagen: Bianco Luno, pp. 1-108.

Lundbeck W. (1905) Porifera. Part II. Desmacidonidae (pars.). In The Danish Ingolf-Expedition, Volume 6(2). Copenhagen: Bianco Luno, pp. 1-219.

Lundbeck W. (1907) Porifères. In Gerlache de Gomery A.V.J. baron de and Orléans L.P.R. duc Duc d' (eds) Croisière Océanographique accomplie à bord de la 'Belgica' dans la Mer du Grönland en 1905. Résultats scientifiques. Bruxelles: Charles Bulens, pp. 558-559.

Lundbeck W. (1909) The Porifera of East-Greenland. Meddelelser om Grønland 29, 423-464.

Lundbeck W. (1910) Porifera. Part III. Desmacidonidae (pars.). In The Danish Ingolf-Expedition, Volume 6(3). Copenhagen: Bianco Luno, pp. 1-124.

Maldonado M., Aguilar R., Bannister R.J., Bell J., Conway K.W., Dayton P.K., Diaz C., Gutt J., Kelly M., Kenchington E.L.R., Leys S.P., Pomponi S.A., Rapp H.T., Rützler K., Tendal O.S., Vacelet J. and Young C.M. (2016) Sponge grounds as key marine habitats: a synthetic review of types, structure, functional roles and conservation concerns. In Rossi S., Bramanti L., Gori A. and Orejas C. (eds) Marine animal forests - the ecology of benthic biodiversity hotspots. New York, NY: Springer, pp. 1-39. On-line first view. Available at http://dx.doi.org/10.1007/978-3-319-17001-5_24-1.

Merejkowsky C.S. (1878) Etudes sur les éponges de la Mer Blanche. Mémoires d l'Académie Impériale des Sciences de St.-Petersbourg Serie $726,1-51$.

Merejkowsky C.S. (1880) Reproduction des éponges par bourgeonnement extérieur. Archives de Zoologie expérimentale et générale 8, 417-432.
Minchin E.A. (1900) Chapter III. Sponges. In Lankester E.R. (ed.) A Treatise on Zoology. Part II. The Porifera and Coelenterata. 2. London: Adam \& Charles Black, pp. 1-178.

Montagu G. (1814) An essay on sponges, with descriptions of all the species that have been discovered on the coast of Great Britain. Memoirs of the Wernerian Natural History Society 2, 67-122.

Morrow C.C. and Boury-Esnault N. (2000) Redescription of the type species of the genus Polymastia Bowerbank, 1864 (Porifera, Demospongiae, Hadromerida). Zoosystema 22, 327-335.

Morrow C.C. and Cárdenas P. (2015) Proposal for a revised classification of the Demospongiae (Porifera). Frontiers in Zoology 12, 1-27.

Morrow C.C., Picton B.E., Erpenbeck D., Boury-Esnault N., Maggs C.A. and Allcock A.L. (2012) Congruence between nuclear and mitochondrial genes in Demospongiae: a new hypothesis for relationships within the $\mathrm{G}_{4}$ clade (Porifera: Demospongiae). Molecular Phylogenetics and Evolution 62, 174-190.

Morrow C.C., Redmond N.E., Picton B.E., Thacker R.W., Collins A.G., Maggs C.A., Sigwart J.D. and Allcock A.L. (2013) Molecular phylogenies support homoplasy of multiple morphological characters used in the taxonomy of Heteroscleromorpha (Porifera: Demospongiae). Integrative and Comparative Biology 53, 428-446.

Müller O.F. (1806) Zoologia danica seu animalium Daniae et Norvegiae rariorum ac minus notorum descriptiones et historia, Volume 4. Havniae: N. Christensen.

Norman A.M. (1869) Notes on a few Hebridean Sponges, and on a new Desmacidon from Jersey. Annals and Magazine of Natural History 3 , 296-299.

Plotkin A. (2004) Biodiversity and distribution of Polymastiidae (Demospongiae, Hadromerida) in the Arctic area. In Pansini M., Pronzato R., Bavestrello G. and Manconi R. (eds) Sponge sciences in new millennium. Bollettino dei Musei e degli Instituti Biologici dell'Universita di Genova 68, Rapallo (Genova). Genoa: Officine Grafiche Canessa, pp. 535-547.

Plotkin A. and Boury-Esnault N. (2004) Alleged cosmopolitanism in sponges: the example of a common Arctic Polymastia (Porifera, Demospongiae, Hadromerida). Zoosystema 26, 13-20.

Plotkin A. and Ereskovsky A.V. (1997) Ecological aspects of asexual reproduction of the White Sea sponge Polymastia mammillaris (Demospongiae, Tetractinomorpha) in the Kandalaksha Bay. Berliner Geowissenschaftliche Abhandlungen Reihe E: Paleobiologie $20,127-132$.

Plotkin A., Gerasimova E. and Rapp H.T. (2012) Phylogenetic reconstruction of Polymastiidae (Demospongiae: Hadromerida) based on morphology. Hydrobiologia 687, $21-41$.

Plotkin A. and Janussen D. (2008) Polymastiidae and Suberitidae (Porifera: Demospongiae: Hadromerida) of the deep Weddell Sea, Antarctic. In Martínez Arbizu P. and Brix S. (eds) Bringing light into deep-sea biodiversity. Zootaxa 1866, 95-135.

Plotkin A., Morrow C.C., Gerasimova E. and Rapp H.T. (2016a) Polymastiidae (Demospongiae: Hadromerida) with ornamented exotyles: a review of morphological affinities and description of a new genus and three new species. Journal of the Marine Biological Association of the United Kingdom 1-56. On-line first view. Available at http://dx.doi.org/10.1017/So025315416000655.

Plotkin A., Railkin A., Gerasimova E., Pimenov A. and Sipenkova T. (2005) Subtidal underwater rock communities of the White Sea: structure and interaction with bottom flow. Russian Journal of Marine Biology 31, 335-343.

Plotkin A., Voigt O., Willassen E. and Rapp H.T. (2016b) Molecular phylogenies challenge the classification of Polymastiidae (Porifera, Demospongiae) based on morphology. Organisms Diversity and 
Evolution 1-22. On-line first view, Available at http://dx.doi.org/10. 1007/s13127-016-0301-7.

Rapp H.T. (2006) Calcareous sponges of the genera Clathrina and Guancha (Calcinea, Calcarea, Porifera) of Norway (NE Atlantic) with the description of five new species. Zoological Journal of the Linnean Society 147, 331-365.

Rapp H.T. (2015) A monograph of the calcareous sponges (Porifera Calcarea) of Greenland. Journal of the Marine Biological Association of the United Kingdom 95, 1395-1459.

Redmond N.E., Morrow C.C., Thacker R.W., Diaz M.C., Boury-Esnault N., Cárdenas P., Hajdu E., Lôbo-Hajdu G., Picton B.E., Pomponi S.A., Kayal E. and Collins A.G. (2013) Phylogeny and systematics of Demospongiae in light of new small subunit ribosomal DNA (18S) sequences. Integrative and Comparative Biology 53, 388-415.

Rezvoj P.D. (1924) Contribution towards the sponge fauna of the Kara and Barents Seas. Bulletin de l'Institut Lesshaft 8, 241-250. [In Russian with English summary]

Rezvoj P.D. (1927) A new species of sponges, Polymastia euplectella, from the Murman Coast. Comptes Rendus de l'Académie des Sciences URSS $18,301-302$.

Rezvoj P.D. (1928) Sponges of the Barents Sea from the samples of the cruises along the Kola meridian. Proceedings of the Institute of the Research of the North, USSR 37, 67-95.

Ridley S.O. and Dendy A. (1886) Preliminary report on the Monaxonida collected by H.M.S. 'Challenger'. Part 1 and 2. Annals and Magazine of Natural History 18, 325-351, 470-493.

Ridley S.O. and Dendy A. (1887) Report on the Monaxonida collected by H.M.S. 'Challenger' during the years 1873-1876. Report on the Scientific Results of the Voyage of H.M.S. 'Challenger', 1873-1876. Zoology 20, 1-275.

Róndani C. (1845) Sulle differenze sessuali delle Conopinae e Myopinae negli insetti ditteri. Memoria undecima per servire alla ditterologia italiana. Nuovi Annali delle Scienze Naturali, Bologna 3, 5-16.

Sars G.O. (1869) Fortsatte bemærkninger over det dyriske livs utbredning i havets dybder. Forhandlinger $i$ Videnskabsselskabet $i$ Christiania $1868,246-275$.

Sars G.O. (1872) On some remarkable forms of animal life from the great deeps off the Norwegian coast. Part 1, partly from posthumous manuscripts of the late Prof. Michael Sars. University Program for the $1^{\text {st }}$ half-year 1869. Christiania: Brøgger \& Christie.

Schander C., Rapp H.T., Kongsrud J.A., Bakken T., Berge J., Cochrane S., Oug E., Byrkjedal I., Cedhagen T., Fosshagen A., Gebruk A., Larsen K., Nygren A., Obst M., Plejel F., Stöhr S., Todt C., Warén A., Handler-Jacobsen S., Kuening R., Levin L., Mikkelsen N.T., Petersen K.K., Thorseth I.H. and Pedersen R.B. (2010) The fauna of hydrothermal vents on the Mohn Ridge (North Atlantic). Marine Biology Research 6, 155-171.

Schmidt O. (1862) Die Spongien des adriatischen Meeres. Leipzig Wilhelm Engelmann.

Schmidt O. (1870) Grundzüge einer spongien-fauna des Atlantischen gebietes. Leipzig: Wilhelm Engelmann.

Schmidt O. (1875) Spongien. In Die Expedition zur physikalischchemischen und biologischen Untersuchung der Nordsee im Sommer 1872. Jahresbericht der Commission zur Wissenschaftlichen Untersuchung der Deutschen Meere in Kiel, Volume 2-3. Berlin: Wiegandt, Hempel \& Parey, pp. 115-120.

Schmidt O. (1880) Die Spongien des Meerbusen von Mexico (und des caraibischen Meeres). Heft II. Abtheilung II. Hexactinelliden. Abtheilung III. Tetractinelliden. Monactinelliden und Anhang. Nachträge zu Abtheilung I (Lithistiden). In Reports on the dredging under the supervision of Alexander Agassiz, in the Gulf of Mexico, by the USCSS 'Blake'. Jena: Gustav Fischer, pp. 33-90.

Schulze F.E. (1885) The Hexactinellida. In Tizard T.H., Moseley H.M., Buchanan J.Y. and Murray J. (eds) Report on the Scientific Results of the Voyage of H.M.S. 'Challenger', 1873-1876, Volume 1. Narrative, pp. $437-451$.

Shields M.A. and Hughes D.J. (2009) Large-scale variation in macrofaunal communities along the eastern Nordic Seas continental margin: a comparison of four stations with contrasting food supply. Progress in Oceanography 82, 125-136.

Sollas W.J. (1882) The sponge-fauna of Norway; a report on the Rev. A.M. Norman's collection of sponges from the Norwegian Coast. Annals and Magazine of Natural History 9, 141-165, 426-453.

Sollas W.J. (1885) A classification of the Sponges. Scientific Proceedings of the Royal Dublin Society (new series) 5, 112.

Sollas W.J. (1886) Preliminary account of the Tetractinellid sponges dredged by H.M.S. 'Challenger' 1872-76. Part I. The Choristida. Scientific Proceedings of the Royal Dublin Society (new series) 5, 177-199.

Stephens J. (1915) Sponges of the coasts of Ireland. I. The Triaxonia and part of the Tetraxonida. Fisheries, Ireland Scientific Investigations 1914, $1-43$.

Swarczewsky B.A. (1906) Beiträge zur Spongien-Fauna des Weissen Meeres. Mémoires de la Société des Naturalistes de Kiew 20, 307-371.

Tabachnick K.R. and Menshenina L.L. (2007) Revision of the genus Asconema (Porifera: Hexactinellida: Rossellidae). Journal of the Marine Biological Association of the United Kingdom 87, 1403-1429.

Thiele J. (1903) Beschreibung einiger unzureichend bekannten monaxonen Spongien. Archiv für Naturgeschichte 69, 375-398.

Thomson C.W. (1873) The depths of the sea. London: Macmillan and Co.

Topsent E. (1888) Contribution à l'étude des Clionides. Archives de Zoologie expérimentale et générale 2, 1-165.

Topsent E. (1892) Contribution à l'étude des Spongiaires de l'Atlantique Nord (Golfe de Gascogne, Terre-Neuve, Açores). Résultats des campagnes scientifiques accomplies par le Prince Albert I de Monaco 2, $1-165$.

Topsent E. (1898) Eponges nouvelles des Açores. Première serie. Mémoires de la Société zoologique de France 11, 225-255.

Topsent E. (1900) Etude monographique des spongiaires de France. III. Monaxonida (Hadromerina). Archives de Zoologie expérimentale et générale 3, 1-331.

Topsent E. (1904) Spongiaires des Açores. Résultats des campagnes scientifiques accomplies par le Prince Albert I de Monaco 25, 1-280.

Topsent E. (1913) Spongiaires provenant des campagnes scientifiques de la 'Princesse Alice' dans les Mers du Nord (1898-1899, 1906-1907). Résultats des Campagnes Scientifiques Accomplies par le Prince Albert I de Monaco 45, 1-67.

Topsent E. (1927a) Croisière du 'Pourquoi-Pas?' en 1926. Eponges du Scoresby Sund (Groenland oriental). Annales de l'Institut Océanographique 4, 253-260.

Topsent E. (1927b) Diagnoses d'Éponges nouvelles recueillies par le Prince Albert 1er de Monaco. Bulletin de l'Institut océanographique, Monaco 502, 1-19.

Topsent E. (1928) Spongiaires de l'Atlantique et de la Méditerranée provenant des croisières du Prince Albert ler de Monaco. Résultats des campagnes scientifiques accomplies par le Prince Albert I de Monaco $74,1-376$.

Topsent E. (1933) Eponges de Lamarck conservées au Muséum de Paris. Fin. Archives du Muséum national d'histoire naturelle Paris 6, 1-60. 
Uriz M.-J. and Rosell D. (1990) Sponges from bathyal depths (1000$1750 \mathrm{~m}$ ) in the Western Mediterranean Sea. Journal of Natural History 24, 373-391.

Vacelet J. (1961) Quelques Eponges remarquables de Méditerranée. Revue des Travaux de l'Institut des Pêches maritimes 25, 351-354.

Vacelet J. (2006) New carnivorous sponges (Porifera, Poecilosclerida) collected from manned submersibles in the deep Pacific. Zoological Journal of the Linnean Society 148, 553-584.

Van Soest R.W.M. (2001) Porifera. In Costello M.J., Emblow C. and White R. (eds) European register of marine species: a check-list of the marine species in Europe and a bibliography of guides to their identification. Collection Patrimoines Naturels, 50, 70-86, pp. 362-363.

Van Soest R.W.M., Boury-Esnault N., Hooper J.N.A., Rützler K., de Voogd N.J., Alvarez de Glasby B., Hajdu E., Pisera A.B., Manconi R., Schoenberg C., Janussen D., Tabachnick K.R., Klautau M., Picton B.E., Kelly M., Vacelet J., Dohrmann M., Díaz M.-C. and Cárdenas P. (2016) World Porifera database. Available at http:// www.marinespecies.org/porifera (accessed 5 November 2016).

Van Soest R.W.M., Picton B.E. and Morrow C.C. (2000) Sponges of the North East Atlantic. In World Biodiversity Database CD-ROM Series, Windows/Mac version 1.o. Amsterdam: ETI, University of Amsterdam. Available at http://species-identification.org/species. php?species_group $=$ sponges\&id $=104 \&$ menuentry $=$ soorten $\quad($ accessed 5 November 2016).

Verrill A.E. (1874) Results of recent dredging expeditions on the coast of New England. American Journal of Science and Arts Series 37 , $498-505$.

von Marenzeller E. (1878) Die Coelenteraten, Echinodermen und Würmer der K.K.Österreichisch-Ungarischen Nordpol-Expedition. Denkschriften der Kaiserlichen Akademie der Wissenschaften, Mathematisch-naturwissenschaftliche Classe Wien 35, 357-398.

von Lendenfeld R. (1887) On the systematic position and classification of sponges. Proceedings of the Zoological Society of London 1886, 558-662.

von Lendenfeld R. (1898) Die Clavulina der Adria. Nova acta Academiae Caesareae Leopoldino Carolinae germanicae naturaecuriosorum 69, $1-251$.

Vosmaer G.C.J. (1882) Report on the sponges dredged up in the Arctic Sea by the 'Willem Barents' in the years 1878 and 1879 . Niederländisches Archiv für Zoologie Supplement 1, 1-58.

Vosmaer G.C.J. (1885) The sponges of the 'Willem Barents' expedition 1880 and 1881. Bijdragen tot de Dierkunde 12, 1-47.

Vosmaer G.C.J. (1887) Klassen und Ordnungen der Spongien (Porifera). In Bronn H.G. (ed.) Die Klassen und Ordnungen des Thierreichs, Volume 2. Leipzig-Heidelberg: C.F. Winter'sche Verlagshandlung, pp. 1-496.

Weber J. (1989) Physiography and bathymetry of the Arctic Ocean seafloor. In Herman Y. (ed.) The Arctic Seas. Climatology, oceanography, geology, and biology. New York, NY: Springer, pp. 797-828.

Whiteaves J.F. (1874) Report on deep-sea dredging operations in the Gulf of St. Lawrence with notes on the present condition of the marine fisheries and oyster beds of part of the region. In Annual Report of the Department of Marine and Fisheries, Canada, for 1873 Appendix U. Ottawa: I.B. Taylor, pp. 178-204.

Whiteaves J.F. (1901) Catalogue of the marine invertebrata of eastern Canada. Geological Survey of Canada, Publication No. 772. Ottawa: S.W. Dawson.

Wilson H.V. (1925) Siliceous and horny sponges collected by the U.S. Fisheries Steamer 'Albatross' during the Philippine Expedition 1907-10. Contributions to the biology of the Philippine Archipelago and adjacent regions. Bulletin of the United States National Museum $100,273-532$. and

Witte U. (1996) Seasonal reproduction in deep-sea sponges - triggered by vertical particle flux? Marine Biology 124, 571-581.

\section{Correspondence should be addressed to:}

A. Plotkin

Department of Biology, University of Bergen, Postbox 7803 , 5020 Bergen, Norway.

email: alexander.s.plotkin@gmail.com

\section{APPENDIX1}

\section{KEY FOR THE NORDIC AND ARCTIC SPECIES OF THE}

\section{FAMILY POLYMASTIIDAE}

1. Pedunculate, columnar, fungiform or drum-shaped

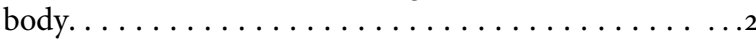
- Other body shape ................... 3

2. Body pedunculate or columnar, but never fungiform or drum-shape. Choanosome is a semi-fluid, amorphous mass with free-scattered bundles of small spicules. Tracts of principal spicules stretch in the cortex parallel to the surface. ..............Quasillina brevis

- Body columnar, pedunculate, fungiform or drumshaped. Choanosome dense, with longitudinal tracts of principal spicules crossing the upper surface............ Tentorium semisuberites

3. Raphids in trichodragmata present (in the subcortical area) ................ Spinularia spinularia - Raphids in trichodragmata absent. . . . . . . . . 4

4. Exotyles with ornamented distal knobs present. . . . . .5

- Exotyles absent or, if present, without any distal ornamentations. ...................6

5. Exotyles $5-7.5 \mathrm{~mm}$ long, with distal knobs of irregular shape varying from fungiform and umbrelliform to hemispherical or subspherical . . . . . . Sphaerotylus borealis - Exotyles not exceeding $1.5 \mathrm{~mm}$ in length, with regular, spherical distal knobs ....... Sphaerotylus capitatus

6. Body discoid, hemispherical or lenticular, attached to the substrate only by the central basal point. A prominent spicule fringe present at the boundary between the upper and basal surface ................ - Body globular, massive, cushion-shaped or encrusting. Basal surface completely attached to the substrate. Marginal spicule fringe tiny or absent. . . . . . . . 9

7. Upper surface smooth ....... Polymastia hemisphaerica - Upper surface hispid . . . . . . . . . . . . 8

8. Papillae well-developed. Body may reach $80 \mathrm{~mm}$ in diameter and possess up to 300 papillae, of which most are inhalant (blind) and few are exhalant (with oscula at the summits). Exhalant papillae larger than the inhalant ones.................... Polymastia grimaldii - One to five weakly developed papillae, of which all are exhalant. Body not larger than $13 \mathrm{~mm}$ in diameter.

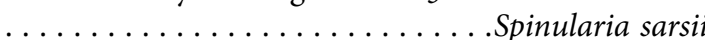

9. Surface completely, or at least for the most part smooth or

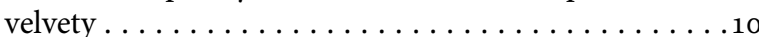
- Surface completely hispid or shaggy . . . . . . . . 16 10. Main choanosomal skeleton is a reticulation of spicule

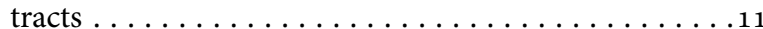


- Main choanosomal skeleton composed of radial or longitudinal spicule tracts, occasionally meandering or anastomosing ................

11. Colour in life intensively orange or yellow. Exhalant papillae larger than the inhalant ones. Polymastia boletiformis

- Colour in life pale cream or whitish. All papillae are exhalant and do not differ in size or shape ..................Weberella bursa

12. Body massive or globular. . . . . . . . . . . . .13

- Body cushion-shaped or encrusting. . . . . . . . 14

13. Surface uniformly smooth or velvety, with not more than 30 papillae, crater-shaped (very short and wide) in life. Aquiferous cavities all over the cortex. Choanosomal spicule tracts may meander or anastomose ............. Polymastia thielei

- Surface smooth or velvety, but with a marginal hispid collar. Up to 150 conical or cylindrical papillae. Aquiferous cavities concentrated in the cortical areas around the papillae. Choanosomal skeleton spicule tracts never meander or anastomose

................. Polymastia uberrima

14. Although the spicules considerably vary in length, only two size categories can be distinguished. Large spicules present both in cortex and choanosome. Cortex comprises three prominent layers, a superficial palisade of small spicules, a middle layer of loosely lying criss-cross large spicules and an internal layer of densely packed criss-cross large spicules . ..............Polymastia svenseni - Three size categories of spicules clearly distinguished. Large spicules comprise choanosomal tracts. Cortex of two layers, a superficial palisade of small spicules and an internal layer of densely packed criss-cross intermediary spicules. . . . . . . . . . . . . . . 15
15. Oscula at the summits of papillae not visible. In the cortex superficial spicule palisade and internal layer of criss-cross spicules intermingle. . . Polymastia bartletti or Polymastia nivea (discrimination possible only based on molecular data)

- In life some papillae with visible oscula at the summits. In the cortex superficial spicule palisade and internal layer of criss-cross spicules clearly segregated ............. Polymastia penicillus

16. Body not exceeding $24 \mathrm{~mm}$ in diameter, with a single weakly developed papilla and a tiny marginal spicule fringe. Cortex comprises a superficial palisade of small spicules and an internal layer of criss-cross spicules in the central area and only the palisade in the periphery .................Spinularia njordi

- Body with numerous well-developed papillae, usually exceeds $30 \mathrm{~mm}$ in diameter, often reaching up to $100 \mathrm{~mm}$. Marginal spicule fringe absent. Cortex uniform, comprising a superficial palisade of small spicules, a middle layer of collagen fibres with low density of spicules and an internal layer of criss-cross spicules . . . . . . . . . . . . . . 17

17. Four size categories of spicules including filiform monactines averaging $2.5 \mathrm{~mm}$ in length and reinforcing the surface hispidation. Polymastia andrica or Polymastia sp. (discrimination possible only based on molecular data)

- Three size categories of spicules with the largest not exceeding $1.8 \mathrm{~mm}$ in length. Filiform monactines

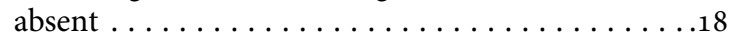

18. Inhalant papillae often bear at the summits threads with buds. Middle cortical layer up to $180 \mu \mathrm{m}$ thick ................. Polymastia arctica - Inhalant papillae without buds. Middle cortical layer thinner than $110 \mu \mathrm{m}$....... Polymastia mamillaris 